\title{
Assessing retention and motivation of public health-care providers (particularly female providers) in rural Pakistan
}

\author{
Ali M. Mir \\ Population Council \\ Gul Rashida Shaikh \\ Population Council \\ Saleem Shaikh \\ Neha Mankani \\ Anushe Hassan
}

See next page for additional authors

Follow this and additional works at: https://knowledgecommons.popcouncil.org/departments_sbsr-rh

Part of the Gender and Sexuality Commons, International Public Health Commons, Maternal and Child Health Commons, and the Women's Health Commons How does access to this work benefit you? Let us know!

\section{Recommended Citation}

Mir, Ali M., Gul Rashida Shaikh, Saleem Shaikh, Neha Mankani, Anushe Hassan, and Maqsood Sadiq. 2013. "Assessing retention and motivation of public health-care providers (particularly female providers) in rural Pakistan." Islamabad: Population Council. 
Authors

Ali M. Mir, Gul Rashida Shaikh, Saleem Shaikh, Neha Mankani, Anushe Hassan, and Maqsood Sadiq 
1 Population Council

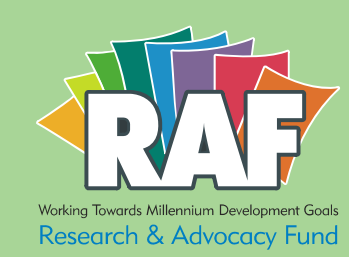

ASSESSING RETENTION

AND MOTIVATION OF PUBLIC

HEALTH-CARE PROVIDERS

(PARTICULARLY FEMALE PROVIDERS) IN RURAL PAKISTAN

\section{A STUDY FUNDED BY}

THE MATERNAL AND NEWBORN HEALTH PROGRAMME - RESEARCH AND ADVOCACY FUND (RAF)

ALI MOHAMMAD MIR, GUL RASHIDA SHAIKH, SALEEM SHAIKH, NEHA MANKANI, ANUSHÉ HASSAN, AND MAQSOOD SADIQ 



\section{Q Population Council}

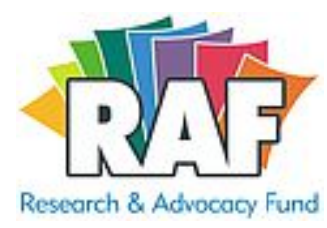

\section{ASSESSING RETENTION \\ AND MOTIVATION OF}

PUBLIC HEALTH-CARE PROVIDERS

(PARTICULARLY FEMALE PROVIDERS) IN

\section{RURAL PAKISTAN}

A STUDY FUNDED BY

THE MATERNAL AND NEWBORN HEALTH PROGRAMME - RESEARCH AND ADVOCACY FUND (RAF)

ALI MOHAMMAD MIR, GUL RASHIDA SHAIKH, SALEEM SHAIKH, NEHA MANKANI, ANUSHÉ HASSAN, AND MAQSOOD SADIQ 


\section{(2) Population Council}

The Population Council confronts critical health and development issues-from stopping the spread of HIV to improving reproductive health and ensuring that young people lead full and productive lives. Through biomedical, social science, and public health research in 50 countries, we work with our partners to deliver solutions that lead to more effective policies, programs, and technologies that improve lives.

(C) 2013 The Population Council, Inc.

\section{Declaration:}

"We have read the report titled "Assessing Retention and Motivation of Public Healthcare Providers [particularly Female Providers] in Rural Pakistan", and acknowledge and agree with the information, data and findings contained".

\section{Principal Investigator}

Dr Ali Mohammad Mir: Co har hiß

\section{Principal Co-investigator}

Dr Gul Rashida Shaikh:

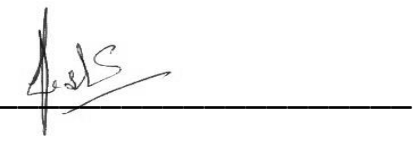

\section{Disclaimer:}

This document is an output from a project funded by the UK Department for International Development (DFID) and the Australian Agency for International Development (AusAID) for the benefit of developing countries. The views expressed and information contained in it are not necessarily those of or endorsed by DFID, AusAID or the Maternal and Newborn Health Programme Research and Advocacy Fund (RAF), which can accept no responsibility or liability for such views, for completeness or accuracy of the information, or for any reliance placed on them. 


\section{TABLE OF CONTENTS}

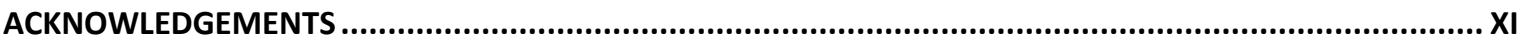

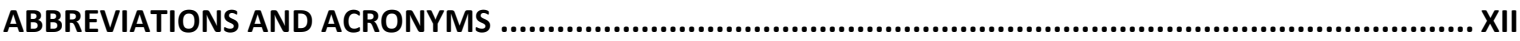

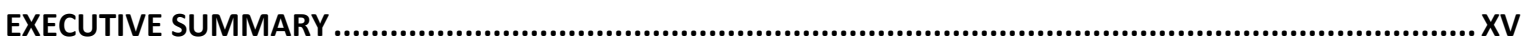

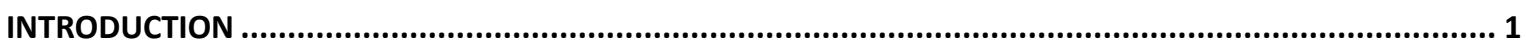

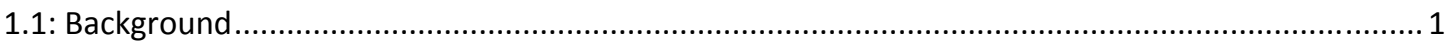

1.2: Rationale

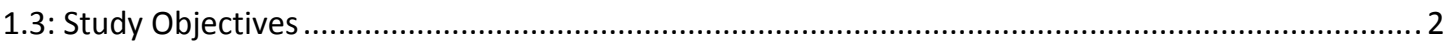

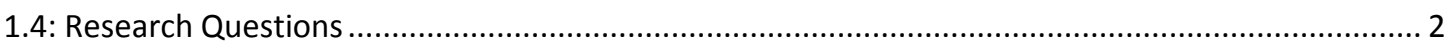

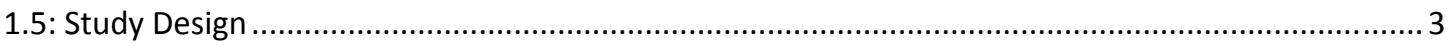

1.6: Review of Literature and Secondary Analysis of Existing Data..................................................... 3

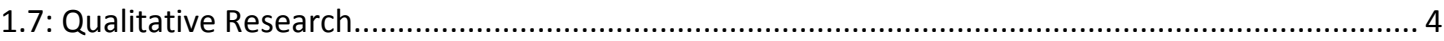

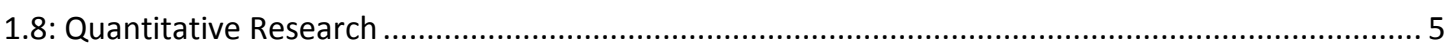

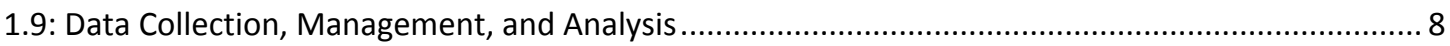

1.10: Study Limitations and Implications for Future Research....................................................... 10

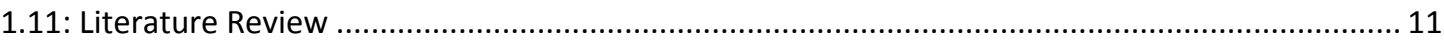

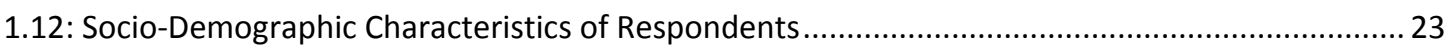

ORGANIZATIONAL FACTORS INFLUENCING PROVIDER MOTIVATION - AVAILBILITY OF RESOURCES

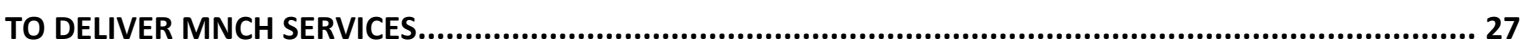

2.1: Health Facility Assessment -Equipment, Supplies \& Staff Availability........................................... 27

2.2: Service Delivery in Districts According to UN Process Indicators ..................................................... 46

ORGANIZATIONAL STUCTURES AND PROCESSES INFLUENCING MNCH STAFF MOTIVATION AND

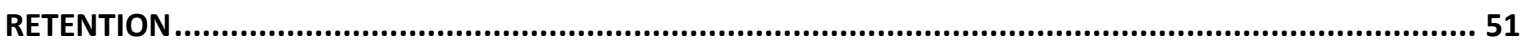

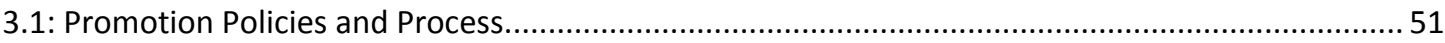

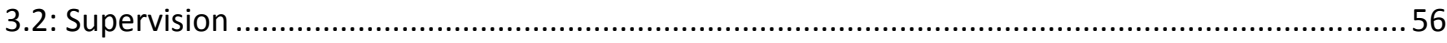

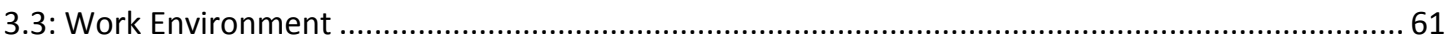

3.4: Social Factors Influencing MNCH Staff Motivation and Retention ................................................67

INDIVIDUAL LEVEL FACTORS INFLUENCING STAFF MOTIVATION AND OUTCOMES .................................. 73

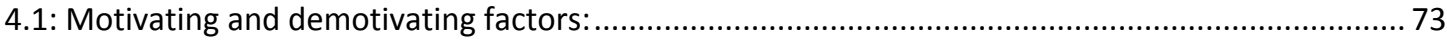

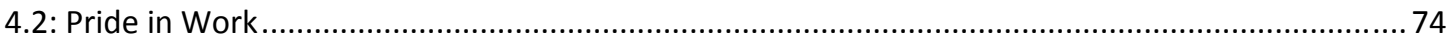

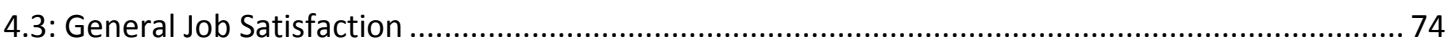

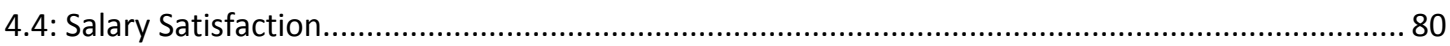

4.5: Organizational commitment and willingness to consider leaving government service based

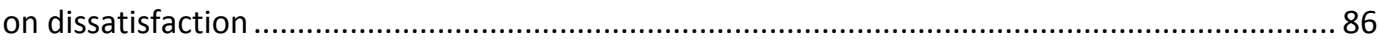

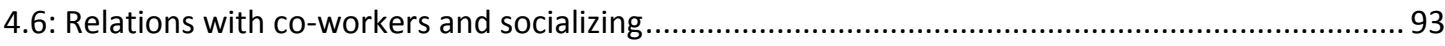

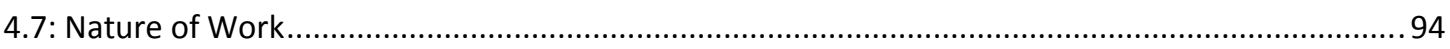

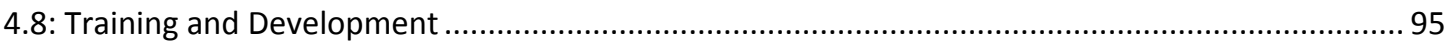




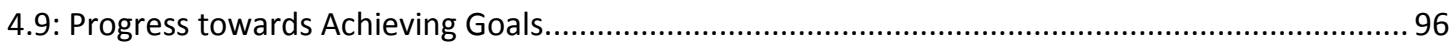

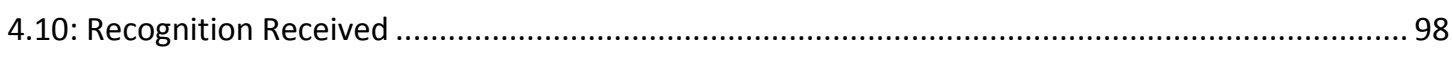

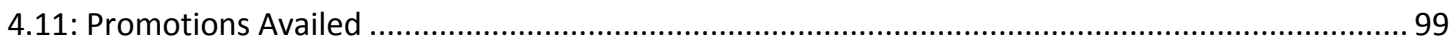

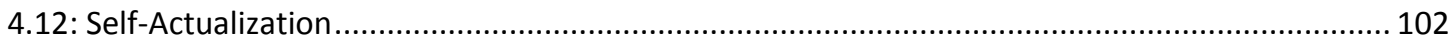

FEMALE PROVIDERS' PERCEPTIONS ON WORKING IN THE PUBLIC SECTOR: FINDINGS FROM

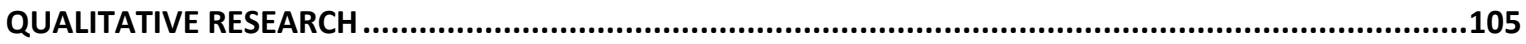

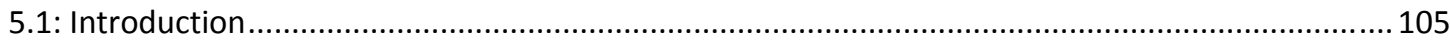

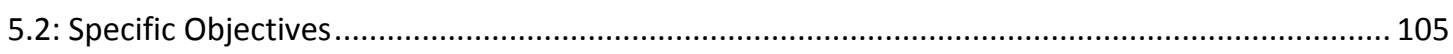

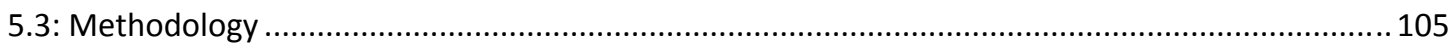

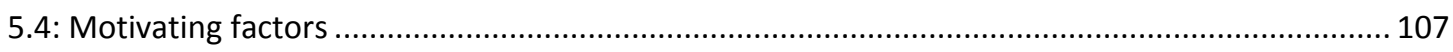

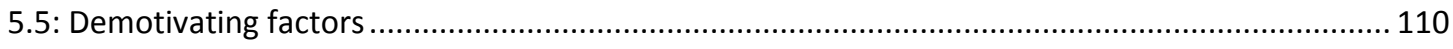

DISCUSSION AND RECOMMENDATIONS..............................................................................119

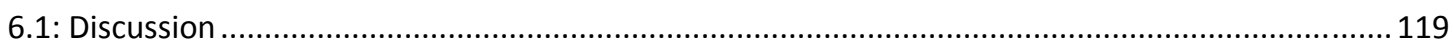

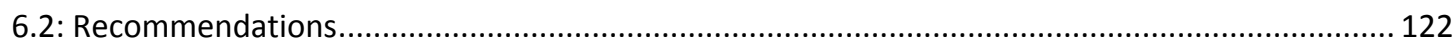

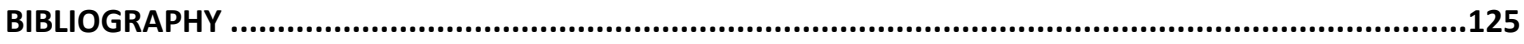

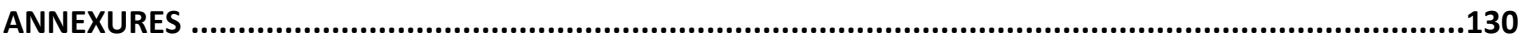

Annex 1 (a): List of Sampled Districts for the Qualitative Component......................................... 130

Annex 1 (b): District ranking on the basis of socio-economic index and skilled birth attendance....... 131

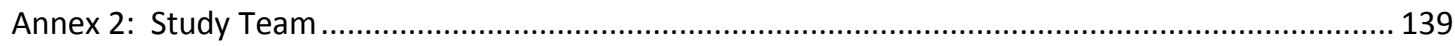

Annex 3A: Institutional Review Board Approval.................................................................... 140

Annex 3B: National Bioethical Committee (NBC) Pakistan Approval ............................................. 141

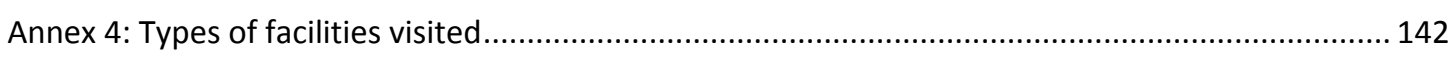

Annex 5: Availability of Basic EmOC-Percentage of Unmet Need ............................................... 143

Annex 6: Availability of CEmOC-Percentage of Unmet Need ....................................................... 144

Annex 7: Basic Information on Provinces and Regions ........................................................... 145 


\section{LIST OF TABLES}

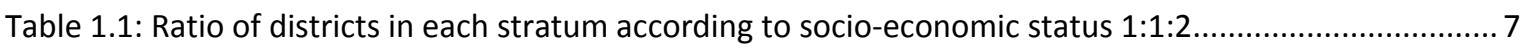

Table 1.2: Number of providers interviewed by cadre and by region ................................................... 8

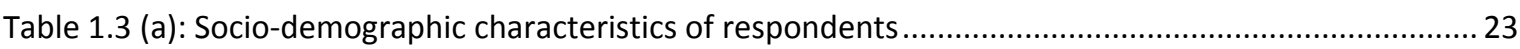

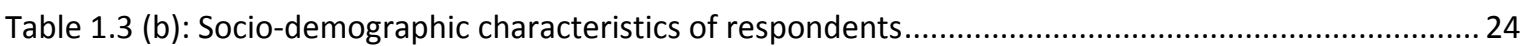

Table 2.1: Proportion of BHUs and $\mathrm{MCH}$ centres with necessary infrastructure .....................................29

Table 2.2: Status of availability of basic PHC equipment at the assessed facilities ....................................30

Table 2.3: Proportion of BHUs/MCH centres offering selected primary healthcare services .......................31

Table 2.4: Proportion of $\mathrm{BHU} / \mathrm{MCH}$ centres offering contraceptive methods .........................................32

Table 2.5: Proportion of $\mathrm{BHUs} / \mathrm{MCH}$ centres with selected drugs for providing routine ante, natal and

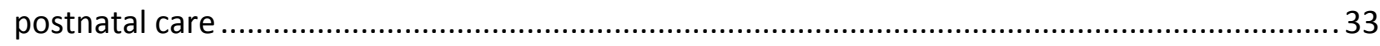

Table 2.6: Proportion of BHUs and $\mathrm{MCH}$ centres with obstetric first aid medicines ....................................33

Table 2.7: Proportion of $\mathrm{BHUs} / \mathrm{MCH}$ centres that have infection prevention supplies and equipment

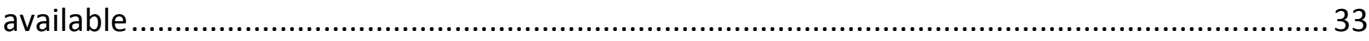

Table 2.8: Proportion of rural health centres with necessary infrastructure available ...............................34

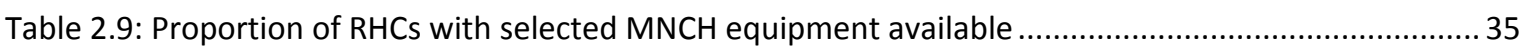

Table 2.10: Proportion of RHCs offering selected preventive and diagnostic services .................................36

Table 2.11: Proportion of RHCs with availability of selected MNCH medicines ........................................36

Table 2.12 Proportion of RHCs with selected support services available ..............................................37

Table 2.13: Proportion of RHCs with infection prevention measures available ....................................... 37

Table 2.14: Proportion of RHCs with different types of contraceptives available......................................38

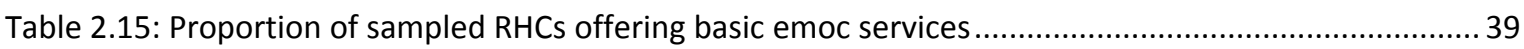

Table 2.16: Proportion of THQs and DHQs with necessary infrastructure available ...................................40

Table 2.17: Proportion of THQs and DHQs with selected MNCH equipment available..............................41

Table 2.18: Proportion of THQs and DHQs offering selected preventive and diagnostic services ............... 42

Table 2.19: Proportion of THQs and DHQs with availability of selected MNCH medicines..........................42

Table 2.20: Proportion of THQs and DHQs with selected support services available..............................43

Table 2.21: Proportion of THQs and DHQs with infection prevention measures available.........................43

Table 2.22: Proportion of THQs and DHQs offering contraceptive methods ............................................44

Table 2.23: Proportion of THQs and DHQs having basic EmOC services .............................................45

Table 2.24: Proportion of THQs and DHQs having comprehensive EmOC services..................................46

Table 3.1: Factors contributing to perception that promotion are fair and impartial...............................55

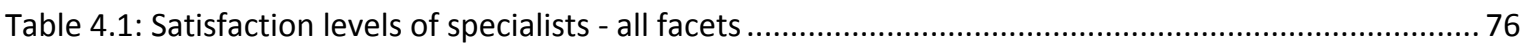

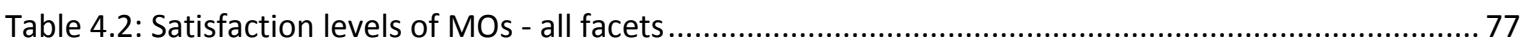

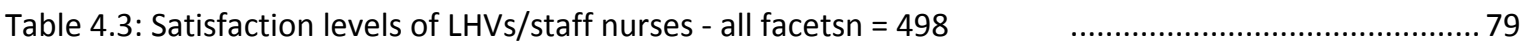

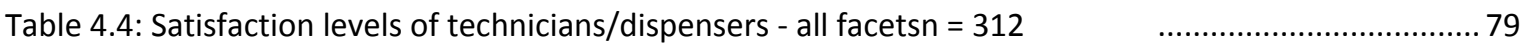




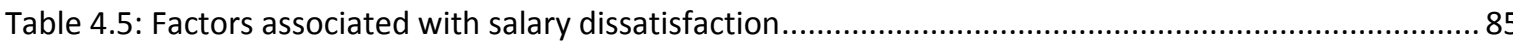

Table 4.6: Logistic regression showing association between providers' willingness to consider shifting and various individual-level factors.

Table 5.1: Number of FGDs conducted in each strata with number of participants .............................. 106 


\section{LIST OF FIGURES}

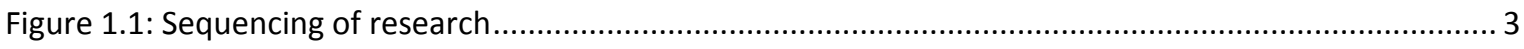

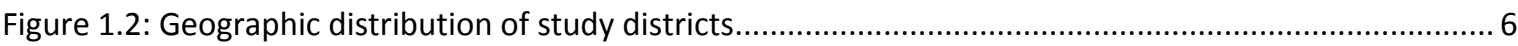

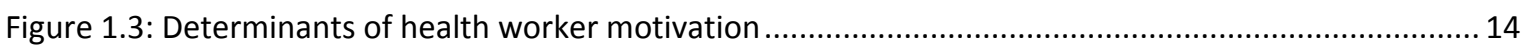

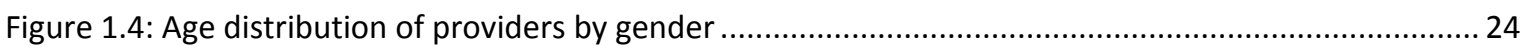

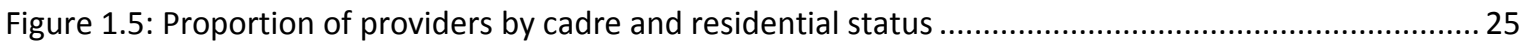

Figure 1.6: Availability of schooling for children by type of health facility .................................................... 26

Figure 2.2: Proportion of primary healthcare facilities offering range of phc services by region ...................31

Figure 2.3: Proportion of facilities providing family planning services by region ............................................ 32

Figure 2.4: Regional assessment of family planning method availability at the rhc level .............................. 38

Figure 2.5: Proportion of THQs offering basic EmOC and DHQs offering family planning services by

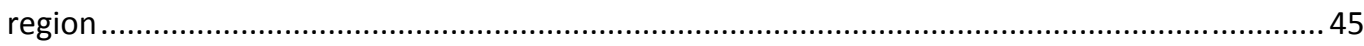

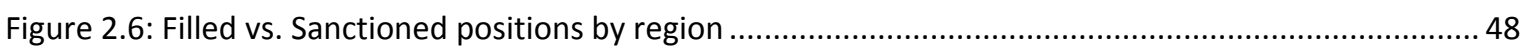

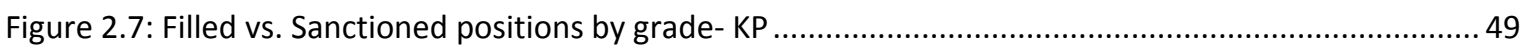

Figure 2.8: Filled vs. Sanctioned positions by cadre-Balochistan ................................................................... 49

Figure 3.1: Proportion of staff reporting partiality in promotions by cadre .............................................. 51

Figure 3.2: Proportion of providers reporting partiality in promotions by region......................................... 52

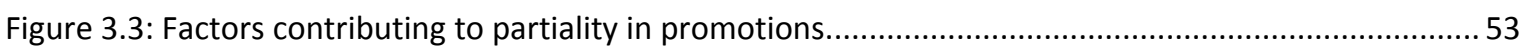

Figure 3.4: Proportion of providers who reported dissatisfaction with the current method of annual

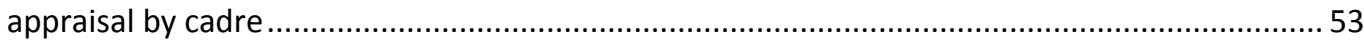

Figure 3.5: Proportion of providers who reported dissatisfaction with the current method of annual

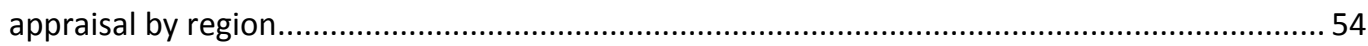

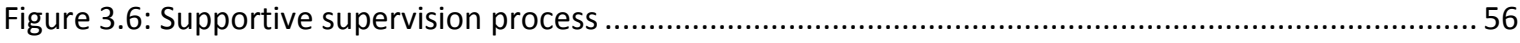

Figure 3.7: Proportion of providers reporting involvement in decision making ...........................................57

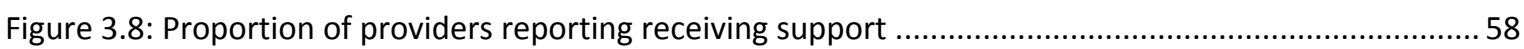

Figure 3.9: Proportion of providers reporting receiving appreciation and encouragement ..........................58

Figure 3.10: Proportion of providers receiving level of supportive supervision by cadre ..............................59

Figure 3.11: Proportion of providers receiving supportive supervision - regional analysis .............................60

Figure 3.12: Proportion of contractual vs. Permanent providers receiving supportive supervision ...............60

Figure 3.13: Proportion of providers having separate designated office by type of facility............................ 62

Figure 3.14: Proportion of providers who have a separate designated office by cadre................................... 63

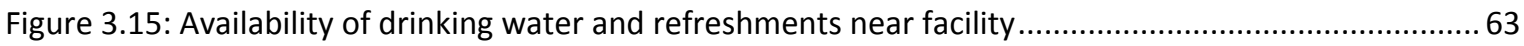

Figure 3.16: Proportion of providers who experience stress and report excessive workloads by cadre ....... 65

Figure 3.17: Proportion of providers reporting opportunities to socialize with their colleagues by cadre. 
Figure 3.18: Proportion of providers who report having a private practice in addition to their regular job

Figure 3.19: Proportion of managers who reported receiving complaints from staff on being overworked 66

Figure 3.20: Factors influencing health worker's motivation 67

Figure 3.21: Proportion of providers experiencing political and community interference by region ............68

Figure 3.22: Safety and comfort levels of providers while using public transport - regional analysis........... 70

Figure 3.23: Residential status of providers by cadre ....................................................................... 70

Figure 3.24: proportion of providers who feel comfortable using public transport and who feel safe while travelling from home to work

Figure 3.25: Proportion of managers reporting receiving complaints regarding travel, work environment, and political interference by regions. 72

Figure 4.1: Proportion of provider reported having pride in their work by type of facility..... 74

Figure 4.2: Satisfaction levels of specialists - all facets. 76

Figure 4.3: Satisfaction levels of MOs - all facets. 77

Figure 4.4: Satisfaction levels of LHVs/staff nurses - all facets.... .78

Figure 4.5: Satisfaction levels of technicians/dispensers - all facets 78

Figure 4.6: Proportion of respondents reporting salary dissatisfaction by gender

Figure 4.7: Proportion of providers reporting level of contribution of salary to overall household income by gender 81

Figure 4.8: Proportion of respondents who reported dissatisfaction with current salary by region ............82

Figure 4.9: Proportion of respondents that reported dissatisfaction with current salary by cadre .............. 82

Figure 4.10: Salary dissatisfaction relation to years of experience.

Figure 4.11: Perception of respondents regarding the salary they are currently receiving vis-à-vis that offered in the private sector

Figure 4.12: Perception of own salary relative to private sector, differentiated by permanent vs. Contractual employees 84

Figure 4.13: Reasons given by providers considering the shift to the private sector 86

Figure 4.14: Providers who would consider shifting, breakdown by gender $(n=425)$ 87

Figure 4.15: Providers who would consider shifting to the private sector, by cadre $(n=425)$

Figure 4.16: Proportion of providers who would consider leaving by level of salary satisfaction 88

Figure 4.17: Proportion of providers who would consider leaving government service breakdown by region

Figure 4.18: Proportion of providers who would consider leaving government service by district ranking

Figure 4.19: Proportion of providers who would consider leaving government service by promotion status. 89

Figure 4.20: Infrastructure: proportion of providers that would leave due to poor infrastructure 90 
Figure 4.21: Medicines: proportion of providers that would leave due to lack of medicines......

Figure 4.22: Proportion of providers reporting retention efforts by the department ...............................92

Figure 4.23: Proportion of respondents reporting retention efforts by region..........................................93

Figure 4.24: Proportion of providers by level of satisfaction with their current work by cadre ..................94

Figure 4.25: Proportion of providers satisfied with the relevance of work with their skills by cadre ...........95

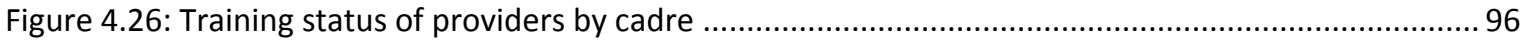

Figure 4.27: Proportion of providers who have a vision and are satisfied with progress towards

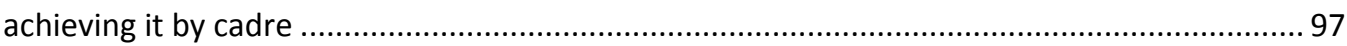

Figure 4.28: Proportion of providers satisfied with progress towards achieving their vision/goal by

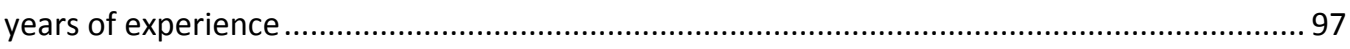

Figure 4.29: Proportion of providers receiving appreciation from supervisors by cadre ............................98

Figure 4.30: Proportion of providers motivated by monetary vs. non-monetary benefits .........................99

Figure 4.31: Promotion status of providers by cadre ..................................................................... 100

Figure 4.32: Promotion status of providers by region ...................................................................... 100

Figure 4.33: Promotion status of providers by years of experience .................................................... 101

Figure 4.34: Distribution of providers at the same grade by cadre by length of service.......................... 102

Figure 4.35: Proportion of providers who feel they have reached self-actualization by cadre .................. 103 



\section{ACKNOWLEDGEMENTS}

The national study on "Assessing Retention and Motivation of Public Healthcare Providers (Particularly Female Providers) in Rural Pakistan" was funded by the Maternal and Newborn Health Programme Research and Advocacy Fund (RAF). The study determines the key factors that motivate or constrain healthcare providers to serve in the rural areas of Pakistan.

We would like to express our gratitude to Dr. Zeba A. Sathar (T.I.) Country Director at the Population Council Islamabad Office who provided invaluable guidance and support right from the inception of the project to its completion. We would like to thank the external reviewer for having painstakingly reviewed the report and for providing valuable suggestions.

Apart from the contribution of the authors, several individuals have also played a major role in the conduct of this study and in the preparation of this report. We gratefully acknowledge the help and support of the Director Generals of Health Punjab, Sindh, KP, Balochistan, KP, GB and the respective Executive District Health Officers of our sampled districts in undertaking this national study. Their valuable suggestions have helped in formulating the recommendations of the report.

Mr Mumraiz Khan, Mr. Khan Muhammad, Ms Shagufta Parveen, Ms Zeba Tasneem, Mr. Mansoor Qaisar, Ms Lubna Mahmood, Ms Ashfa Hashmi, Ms Farzana Arif, Ms Bushra Bano, and Mr. Usman Asif expertly supervised all the field activities. We are also thankful for the advice on data analysis given by Dr Asif Wazir. Mr Rehan Niazi, Mr Usman Ghani and Mr Muhammad Ali worked very hard and often late hours to complete the data entry and nalysis on time. Mr Imran Ahmed, Director Finance, Admin and HR and his team expertly handled all logistic and financial matters. Mr. Ali Ammad was responsible for the final formatting of the report. Mr. Waqas Abrar, Project Coordinator, has worked tirelessly in helping with the preparation of the list of references and compiling the report.

Finally, we want to thank the interviewers, their supervisors and all study respondents who willingly gave their time to participate in this study. 


\section{ABBREVIATIONS AND ACRONYMS}

\begin{tabular}{|c|c|}
\hline$A C R$ & Annual Confidential Report \\
\hline AJK & Azad Jammu and Kashmir \\
\hline BEmOC & Basic Emergency Obstetric Care \\
\hline $\mathrm{BHU}$ & Basic Health Unit \\
\hline CEmOC & Comprehensive Emergency Obstetric Care \\
\hline $\mathrm{CHW}$ & Community Health Worker \\
\hline $\mathrm{CMW}$ & Community Midwife \\
\hline $\mathrm{DHQ}$ & District Headquarters \\
\hline $\mathrm{DOH}$ & Department of Health \\
\hline EmOC & Emergency Obstetric Care \\
\hline EmONC & Emergency Obstetric and Newborn Care \\
\hline FANA & Federally Administered Northern Areas \\
\hline FATA & Federal Administered Territory Areas \\
\hline FGD & Focus Group Discussion \\
\hline FLCF & First-Level Care Facility \\
\hline $\mathrm{FP}$ & Family Planning \\
\hline GB & Gilgit-Baltistan \\
\hline HR & Human Resource \\
\hline $\mathrm{HRH}$ & Human Resource in Health \\
\hline IDI & In-Depth Interview \\
\hline IEC & Information, Education, and Communication \\
\hline IRB & Institutional Review Board \\
\hline IUCD & Intrauterine Contraceptive Device \\
\hline JDI & Job Descriptive Index \\
\hline JIG & Job inGeneral \\
\hline KP & Khyber Pakhtunkhwa \\
\hline LHV & Lady Health Visitor \\
\hline LHW & Lady Health Worker \\
\hline OT & Operation Theatre \\
\hline $\mathrm{MCH}$ & Maternal and Child Health \\
\hline MDGs & Millennium Development Goals \\
\hline MLC & Medico Legal Case \\
\hline $\mathrm{MNCH}$ & Maternal, Newborn and Child Health \\
\hline MO & Medical Officer \\
\hline
\end{tabular}




\begin{tabular}{ll} 
MS & Medical Superintendent \\
MVA & Manual Vaginal Aspiration \\
PMDC & Pakistan Medical and Dental Council \\
PPH & Post-Partum Haemorrhage \\
PPHI & People's Primary Healthcare Initiative \\
PRSP & Punjab Rural Support Programme \\
RH & Reproductive Health \\
RHC & Rural Health Centre \\
RSP & Rural Support Programme \\
SAHR & Salutation, Assessment, Help, and Reassurance \\
THQ & Tehsil Head Quarters \\
TT & Tetanus Toxoid \\
TL & Tubal Ligation \\
UN & United Nations \\
UNFPA & United Nations Population Fund \\
UNICEF & United Nations Children Fund \\
WHO & World Health Organization \\
WMO & Women Medical Officer \\
\hline
\end{tabular}





\section{EXECUTIVE SUMMARY}

One of the critical issues influencing reproductive health indicators in Pakistan has been access to services that are linkedclosely on the availability and quality of appropriate health care providers. This constraint applies in particular to women and their special needs, given limited autonomy and mobility, especially in rural and distant areas.

The main objectives of this project were to explore the core issue of availability of health providers, especially female providers that are required for provision of maternal and neonatal healthcare in Pakistan and determine the range of factors that either constrain or motivate providers to serve in key positions in public facilities in rural areas.

To this end, a national study on 'Assessing Retention and Motivation of Public Healthcare Providers (particularly female providers) in Rural Pakistan' was conducted in 2012 in a representative sample of 28 randomly selected districts within sevenregions in Pakistan. It consisted of a survey of health professionals interviewing1,365 providers and managers.A qualitative component comprisedFocus Group Discussions with female providers and in-depth interviews with selected health providers and managers. Additionally, 533 primary, referral and tertiary care health facilitieswere assessed in the sampled districts to gauge the capacity of these facilities to provide $\mathrm{MNCH}$ services, as well as to explore the relationship between availability of equipment, medicines and supplies and health worker'smotivation and retention. Secondary analysis of human resourcedata received from the health departments within the regions was also carried out to identify gaps in human resource availability.

Methodology was employed to determine the range of factors that contribute to provider motivation and retention in the system. The study shows that a sizeable number of staff positions are vacant. This includes two thirds of the gynaecologists in Punjab and three fourths in Sindh. One third of the positions forwomen medical officers in Punjab and Sindh and slightly more than half in GB and FATA are vacant. Positions of LHVs are also vacant in Balochistan. As a result, provision of specialized $\mathrm{MNCH}$ care in the rural areas remains a major challenge.

The compelling factors that would lead them to leave include dissatisfaction with salary, political interference, andlack of infrastructure and medicines. While the providers' general level of satisfaction with their current jobswas high, more than half of themreported dissatisfaction with promotion opportunities,and more than a quarter of them were dissatisfied with the current method of annual appraisal. Theyreported that it lacked objectivity and transparency as it fails to capture staff performance and accomplishments. An important finding from this study is that $32 \%$ of all providers had never been promoted despite being in service for more than 16 years. These findings are a reason for concern as staff attrition can further compound the issue of staff non-availability in rural areas. Political interference was cited as a major issue impacting work by providers in FATA and AJK.

Of the providers interviewed, nearly a fifth had not received any training at all since they joined the serviceidentifying the need for having a Human Resource Development Policy.The research evidence raises 
serious concerns about safety and security issues confronting providers. Almost a quarter of providers reported not having a boundary wall around their facilities, which significantly impacts their perceived and actual safety levels. A fairly low proportion of providers are residing within the facilities due to nonavailability of staff residences. This means long commutes from their residences to places of work. Compassion and altruism were identified as important reasons for joining as well as choosing to remain in government service. The top three factors that motivated staff in their work included an opportunity to serve the community, professional growth and the respect accorded to them by the people because of the nature of their profession. This study also highlights some of the specific problems confronting female providers, such as issues of mobility, safety and security and community interference. These factors have been discussed in detail in chapter 5 .

This study identifies a number of problems faced by healthcare providers working in the public healthcare system in Pakistan. In order to increase the quality of and accessibility to healthcare, especially for women and children, policy makers must take steps to rectify the problems identified by the study.

The following recommendations that stem directly from the findings of the study are being put forward for consideration by the policy makers:

- Ensure Implementation of a Human Resource for Health Management System:All provinces must ensure implementation of a "Human Resources for Health Management System" that includes the following components:-

\section{$0 \quad$ Training and development}

A staff training and career development strategy must be established to include routine new and refresher trainings as part of a continuing education system. The training must include updates in clinical and administrative management,how to work with communities, improving inter-personal communications and leadership skills, thereby equipping providers to work optimally and also helping improve quality of care.

\section{$0 \quad$ Filling of vacant posts}

There should be a functioning MIS that can be used to identify staff vacancies and these can then be filledeither though redistribution of and periodic changes in existing staff from urban to rural areas, or by hiring new staff.Wherever possible, providers should be recruited from the areas in which they are to serve. Additionally, the government should consider an alternative strategy of developing skills of lower cadre staff and through task sharing fill in the gaps of specialized care e.g. training medical officers in basic anaesthesia and LHVs in assisted vaginal delivery.

- Adhering strictly to organizational policies on recruitment, transfer, and promotion: All provincial health departments must adhere to the existing staff recruitment, promotion, and transfer policies. Holding of timely Departmental Promotional Committees (DPC) is important for this process. At the same time, certain administrative reforms are also necessary - these include revision of the existing performance evaluation system and introduction of new forms and an examination system that can 
objectively measure staff performance, ensuring adherence to the requirements of the existing career structure. Strict adherence to rules and regulations already in place regarding postings and transfers can mitigate undue political interference.

- Improving the Physical Work Environment and Ensuring the Availability of Equipment, Medicine, and Supplies:All provinces must undertake a comprehensive facility infrastructure assessment; draw up a list of infrastructure repair, refurbishment and upgradation requirements and also carry out new construction such as of boundary walls and staff residences. If all facilities are equipped to meet their mandate, then the burden on higher level facilities is reduced, and the quality of care delivered increases at all facility levels.

- Putting in Place a National Private Practice Regulation Policy: A national private practice regulation policy can contribute to improving providers' performance as it will help in ensuring that theyare able to rationally devote time to their official duties, both within and after office hours and to their private practice.

- Incentives for Attracting and Retaining Staff: A comprehensive rural services package needs to be developed that clearly incentivizes and makes working in the rural areas more attractive, especially for female providers. This should include monetary and non-monetary rewards, including a salary package that is competitive to the market.Provincial managers have suggested dividing the districts into zones and based on hardship level such as non-availability of schools, security situation, and accessible roads; the providers in these zones should be offered higher financial incentives. The package should include increasing the existing allowances to compensate for the working conditions in the rural regions of the country and a travelling allowance especially for those providers who have not been provided residence within the facility premises need to be revised to cover inflation. It has been seen that non-monetary rewards influence motivation more substantially such as recognition and rewarding performance. Some non-monetary incentives that can be introduced includeletters, certificates or shields of appreciation awarded to staff who meet pre-developed indicators, and consideration of providers with outstanding performance for civil awards such as pride of performance awards.

Posting in rural areas should be on tenure basis and must be made mandatory by the Pakistan Medical and Dental Council (PMDC) as a requirement for registration. To increase access to specialized care in rural areas, the College of Physicians and Surgeons of Pakistan should make serving in these areas a requirement for obtainingpost graduate fellowship.

To facilitate availability of female providers especially WMOs and female specialists in rural areas, a specific tenure system should be introduced and postings be on a rotation basis. Female paramedical staff should wherever possible belong to the area of their positing and residences for female providers must be provided to ensure their safety and security as well as enable them to be available to cater to emergency cases. 



\section{INTRODUCTION}

\section{1:Background}

Pakistan is a long way from achieving its Millennium Development Goals (MDGs) 4 and 5 . There is a strong need to develop a strategic direction identifying priorities that will have the greatest leverage to move closer to reducing maternal mortality by three-quarters and child mortality by two-thirds. While many outcomes in the MDGs are related to development and policy directives, the reduction of maternal and child mortality requires a clear understanding of the social and programmatic determinants that have a bearing on maternal and child health $(\mathrm{MCH})$ outcomes.

One of the critical issues influencing reproductive health $(\mathrm{RH})$ indicators in Pakistan has been that of access to services-particularly RH services-which depend on the availability and quality of appropriate healthcare providers. This constraint applies in particular to women and their special needs, given limited autonomy and mobility, especially in rural and distant areas. It is strongly desirable for women to see and interact with female providers, considering the cultural constraints they face. However, female providers in these remote areas are also confined by the same societal values as the women they are serving.This is especially the case for women working in areas to which they themselves do not belong.

The problem is self-reinforcing: areas that are backward in terms of female education and reflect the poor status of women are unlikely to have trained female providers - especially when training requires long periods of time spent away from home - or have conditions favourable for high retention. These areas lack indigenous healthcare providers and therefore have to depend on workers to come in from other districts. These workers require both residences and strong incentives to serve the villages and remote settlements they are relocating to. Pakistan therefore suffers from the double dilemma of gender issues and human resources (HR) for health shortages in catering to the demands of poor rural women, especially in underserved areas such as Balochistan, Gilgit-Baltistan (GB), Azad Jammu and Kashmir (AJK), and the Federal Administered Territory Areas (FATA).

The shortage of female healthcare providers has the potential of exacerbating inequalities in indicators of maternal and child mortality in these areas. Women in remote areas face exclusion, particularly in obtaining maternal healthcare, including family planning (FP) services, thus limiting the progress that other initiatives such as community mobilization and media campaigns may be making, since this is a road block to appropriate care-seeking behaviour.

This research addressed the core issue of availability of health providers, especially female providers (required for the specialized RH needs of women and children, particularly neonates), and other issues such as work status and motivation, which affect the availability and quality of care in Pakistan. Geography was a key element of this research. We looked at differentials across various regions of Pakistan: Punjab, Sindh, Khyber Pakhtunkhwa (KP), Balochistan, GB, FATA, and, AJK, given the different situation in all of these regions. The audienceis the main line departments of the provinces (i.e., planning, finance, and health) that 
collectively decide how to allocate resources and where greater investments are required to ensure that the RH needs of poor and marginalized communities are met.

\section{2: Rationale}

The rationale for this study was to produce insightful and policy-relevant research on the range of factors that either constrain or motivate mid-level providers, particularly women, to serve in key positions in public health facilities in rural Pakistan. While the research utilized a health systems approach in looking at institutional and personal factors for men and women, it also included a gender focus to examine the challenges faced by women particularly. We also looked at how these varied across economic and cultural boundaries. The literature reviewed showed a need to compare different cadres of workers as their issues would also be quite varied. Regional differences were expected to be of paramount importance. Above all, the relative weight of monetary versus non-monetary concerns was expected to vary depending on the availability of other opportunities, especially in the private sector. This research tackled the confluence of job-related, institutional, demographic, social, and economic issues that health workers face in rural Pakistan. Multivariate analysis was undertaken to identify the most important areas that can help prioritize interventions.

\section{3: Study Objectives}

The following is a list of objectives that were identified for this study:

- To review and critically analyse literature on past and existing intervention programmes on improving health worker retention in Pakistan and globally, and learn how the results were translated into specific policies;

- To analyse factors influencing the decisions and choices of health providers in rural and hard-to-reach areas by cadre (general, including MOs, WMOs, LHVs, nurses, dispensers and health techniciansand specialists)and gender, on what motivates their retention or contributes to their leaving;

- To recommend strategies that can be employed in the provincial context to increase the retention of health providers in rural and remote areas in a sustainable manner, especially to improve maternal and newborn health outcomes.

\section{4: Research Questions}

How can healthcare providers be attracted, motivated and retained at primary-, secondary-, and tertiarylevel health facilities in rural and hard-to-reach areas?

The first step in the research was to review all available evidence of research and programmatic interventions in the area of public healthcare providers' motivation and retention. This review helped frame and sharpen our research questions and survey instruments.

The following three research questions were then examined:

- What is the difference in the availability of $\mathrm{MNCH}$ care providers of different cadres across the regions? 
- What is the level of retention and attendance of $\mathrm{MNCH}$ care providers in the sevenstrata based on staff allocation?

- What challenges do $\mathrm{MNCH}$ care providers face which affect their retention and motivation?

\section{5: Study Design}

The research involved three distinct approaches: primary qualitative and quantitative data collection and analysis, and secondary analysis of existing data. Each approach addressed the same topic from a different perspective and study methodology. Triangulation of results during the final analysis allowed for a more comprehensive understanding of the subject matter. The sequencing and timing of the three research approaches is depicted in Figure 1.1.

Figure 1.1: Sequencing of research

\section{Review of Literature and}

Secondary data analysis

June 2012

Preliminary Qualitative Data Collection (FGDs)

July-August2012

\section{Focus Group Discussions}

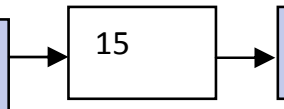

providers in seven strata: 54 LHVs and 54 WMOs

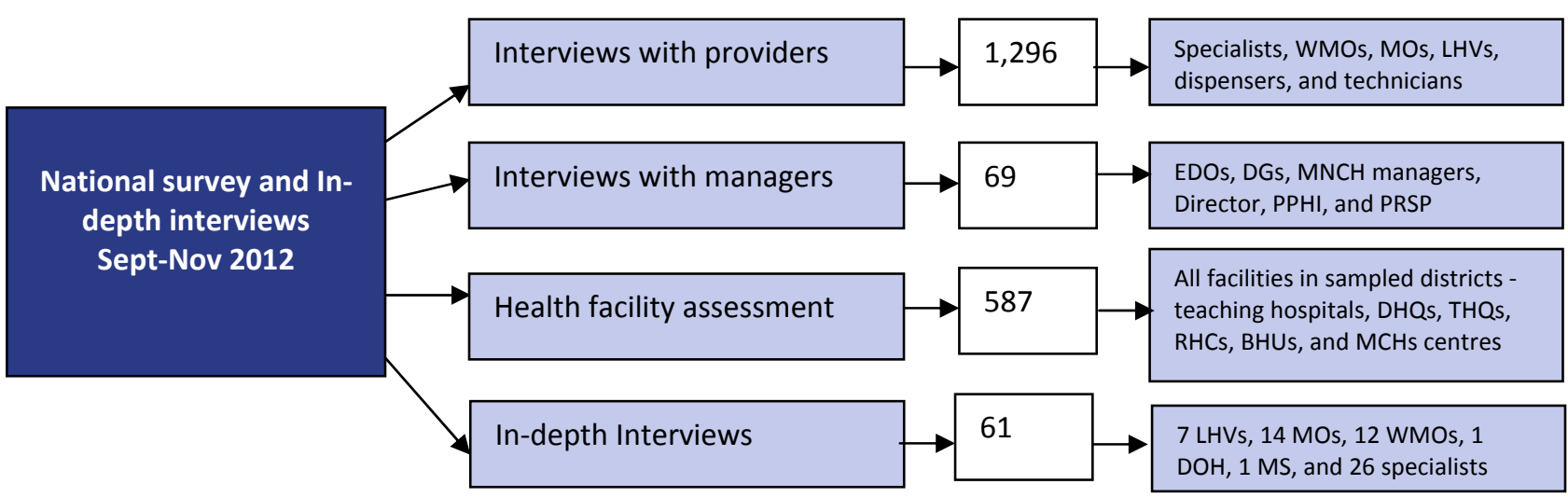

\section{6: Review of Literature and Secondary Analysis of Existing Data}

1.6.1: Review of Literature:A systematic review of material published on worker motivation was carried out for this study. Its purpose was to identify relevant issues regarding health worker motivation both globally and within Pakistan and to provide a better and holistic understanding of the topic. Various debates on the matter were studied and some themes and models pertinent to the aims of our study focused on in detail. Primary sources of data included online search engines (leading to a snowball effect), websites and grey literature.

1.6.2: Secondary Analysis of Existing Data: Secondary data analysis involved the study of all existing datasets showing current staff positions. The objective of the data analysis was to assess the 
availability of health staff at public-level facilities that are essential for delivering $\mathrm{MNCH}$ services. The data was collected from the HMIS and DHIS through brief visits of provincial and district health directorates, separate visits of sampled facilities, and through telephone contact.

\section{7: Qualitative Research}

Qualitative formative research included in-depth interviews (IDIs) and Focus Group Discussions (FGDs) with healthcare providers and managerial supervisors to probe the reasons for the selection of careers, motivations, and constraints, and understanding cultural diversity.

\section{Focus group discussions (FGDs)}

FGDs were held in all seven regions including four provinces i.e. Punjab, Sindh, Balochistan, KP, AJK, FATA, and GB. One district from each of the region was selected randomly. The list of the sampled districts is attached (Annex 1-a) The Population Council contacted district health managers who were briefed about the study objectives and methodology. The health managers facilitated the selection of FGD participants who were selected through purposive sampling. Two FGDs were conducted per district. Each FGD was conducted by a two-member team of trained social scientists (a moderator and a note-taker). Separate FGDs were conducted with WMOs and LHVs, and included eight to ten participants. Consent was taken from participants for participation and for recording and further use of data prior to the beginning of each session. The FGDs were conducted using a pre-constructed guide, to ensure they covered all of the relevant topics. FGDs lasted for an average time of one-and-a-half hours; each was conducted in the local language and was tape-recorded.

Fifteen FGDs were conducted during July and August 2012. The purpose of the FGDs was to elicit information on motivational determinants and retention on the job such as the push of travelling long distances, not having accommodation, and the pull of better paid private sector options. Issues of safety and security, leadership, recognition, and promotion processes were also explored. Data extracted from the FGDs was used to refine the structured questionnaire; it also helped provide insights and a contextual understanding of the perceptions of healthcare providers on factors contributing to motivation and retention.

\section{In-depth Interviews}

The second phase of qualitative research consisted of IDIs with healthcare providers from different cadres and managers to obtain detailed information to help probe the factors that motivate and demotivate staff and lead to either retention or attrition. These IDIs were carried out with respondents who were not introduced to the structured questionnaire (quantitative component of the study). A total of 61 IDIs were conducted: two interviews per cadre per province. This included two specialists from DHQs, two MOs (male and female) each from THQs and RHCs, and one LHV and one WMO at BHUs, all in the local language.

A separate set of IDI guidelines was used for the purpose. Informed consent was obtained from the respondents. Each IDI took approximately 40 minutes and followed a basic set of topics with probes being used by facilitators when considered appropriate Information gained was used to help interpret the quantitative data and expand upon and explain the findings. 
The Focus Group Discussions preceeded the qualitative research. However, the IDIs were carried out along with the quantitative data collection.

\section{8: Quantitative Research}

The nationally representative study on 'Assessing Retention and Motivation of Public Health Providers in Rural Pakistan', which followed the formative research was carried out between September 20 and November 15, 2012, and involved 1,296 male and female public sector healthcare providers from different cadres. Although the original sample size included 1,372 interviews, this number was changed due to low availability of providers.

The structured questionnaires included questions on motivation which were developed using previously validated motivation assessment tools (e.g. Mbindyo et al. 2009; Taylor and Bowers 1972; Seashore et al. 1982, University of Aberdeen 2007). The initial results from the FGDs were also used to guide questionnaire development. The questionnaire also included a section on measuring respondent job satisfaction. It used a tool entitled "Job Descriptive Index" (JDI) which was developed at Bowling Green State University, USA in 1969 (Smith et al. 1969) and has since been used extensively globally (Bowling et al 2008 and Hakim \& Viswesvaran 2005). The questionnaire was subsequently translated into Urdu and retranslated into English to ensure consistency. The final version was in both languages. The questionnaire was pilot tested in one of the non-sampled districts and further refined..

\section{Sampling Strategy}

The following section describes how the probability-based sample size was determined and how it was distributed across regions. We divided the country into seven strata. They comprised North and South Punjab, Sindh, KP, Balochistan, AJK, Gilgit Baltistan, and FATA. The reason for assigning two strata to Punjab was the vast differences in health outcomes between Northern and Southern Punjab. In the case of GB and FATA, we collapsed them into one stratum due to the paucity of health providers in these areas. However, due to the socio-demographic, cultural, political and geographical differences between GB and FATA, they were analysed as two separate strata. We have provided a brief description of the provinces and regions in Annex 7).

\section{Sample Size}

Since there was no previous research available to determine suitable sample sizes to measure retention at the national and provincial levels, we utilized the findings from a census of health facilities in the public and private sectors conducted earlier by the Population Council in 34 districts of Pakistan. This data provided information on healthcare providers' availability at each different level of facilities. 


\section{Figure 1.2: Geographic distribution of study districts}

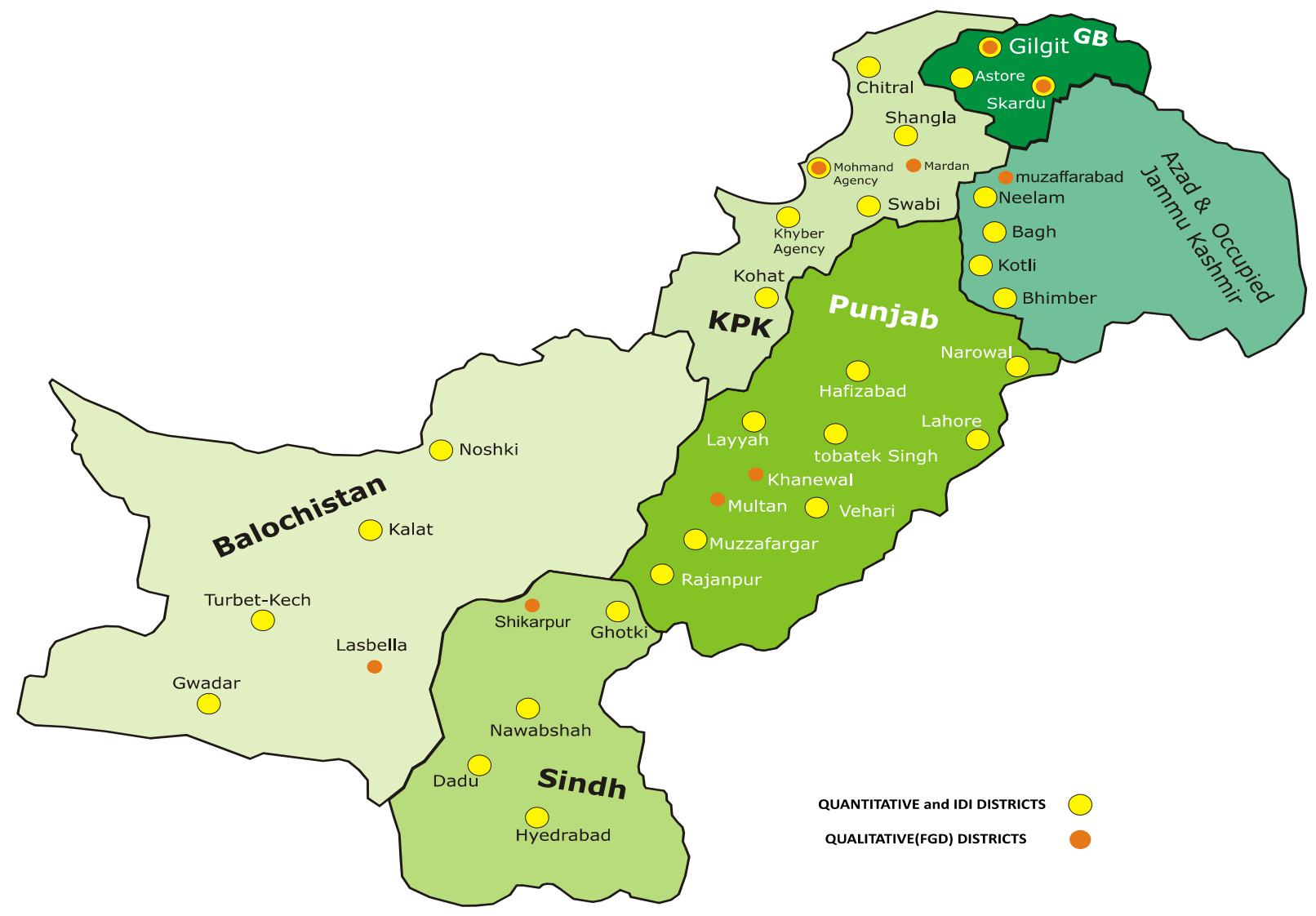

The Census of the Health Facility carried out through GIS mappingrevealed that female staff availability (available on the day of the visit) varied considerably; $12 \%$ at BHUs, $20 \%$ at RHCs, $52 \%$ at THQs, and $80 \%$ at DHQs. We utilized the lowest availability of female staff in order to determine sample sizes. A $15 \%$ level of variation across provinces was used as our criterion for sample selection. A sample of 196 per stratum was selectedusing standard parameters (95\% level of significance [Alpha], $80 \%$ power [Beta], and a design effect of two to allow the effect of clustering.

\section{Stage 1: District selection}

We randomly selected four districts on the basis of socio-economic index rankings and skilled birth attendance in each strata mentioned above. One district per strata in the upper and middle socio-economic bands and two districts from the lower rung of district ranking were selected to over-represent the less or underserved areas of each strata (please see District Ranking in Annex 1-b) This was because we recognized that the problem of staff motivation and retention was greater in these areas. The oversampling of the lower-ranked districts was to ensure provider representation in precisely the areas where staff retention and motivation were problems. Moreover, the district of Astore in GB was included in addition to two sampled districts due to very few facilities being available in these districts. 
Table 1.1: Ratio of districts in each stratum according to socio-economic status 1:1:2

\begin{tabular}{lll}
\hline Number of districts & Status & Select \\
\hline 7 & High & 1 in each strata \\
7 & Medium & 1 in each strata \\
14 & Low & 2 in each strata \\
Total 28 districts visited & & \\
\hline
\end{tabular}

Stage 2: Facility selection (clusters)

All facilities providing basic and comprehensive care, including teaching hospitals within the sampled districts were assessed as part of a situation analysis. Different levels of facilities that qualified as potential MNCH service outlets were randomly selected in each district, which included DHQs, THQs, RHCs, BHUs, and $\mathrm{MCH}$ centres.

We randomly selected one DHQ, two THQs three RHCs, and ten BHUs within each district to select and interview healthcare providers. All $\mathrm{MCH}$ centres and the maintertiary care hospital catering to gynaecology/obstetric patients within the sampled districts were included.The justification for this inverse selection of facilities with more providers was precisely that greater numbers of female staff leave lowerlevel healthcare facilities (Technical Resource Facility 2012). On average we interviewed seven providers in DHQs, five in THQs, three in RHCs, two in BHUs, and one at MCH Centers. This design was based on the knowledge of allocated numbers of staff in each level of facility and the expectation that we would find more staff to be interviewed in the higher-level facilities, and smaller numbers of staff in the lower-level facilities.

Table 1.2 below shows the breakdown of cadres that were interviewed and the number of interviews conducted at each facility based on staff availability. In actuality, 533 facilities were visited and 1,296 interviews were conducted with healthcare providers from different cadres and 69 managers. 
Table 1.2: Number of providers interviewed by cadre and by region

\begin{tabular}{|c|c|c|c|c|c|c|c|c|c|}
\hline & $\begin{array}{l}\text { Punjab } \\
\text { North }\end{array}$ & $\begin{array}{l}\text { Punjab } \\
\text { South }\end{array}$ & Sindh & KP & FATA & GB & Balochistan & AJK & Total \\
\hline $\begin{array}{l}\text { Medical } \\
\text { superintendent } \\
(\mathrm{MS})^{*}\end{array}$ & 0 & 4 & 8 & 1 & 0 & 2 & 3 & 4 & 22 \\
\hline Specialists & 20 & 17 & 18 & 13 & 3 & 5 & 4 & 7 & 87 \\
\hline MOs & 44 & 45 & 41 & 37 & 17 & 16 & 24 & 18 & 242 \\
\hline WMOs & 24 & 24 & 31 & 11 & 9 & 7 & 9 & 15 & 130 \\
\hline LHVs/nurses & 101 & 76 & 57 & 75 & 38 & 39 & 42 & 75 & 503 \\
\hline $\begin{array}{l}\text { Technicians/ } \\
\text { dispensers }\end{array}$ & 42 & 35 & 47 & 37 & 20 & 21 & 58 & 52 & 312 \\
\hline Total & 231 & 201 & 202 & 174 & 87 & 90 & 140 & 171 & 1296 \\
\hline
\end{tabular}

*The Medical Superintendents (MS) interviewed are a small sample of providers who had a dual role at the health facility and were specialists/medical officers as well as administrators. Therefore they are not treated and analysed as a separate cadre.

\section{9: Data Collection, Management, and Analysis}

This stage of primary data collection depended on interviewing staff available at facilities; the teams made three attempts to interview the relevant selected providers. We looked at problems of motivation and resilience in the face of poor working conditions to provide a more complete picture of retention. Information about professional and personal characteristics was collected and responses were linked to geographic area, facility level, cadre type, and other such characteristics. Major factors impacting motivation (pay, promotion opportunities, supervision, relations with colleagues, and work conditions) were assessed through the standard Job Descriptive Index (JDI). Similarly, as part of a 360 degree assessment, there was another structured questionnaire for managers. Providers and managers were asked different questions, but with common themes so as to offer the possibility of comparing responses on similar issues, e.g. housing, pay, safety and security, and incentives to allow a comprehensive view of working environments.

A situation analysis methodology was employed to rapidly assess whether the facility being evaluated was in fact capable and equipped to deliver $\mathrm{MNCH}$ services. Then, all the specified health provider cadres were randomly selected, interviewed, and data collected on socio-demographic factors, along with factors affecting retention and motivation.

Data collected during the primary phase was entered using the CSPro 3 data entry programme and analysed using SPSS (Statistical Package for the Social Sciences) version 14. The data collected though IDI and FGD sessions were digitally recorded, and discussions were transcribed and stored in an $\mathrm{mp} 3$ audio file format along with respondent face sheets. Data was electronically forwarded on a daily basis to the data manager 
who collated and prepared it for analysis. The data manager conducted quality checks on questionnaire completeness, inter-record checks, and mistakes in data files, and suggested corrections in consultation with the principal investigator.

The analyses were performed in two stages. The first stage used "secondary data" to identify gaps in sanctioned versus filled posts. The second part of the analysis classified answers to key questions about motivation and turnover and retention against some basic demographic features such as region, cadre, years of experience, and employment status etc. Gender differences in responses were analysed based on data related to WMOs and LHVs. Univariate analysis was first carried out to obtain descriptive statistics, and this was then supplemented by advanced inferential bivariate analysis. Significant relationships at the bivariate level, as well as theoretically relevant factors were further analysed using logistic regression at the multivariable level.

Analysis of various tested differences between demographic groups and linear regressions measured the association between motivational determinants and outcomes. For the qualitative data, after a thorough content analysis, codes were given and a matrix was developed and themes identified. Data was sorted based on themes and sub-themes and subsequently analysed to identify the social and organizational factors influencing motivation of female healthcare providers.

\section{Study team}

Eight teams were constituted to carry out the field work. Each study team comprised nine members with sub-teams of two members each, with one person entering data in the field. The teams consisted of medical doctors, sociologists, and anthropologists. Facility assessments were carried out by medical doctors and the providers were interviewed by trained and experienced enumerators.

\section{Quality assurance}

A number of measures were instituted to ensure the maintenance of the highest quality standards in both data collection and data analysis. These measures are discussed below.

\section{Standard operating procedures}

The Population Council developed standard operating procedures for carrying out all processes to ensure quality assurance. A number of measures were instituted to ensure the maintenance of the highest quality standards in both data collection and data analysis.

\section{Determination of roles and responsibilities}

Team member and field coordinator roles and responsibilities were clearly identified. Members were provided a written set of roles and responsibilities that they were required to follow.

\section{Training}

The interviewers received nine days of training conducted by the Population Council. The training included sessions on the research protocol, ethics, obtaining informed consent, maintaining privacy during the interview process, sampling methodology, and interviewing techniques. 
The training focused on how to adhere to the standard operating procedures and familiarized participants with study objectives. Two nine-day trainings on research methods and data collection tools were conducted for the data collection teams.

A questionnaire manual was prepared for interviewers and each member was provided with a written set of responsibilities and standard quality checklists. Each team had a quality control supervisor for on-the-spot data verification during the data collection phase.

\section{Monitoring}

The principal investigator, study coordinator, and field coordinators regularly visited randomly selected districts in each region to ensure all protocols were being followed. They randomly selected completed questionnaires during monitoring visits to check for completeness, data accuracy, and to determine reinterviewing requirements.

\section{Ethical considerations}

Ethical approval was obtained from the Institutional Review Board (IRB) of the Population Council's headquarters in New York (Annex3A) and by the National Bioethics Committee (NBC) Pakistan(Annex 3B). Informed consent was obtained from all study participants after describing to them in detail the issues related to the study. For the structured questionnaire, the interviewers described the scope and purpose of the questionnaire and its approximate length, and stressed that participation was voluntary.

The structured questionnaires were administered in private. All data collected in each phase of the study was kept confidential and anonymous. The structured questionnaires and IDIs were identified by personal identification numbers rather than participant names.

\section{Response Rates and Refusals}

A total of 1296 interviews were conducted out of a sample size of 1372. The number of interviews that took place depended on staff posting at the facility at the time of visit. The response rate was $94 \%$, and refusal rate less than $0.1 \%$

\subsection{0: Study Limitations and Implications for Future Research}

One of the most challenging aspects of this study was the fact that motivation is a complex issue and difficult to measure because of the subjectivity of the topic and the lack of standard measurement tools. Furthermore, motivation levels do not remain static but vary depending upon conditions and circumstances affecting an individual's life.

Another limitation of this study is that interviews were only conducted with current employees and not with providers who have left the system, which means we do not have a complete picture of reasons that contribute to attrition and turnover. It can be assumed that providers who remain within the system have higher motivation levels than those who have left.

The availability and quality of secondary data on HRH was a limitation. Data on sanctioned and filled posts for providers was not available in Balochistan, and was only available according to grades for KP which 
made a comparative analysis difficult. Additionally, while managers have given us estimates; proper data on attrition rates and attendance records is lacking, because of which the findings of this study could not be used to make a cause and effect assumption about turnover.

The results from this study have now put in place a point of referenceon determinants of motivation and retention for healthcare providers working in the public health system in Pakistan. Future research should use this studyas a measure against which to gauge the impact of the health sector reform efforts that are underway, and to analyse the extent to which the recommendations put forward here have translated into policies and programs. This study design can also be used amongstprivate sector employees of the same cadre in order to create a true comparison between the public and private sector employees.

\subsection{1: Literature Review}

\section{Introduction}

Staff retention at healthcare facilities is a complex issue, which has been researched extensively. The literature reviewed for this study focused on factors that affect healthcare providers' retention and motivation in developing country settings, especially South Asia, to find global examples of such problems and solutions. Although some general motivational themes could be identified (Shattock et al. 2008; Dubois and Singh 2009; Lehmann, Dieleman, and Martineau 2008; Benson and Dundis 2003), it was found that many issues were born out of personal and socio-economic problems understood only within certain cultural contexts. 


\section{Methods}

Extensive use was made of online search engines including Jstor, GoogleScholar, Science Direct, PopLine and Pubmed. Specific terms used in these searches included 'Pakistan', 'South Asia', 'motivation', 'rural', 'health worker', 'female', 'retention', 'incentives', 'LHWs', 'doctors' 'human resources' 'developing countries', and 'job satisfaction' amongst others. Various combinations of these keywords and terms were entered to produce maximum results. The development ofa repository of relevant journal articles led to a snowball effect, with other sources and research papers identified through the use of bibliographies within the material being studied.

Publications were also accessed through the websites of the Population Reference Bureau, the Population Council, the World Bank, the World Health Organisation (WHO) and the United States Agency for International Development (USAID); these were a large source of information. We also reviewed grey literature such as the HLSP 2012 Roadmap for Health Systems Strengthening in Sindh, Pakistan; the 2000 and 2006 World Health Organization (WHO) reports on improving health worker performance, and the TRF Health Facility Assessment 2012.

\section{Context}

Approximately half of the world's population resides in rural communities; however, only $38 \%$ of the total nursing workforce and less than $25 \%$ of the total physicians' workforce serve these areas (WHO 2006). The lack of staff to serve these rural populations is a substantial problem in certain countries and therefore, at times, unqualified workers take up posts to provide healthcare services (WHO 2006). As can be deduced, both these circumstances can have severe and adverse effects on the health conditions in these communities.In 2009, the WHO identified Pakistan as one of 57 countries facing a 'human resources for health' (HRH) crisis, placing it below the required level to deliver essential health interventions to meet the MDGs by 2015.

A recent health facility assessment carried out by HLSP in Pakistan points out some of Pakistan's greatest HRH-related challenges: rural/urban mal-distribution of health workers, a weak HRH management system, a shortage of $\mathrm{HRH}$, brain drain of skilled health workers to other countries, and anunregulated private sector that operates primarily in urban areas. There is no comprehensive strategy for staff production and posting and training in Pakistan, which is worsened by an extreme shortage of female workers and specialists in rural districts and an excess of general cadre and support staff (HLSP 2012).

\section{Understanding motivation}

It is essential to understand what motivates health workers to retain their jobs and perform optimally. However, 'motivation' itself must be defined first. Psychologically, it can refer to an individual's driving force and desire to work towards a goal or accomplish an objective. In the work context, it has been described as the 'degree of willingness to exert and maintain an effort towards organizational goals' (Franco et al. 2002). Being motivated at work plays a large role in how individuals perform and can be an indicator of their intention to quit their jobs (Zurn et al. 2005). Not only does the quality of workers' performance 
deteriorate due to low motivation, but it also leads to an increase in worker migration (from rural to urban areas and abroad) (Mathauer and Imhoff 2006).

The concept of motivating workers in the health workforce is a complex one: it spans many disciplinary boundaries, and motivation levels can fluctuate over time for various reasons including external events (Franco et al. 2002). Moreover, individuals within the same environment or community may not be affected the same way by external motivational factors - this is because these factors will interact with each health worker's personal goals and inherent physiological and psychological needs in a different manner. Due to the relevance of intrinsic factors in the healthcare field where each care provider deals with clients and the community on a personal platform, it is vital to understand the importance of internal dynamics and how these must be utilized to effectively motivate health workers to stay in their jobs.

Three theories of motivation were examined to understand this concept thoroughly: Maslow's Hierarchy of Needs, Herzberg's Two-Factor (motivator-hygiene) Theory, and Vroom's Expectancy Theory of Motivation. All three explain the interaction between internal and external factors that affect worker motivation. Vroom's theory focused on the need to link deserved and wanted rewards to performance (Isaac, Zerbe, and Pitt 2001).

Herzberg described satisfaction and dissatisfaction as two separate constructs affected by different factors at the job. Therefore, workers' satisfaction levels remain independent of their level of dissatisfaction. This means that workers may simultaneously be both satisfied and dissatisfied (Herzberg et al. 1959; Maddox 1981). Moreover, Herzberg differentiated between maintenance or hygiene factors (factors that lead to staff retention) and motivating factors (factors that stimulate good job performance) (Dieleman et al. 2006). The former influenced by 'dissatisfiers' (e.g. working conditions, salary, supervision) and the latter by 'satisfiers' (e.g. achievement, recognition).

Maslow's 'Hierarchy of Human Needs' theory posited deficiency needs and growth needs: each deficiency need must be met for the individual to move on to meeting the next need. It is only when all deficiency needs are met that one moves on to fulfilling one's growth needs (Maslow 1954). Benson and Dundis (2003) incorporated Maslow's Hierarchy into a general framework of worker motivation which has been referenced in this review.

Franco et al. (2002) utilized these theories, amongst others, to form an argument that all of them are common at least in their recognition of the existence of three broad categories of internal influences on worker motivation. These are:

- An individual's goals, motives, and values (further categorized into those related to satisfaction of basic survival needs and those related to fulfilment and self-satisfaction);

- The idea of self-concept and self-variables such as self-esteem and workers' evaluation of their own competencies;

- Cognitive expectations about the relationship between workers' actions and their outcomes. 
When combined, these internal components eventually determine the time and effort individuals will dedicate to their work. However, it has been suggested that workers are impacted by these components in two ways. First, they can adopt organizational tasks as personal goals - Kanfer refers to this as the 'will do' part of their motivation process. Second, they may mobilize their resources to accomplish said goals - what Kanfer calls the 'can do' portion of this process (Mathauer and Imhoff 2006). According to Franco et al. (2002), it is influencing the 'can do' or 'will do' parts of the process that has a direct impact on worker performance, productivity and satisfaction.

In the workplace context motivation has been defined as an individual's willingness to exert and maintain an effort towards achieving organizational goals (Franco et al 2000). According to Karnfer (1990) and Mitchel (1997), motivation is not an attribute of an individual or organization; rather it results from the transaction between individuals and their work environment. Organizational factors that contribute to the work environment include resources, processes, human resource management practices and organizational culture (Franco et al 2000).

Figure 1.3: Determinants of Health Worker Motivation

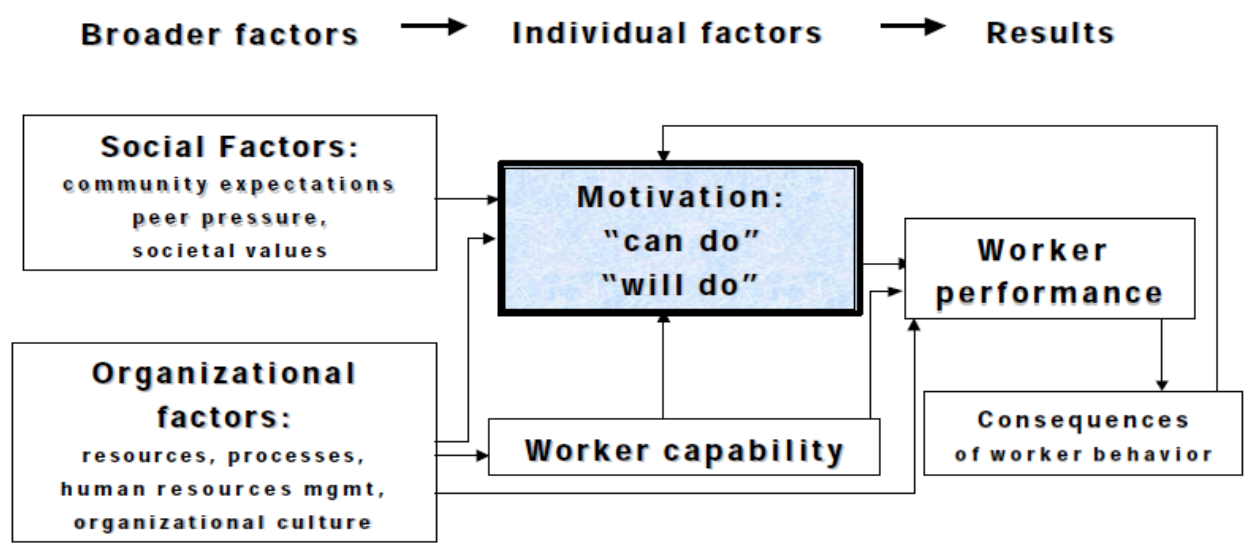

Source: Franco et al. 2000

There is a strong linkage between worker satisfaction and retention. It is necessary for policymakers and department heads to focus extensively on both recruiting workers to the health force and motivating existing staff to stay at their posts. This is where incentive systems play a role (Zurn et al. 2005). The World Health Report emphasizes the importance of incentives as tools that facilities can use to attract, retain, motivate, and satisfy employees, and defines them as 'all the rewards and punishments that providers face as a consequence of the organizations in which they work, the institutions under which they operate, and the specific interventions they provide' (WHO 2000).

Interventions can also be separated into macro (health-system) and micro (facility) levels. The former targeted through HR policy and planning, rural recruitment, and training, and the latter through improving job satisfaction (Dieleman and Harnmeijer 2006), for example, perhaps, by closely examining Herzberg's satisfiers and dissatisfiers. 'Satisfiers' can be targeted by organizations through human resource 
management tools such as job descriptions, supervision, continuous education/training, and rewards. It was found that the main motivators for health workers were related to recognition, responsibility, and training (Dieleman et al. 2006). This finding correlated with other such studies on motivation in resource-poor facilities (Dieleman et al. 2003) where HR shortages had reached critical levels (Dieleman and Harnmeijer 2006) - qualified as well as motivated HR are crucial for the provision of satisfactory health services.

\section{Incentives}

Extent of job security and monetary incentives like high salaries and adequate allowances or stipends received from employers have been mentioned frequently as important retention factors (Dieleman et al 2003; Agyepong et al. 2004; Shattuck et al. 2008; Rehman et al. 2012; Haq et al. 2008). If financial needs are not satisfied, workers try to earn more in ways other than working hard for their public service post (Dieleman et al. 2003), which can be detrimental to the quality of the healthcare they provide.

Workers will work with a certain employer only if the rewards of working there are higher than those they might receive elsewhere. Moreover, higher salaries would be required to attract additional professionals to the job, and so departmental funding would have to increase at a proportion higher than the number of workers employed (Hongoro and Normand 2006). If the aim is to retain employees, any alternate employment must be made less attractive. If wages are low, then this should be made up through alternative financial allowances. A study on financial incentives in South Africa showed that extra allowances had positively affected health workers' future plans (especially nurses) to work in rural areas (Reid 2004). Wages also form the base of Maslow's Hierarchy (Benson and Dundis 2003), providing financial security (Rehman et al. 2012), and satisfying basic survival needs such as food and shelter.

However, financial incentives alone are not sufficient to motivate personnel to perform better. As evidenced by a study conducted in Lahore by Malik et al. (2010) and supported by others (Ssengooba et al. 2007; Franco et al. 2000), less salary was the most commonly reported demotivating factor for respondents, but it was only one amongst several. As ratified by other studies, money is not always the most important motivating factor (Franco et al. 2002; Rector and Kleiner 2002; Dieleman and Harnmeijer 2006). Therefore, to retain an employee, if salary or allowances cannot be raised due to funding difficulties, it is essential that other job characteristics be made more attractive as there are a number of non-financial mechanisms that can improve worker motivation (Hongoro and Normand 2006; Franco et al. 2000). Many factors tend to be related and their effect on health providers relies on the prevailing political, socioeconomic, and cultural environment (Dieleman and Harnmeijer 2006). Methods such as pay for performance have been receiving increasing attention in low to middle income countries as ways to improve the performance of health care providers and align incentives for health worker to public health goals. However, it is important to note that there is currently not enough research available as proof for the effectiveness of these strategies (Witter et al 2012); this has also been evidenced in Pakistan, in the Battagram district where a study revealed many challenges for performance-based pay approaches as well as the need for further research (Witter et al 2011). A study carried out in Tanzania looking at intrinsic motivation in the absence of extrinsic motivating factors found that 20 percent of the sampled healthcare workers provided high quality care even when they received no additional benefits for their efforts. This is an important finding to keep in mind while considering giving performance based incentives (Leonard 
\&Masatu 2010). A number of examples are available from Pakistan where incentives have helped attract providers to work in rural communities.

The People's Primary Healthcare Initiative (PPHI) enables district governments to contract provincial rural support programmes (RSPs) to manage first-level care facilities (FLCF) in their districts - PPHI has been implemented in over $60 \%$ of districts in Pakistan. One of the reasons for its launch was the difficulty government basic health units (BHUs) experienced in attracting and retaining the correct type of HR, especially medical officers (MOs) and lady health visitors (LHVs) due to inadequate compensation and poor infrastructure.

PPHI provides its staff with high financial incentives (Martinez et al. 2010). MOs operating in PPHI facilities receive salaries similar to those of their counterparts in non-PPHI districts. However, they also receive attractive salary complements if they manage more than one BHU. The women medical officers (WMOs) are also paid a higher salary through the PPHI. Moreover, a hard area allowance is available to all employees in a PPHI district, whether they are PPHI or government employees. This allowance or its substitute was not found to be available in non-PPHI districts.

Results of the PPHI scheme were evaluated by a third party (Martinez et al. 2010). It was clear that PPHIoperated districts (at least two-year presence) had achieved significant improvements in staffing, drug and equipment availability, and facility physical conditions, including rehabilitation and repossession of previously dysfunctional BHUs.

Offering incentives to urban dwellers, such as schooling for children, housing, security, and financial allowances have dramatically improved staff coverage in various countries. The Norway-Pakistan Partnership Initiative Project for improving child and maternal health has made progress in increasing the number of female health workers using means such as subsidizing $50 \%$ of travel costs. However, long-term sustainability depends on the maintenance of these costs by the Government (HLSP 2012).

The Chief Minister's Health Initiative for the Attainment and Realization of the MDGs (CHARM) project, in Punjab, Pakistan, focused on strengthening healthcare provision by improving services provided at BHUs and rural health centres (RHCS). CHARM ensured the provision of additional health workers for 24-hour services at facilities, top-up salaries for existing staff working night shifts, and a continuous supply system for the regular delivery of essential medicines, vaccines, and FP material. Service delivery mechanisms were expanded (e.g. local paramedics hired) and HR capacity increased through competency-based trainings for existing staff.

The project provided funds for minor repairs and renovations and furniture and equipment. Community participation was promoted by involving lady health workers (LHWs) and community health workers (CHWs) in health education seminars and awareness campaigns. Health melas were organized at weak health facilities to encourage community participation. The United Nations Children Fund (UNICEF), the United Nations Population Fund (UNFPA), and the LHW programme provided extra supplies to meet the increased demand, while some medicines were purchased from the CHARM Programme budget. From a management perspective, a new innovative e-monitoring system was devised enabling LHVs to report 
directly to the central database via SMS on a mandatory daily basis - all LHVs were trained to use this. Monthly reports were also submitted via e-mail by the district monitor hired for the CHARM project, and monitored fortnightly by district monitors or managers (e.g. Executive District Officers-Health) (CHARM Annual Report 2011).

CHARM proved to be extremely successful. BHUs where no more than one delivery was conducted monthly now boasted an average of 40 per centre. This accomplishment stemmed from the decision to strengthen existing systems instead of creating new structures.

\section{Infrastructure and resources}

Researchers emphasized the quality, quantity, and consistency of resources and medical supplies that facilities were able to provide employees to treat patients (Franco et al. 2002; Dieleman et al. 2003; Fort and Voltero 2004). A lack of essential equipment, deprivation of resources such as safe water, electricity, and a communication system as well as isolation of health units, were some of the infrastructural factors affecting motivation in a study in Pakistan (Farooq et al. 2004). The lack of transport facilities and factors like fuel reimbursement played a major role in attracting workers to jobs, as well (Mumtaz and Salway, 2005; Haq et al. 2008).

Maji et al. (2010) highlighted the relevance of adequate facility infrastructure; limited space caused overcrowding and discomfort, and the lack of privacy was detrimental to antenatal check-up performances and FP service provision. Poor, difficult working conditions impacted health and safety on the job and can turn into major disincentives to stay (Dieleman et al. 2003).

Facility assessments as well as other studies conducted in Pakistan show that the country faces many problems regarding quality of infrastructure and resource availability. An HFA conducted by PAIMAN in ten districts of Pakistan in 2005 depicted the conditions of 72 facilities (44 RHCs, 20 THQs and 8 DHQs). Basic EmONC services were only available in $23 \%$ of RHCs, $40 \%$ of THQs and in all the DHQs; comprehensive services in 20\% THQs and 63\% DHQs. None of the RHCs and THQs and 2 of the DHQs had all of the service delivery protocols available; 6 RHCs, 6 THQs and 2 DHQs had none. All essential MNH drugs/supplies were available at only 2 RHCs and THQs and $1 \mathrm{DHQ}$. On the positive side almost $80 \%$ of posts were occupied at the RHCs. However, only $10 \%$ of sanctioned posts for anaesthetists were filled at the THQs and $27 \%$ at the DHQs; and $47 \%$ of sanctioned posts for gynaecologists at THQs and $75 \%$ at DHQs; and $66 \%$ of posts for paediatricians at THQs and 75\% at DHQs (PAIMAN 2005).

A study conducted in Multan (Fikree et al. 2006)described the poor state of public sector obstetric facilities in the city in terms of structure (spatial distribution of emergency obstetric care [EmOC] facilities, staffing patterns, and equipment and supplies) and process (knowledge and management skills) indicators. This evidence from Pakistan reflected the lack of essential newborn equipment such as baby scales, foetal stethoscopes or bulb syringes at the BHU, RHC and THQ level facilities. It provided evidence of the shortcomings in the provision of efficient and effective maternal and newborn child health (MNCH) services in Pakistan. 
Another study undertaken in Punjab (Mir and Gull 2012) brought to light the challenges confronting the province in delivering $\mathrm{MNCH}$ services at the district level and the inadequacy of existing health facilities in the areas studied. Distribution of basic emergency obstetric care (BEmOC) facilities was not sufficient with regard to population size in all districts. The lack of staff availability and equipment compromised the quality of care being provided at facilities.

The TRF Health Facility Assessment (2012) in Pakistan reconfirmed the gaps stated in the HLSP document (2012) and the studies above, through an appraisal of 2,018 health facilities in the country. There has not been much of a positive change in the past decade, and comparisons of studies undertaken over the years show that the trend is mostly static. Some of its findings showed that only $67 \%$ of the 992 BHUs and $42 \%$ of the tehsil headquarters (THQ) possessed the assessed infrastructure components available. There was a major gap found in the availability of WMOs and technical staff at RHCs, with only $43 \%$ having a WMO on site. Of 280 THQs, 206 did not have gynaecologists and 229 did not have anaesthetists. A total of 4,029 CMWs had been verified for residential status in the country, with 4,353 having completed training, but only 1,999 had been deployed. Only one BHU had $100 \%$ availability of assessed equipment. None of the RHCs, THQs, or district headquarters (DHQs) had a complete set of equipment.

These studies and statistics reiterate the need for rectifying the substandard functioning of health facilities so that they can run at optimum levels and so that workers can be motivated and satisfied enough to provide patients with the best possible care.

\section{Training}

Most researchers place emphasis on the level of training and technical support an organization is able to provide its employees. Workers need to be able to meet the challenges they encounter with new technologies and should be able to develop their practical knowledge and skills at work (Henderson and Tulloch, 2008; Dieleman et al. 2003; Haq and Hafeez 2009; Fort and Voltero 2004). An organization's willingness to spend time and resources on its employees can be shown through training sessions enabling them to continue their education. This would also make them feel more needed, thus increasing motivation. According to Maslow, training also presents workers with opportunities to feel and be more productive and confident at their jobs.

Training can be further classified into pre-service and in-service training - they are equally important. Continuing professional development through training prevents staffs' skill levels decreasing over time (Hongoro and Normand 2006). For example, all the respondents in a study conducted in Pakistan (Haq and Hafeez 2009) felt that some means of continuing education (or in-service training) would help them improve their knowledge. Around $94 \%$ of them felt a regular source of information (e.g. a bulletin sent by the programme) would enable them to respond to patients' questions, adequately. This outlook helped achieve area- and culture-specific solutions along with general ones such as refresher training sessions which would improve workers' communication skills.

The Salutation, Assessment, Help, and Reassurance (SAHR) approach used in Pakistan (Sathar et al. 2005) is an excellent example of the importance of both training health workers and their engagement with the 
community through a behavioural change training, focusing on influencing internal motivation through such psychological techniques as enhancing one's feelings of self-worth and considering their work as social obligations and responsibility. A recent evaluation of the training imparted to provides in twenty districts of Paksitan showed that trained providers received $60 \%$ more clients than their untrained counterparts (TNSAftab, 2012)

\section{Management}

Good hospital/facility management results in positive working relationships between employers and employees and develops good communication pathways as employers provide feedback to their workers (Shattuck et al. 2008). This includes instating codes of conduct in the work place with clearly defined roles and responsibilities for all tiers of workers, which are met through good supervision (Henderson and Tulloch 2008; Fort and Voltero 2004). Interventions designed to strengthen leadership and management in the workplace produced positive changes in health-service delivery in Kenya (Seims et al. 2012).

An appreciation by superiors, impartial performance appraisals, recognition of good work ethic and achievements, and various forms of non-monetary incentives such as letters of appreciation and rewards, all have an impact on worker motivation (Henderson and Tulloch 2008; Dieleman et al. 2003; Benson and Dundis 2003). This means employers are considering the psychosocial needs of their employees, the importance of which is emphasized in most literature and is a part of Maslow's Hierarchy, as well.

\section{Feedback and appreciation from the community}

The level of appreciation and belongingness workers receive from their community has a large impact on their quality of work (Huitt 2007). Feeling needed by clients brings credibility to the workers' persona e.g. by boosting their self-esteem and confidence (Haq and Hafeez 2009; Huitt 2007). Feedback from the community plays an even larger role when official supervision is lacking and positive comments from colleagues are rare. Patient reactions can help healthcare providers gauge the quality of their services and motivate them to put more effort into their work (Dubois and Singh 2009). 'Public honouring,' seen through the involvement of health workers in public meetings and appreciation from within their group meetings, was seen as an impetus for social commitment in a study conducted in India (Gopalan et al. 2012). Research in Kenya also showed health workers to prefer community acceptance over supervisors' recognition (Mbindyo et al. 2009).

\section{Cultural constraints and family obligations}

Franco et al. (2000) stated through their comparative study on health worker motivation in Jordan and Georgia that local culture was found to impact motivation issues significantly, as was evident through differences in the results obtained from both countries. They stressed upon the need to shape motivational interventions according to the particular needs of groups within different cultures, while fully taking into consideration the local workforce.

A qualitative study conducted in Papua New Guinea (Tynan et al 2013) emphasized the importance of taking cultural values of communities into account when measuring determinants of motivation. Results showed that for a health program to be successful it is important to address local contextual motivational factors that exist within a particular community or sociocultural environment. A Male Circumcision Program 
in PNG was a great example of the importance of sociocultural determinants due to the impact of community influence and expectations and strong religious beliefs on health workers' motivation, performance and service delivery. The authors found the strong linkages between health workers and their community in PNG to be unique in comparison to findings from other studies; this reiterates the need to focus on the different needs of different communities when designing health policies and programs.

In South Asia, not being able to communicate with family effectively can be a major problem (Haq et al. 2008). Simple physical distance is aggravated by weak infrastructure and poor communication services in rural areas. A bigger constraint is opposition from one's family regarding the job (more common amongst female workers), especially due to issues such as night visits and working outside one's immediate home area (Rahman et al. 2010). Cultural barriers can also affect motivation in healthcare centres (Haq and Hafeez 2009) e.g. not being able to talk about certain topics or difficulty in convincing village communities to follow their instructions, simply because one is female.

\section{Gender bias}

Women comprise the majority of the global health workforce, especially when unpaid healthcare is included. It is mostly female providers who address the largest burden of disease at the primary care level. In 2006, 80\% of frontline health workers in the USA were female (HWS 2006 as in Reichenbach 2007). Taking this under consideration, the gender differentials in health workforce management and incentivizing are quite large. Social and cultural restrictions, fears of physical and sexual assault, and discrepancies in financial compensation and promotions due to gender, are all common amongst CHWs and LHWs in Pakistan (Mir and Rashida 2007). Abusive hierarchical management structures, disrespect from male colleagues, a lack of sensitivity to women's cultural constraints, and clashes between domestic and work responsibilities (Mumtaz et al. 2003) are also major issues.

Mir and Rashida (2007) stress the importance of providing gender awareness to health workers, thereby equipping them to become autonomous and conscious of gender equality. Gopalan et al. (2012) found that empowering unemployed rural women as CHWs could become a 'replicable and sustainable model' in community health management. Rural sustainable models like these can perhaps make up for the dearth of higher-level workers.

\section{Self-actualization}

Issues such as utilizing one's full potential at work and practicing to the full extent of one's education and competence have been raised (Dubois and Singh 2009). Career development and opportunities to specialize or be promoted have an impact on motivation (Shattuck et al. 2008; Rehman et al. 2012; Haq et al. 2008), as does the ability to continue education and attend classes and seminars to increase existing levels of knowledge and skills, eventually reaching a stage of self-fulfilment (Dieleman et al. 2003). Dubois and Singh (2009) also stressed the importance of performance management systems that enable health workers to see their achievements themselves and have others recognize and appreciate them. Maslow saw this learning of new things and growing in the work environment as a form of 'self-actualization' (Huitt 2007), which motivated workers to want to do better, and therefore provide their clients with the best care possible - which is the aim. 
This has also been described by Franco et al. (2002), that individuals with more self-efficacy and self-esteem have a higher likelihood to agree to difficult organizational tasks and to continue working at them despite difficulties faced, than those with low self-concept. These 'self' variables are influenced by external factors e.g. training opportunities, as was seen in the SAHR model discussed above (Sathar et al. 2005). Healthy levels of self-concept present workers with personal reasons and incentives to achieve organizational goals, and they help maintain continued task effort once these goals have been internalized by the worker.

Politics and policymakers

Political meddling with recruitment, corruption, and issues in deployment like detailment ${ }^{1}$ create complexities in Pakistan (HLSP 2012). At times, political pressure to find short-term solutions can lead to countries not addressing HR problems, appropriately (Hongoro and Normand 2006). Problems such as regulatory ineffectiveness, low institutional capacity, and widespread corruption greatly hinder progress in efforts towards increasing motivation and retaining government employees, especially in the health workforce. Some countries have focused on bringing in better incentives through government reforms such as performance-based pay, renewable contracts, and removing underperformers and ghost workers (Hongoro and Normand 2006).

A recent study conducted by Callen, Gulzar, Hasanain and Khan (2013) in Pakistan during the election period revealed some interesting statistics about the relation between health service provision and local political outcomes.

Data on parliamentary election outcomes was combined with data collected on doctor absence; doctors were interviewed to ascertain whether they had connections to politicians and if this was related to their performance at work or their choice of posting; a smartphone attendance monitoring program was studied across 81 percent of the Provincial Assembly constituencies in Punjab; and the smartphone program was examined to see whether its role in providing health worker attendance information to senior officials actually impacted doctors' absences. Results showed that more health worker absence was found in constituencies that were less politically competitive; doctors with political connections were absent more; and while the smartphone program doubled health worker attendance (and only 90 smartphones served to increase health inspections twofold, in half the province), these effects were highly concentrated to politically competitive districts.

The authors also realized that health worker absence is tricky to address, as public jobs appear to represent a central form of patronage; doctors in such positions might be expected to do less work. It was found that doctors who did not know their local parliamentarian directly were present at 1.309 of the authors' 3 facility visits; and those who did know their parliamentarian were present at only 0.727 visits. Moreover, fixing the problem is challenging, as well-protected government jobs are 'an attractive means of patronage' for politicians and constituents. Therefore it is vital to reduce the influence that elected politicians have on the allocation of public sector jobs.

\footnotetext{
${ }^{1}$ sanctioned relocation of a health provider, leaving her vacant post blocked and overstaffing at the facility she works at where she occupies a non-vacant position
} 
Although policymakers and planners are finally beginning to realize that to achieve the MDGs, they must focus on fixing the HR crisis discussed (Dieleman and Harnmeijer 2006), a lot more effort needs to be put into the solution especially in Pakistan's case.

\section{What pushes providers away from rural areas}

Dieleman et al. (2003) addressed the private and public sector divide in healthcare provision. There is more of a potential market for private practices in urban areas, and public health sector salaries are not sufficient, encouraging doctors to stay in urban areas. Studies conducted in low-and middle-income countries emphasized the difficulty in recruiting staff to the public sector (and to rural areas) and if recruited, difficulty in retaining them (Hongoro and Normand 2006). The combination of a public sector job in a rural setting is unattractive to many, especially if there is a possibility to move to cities and earn more income through private clinics and have a better standard of living (Hongoro and Normand 2006). The ability to generate additional income on top of a government salary is an important motivational factor. Moreover, working conditions in rural/public health facilities tend to be much worse than their counterparts in urban areas.

Farooq et al. (2004) found that doctors from Pakistan (with relatively high social and economic status) were unwilling to work in public rural facilities because they felt it would have a negative impact on their professional and family lives. A lack of clinical experience and professional growth, distances between facilities and homes, bad transport facilities, poor living conditions, low wages, and weak schooling systems for children were all seen as hindrances. Again, the main incentives to work were similar to most other places: salary increases, grants and allowances, training and refresher courses (preferably through the establishment of a rural health academy), and regular contact with management and administration.

In this global (and regional) context of increasing inequities, health service policymakers are trying to find ways in which staff retention can be increased in inaccessible and socio-economically poor areas.Some countries have considered delinking health workers from public service commissions and setting up independent health commissions to run the health sector (Hongoro and Normand 2006). Hongoro and Normand (2006) also mentioned training a new kind of health worker who would be more useful to lowand middle-income countries: developing only the most important skills and keeping in mind the decline of skill over time, thereby allocating resources appropriately between basic training and continuing skills development. They also recommended embodying new financial incentives and developing more innovative cultures.

The government of Thailand resolved its issue of limited staff in rural areas by recruiting and training health workers, locally. These workers were already equipped and prepared for living in remote areas and were assigned placements within their hometowns and licensed to only work in the public sector (Lehmann et al. 2008). This type of approach has been seen to work in Pakistan through the LHW programmes and should perhaps be focused on more than trying to recruit specialists from urban areas, as it can provide better results. Thailand also pays public doctors who work in rural and remote areas a lot more than those working in urban areas (Wibulpolprasert and Pengpaiboon 2003). 
Staff shortages overburden workers and lead to multi-tasking, causing anxiety, stress, and physical exhaustion, and a decline in work quality (Agyepong et al. 2004; Manongi et al. 2006). The link between workers being motivated at their workplace, both internally and as a result of external influences, and their willingness and desire to stay at their jobs, was reiterated in the literature several times. An insight into the complexities of motivating health workers in rural areas specifically was gained along with a better comprehension of the various factors at play that can influence the effort and time individuals are willing to put into their work.

\subsection{2: Socio-Demographic Characteristics of Respondents}

A total of 1,296 providers from different cadres were interviewed, out of which $76 \%$ were regular staff while the rest were contractual. The majority of respondents were females (52\%).

From the table (1.3a) below, it is seen that by cadre, the highest proportion of married providers were specialists and the highest proportion of single providers was of WMOs. The youngest cadre was WMOs (mean age 35 years) who also had the lowest mean number of children (two) (Table 1.3b). Amongh the specialists $86 \%$ had post graduate qualifications, while $36 \%$ of the medical superitendents also had post graduation. Nearly one eighth of the medical officers male and female also had post graduations.

Table 1.3 (a): Socio-demographic characteristics of respondents

\begin{tabular}{|c|c|c|c|c|c|c|c|}
\hline & $\begin{array}{l}\text { MSs } \\
\text { n (\%) }\end{array}$ & $\begin{array}{c}\text { Specialists } \\
\text { n (\%) }\end{array}$ & $\begin{array}{l}\text { MOs } \\
\text { n (\%) }\end{array}$ & $\begin{array}{l}\text { WMOs } \\
\text { n (\%) }\end{array}$ & $\begin{array}{c}\text { LHVs/nurses } \\
\text { n (\%) }\end{array}$ & $\begin{array}{c}\text { Technicians } \\
\text { /dispensers } \\
\text { n (\%) }\end{array}$ & $\begin{array}{l}\text { Total } \\
\text { n (\%) }\end{array}$ \\
\hline \multicolumn{8}{|c|}{ Marital status } \\
\hline Unmarried & $\begin{array}{r}2 \\
\text { (9) }\end{array}$ & $\begin{array}{r}5 \\
(6)\end{array}$ & $\begin{array}{r}40 \\
(16)\end{array}$ & $\begin{array}{r}32 \\
(25)\end{array}$ & $\begin{array}{l}121 \\
(24)\end{array}$ & $\begin{array}{l}26 \\
(8)\end{array}$ & $\begin{array}{l}226 \\
(17)\end{array}$ \\
\hline Married & $\begin{array}{r}20 \\
(91)\end{array}$ & $\begin{array}{r}82 \\
(94)\end{array}$ & $\begin{array}{l}197 \\
(81)\end{array}$ & $\begin{array}{r}98 \\
(75)\end{array}$ & $\begin{array}{l}366 \\
(73)\end{array}$ & $\begin{array}{l}284 \\
(91)\end{array}$ & $\begin{array}{r}1047 \\
(81)\end{array}$ \\
\hline Divorced & - & & $\begin{array}{r}1 \\
(1)\end{array}$ & & $\begin{array}{r}6 \\
(1) \\
\end{array}$ & - & $\begin{array}{r}7 \\
(1) \\
\end{array}$ \\
\hline Widow & & & $\begin{array}{r}4 \\
(2) \\
\end{array}$ & 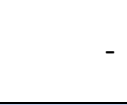 & $\begin{array}{r}8 \\
(2) \\
\end{array}$ & $\begin{array}{r}2 \\
(1) \\
\end{array}$ & $\begin{array}{l}14 \\
(1)\end{array}$ \\
\hline Total & $\begin{array}{r}22 \\
(100)\end{array}$ & $\begin{array}{r}87 \\
(100)\end{array}$ & $\begin{array}{r}242 \\
(100)\end{array}$ & $\begin{array}{r}130 \\
(100)\end{array}$ & $\begin{array}{r}501 \\
(100)\end{array}$ & $\begin{array}{r}312 \\
(100)\end{array}$ & $\begin{array}{l}1294 \\
(100)\end{array}$ \\
\hline
\end{tabular}


Table 1.3 (b): Socio-demographic characteristics of respondents

\begin{tabular}{|c|c|c|c|c|c|c|c|}
\hline & $\begin{array}{c}\text { MSs } \\
(n=22)\end{array}$ & $\begin{array}{c}\text { Specialists } \\
(\mathrm{n}=87)\end{array}$ & $\begin{array}{c}\text { MOs } \\
(n=242)\end{array}$ & $\begin{array}{c}\text { WMOs } \\
(\mathrm{n}= \\
130) \\
\end{array}$ & $\begin{array}{l}\text { LHVs/nurses } \\
(n=503)\end{array}$ & $\begin{array}{l}\text { Technicians } \\
\text { /dispensers } \\
\text { (n= 312) }\end{array}$ & $\begin{array}{c}\text { Total }(n= \\
1296)\end{array}$ \\
\hline \multicolumn{8}{|l|}{ Age } \\
\hline $\begin{array}{l}\text { Mean age of } \\
\text { respondents }\end{array}$ & $\begin{array}{r}50 \\
(\mathrm{SD} \\
12.92)\end{array}$ & $\begin{array}{r}44.3 \\
\text { (SD 9.65) }\end{array}$ & $\begin{array}{r}41.7 \\
\text { (SD 9.97) }\end{array}$ & $\begin{array}{r}34.5 \\
(\mathrm{SD} \\
7.88)\end{array}$ & $\begin{array}{r}34.9 \\
(10.7)\end{array}$ & $\begin{array}{r}40.4 \\
(S D 8.7)\end{array}$ & $\begin{array}{r}38.4 \\
\text { (SD 10.49) }\end{array}$ \\
\hline \multicolumn{8}{|l|}{ Children } \\
\hline $\begin{array}{l}\text { Mean no. of } \\
\text { living children }\end{array}$ & $\begin{array}{r}4.6 \\
\text { (SD2.48) } \\
\end{array}$ & $\begin{array}{r}3.2 \\
\text { (SD 1.78) }\end{array}$ & $\begin{array}{r}3.3 \\
\text { (SD 2.04) }\end{array}$ & $\begin{array}{r}1.98 \\
(\mathrm{SD} \\
1.23) \\
\end{array}$ & $\begin{array}{r}2.4 \\
\text { (SD 1.63) }\end{array}$ & $\begin{array}{r}4.5 \\
\text { (SD 2.64) }\end{array}$ & $\begin{array}{r}3.2 \\
(S D 2.2)\end{array}$ \\
\hline
\end{tabular}

\section{Age distribution}

The mean age of the respondents was 38 years. A third of the respondents were aged $26-35$ years, and another third were $36-45$ years old (Figure 1.4). A quarter were 46 years and above, and the remaining nine percent were less than 25 years of age. Age distribution however varied between male and female providers, with majority of male providers in the 36 to 45 and 46 and above range while majority of the female providers in the 26 to 35 age range. The proportion of women younger than 25 was also significantly higher than the proportion of men.

Figure 1.4: Age distribution of providers by gender
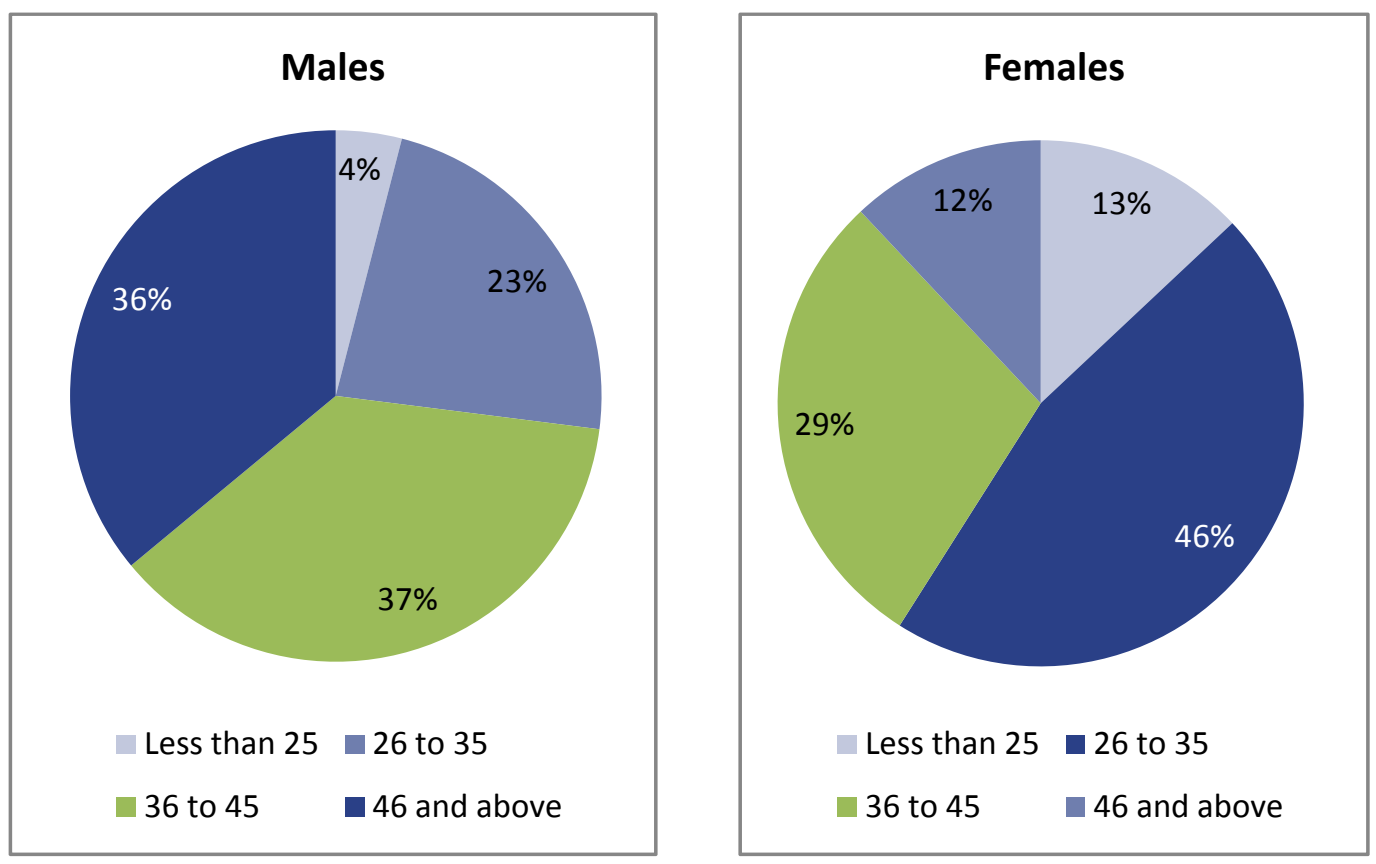


\section{Job Type}

Three-quarters of the respondents were permanent employees while the remaining quarter was contractual. Contractual employees were providers who worked for PPHI (People's Primary HealthCare Initiative) or the Punjab Rural Support Programme (PRSP).

A total of 313 contractual providers of different cadre were interviewed. Out of these 37 percent were LHVs and nurses followed by 25 percent MOS, 18 percent WMOs, 13 percent technicians/dispensers, 5 percent specialists and 1 percent medical superintendents.

\section{Residential status}

Twenty percent of all providers lived within the premises of the facility. Another $56 \%$ lived within the city, and $23 \%$ lived in another city. Of the providers who lived within the premises, a third were specialists, a quarter were LHVs and MOs, while 15\% were WMOs and $9 \%$ were technicians. The highest proportion of providers, who lived within the city but outside the premises were technicians and WMOs. With the exception of specialists (16\%), a quarter of the providers from all other cadres lived in another city (Figure 1.5).

Figure 1.5: Proportion of providers by cadre and residential status

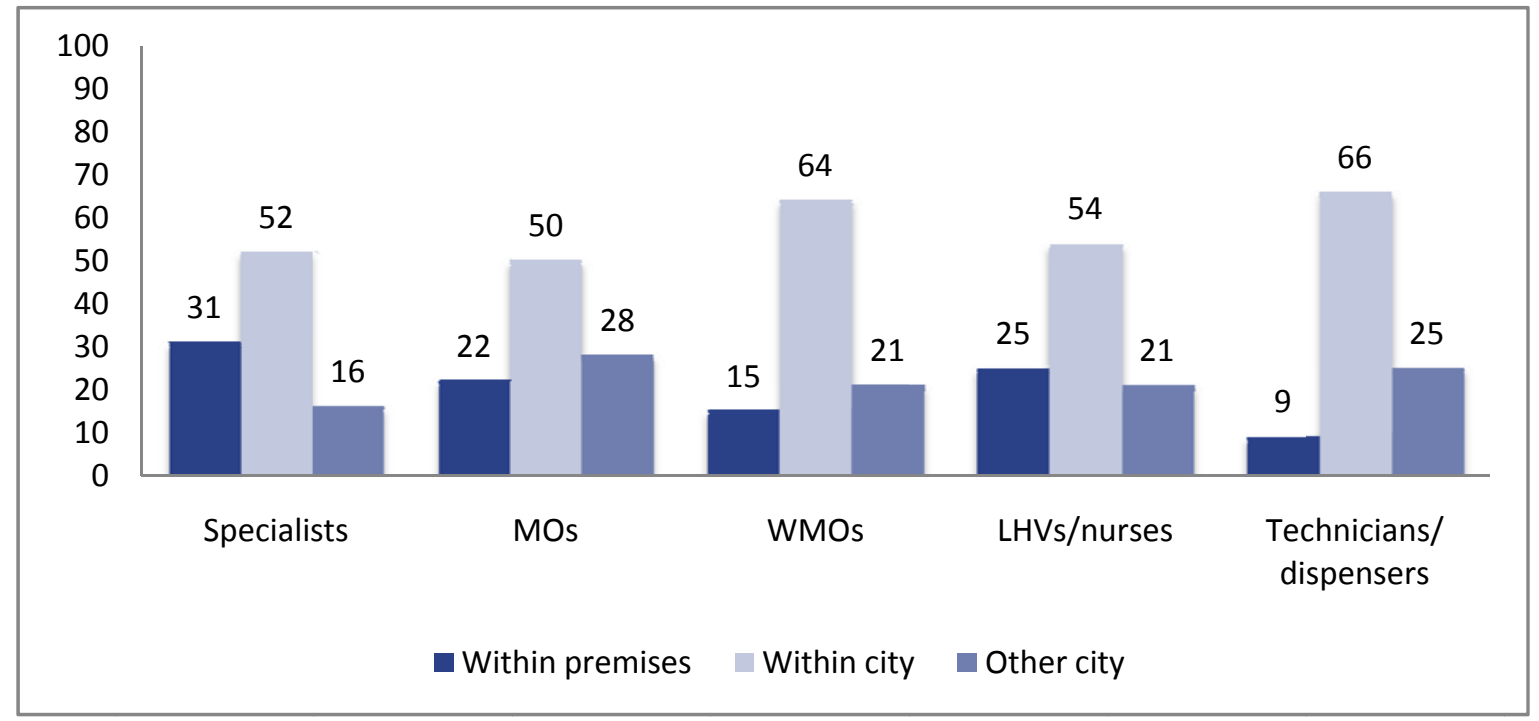

\section{Schooling facility}

The graph below shows the availability of schooling facilities for children near providers' workplaces. The majority reported the availability of schooling near the health facility. This was higher in DHQs and THQs (urban areas), compared to RHCs and BHUs (relatively rural regions) (Figure 1.6). 212 out of 1302 i.e. 15\% of the providers were based in urban areas. 
Figure 1.6: Availability of schooling for children by type of health facility

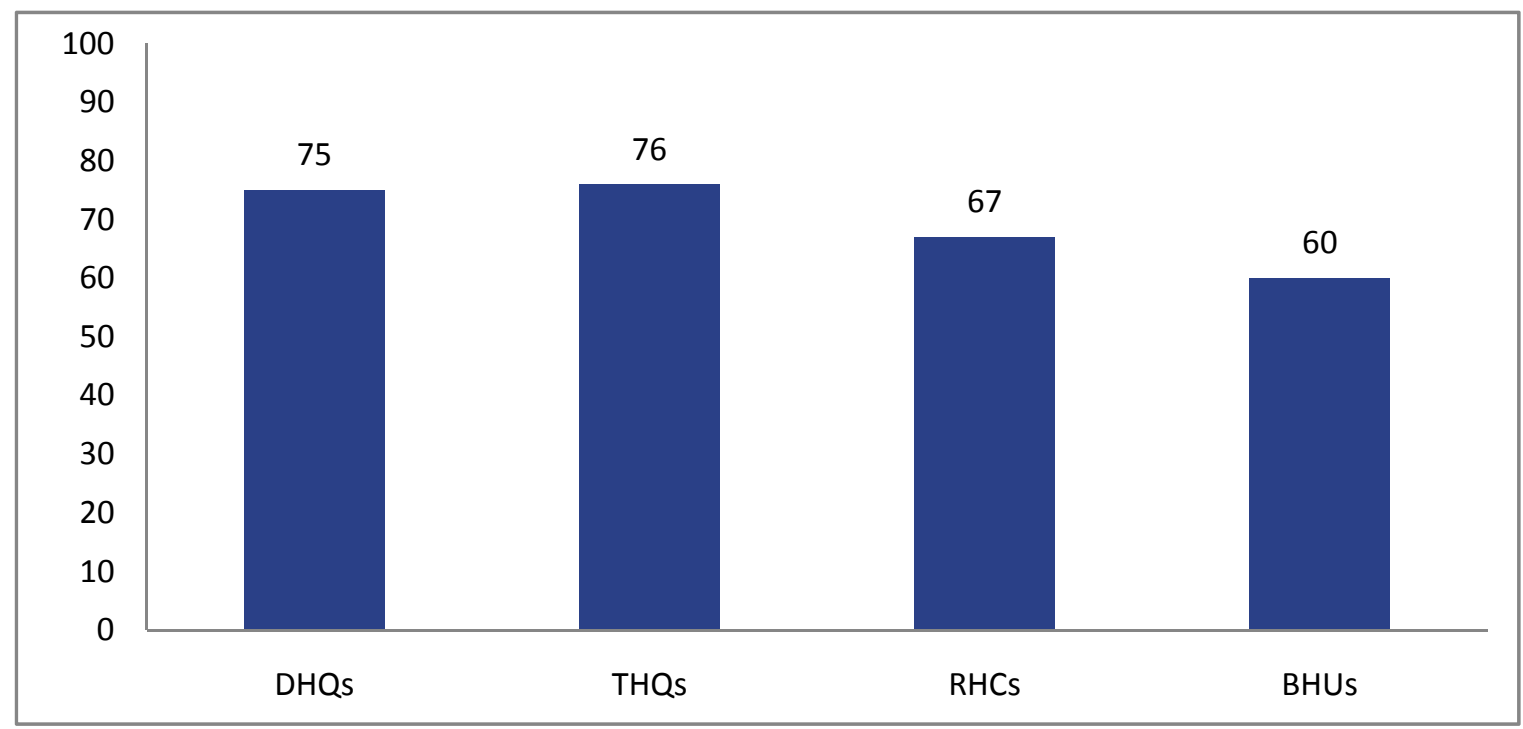

\section{Distance Travelled to reach place of work}

Overall amongst providers living outside their facility, $40 \%$ of the respondents had to travel less than 5 minutes to reach their place of work. A fifth travelled between 6-15 kilometres, 15 percenttravelled between 16-30 kilometres and a quarter travelled between 31-60 kilometres.

\section{Standard of living}

Electricity was available in the homes of all providers. Computers were owned by 100 percentof specialists, 96 percent of WMOs and 88 percentof MOs. Half of the LHVs and 38 percent of dispensers owned a computer. A personal car was owned by 89 percent of specialists, 81 percentof WMOs and 60 percent of MOs, a quarter of LHVs, and 12 percent of the dispensers. 


\section{ORGANIZATIONAL FACTORS INFLUENCING PROVIDER MOTIVATION- AVAILBILITY OF RESOURCES TO DELIVER MNCH SERVICES}

\section{1:Health Facility Assessment -Equipment, Supplies \& Staff Availability}

\section{Introduction}

In this chapter we closely examine resource availability in terms of providing key MNCH services.

For Pakistan to meet MDGs 4 and 5, it needs fully functional and easily accessible preventive and emergency obstetric care (EmOC) services. It is also an important part of a 360 degree assessment of staff motivation and retention because of the causal relationship between workplace environment, availability of optimum resources and infrastructure and staff motivation as well as client satisfaction levels.

It is also essential to assess the availability of facilities and staff in order to determine if they are sufficient for providers working in $\mathrm{MNCH}$ service delivery. In general, research has shown that 15 percent of pregnancies (WHO 2009) will result in life threatening complications; in order to prevent and treat these complications, an adequate number of health facilities and healthcare providers are required.

\section{Health Facility Assessment Objectives}

The objective of the assessment was to generate reliable information on service availability including basic equipment, amenities, essential medicines, and diagnostic capacity and to measure the readiness of health system to provide maternal and child health care.

\section{Geographical Scope of the Assessment}

The assessment was carried out in the sampled districts and included sampled MCH centres, BHUs and all RHCS, THQs and DHQs in the districts. Every facility that was chosen for a provider interview was assessed. A total of 29 DHQs, 37 THQs, 87 RHCs, 282 BHUs and $89 \mathrm{MCH}$ centres were assessed in the 28 sampled districts for the purpose of gauging the status of infrastructure, services offered, infection prevention, and medicine and equipment availability for the providers interviewed. The table in the annex 4shows the number and type of facilities assessed in each province and district.An additional 54 facilities were assessed to gauge Basic and Comprehensive EmOC service status in the sampled districts.

\section{The Health System in Pakistan}

Pakistan has an extensive public sector service delivery infrastructure consisting of primary care facilities which includes Basic Health Units, $\mathrm{MCH}$ centers and Rural Health Centers forming the core of the primary health model.Secondary care includes first and second referral facilities providing acute, ambulatory and 
inpatient care through Tehsil Headquarter and District Headquarter hospitals and tertiary care teaching hospitals.

\section{Primary Care facilities:}

These include $\mathrm{MCH}$ Centers ( $\mathrm{MCHC}$ ), Basic Health Units (BHUs) and Rural Health Centers (RHCs). There is at least one primary health care center present in each Union Council catering to population ranging from ten to twenty five thousand people. MCHCs and BHUs are to operate from 8 am to $2 \mathrm{pm}$, except on Sundays, while RHCs are to provide 24-hour services. $\mathrm{MCH}$ centers are being managed by LHVs and provide basic antenatal care, normal delivery, post-natal and family planning services, and treatment of minor ailments to women and children.

In 2005, the Federal Government launched a country-wide program, known as the People's Primary Health care Initiative PPHI (formerly known as President's Primary Healthcare Initiative) for improving the service delivery at First Level Care Facilities (FLCFs). The purpose of this initiative was to strengthen the curative and preventive services provided in FLCFs, by handing over the management and finances of running the BHUs to the Rural Support Programs (RSPs)/PPHI in their respective provinces. The objective of the initiative was to re-organize and re-structure the management of all the BHUs in the district with a central role for community-based support groups.

They are required to offer first level curative care, $\mathrm{MCH}$ services including obstetric first aid, family planning and preventive services through doctors and paramedics.

RHCs provide more extensive outpatient services and some inpatient services, usually limited to short-term observation and treatment of patients who are not expected to require transfer to a higher level facility. They serve a catchment population of about 50,000 to 100,000 people. They typically have 10 to 20 beds, an x-ray machine, a laboratory and minor surgery facilities. RHCs are mandated to provide Basic Emergency Obstetric Care.

\section{Referral level facilities:}

These include Tehsil Headquarters (THQ - sub district units) and District Headquarters (DHQ) Hospitals that are located at respective levels and offer first line referral services. Tehsil Headquarters Hospitals (THQH) serves a catchment population of about 100,000 to 300,000 people. They typically have $40-60$ beds and appropriate support services including $\mathrm{x}$-ray, laboratory and surgery facilities. District Headquarters Hospitals (DHQH) serve a catchment population of about 1 to 2 million people and typically have about 100150 beds. These hospitals provide Comprehensive EmOC services.

\section{Tertiary care facilities:}

The teaching hospitals in Pakistan provide tertiary as well as sub-specialty care. These hospitals mainly provide curative services and to a limited extent some preventive services.

\section{Indicators for Provision of MNCH services}

Given below are the indicators for provision of $\mathrm{MNCH}$ services at various health facilities. This includes Obstetric First Aid and preventive services at $\mathrm{BHUs}$ and $\mathrm{MCH}$ centres, Primary Healthcare and Basic 
Emergency Obstetric Care (EmOc) at RHCs and Comprehensive Emergency Obstetric and Newborn Care (EmOnC) at THQs and DHQ level facilities.
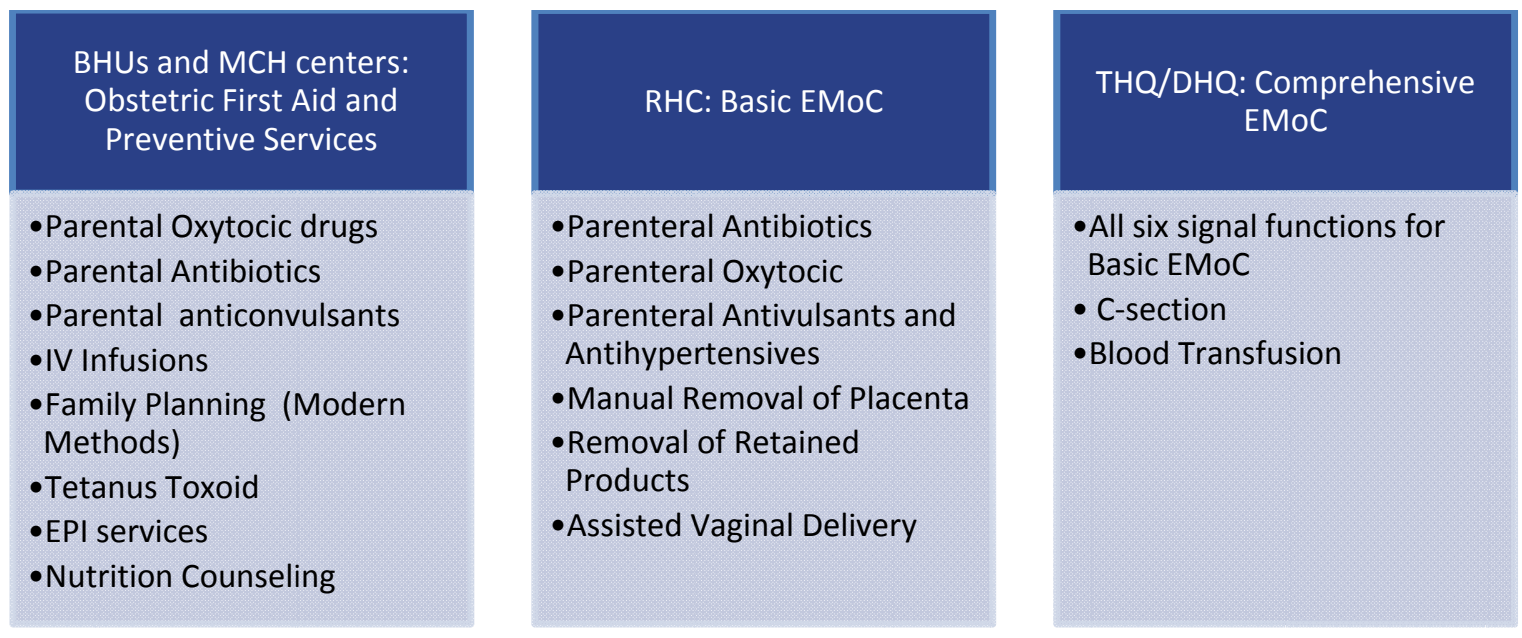

\section{Assessment of Basic Health Units (BHUs) and Maternal and Child Health (MCH) Centres}

An assessment of sampled BHUs and $\mathrm{MCH}$ centers was carried out to observe the antenatal/ natal and postnatal care services in terms of infrastructure, equipment and essential medicines.

\section{Assessment of basic Infrastructure Available at the BHUs and $\mathrm{MCH}$ centres}

The infrastructure of the $\mathrm{BHU}$ and all $\mathrm{MCH}$ centres was assessed in terms of the service and quality of care offered to clients. Indicators included infrastructure, availability of a separate room for consultation (OPD), a private room for examination, separate toilets for male and female patients, availability of electricity in the facility or a backup generator and the presence of a boundary wall for security.

Table 2.1: Proportion of BHUs and MCH centres with necessary infrastructure

\begin{tabular}{lcc}
\hline Basic Amenities & $\begin{array}{c}\text { Number of BHUs and MCH } \\
\text { centres assessed }(\mathbf{n}=\mathbf{3 8 0})\end{array}$ & Percent \\
\hline Separate room for consultation & 308 & 81 \\
with patients & 311 & 82 \\
Separate room for examination & 279 & 73 \\
Boundary wall & 210 & 55 \\
Separate M/F toilets for patients & 346 & 91 \\
Electricity & 66 & 17 \\
Generator & 200 & 53 \\
Water & & \\
\hline
\end{tabular}

Table 2.1 indicates the availabilityof the infrastructure of the assessed Basic Health Units. Majority of the facilities had separate rooms for consultation and examination of patients. Most facilities had electricity and one-fifth had a functional backup generator. Only $53 \%$ of facilities had running water supply. A quarter 
of the BHUs and $\mathrm{MCH}$ centres assessed did not have a boundary wall, and about half did not have separate toilets for male/female patients.

\section{Status of Equipment}

The availability of equipment required for the provision of primary healthcare including antenatal, natal and postnatal care was assessed.

Table 2.2: Status of availability of basic PHC equipment at the assessed facilities

\begin{tabular}{lcc} 
& \multicolumn{2}{c}{ Number of BHUs and MCH } \\
Equipment & Centers with equipment available (n=380) & Percent \\
\hline EPI cold box & 295 & 78 \\
Refrigerator & 276 & 73 \\
Examination tables & 349 & 92 \\
Weighing scales & 331 & 87 \\
Blood pressure equipment & 364 & 96 \\
Stethoscope & 369 & 97 \\
Foley's Catheter & 163 & 43 \\
Delivery Kit & 308 & 81 \\
D\&C Kit & 253 & 67 \\
Bulb Sucker & 179 & 47 \\
Baby Weighing scales & 309 & 81 \\
Baby Ambu Bag & 122 & 32 \\
Oxygen & 185 & 49 \\
\hline
\end{tabular}

Table 2.2 shows the availability of equipment required for the provision of primary health care in the sampled BHUs and $\mathrm{MCH}$ centres. Basic medical equipment was available at most facilities assessed; with $97 \%$ of facilities having a stethoscope, $96 \%$ with blood pressure equipment, $92 \%$ with examination tables and $87 \%$ with weighing scales. The availability of equipment required for the provision of MNCH services was slightly lower, with $81 \%$ of facilities having delivery kits and only $67 \%$ with D\&C kits; for newborn care only $47 \%$ facilities had a bulb sucker, and $32 \%$ of facilities had a baby ambu bag. About three-quarters of facilities were equipped with an EPI cold box most of which were functional. However, three-quarters of the facilities also have a backup functional refrigerator, which can be used to store vaccines in the absence of an EPI cold box. Only $49 \%$ of facilities have oxygen available. Lack of baby bulb suckers and ambu bags signifies the inability of a majority of the facilities to provide care to newborns. 


\section{Assessment of Primary Healthcare/Preventive Services}

The availability of key primary health care services and supplies was also assessed. These are listed in table 2.3.

Table 2.3: Proportion of BHUs/MCH centres offering selected primary healthcare services

\begin{tabular}{lcc} 
Service & $\begin{array}{c}\text { Number of BHUs and } \mathrm{MCH} \text { centres with } \\
\text { service offered }(\mathbf{n}=\mathbf{3 8 0})\end{array}$ & Percent \\
\hline Immunization services & 305 & 80 \\
$\begin{array}{l}\text { Nutrition advice and Growth } \\
\text { Monitoring services }\end{array}$ & 312 & 82 \\
$\begin{array}{l}\text { Tetanus Toxoid } \\
\text { At least four modern FP methods } \\
\text { (pills, condoms, injectables and IUCD } \\
\text { available) }\end{array}$ & 316 & 83 \\
All four services & 211 & 56 \\
\hline
\end{tabular}

It was found that a high proportion of facilities were providing TT and childhood immunization services, as well as nutritional advice and growth monitoring. Most facilities assessed were also displaying IEC (Information Education Communication) materials for reproductive/maternal health (83\%). Provision of FP services was assessed based on the number of modern short-term methods the facility had available and was offering. Slightly more than half of the facilities assessed were providing oral contraceptive pills, condoms, injectables and IUCDs.

Figure 2.2: Proportion of primary healthcare facilities offering range of PHC services by region

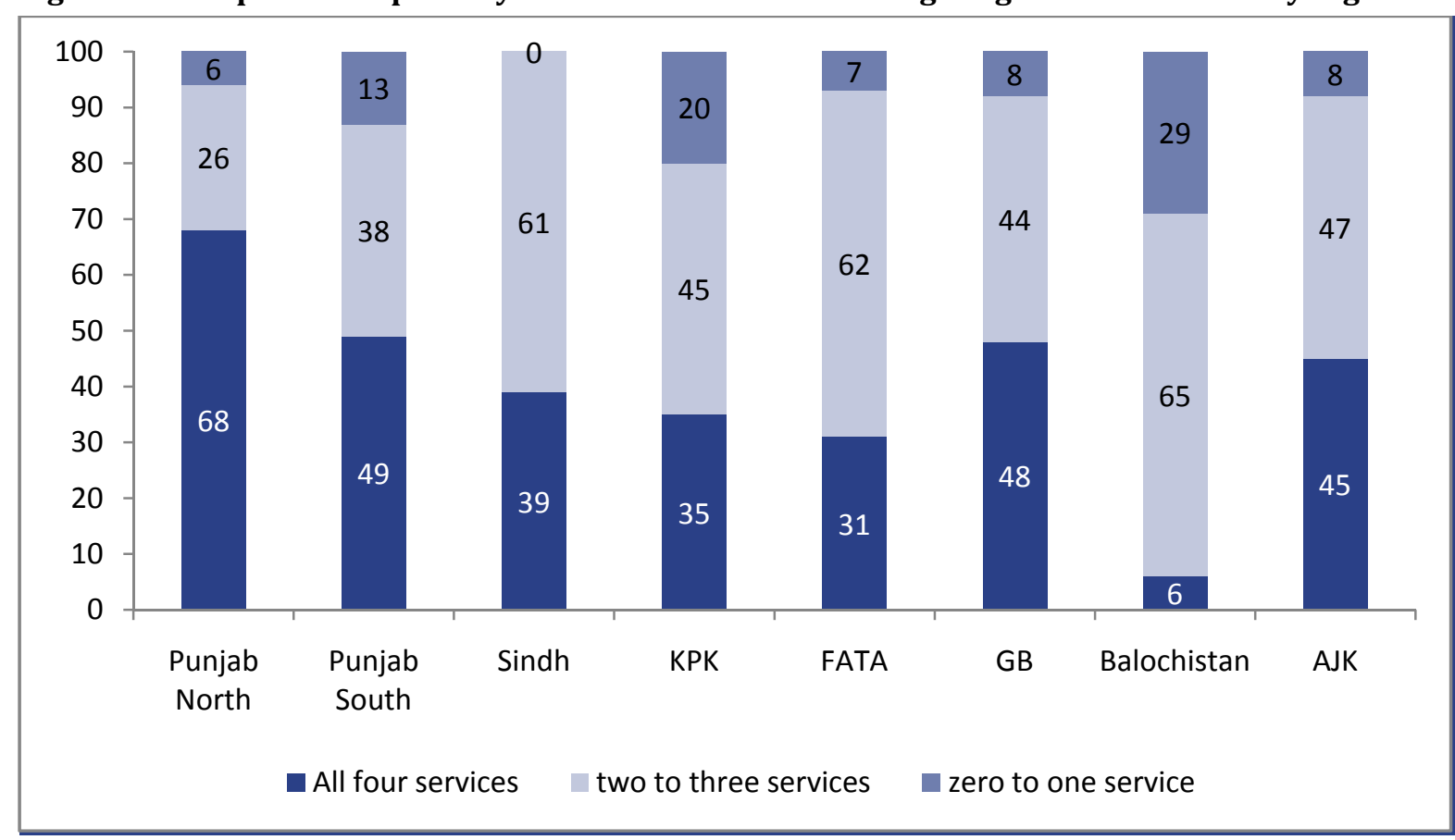


The facility data was disaggregated on the basis of the extent to which preventive services were being provided. Classification was made on the basis of provision of zero to one service, two to three services and all four services. Within the eight regions assessed, two-thirds of the sampled facilities in Northern Punjab were providing all four services, a little less than half of the facilities in Southern Punjab, GB and AJK, followed by a third of the facilities in Sindh, KP and FATA. Only 6\% of the facilities in Balochistan were providing all four services. Majority of the facilities in Sindh, Balochistan and FATA were providing two to three services. The highest proportion of facilities providing either nil or one service was in Balochistan and $\mathrm{KP}$.

Family planning services were assessed by the number and type of modern methods being provided by the facilities, and the proportion of facilities that provided all four of the identified modern methods.

Table 2.4: Proportion of BHU/MCH centres offering contraceptive methods

\begin{tabular}{lcc} 
FP Method & $\begin{array}{c}\text { Number of BHUs and } \mathrm{MCH} \text { centres } \\
\text { with method available }(\mathbf{n}=\mathbf{3 8 0})\end{array}$ & Percent \\
\hline Injectables & 307 & 81 \\
Oral Contraceptive Pill & 308 & 81 \\
Condoms & 295 & 78 \\
IUCD & 239 & 63 \\
All four methods & 211 & 56 \\
\hline
\end{tabular}

Injectables and oral contraceptive pills were available at $81 \%$ of the facilities. Provision of condoms was slightly lower at $78 \%$. Only $56 \%$ of the assessed facilities provided all four contraceptive methods.

Figure 2.3: Proportion of facilities providing family planning services by region

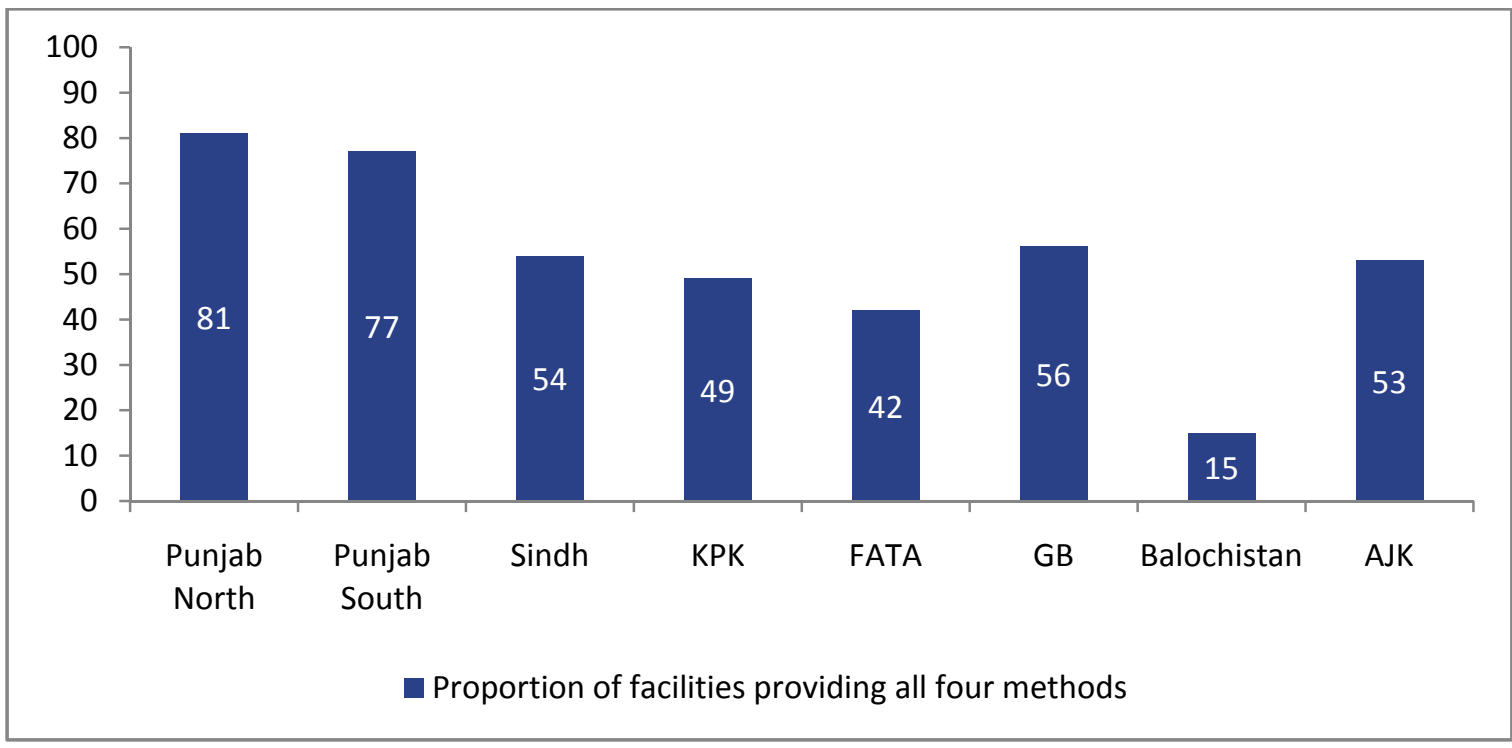

The majority of the facilities in Northern and Southern Punjab were providing all four modern methods. This proportion, however, was lower in the other provinces-with only $15 \%$ of the assessed facilities in Balochistan and less than half the facilities in KP and FATA providing all four contraceptive methods. 


\section{Assessment of Availability of essential MNCH medicines}

The status of medicine availability was assessed according to the list of medicines in table 2.5 that are required for provision of antenatal, postnatal care and basic maternal health services.

Table 2.5: Proportion of BHUs/MCH centres with selected drugs for providing routine ante, natal and postnatal care

\begin{tabular}{lcc}
\hline Medicine & $\begin{array}{c}\text { Number of BHUs and } \mathbf{M C H} \text { centres } \\
\text { with medicine available }(\mathbf{n}=\mathbf{3 8 0})\end{array}$ & Percent \\
\hline Diazepam & 141 & 37 \\
Tetanus Toxoid & 316 & 83 \\
Oral Antibiotics & 354 & 93 \\
Ergometrine/Methergine & 214 & 56 \\
Calcium & 198 & 52 \\
Ferrous Sulphate & 282 & 74 \\
Folic Acid & 299 & 79 \\
\hline
\end{tabular}

In addition, capacity to provide emergency first aid was also assessed. Table 2.6 shows the proportion of facilities providing each element of obstetric first aid.

Table 2.6: Proportion of BHUs and MCH centres with obstetric first aid medicines

\begin{tabular}{lcc}
\hline Medicine & $\begin{array}{c}\text { Number of BHUs and MCH centres with } \\
\text { medicine available (n=380) }\end{array}$ & Percent \\
\hline Anti-hypertensives & 249 & 66 \\
Magnesium Sulphate & 139 & 37 \\
Injectable Antibiotics & 260 & 68 \\
IV Fluids/Plasma Expanders & 173 & 46 \\
\hline
\end{tabular}

The most commonly available medicines out of the list were injectable antibiotics, followed by antihypertensives. However, only a third of the facilities had magnesium sulphate available essential for the management of eclampsia. Less than half of the facilities had plasma expanders available for the management of shock.

\section{Assessment of Infection Prevention Mechanisms}

Infection prevention mechanisms include availability of a mechanism for sharps disposal, a functioning sterilizer, and chlorine solution.

Table 2.7: Proportion of BHUs/MCH centres that have infection prevention supplies and equipment available

\begin{tabular}{lcc}
\hline Mechanism & $\begin{array}{c}\text { Number of BHUs and } \mathrm{MCH} \\
\text { centres with infection prevention } \\
\text { supplies and equipment }(\mathbf{n}=\mathbf{3 8 0})\end{array}$ & Percent \\
\hline Chlorine Solution & 94 & 25 \\
Sterilizer & 269 & 71 \\
Sharp disposal mechanism & 340 & 89 \\
\hline
\end{tabular}


Table 2.7 shows that at the time of the assessment $90 \%$ of the assessed facilities had a sharps disposal container/mechanism, $71 \%$ of the facilities had a sterilizer, $86 \%$ of which were functional. However, only a quarter of the facilities assessed had chlorine solution. The ability to provide primary disinfection at the $\mathrm{BHU} / \mathrm{MCH}$ facilities is compromised.

\section{Summary of Key Findings:}

- Gaps in infrastructure exist at BHUs and $\mathrm{MCH}$ centres that compromise the safety, security and work environment of the providers and their clients.

- Essential drugs required for antennal care and obstetric first aid such as magnesium sulphate required in the management of eclampsia/pre-eclampsia are not available.

- Measures for infection prevention (chlorine solution, sterilisers, and safe (sharp) disposal mechanism are inadequate.

- Injectable and Oral Contraceptives are available at most facilities; however a full range of family planning methods, especially long-term methods such as IUCD are not available at many facilities especially in Balochistan and FATA.

\section{Assessment of Rural Health Centres (RHCs)}

Assessment of basic Infrastructure Available at the Rural Health Centres

Table 2.8: Proportion of Rural Health Centres with necessary infrastructure available

\begin{tabular}{lcc} 
Assessed Infrastructure & $\begin{array}{c}\text { Number of RHCs with } \\
\text { Infrastructure Available (n=86) }\end{array}$ & Percent \\
\hline Separate room for consultation & 31 & 36 \\
Separate room for examination & 53 & 62 \\
Boundary wall & 62 & 72 \\
Separate M/F toilets for patients & 68 & 79 \\
Electricity & 84 & 98 \\
Generator & 54 & 63 \\
Water & 67 & 78 \\
\hline
\end{tabular}

Table 2.8 indicates the results of the assessment of the infrastructure of RHCs. Almost all facilities assessed had electricity. Two-thirds also had a backup generator. As was the case with BHUs and $\mathrm{MCH}$ centres, about a quarter of the facilities assessed did not have a boundary wall which undoubtedly affects the safety and security of providers and patients. Almost a quarter of the facilities also did not have separate toilets for male and female patients. Unlike BHUs, which have fewer staffand a fixed layout, almost two-thirds of the RHCs did not have a separate room for consultation, and a third did not have a separate room for examination. 


\section{Status of Equipment available at RHCs}

RHCs were assessed for equipment required for basic primary healthcare preventive services, routine normal delivery, basic EMoC and newborn care.

Table 2.9: Proportion of RHCs with selected MNCH equipment available

\begin{tabular}{lcc} 
Assessed Equipment & $\begin{array}{c}\text { Number of RHCs with Equipment } \\
\text { Available (n=86) }\end{array}$ & Percent \\
\hline Exam Tables & 82 & 95 \\
Weighing Scales & 84 & 98 \\
Blood Pressure Equipment & 84 & 98 \\
Delivery Kit & 73 & 85 \\
EPI cold box & 83 & 97 \\
Refrigerator & 76 & 88 \\
D\&C kit & 63 & 73 \\
MVA Kit & 19 & 22 \\
Baby Weighing Scales & 70 & 81 \\
Bulb Sucker & 50 & 58 \\
Baby Ambu Bag & 54 & 63 \\
Foley's Catheter & 63 & 73 \\
Baby Endotracheal Tube & 22 & 26 \\
Baby Laryngoscope & 22 & 26 \\
Stethoscope & 86 & 100 \\
Incubator & 17 & 20 \\
\hline
\end{tabular}

As shown in table 2.9 above, almost all RHCs in the sampled districts had examination tables, weighing scales, blood pressure equipment, EPI cold box for vaccines, and a stethoscope. On the other hand, equipment for provision of newborn care was available in fewer facilities with $15 \%$ of facilities not having a delivery kit, a quarter not having D\&C kits, and almost three quarters without an MVA Kit. Status of equipment for provision of neonatal care was also poor-with only $20 \%$ of the facilities having an incubator, a third of which did not work. A quarter of the facilities had an endotracheal tube and laryngoscope for neonates.

\section{Assessment of Service Availability at RHCs}

RHCs were assessed for their ability to provide basic preventive services, including basic emergency obstetric care, paediatric services, and have basic laboratory services. 
Table 2.10: Proportion of RHCs offering selected preventive and diagnostic services

\begin{tabular}{|c|c|c|}
\hline Service & \# of RHCs offering service $(n=86)$ & Percent \\
\hline Immunization Services & 83 & 97 \\
\hline Nutritional advice and Growth Monitoring & 43 & 50 \\
\hline Urine Routine Examination & 58 & 67 \\
\hline Complete Blood Count & 40 & 47 \\
\hline Tetatanus Toxoid Immunization & 82 & 95 \\
\hline IEC & 75 & 87 \\
\hline Pediatric Services $^{2}$ & 25 & 29 \\
\hline Treatment of PPH & 58 & 67 \\
\hline
\end{tabular}

As shown in table 2.10, almost all RHCs were providing immunization services (including Tetanus Toxoid) and a large percentage had IEC material on reproductive health, family planning and $\mathrm{MNCH}$ issues displayed. Other indicators were low; with only half of the facilities providing nutritional advice and growth monitoring services, about two thirds were providing post-partum haemorrhage treatment, and a quarter were providing paediatric services. Two-thirds of the facilities were equipped to run a Urine Routine Exam and about a half could do a complete blood count.

\section{Assessment of Availability of Essential MNCH medicines}

Assessment of essential medicines required for provision of basic EMoC, antenatal, natal and postnatal care at the RHC is shown in table 2.11.

Table 2.11: Proportion of RHCs with availability of selected MNCH medicines

\begin{tabular}{lcc}
\hline Medicine & \# of RHCs with Medicine available $(\mathbf{n}=86)$ & Percent \\
\hline Diazepam & 52 & 60 \\
Anti-Hypertensives & 45 & 52 \\
Magnesium Sulphate & 44 & 51 \\
Tetanus Toxoid & 82 & 95 \\
Oral Antibiotics & 75 & 87 \\
Injectable Antibiotics & 67 & 78 \\
Ergometrine/Methergine & 43 & 50 \\
Injectable Oxytocin & 67 & 78 \\
Calcium & 28 & 33 \\
Ferrous Sulphate & 59 & 69 \\
Folic Acid & 66 & 77 \\
Insulin & 27 & 31 \\
IV Fluids/Plasma Expanders & 78 & 91 \\
\hline
\end{tabular}

12 Includes availability of paediatrician at the facility 
Tetanus Toxoid, IV fluids/Plasma Expanders and Oral Antibiotics were commonly available. Three quarters of the facilities assessed had injectable antibiotics, injectable oxytocin and ergometrine/methergine; availability of all other medicines required for treatment of maternal morbidities was low with only a third of the facilities having insulin and calcium and half having anti-hypertensives and magnesium sulphate available.

\section{Assessment of Support Services}

Table 2.12 Proportion of RHCs with selected support services available

\begin{tabular}{lcc}
\hline Support Service & \# of RHCs offering service $(\mathbf{n = 8 6 )}$ & Percent \\
\hline Laboratory & 69 & 80 \\
Ambulance & 69 & 80 \\
Ultrasound & 31 & 36 \\
Radiology & 64 & 74 \\
Blood Bank & 3 & 3 \\
Blood transfusion facility & 32 & 37 \\
Operation theater & 50 & 58 \\
\hline
\end{tabular}

Assessment of the support services that should be routinely available at RHC level showed that $80 \%$ of the facilities had a functional laboratory service and an ambulance. Three-quarter of the facilities also had radiology services. Operation theatre availability was lower with a little more than half the facilities having an OT, however, only half of these were functional. Ultrasound facilities were also low at 36 percent. Only three of the RHCs assessed had a blood bank, one of which was not functional but 32 percent had the facility to provide blood transfusion if required.

\section{Assessment of Infection Prevention}

RHCs were assessed for the presence of infection prevention measures in place. This included functioning equipment for sterilization, chlorine solution, a method for disposal of sharps and screening for Hepatitis $B / C$ and HIV.

Table 2.13: Proportion of RHCs with infection prevention measures available

\begin{tabular}{lcc} 
Mechanism & \# of RHCs with mechanism in place $(\mathbf{n = 8 6 )}$ & Percent \\
\hline Chlorine Solution & 28 & 33 \\
Sterilizer & 74 & 86 \\
Autoclave & 57 & 66 \\
Hepatitis B/C Testing & 44 & 51 \\
HIV screening & 24 & 28 \\
Sharps disposal & 77 & 90 \\
\hline
\end{tabular}

Almost all assessed facilities had a sharps disposal mechanism in place; and $86 \%$ had a sterilizer. All other indicators were low; with only two-thirds of the RHCs having an autoclave, of which $16 \%$ did not work. Two- 
thirds of the facilities did not have chlorine solution for use as a disinfectant. The proportion of facilities offering screening for infections was also low with only half providing Hepatitis B and C screening, and less than a third providing HIV screening.

\section{Assessment of Family Planning Service Delivery}

The capacity of RHCs to deliver family planning services was assessed by the range and type of contraceptive methods that were available to clients. As seen in table 2.14 , more than three quarter of the facilities offered injectables and condoms, and $80 \%$ offered the pill. $71 \%$ of the facilities assessed had all three methods available.

Table 2.14: Proportion of RHCs with different types of contraceptivesavailable

\begin{tabular}{lcc}
\hline Method & \# of RHCs offering method $(\mathbf{n}=\mathbf{8 6})$ & Percent \\
\hline Injectables & 66 & 77 \\
Condoms & 66 & 77 \\
Oral Contraceptive Pill & 69 & 80 \\
IUCD & 54 & 63 \\
All four methods & 61 & 71 \\
\hline
\end{tabular}

Figure 2.4 shows the proportion of RHCs in each province providing all four modern contraceptive methods (condoms, pill, injectables and IUCD). This was highest in South Punjab followed by Sindh where the majority of the RHCs assessed were providing all four modern methods. This was followed by Northern Punjab, KP and AJK. Availability of FP Serviceswas lowest in Balochistan, FATA and GB.

Figure 2.4: Regional assessment of Family Planning Method Availability at the RHC level

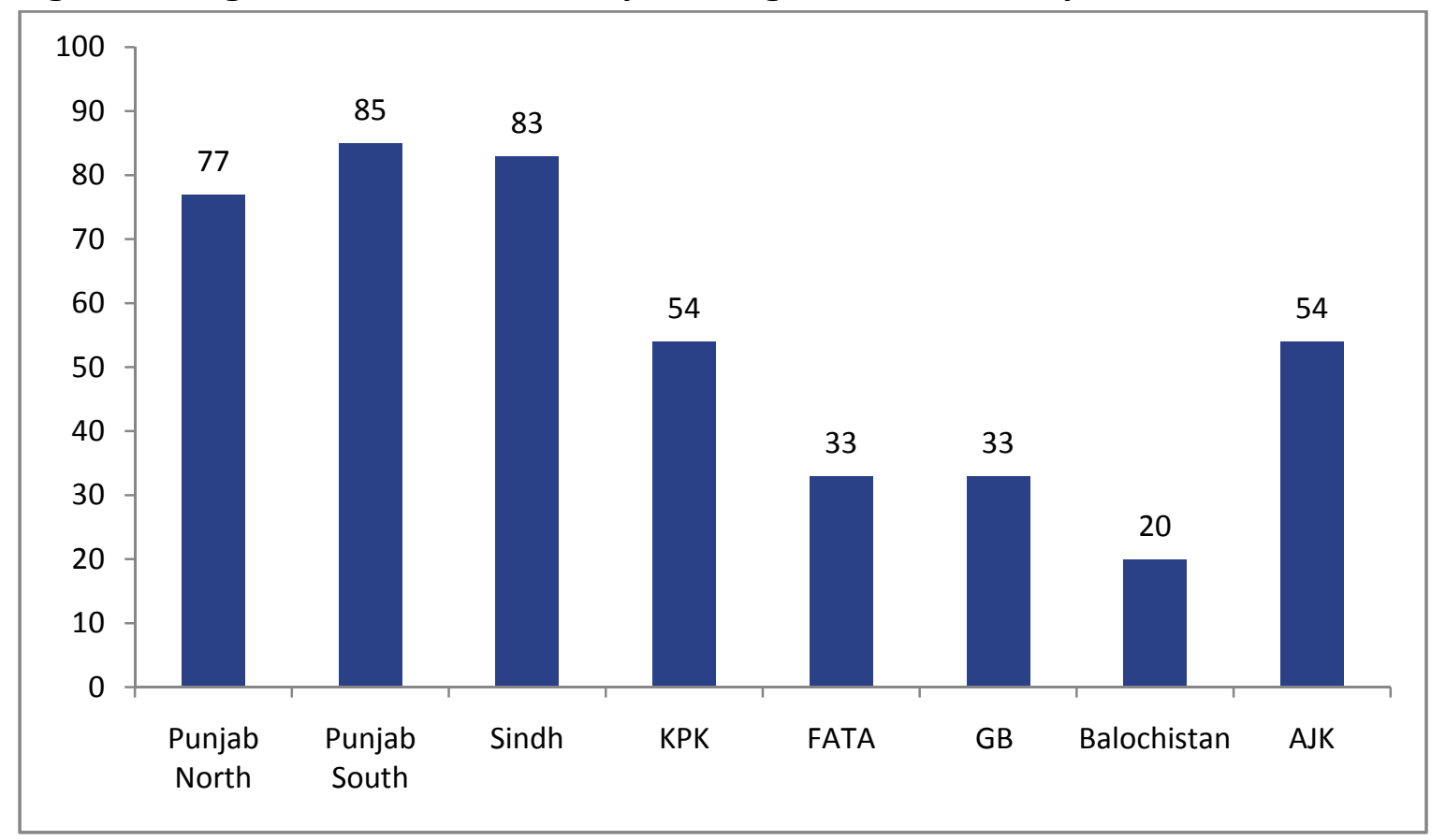




\section{Provision of Basic EmOC in sampled facilities}

Emergency obstetric care $(\mathrm{EmOC})$ refers to a series of crucial life-saving functions, ideally performed in a medical facility, which can prevent the death of a woman experiencing the start of complications during pregnancy, delivery, or the post-partum period. EmOC is a medical response to a life-threatening condition and is not a standard for all deliveries. EmOC functions are often divided into two categories: (1) basic EmOC, which can take place at a health centre and be performed by a nurse, midwife or doctor, and (2) comprehensive $\mathrm{EmOC}$, which usually requires the facilities of a district hospital with an operating theatre.

The proportion of RHCs offering the six functions that compromise basic EmOC is seen in table 2.15, which shows the proportion of RHCs equipped to provide various signal function.

Table 2.15: Proportion of sampled RHCs offering Basic EMoC Services

\begin{tabular}{lrr}
\hline Function & $\begin{array}{r}\text { \# of RHCs with function } \\
\text { in place }(\mathbf{n = 8 6})\end{array}$ & Percent \\
\hline Injectable Antibiotics & 71 & 83 \\
Injectable Oxytocin & 67 & 78 \\
Injectable Anti-convulsants & 42 & 49 \\
Manual Removal of Placenta & 63 & 73 \\
Removal of Retained Products & 59 & 69 \\
Assisted Vaginal Delivery & 25 & 29 \\
Provision of all six signal basic EmOC functions & 12 & 14 \\
\hline
\end{tabular}

The highest availability was of injectable antibiotics, injectable oxytocin, and manual removal of placenta. However, only half of the assessed facilities had injectable anti-convulsants, and less than a third were able to conduct assisted vaginal deliveries. As a result, only $14 \%$ of the facilities assessed were providing all six essential (signal) functions required for the provision of Basic EmOC.

\section{Summary of Key Findings:}

- A very low proportion of facilities have functional diagnostic services available

- There is a lack of essential equipment and medicines required for managing maternal morbidities and neonatal care

- The majority of the RHCs assessed were able to provide four modern short term contraceptive methods. Proportions were particularly high in Punjab North and South as well as Sindh.

- Infection prevention mechanisms at RHCs are inadequate-only a third of the facilities have chlorine solution

- Only $14 \%$ of facilities in the sampled districts are equipped to provide BEmOC because of the lack of assisted vaginal delivery and certain required medications 


\section{Assessment of Provision of MNCH services at Tehsil Head Quarters (THQs) and District Head Quarters (DHQs) Hospitals}

All THQs and DHQs in the sampled districts were assessed for infrastructure number and type of services being offered. This included preventive and primary healthcare services, paediatric services, diagnostic services, and availability of comprehensive EmOC.

Assessment of Available Infrastructure at THQs and DHQs

Table 2.16: Proportion of THQs and DHQs with necessary infrastructure available

\begin{tabular}{lrr}
\hline Assessed Infrastructure & $\begin{array}{c}\text { Number of THQs and DHQs with } \\
\text { Infrastructure Available ( } \mathbf{n}=\mathbf{6 5})\end{array}$ & \multicolumn{1}{c}{ Percent } \\
\hline Separate room for consultation & 41 & 63 \\
Separate room for examination & 51 & 78 \\
Boundary wall & 55 & 85 \\
Separate M/F toilets for patients & 57 & 88 \\
Electricity & 65 & 100 \\
Generator & 61 & 94 \\
\hline
\end{tabular}

All the assessed THQs and DHQs had functioning electricity and almost all also had a backup generator. Separate male and female toilets for patients were available in $88 \%$ of the facilities. Boundary wallswerenot presentin $15 \%$ of the assessed facilities. The proportion of facilities with provision of privacy for the patients was relatively low; with a quarter of the facilities lacking a separate room for examination, and more than a third without a separate room for OPD consultations.

\section{Status of Equipment}

Facilities were assessed for the availability of equipment required for Preventive Services, Primary Healthcare, Normal Deliveries, Basic EMoC, Neonatal Care, and Comprehensive EMoC. Table 2.17 below shows the results: 
Table 2.17: Proportion of THQs and DHQs with selected MNCH equipment available

\begin{tabular}{|c|c|c|}
\hline Assessed Equipment & $\begin{array}{l}\text { Number of THQs and DHQs with } \\
\text { Equipment Available }(n=65)\end{array}$ & Percent \\
\hline Exam Tables & 65 & 100 \\
\hline Weighing Scales & 63 & 97 \\
\hline Blood Pressure Equipment & 65 & 100 \\
\hline Delivery Kit & 59 & 91 \\
\hline EPI cold box & 65 & 100 \\
\hline Refrigerator & 63 & 97 \\
\hline D\&C kit & 59 & 91 \\
\hline MVA Kit & 32 & 49 \\
\hline Baby Weighing Scales & 58 & 89 \\
\hline Bulb Sucker & 57 & 88 \\
\hline Baby Ambu Bag & 56 & 86 \\
\hline Foley's Catheter & 63 & 97 \\
\hline Baby Endotracheal Tube & 42 & 65 \\
\hline Incubator & 45 & 69 \\
\hline Baby Laryngoscope & 47 & 72 \\
\hline Stethoscope & 65 & 100 \\
\hline
\end{tabular}

Almost all facilities assessed had the basic equipment required for primary healthcare. All had examination tables, blood pressure equipment, a stethoscope, EPI cold box for immunization (and backup refrigerator), Foleys Catheter and Weighing Scales. When assessing equipment for maternal healthcare, proportions were slightly lower with almost $10 \%$ of the facilities not having a delivery kit, and another $10 \%$ without D\&C kits, and only half with MVA kits. Availability of neonatal care equipment was still lower; a quarter of the assessed facilities did not have a baby laryngoscope, and almost a third did not have an endotracheal tube. While two-thirds of the assessed facilities had an incubator, a quarter of these were not functional. Baby weighing scales, bulb suckers and ambu bags were more commonly available.

From table2.17, we can infer that the capacity of nearly a third of THQs and DHQs to provide emergency neonatal care is compromised due to lack of essential equipment for dealing with neonatal emergencies such as birth asphyxia and respiratory distress-a major cause of neonatal mortality in Pakistan. 
Assessment of Service Availability at THQs and DHQs

Table 2.18: Proportion of THQs and DHQs offering selected preventive and diagnostic services

\begin{tabular}{lcc} 
Service & $\begin{array}{c}\text { \# of THQs and DHQs offering } \\
\text { service }(\mathbf{n = 6 5 )}\end{array}$ & Percent \\
\hline Immunization Services & 64 & 98 \\
Nutrition and Growth Monitoring & 44 & 68 \\
Urine R/E & 62 & 95 \\
CBC & 57 & 88 \\
Tetatanus Toxoid & 63 & 97 \\
IEC Material displayed & 57 & 88 \\
Pediatric Services & 47 & 72 \\
Treatment of PPH & 53 & 82 \\
General Surgery & 46 & 71 \\
Anesthesia & 49 & 75 \\
\hline
\end{tabular}

Table 2.18 above shows the number and proportion of facilities offering these services. Almost all assessed facilities were providing immunization services (including tetanus toxoid) and urine routine examinations;provision of a complete blood picture examwas available at a slightly lower proportion of facilities. Only two-thirds of the facilities were providing nutritional advice and growth monitoring; and three-quarter had paediatric services. Anesthesia services were available at $75 \%$ percent of the facilities, and management of post-partum haemorrhage was available at $82 \%$ of the facilities.

Assessment of Availability of essential MNCH care medicines

Availability of essential medicines for $\mathrm{MNCH}$ care was assessed and is depicted in table 2.19.

Table 2.19: Proportion of THQs and DHQs with availability of selected MNCH medicines

\begin{tabular}{lcc}
\hline Medicine & $\begin{array}{c}\text { \# of THQs and DHQs with } \\
\text { Medicine available }(\mathbf{n}=65)\end{array}$ & Percent \\
\hline Diazepam & 58 & 89 \\
Anti-Hypertensives & 48 & 74 \\
Magnesium Sulphate & 47 & 72 \\
Tetanus Toxoid & 63 & 97 \\
Oral Antibiotics & 63 & 97 \\
Injectable Antibiotics & 64 & 98 \\
Ergometrine/Methergine & 44 & 68 \\
Injectable Oxytocin & 60 & 92 \\
Calcium & 37 & 57 \\
Ferrous Sulphate & 53 & 82 \\
Folic Acid & 52 & 80 \\
Insulin & 37 & 57 \\
IV Fluids/Plasma Expanders & 61 & 94 \\
\hline
\end{tabular}


The most frequently available medicines were Tetanus Toxoid, Oral and injectable antibiotics, IV Fluids and Diazepam. A quarter of the assessed facilities did not have anti-hypertensives and Magnesium Sulphate used for the management of eclampsia. A slightly higher proportion did not have ergometrine/methergine. Insulin and calcium were not available at half of the facilities. Availability of folic acid and ferrous sulphate was moderate-with $80 \%$ of facilities having them at the time of assessment.

Assessment of Support Services available at the THQ and DHQ hospitals

Table 2.20: Proportion of THQs and DHQs with selected support services available

\begin{tabular}{lcc}
\hline Support Service & $\begin{array}{c}\text { \# of THQs and DHQs offering } \\
\text { service (n=65) }\end{array}$ & Percent \\
\hline Laboratory & 64 & 98 \\
Ambulance & 64 & 98 \\
Ultrasound & 56 & 86 \\
Radiology & 62 & 95 \\
Blood Bank & 47 & 72 \\
Operation theater & 57 & 88 \\
\hline
\end{tabular}

With the exception of one facility, all the assessed facilities had a laboratory and functioning ambulance. Majority had an ultrasound and radiology service in place. $88 \%$ of the facilities had an Operation Theatre but $14 \%$ of these were not functional. Nearly three quarters of the facilities had a blood bank.

\section{Assessment of Infection Prevention Mechanism}

Table 2.21 shows the number of infection prevention mechanisms in place at THQs and DHQs:

Table 2.21: Proportion of THQs and DHQs with infection prevention measures available

\begin{tabular}{lcc}
\hline Mechanism & $\begin{array}{c}\text { \# of THQs and DHQs with infection } \\
\text { prevention measures in place }(\mathbf{n = 6 5})\end{array}$ & Percent \\
\hline Chlorine Solution & 33 & 51 \\
Sterilizer & 60 & 92 \\
Autoclave & 62 & 95 \\
Hep B \&C Testing & 56 & 86 \\
HIV screening & 44 & 68 \\
Sharps disposal & 62 & 95 \\
\hline
\end{tabular}

Majority of the assessed facilities had a sharps disposal container, a sterilizer and an autoclave. $10 \%$ of the autoclaves were not functional. Only half the facilities had chlorine solution, and screening for infection prevention was also low with two-thirds of facilities not having HIV screening facility, and a fifth not offering Hepatitis B and C screening. 


\section{Assessment of Family Planning Service Delivery}

Modern hormonal FP methods as well as longer term methods such as the IUCD and permanent methods (TL and Vasectomy) were assessed and table 2.22 shows the availability status of these at the THQ and DHQ hospitals in the sampled districts.

Table 2.22: Proportion of THQs and DHQs offering contraceptive methods

\begin{tabular}{lcc} 
Method & $\begin{array}{c}\text { \# of THQs and DHQs offering } \\
\text { method }(\mathbf{n}=65)\end{array}$ & Percent \\
\hline Injectables & 56 & 86 \\
Condoms & 60 & 92 \\
Oral Contraceptive Pill & 59 & 91 \\
IUCD & 51 & 78 \\
Tubal Ligation & 39 & 60 \\
Vasectomy & 21 & 32 \\
All modern methods (comprehensive) & 20 & 31 \\
\hline
\end{tabular}

More than $90 \%$ of facilities had condoms and the oral pill available at the time of the assessment, followed by injectables. Availability of IUCDs was slightly lower at $78 \%$. Provision of permanent methods was low, with only a third of the facilities providing vasectomy service. However, nearly $60 \%$ of the facilities were providing tubal ligation services. Only $31 \%$ of all assessed facilities were providing comprehensive FP services, which included the full range of contraceptive choices.

\section{Regional assessment of Family Planning Method Availability}

Figure 2.5 below shows the proportion of facilities in each province providing all three modern methods (condoms, pill and injectables) and the proportion offering comprehensive FP (temporary methods along with long acting methods and permanent methods). This is highest in districts ofNorthern Punjab where all facilities assessed were providing comprehensive family planning. Temporary contraceptive methods were available at most THQs and DHQs in all districts except Balochistan where the proportion was relatively lower. Comprehensive FP i.e. the full range of short and long-term methods were available at less than half the facilities in AJK, Sindh and Southern Punjab, and at none of the THQs and DHQs in KP, FATA, GB and Balochistan. 
Figure 2.5: Proportion of THQs offering Basic EmOC and DHQs offering Family Planning services by region

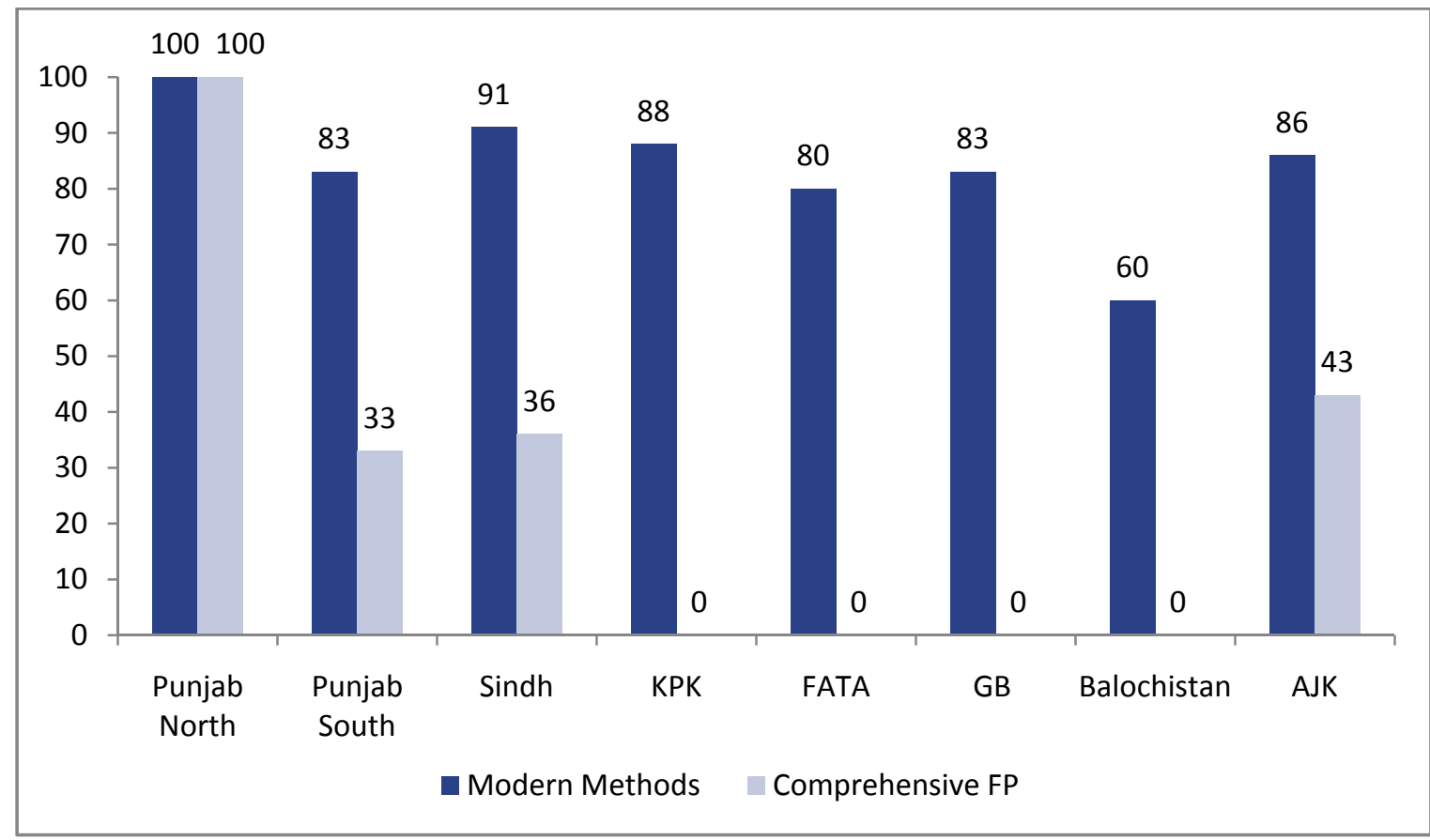

Provision of Basic EmOC at sampled facilities

Provision of Basic and Comprehensive EmOC services was assessed by observing the availability of six signal functions required for the provision of basic EmOC and two additional functions i.e. capacity to carry out caesarean sections and blood transfusions.

Table 2.23: Proportion of THQs and DHQs having Basic EmOC services

\begin{tabular}{lrr}
\hline Function & $\begin{array}{c}\text { \# of THQs and DHQs with } \\
\text { function in place }(\mathbf{n = 6 5})\end{array}$ & Percent \\
\hline Injectable Antibiotics & 65 & 100 \\
Injectable Oxytocin & 60 & 92 \\
Injectable Anti-convulsants & 47 & 72 \\
Manual Removal of Placenta & 57 & 88 \\
Removal of Retained Products & 58 & 89 \\
Assisted Vaginal Delivery & 48 & 74 \\
Provision of all six signal Basic EmOC functions & 35 & 54 \\
\hline
\end{tabular}

As seen in table 2.23, a little more than half of the assessed facilities were providing all six signal functions required for the provision of BEmOC. While almost all facilities were providing injectable antibiotics and oxytocin, and majority were equipped for removal of retained products and manual removal of placenta, a quarter of the assessed facilities did not conduct assisted vaginal deliveries or have injectable anti- 
convulsants. As a result, the proportion of facilities able to provide all six BEmOC signal functions was lowered.

Provision of Comprehensive EmOC at sampled facilities

Table 2.24 below shows provision of Comprehensive EmOC at THQs and DHQs:

Table 2.24: Proportion of THQs and DHQs having Comprehensive EmOC services

\begin{tabular}{lcc}
\hline Function & $\begin{array}{c}\text { \# of THQs and DHQs with } \\
\text { function in place }(\mathbf{n}=65)\end{array}$ & Percent \\
\hline All Six Signal Functions & 35 & 54 \\
Blood Transfusion & 53 & 82 \\
C-Section & 43 & 66 \\
All Eight Comprehensive EmOC Signal Functions & 29 & 45 \\
\hline
\end{tabular}

As shown in table 2.24, half of the assessed facilities were providing BEmOC. Blood transfusion facilities were available at $82 \%$ of the facilities. However, only two-thirds were equipped to carry out C-sections. As a result, only $45 \%$ of the assessed THQs and DHQs were offering Comprehensive EmOC.

\section{Key Finding:}

- Provision of both basic and comprehensive $\mathrm{EmOC}$ is low because of lack of availability of assisted vaginal delivery and essential medicines as well as lack of c-section facility.

\section{2:Service Delivery in Districts According to UN Process Indicators}

The set of six EMoC process indicators known as the United Nations (UN) process indicators measure aspects of the health system to deliver $\mathrm{MNCH}$ services using emergency obstetric services as a 'tracer'. Two of the indicators measure availability of $\mathrm{EmOC}$, three measure utilization of these services, and one addresses the quality of care provided (Paxton et al. 2006).

For the purpose of this assessment, we used the first EmOC process indicator that looks at the number of facilities that provide EmOC in relation to the size of the population. In order to measure this, availability of basic and comprehensive EmOC was assessed at all available facilities in the sampled districts. We have looked at whether there are enough functioning EmOC services to serve the population in each sampled district.

Indicator 1: Availability of EmOC:

For every 500,000 population, there should be at least:

- 4 Basic EmOC facilities

- 1 Comprehensive EmOC facility 
The percentage of coverage in the district is calculated as the discrepancy between the required facilities and the actual number of facilities in the district that had all six signal functions for $\mathrm{BEmoC}$ or all eight signal function for CEMOC available (as shown in Annex 5 and 6).

It was found that not only is there a discrepancy between the number of existing facilities and recommended facilities in many districts, the lack of functioning equipment and capacity to provide signal functions makes the discrepancy even larger.

Unavailability of services for basic EmOC is the highest in Balochistan, FATA and AJK where none of the assessed facilities were in a position to provide basic EmOC services. Out of the four districts of AJK, provision of BEmOC existed in only one facility each in Kotli and Bagh. Coverage in the other two districts was at 100 percent. Unavailability was also high in both Northern and Southern Punjab districts. Population numbers in the districts here are relatively higher, and the number of existing facilities is very small. Out of the seven districts visited in these two regions, three districts did not have any provision for BEmOC. In South Punjab only two facilities were providing BEmOC, and only three in North Punjab. The signal functions were available in one district out of four in Sindh, and in four facilities in three of the sampled districts in KP. Compared to provision of basic EmOC services, availability of comprehensive EMoC services is relatively higher. Coverage is lower in FATA and GB where none of the districts and two out of three districts respectively have no facilities offering comprehensive CEmOC. Coverage is higher in AJK and Balochistan.

Without improvement in the indicators for maternal mortality, progress towards MDGs will be slow. It is important that emphasis be placed on up grading of facilities providing basic EMoC. This in turn will decrease the need for use of comprehensive $\mathrm{EMOC}$ and reduce the burden on comprehensive care facilities.

Human Resource Availability

Analysis of Secondary Data

In 2009, the WHO identified Pakistan as one of 57 countries facing a Human Resources for Health (HRH) crisis - placing it below the required level to deliver essential health interventions to meet the MDGs by 2015 (WHO2006).

Shortage of staff in rural and hard to reach areas diminishes quality of care and prevents the scaling up of interventions to achieve health goals, including disease treatment targets, Immunization coverage and the Millennium Development Goals.

The purpose of this comprehensive analysis of secondary data was to gather and consolidate the available data on $\mathrm{MNCH}$ health workforce from the provinces in order to identify the gaps in human resources staffing in Pakistan and translate the findings into policy recommendations.

Data Collection and analysis:

Data for the human resource strength in the public health sector has been gathered from multiple sources, including Departments of Health, Provincial and District Directorates of Health and Finance Departments that keep records of sanctioned and filled positions for budgeting purposes. 
It is important to recognize that this analysis has been conducted in an environment where human resource information lacks coordination, is fragmented and is not disaggregated by gender. There has also been insufficient use of this information despite a growing need for in-depth review and planning. In order to validate the findings from this secondary data analysis, information on sanctioned and filled staff positions was also collected at the facility level through the health facility assessment tool.

Figure 2.6 below shows filled versus sanctioned posts by cadre in Punjab, Sindh, GB, AJK and FATA. An analysis by cadre shows that the largest proportion of filled posts is of LHVs. In AJK and FATA all sanctioned positions for LHVs are filled. Almost all positions in Punjab are also filled. $13 \%$ of the sanctioned positions in GB and a quarter of the sanctioned positions in Sindh are vacant. For medical officers, majority of the sanctioned positions in FATA are filled, but between a quarter and two-third of the positions are vacant in GB, Sindh and Punjab and more than half the positions in AJK are vacant. A high proportion of the sanctioned positions for women medical officers are vacant in all regions. One-third of the positions in Punjab and Sindh and more than half the positions in FATA, AJK and GB are vacant. Majority of the sanctioned positions for pediatricians and gynecologists in AJK are filled. Filled positions of gynecologists are low in all other regions ranging from one-third vacant posts in Punjab to three-quarter vacant posts in Sindh. Filled positions of pediatricians are also low in Sindh and GB.

Figure 2.6: Filled vs. Sanctioned Positions by Region

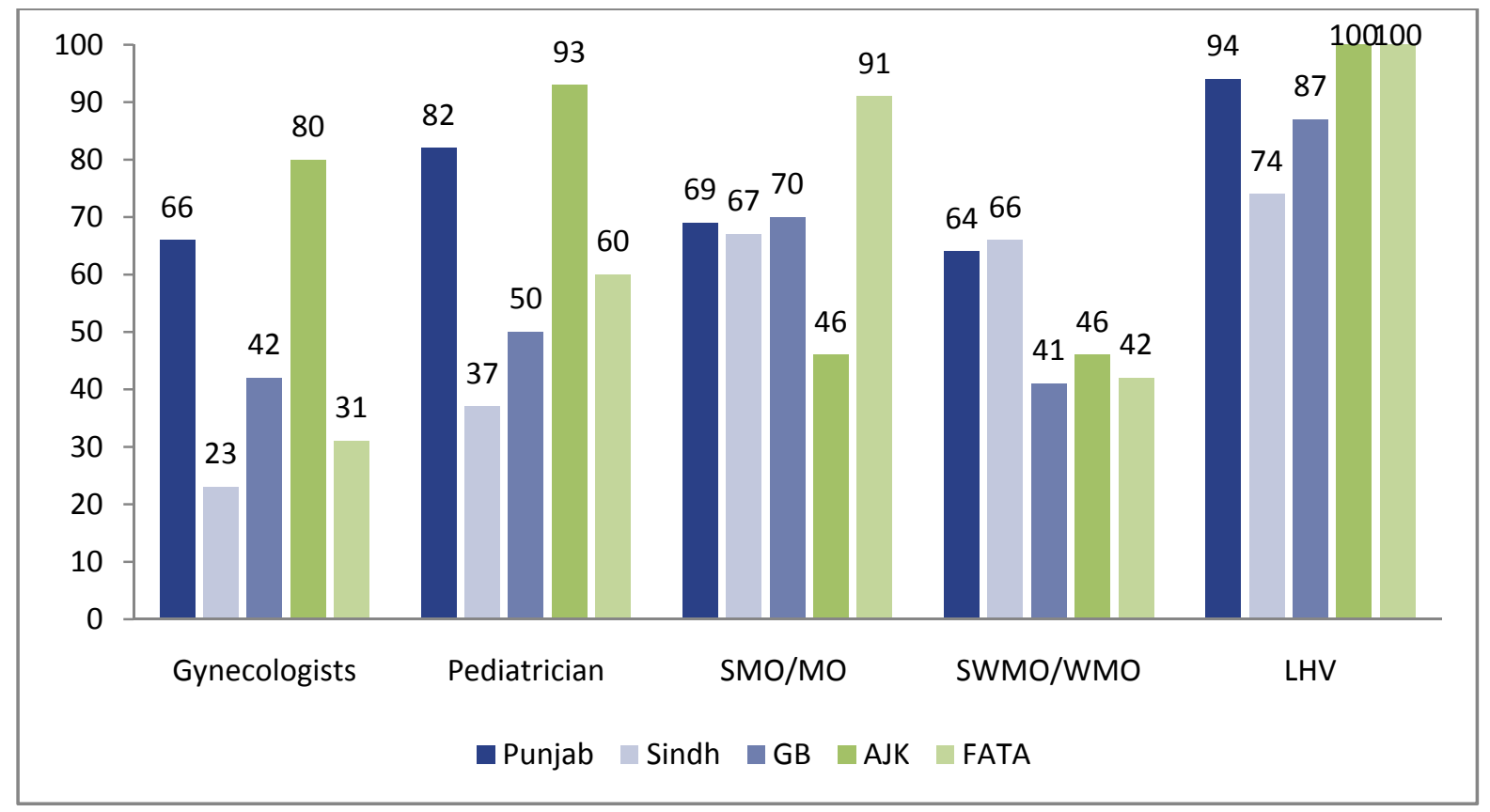

Due to a lack of available provincial data on staffing of specific cadre in KP, filled vs. sanctioned posts were analyzed by grade. Although this approach has limitations, larger trends can be identified and it can be seen in figure 2.7 below that two-thirds to a quarter of the sanctioned positions at grade 17, 18 and 19, which are mostly supposed to be occupied by male and female medical officers and specialists are vacant. The discrepancy between filled and sanctioned positions at grade 20 is lower, but this grade is often filled by management positions. 
Figure 2.7: Filled vs. sanctioned positions by grade- KP

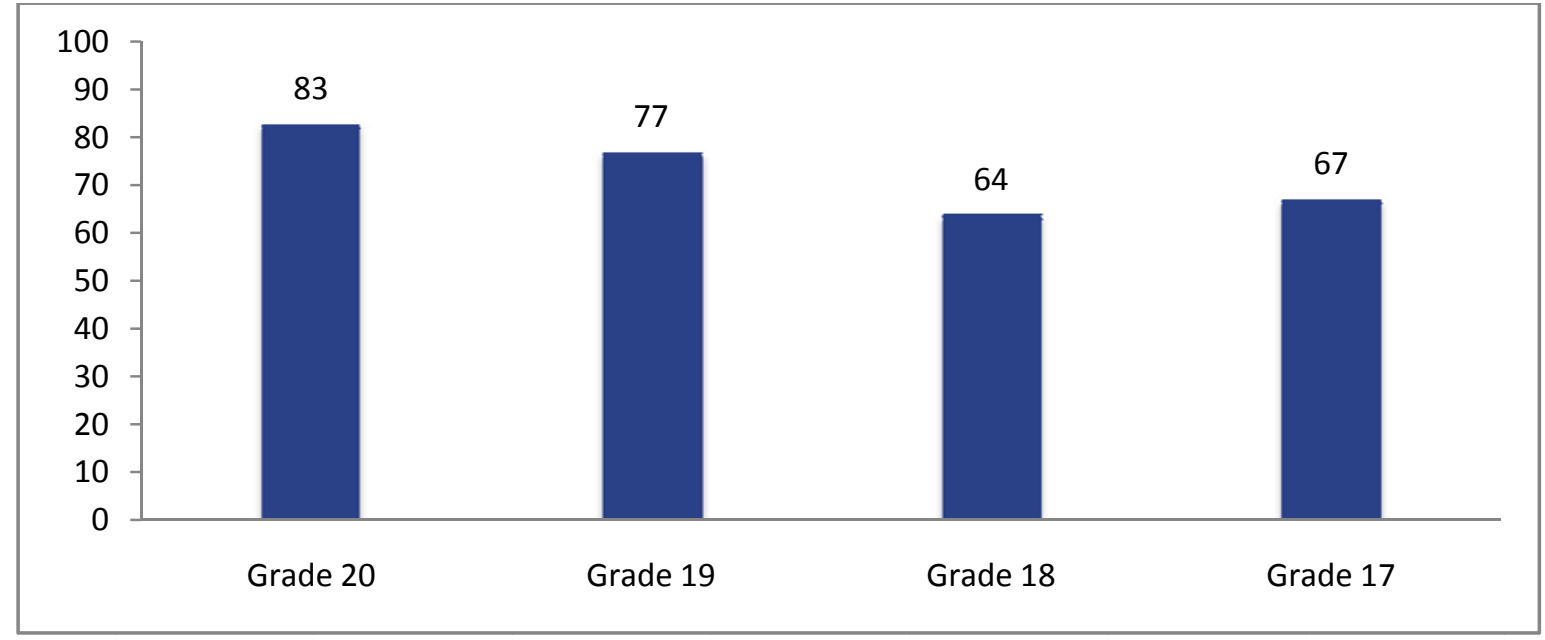

There was also unavailability of provincial data for the province of Balochistan, instead of which figure 2.8 below presents an average of staffing in the sampled districts as found in the health facility assessment. Out of the four districts assessed, three had filled positions for Gynecologists. Majority of the positions for technicians/dispensers and pediatricians are filled. About two-thirds of the medical officer positions are filled. Staffing of LHVsand anesthetists islower; with less than half the sanctioned positions for both these cadre being filled. It is also interesting to note that while majority of the sanctioned positions for some cadre are filled, the number of sanctioned positions is extremely low and not commensurate with the size of the population to be covered.

Figure 2.8: Filled vs. Sanctioned Positions by cadre-Balochistan

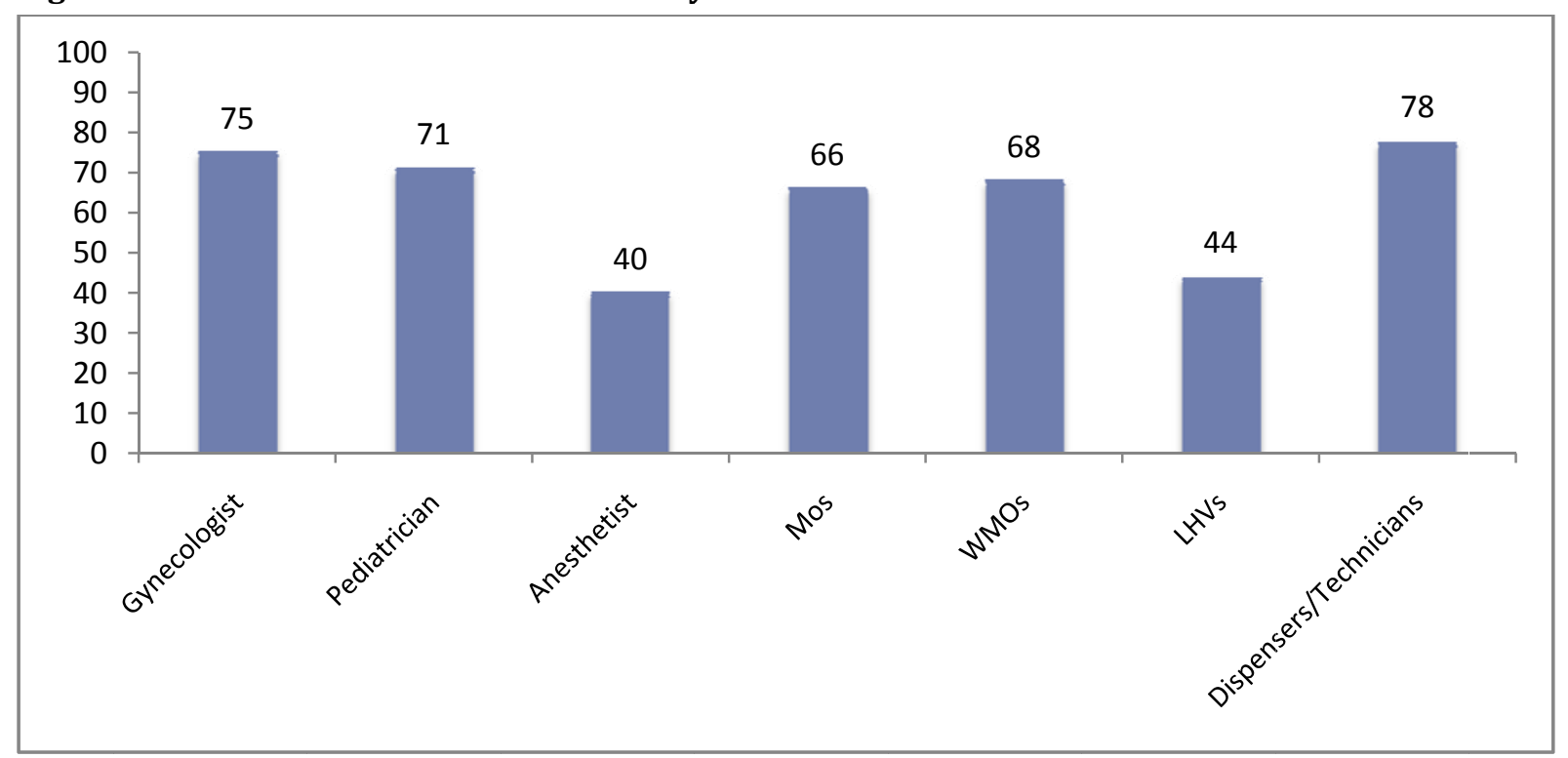





\section{ORGANIZATIONAL STUCTURES AND PROCESSESINFLUENCING MNCH STAFF MOTIVATION AND RETENTION}

The organizational structures and processes that influence worker motivation include level of worker autonomy, delegation of responsibility and authority through staff promotion, and the relative status of different workers (Franco et al 2002).

In this section we shall be discussing processes and policies related to promotion and staff appraisal, obtaining leaves, andautonomy and support offered through appropriate supervision including feedback offered through verbal and written appreciation.

\section{1:Promotion Policies and Process}

Respondents were asked how they viewed the current organizational policies related to evaluating staff performance, and whether promotions were taking place in a fair and impartial manner. As shown in Figure 3.1, majority (two-thirds to three-quarters) of the specialists, MOs and WMOs and more than half of the LHVs and dispensers reported that members of staff werenot promoted in a fair and impartial manner. Seven out of twenty two medical superintendents reported that promotions were conducted in a fair and honest manner.

Figure 3.1: Proportion of staff reporting partiality in promotions by cadre

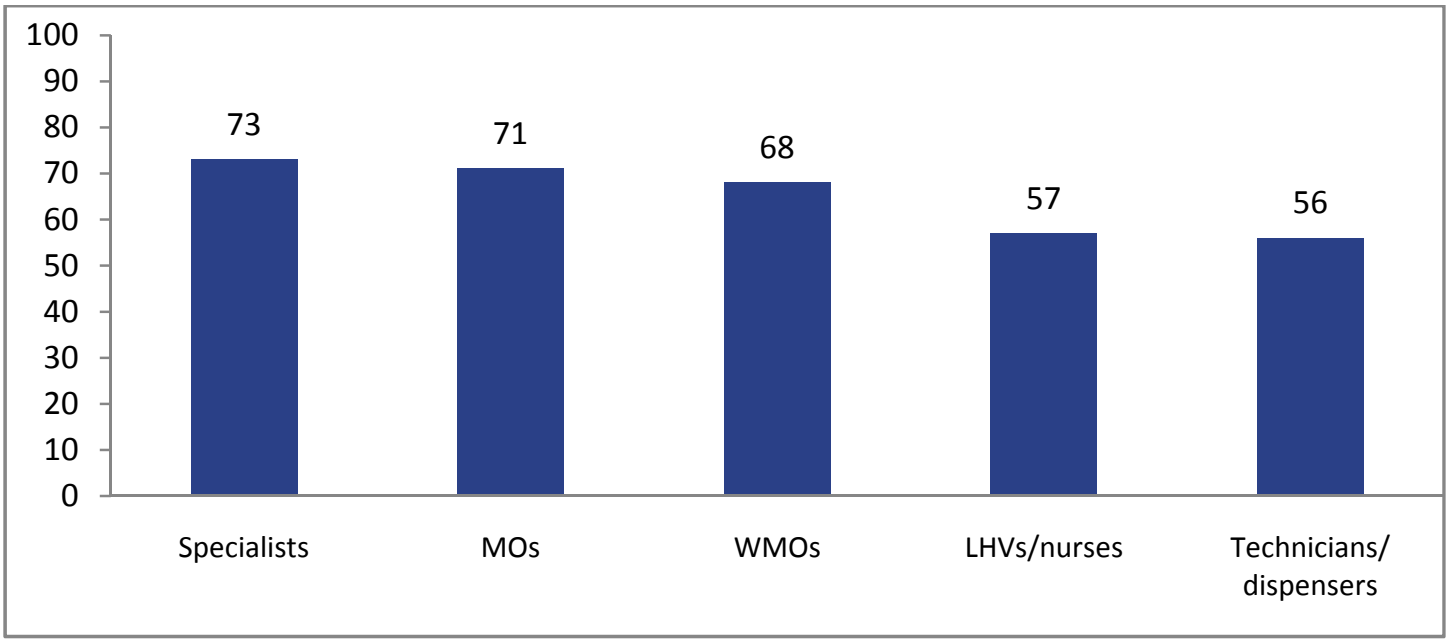

By region, it was seen (figure 3.2) that the highest level of dissatisfaction with the promotion process was in FATA, followed by KP and North Punjab. The lowest proportion was reported in Balochistanand GB. 
Figure 3.2: Proportion of Providers reporting partiality in promotions by region

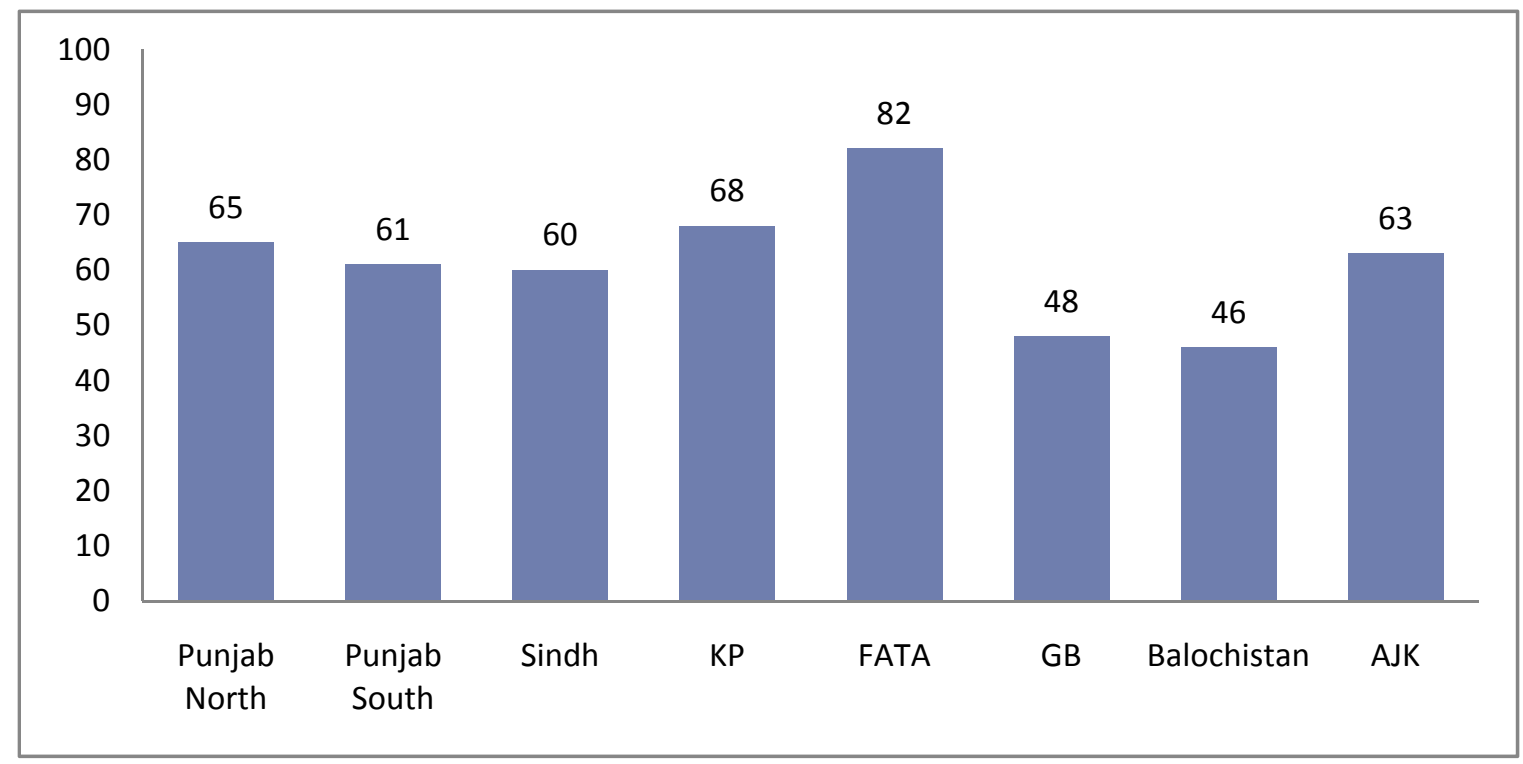

When asked about the reasons leading to the partiality of the system, the most important factor reported was the lack of adherence to the existing career structure (figure 3.3). Half of the respondents were of the view that partiality in promotions was the result of undue political influence, followed by nepotism (which denotes favouring relatives, peoples of the same tribe/caste, or locality), financial manipulation, and favouritism (which denotes rewarding an individual based on personal preference). A quarter of the respondents reported that promotions could be influenced by manipulating the system usingmoney, while a fifth felt that the supervisors' personal preferences also played a part in who got promoted and who didnot.

These views were endorsed by senior provincial health officials during the IDIs:

"Yes, it is true. Through political influence, it is possible to get out-of-turn promotions. We are trying to resist this now." IDI, Director General-Health, Balochistan

"There is very much a career structure in place. However, it is not being fully followed. Several extraneous factors compel supervisors to bypass it." IDI, Director General-Health, Punjab 
Figure 3.3: Factors contributing to partiality in promotions

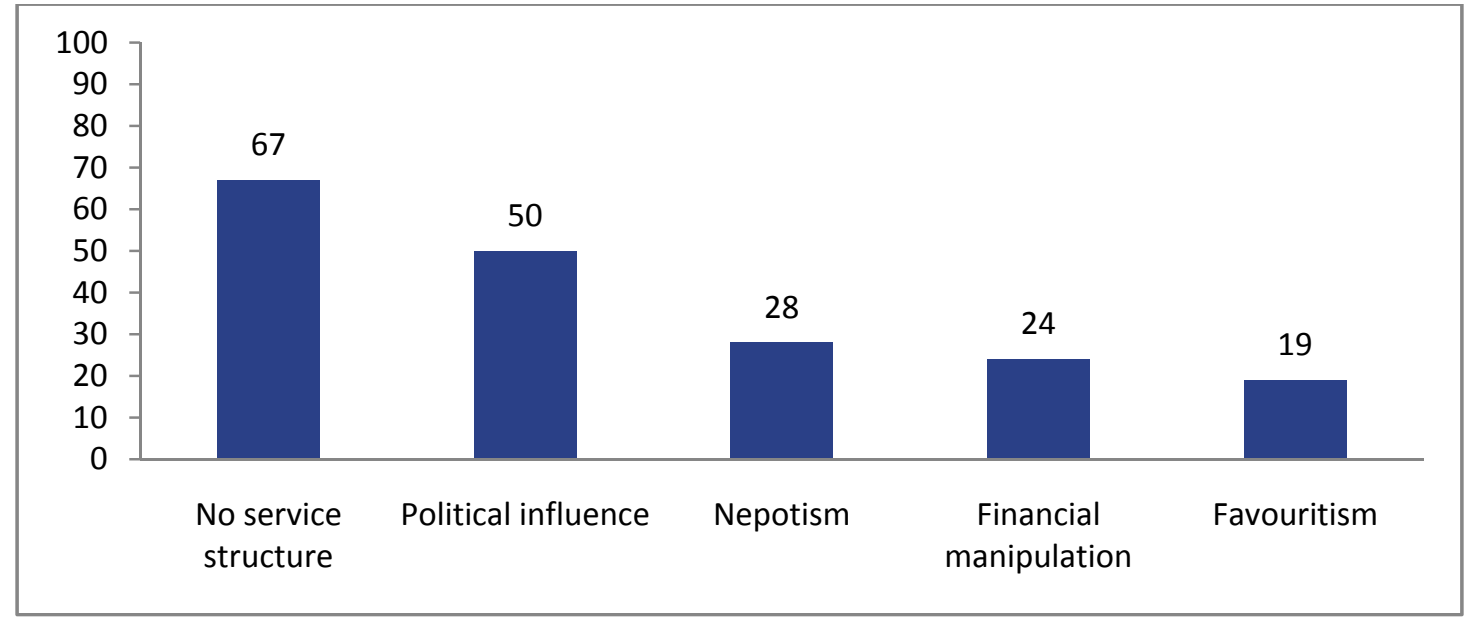

\section{Current System for Staff Appraisal}

Currently, the only formal mechanism for evaluating staff performance is through the filling in of the Annual Confidential Report (ACR) at the end of each year.

Respondents were asked about their views regarding the system. Half of the specialists and MOs reported being dissatisfied with the current system. In comparison, LHVs and dispensers seem to be less dissatisfied. As there is a limited career hierarchy available for the paramedical staff (non-gazetted staff grade 1-16) and their promotions are not entirely dependent upon ACRs but rather on their length of service, they seem to be less affected by the filling in of the annual report. On the other hand, promotion of gazetted officers is largely dependent upon the availability of filled in reports that should ideally not have negative comments.

Figure 3.4: Proportion of providers who reported dissatisfaction with the current method of annual appraisal by cadre

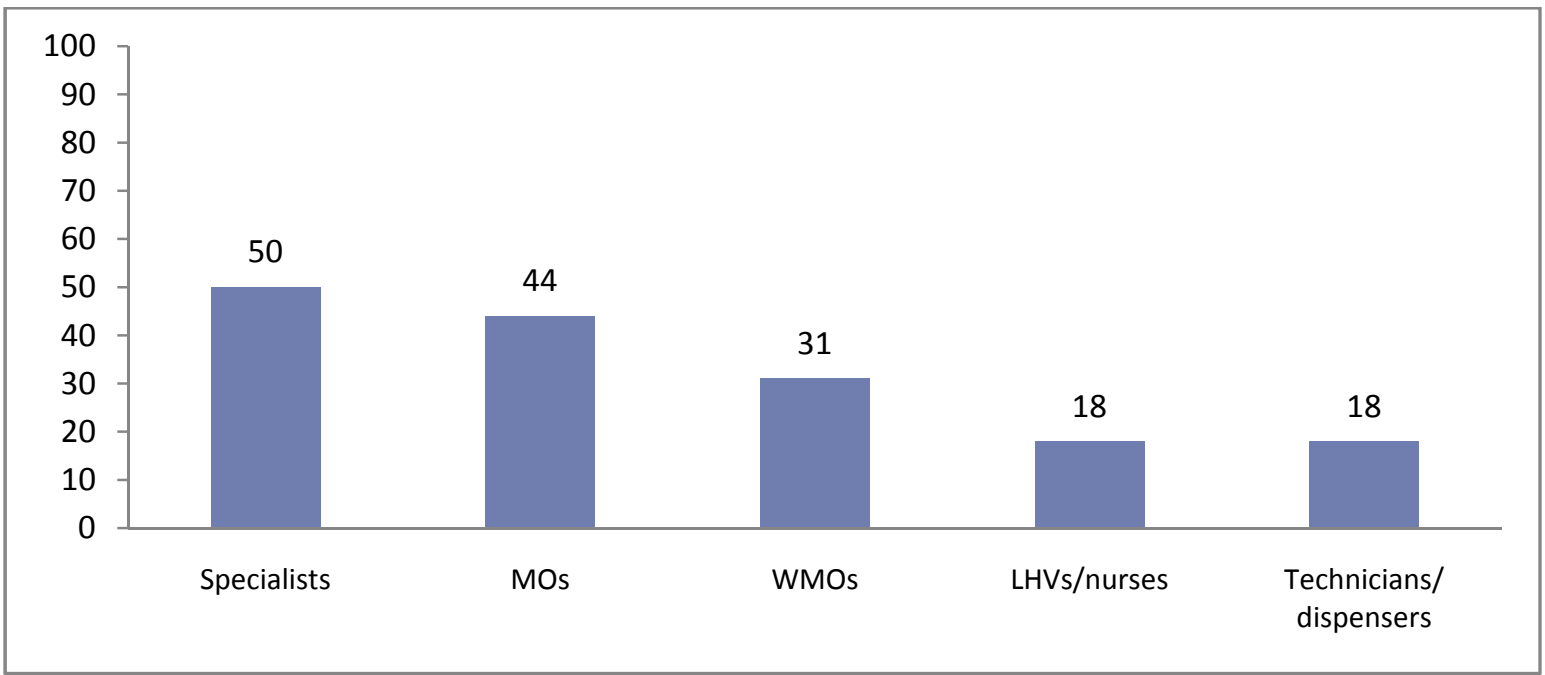


When assessed by region, we found that the level of dissatisfaction with the current method of appraisal was the highest in FATA followed by AJK and Balochistan. Respondents were seen to be less dissatisfied in $K P$ and $G B$ (figure 3.5).

Figure 3.5: Proportion of providers who reported dissatisfaction with the current method of annual appraisal by region

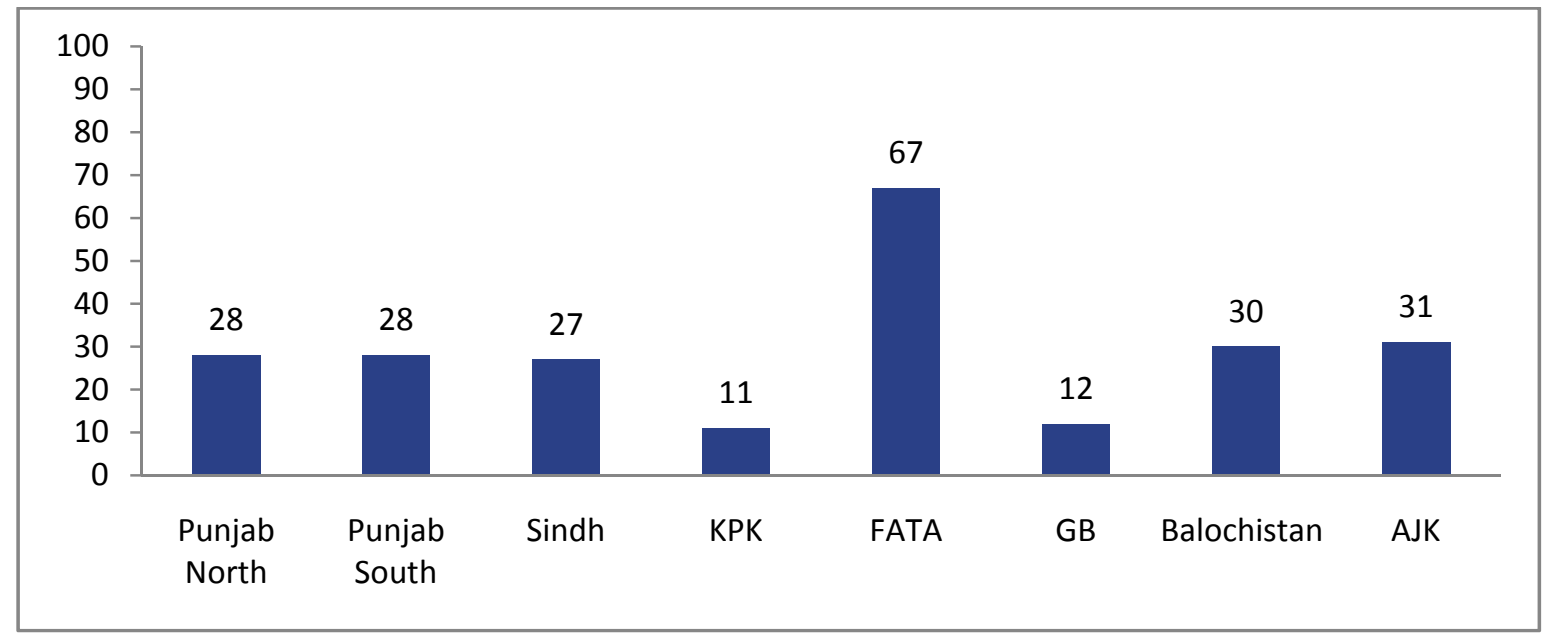

Findings from the IDIs showed that the most commonly cited reasons for dissatisfaction were related to loss of objectivity within the evaluation system that had eroded over the years. Other issues highlighted included ACRs not being routinely filed, the onus of getting the ACRs filled being on the supervisee, and the annual evaluation failing to capture individual effort, achievements, or accomplishments. The utility of the ACRs was compromised as the system did not include providing feedback, especially positive feedback, to the employees. Moreover, the member of staff who ultimately filled in the report was often not fully acquainted with the worker who was being evaluated i.e. was not their direct supervisor.

"Writing a good or bad evaluation makes no difference to performance. We are not receiving any benefits - there are no advantages attached to this system for us, right now. Therefore, whether you write us a good ACR or a bad one, in both situations it serves the same purpose." IDI, MO, Astore

"On some occasions, we do not even know if someone has even written our ACRs or not. Sometimes they even get a few years' ACRs written at the same time."FGD, Gynaecologist, Gilgit

"Promotion proceduresare not fair according to our education and seniority." FGD, LHV, Khanewal

Valuable suggestions were received from the respondents regarding improving the system. These included sharing the findings with the supervisees, highlighting both positive and negative aspects of their work, and enhancing objectivity by building in performance measurement indicatorsand maintaining a computer based record of all ACRs. The ACR form is similar for all government servants irrespective of professional 
affiliation and therefore it is unable to capture an individual's department specific accomplishments. A new form has been developed in Punjab, although it has not been officially introduced. Respondents were of the view that there should be a system to provide regular and timely performance-based feedback to the staff.

"There is a communication gap that needs to be filled through a system." IDI, MO, Hyderabad, Sindh

Factors associated with providers' perception that promotions are fair and impartial Running a logistic regression model, we found that providers who had been at the same grade for over ten years were $40 \%$ less likely to agree that promotions were carried out in a fair and impartial manner. Those who had received at least two promotions since they joined the service were 2.5 times more likely to perceive promotions to be fair and they were also 2.9 times more likely to be satisfied with the annual evaluation system (table 3.1).

Table 3.1: Factors contributing to perception that promotion are fair and impartial

\begin{tabular}{|c|c|}
\hline Variable & Adjusted Odds Ratio $(95 \% \mathrm{Cl})$ \\
\hline \multicolumn{2}{|l|}{ Cadre } \\
\hline LHVs & 1.00 (Ref) \\
\hline Specialists & $0.652(0.312-1.363)$ \\
\hline MOs & $0.750(0.32-1.761)$ \\
\hline WMOs & $0.657(0.371-1.162)$ \\
\hline Technicians & $1.256(0.554-2.847)$ \\
\hline MSs & $0.768(0.226-2.610)$ \\
\hline \multicolumn{2}{|l|}{ Gender } \\
\hline \multicolumn{2}{|l|}{ Male } \\
\hline Female & $1.075(0.495-2.335)$ \\
\hline \multicolumn{2}{|c|}{ Years at current grade } \\
\hline $0-5$ & 1.00 (Ref) \\
\hline $6-10$ & $0.651(0.408-1.036)$ \\
\hline$>10$ & $0.495(0.337-0.726)^{* *}$ \\
\hline \multicolumn{2}{|c|}{ Number of promotions } \\
\hline 0 & 1.00 (Ref) \\
\hline 1 & $1.363(0.991-1.874)$ \\
\hline 2 & $2.532(1.394-4.596)^{* *}$ \\
\hline 3 & $1.015(0.377-2.738)$ \\
\hline \multicolumn{2}{|c|}{ Satisfaction with ACR } \\
\hline Dissatisfied & 1.00 (Ref) \\
\hline Satisfied & $2.908(2.037-4.152)^{* *}$ \\
\hline
\end{tabular}

$* * p<0.01$ 
Summary

- More than two-thirds of the gazetted providers and half of the non-gazetted providers consider the promotion process to be partial.

- Half of all specialists reported dissatisfaction with the current system of evaluating performance.

- More than two-thirds of the respondents in FATA were dissatisfied with the current annual performance evaluation process.

\section{2:Supervision}

Staff supervision plays a major role in promoting quality at all levels of the health system by focusing on the identification and resolution of problems, and helping staff to perform optimally through guidance and assistance in carrying out tasks. A cornerstone of supportive supervision is advocating the due and just rights of employees. Supportive supervision eventually contributes to improvement in staff performance (McMahon et al. 1992).

Figure 3.6: Supportive supervision process

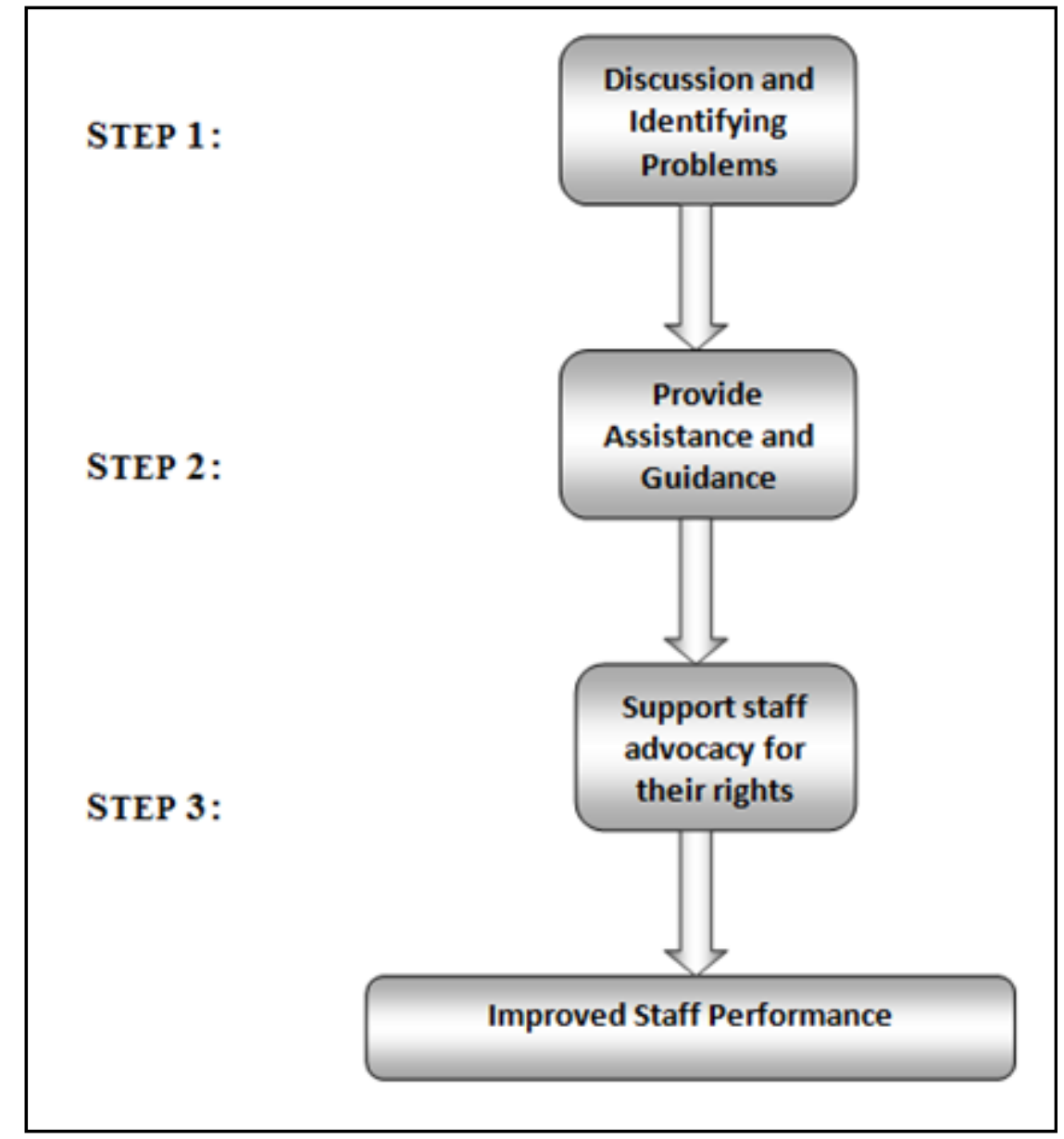

According to the two-factor motivation theory of Herzberg, one of the steps required to reduce dissatisfaction among employees is to provide effective, supportive, and non-autocratic 
supervision(Herzberg 1959). Supportive supervision requires supervisors to discuss with their employees issues pertaining to their work and encouraging the participation of employees in decision-making and problem resolution.

Based on the above, providers were asked if their supervisors let them take ownership of their work and involved them in decisions pertaining to the functioning of their facility and staff. This participatory approach is an important element of supportive supervision. As seen in Figure 3.7, between two-thirds and three-quarters of all cadres of providers reported that they were included in discussions by their supervisors on ways to improve the work environment of their facility.

\section{Figure 3.7: Proportion of providers reporting involvement in decision making}

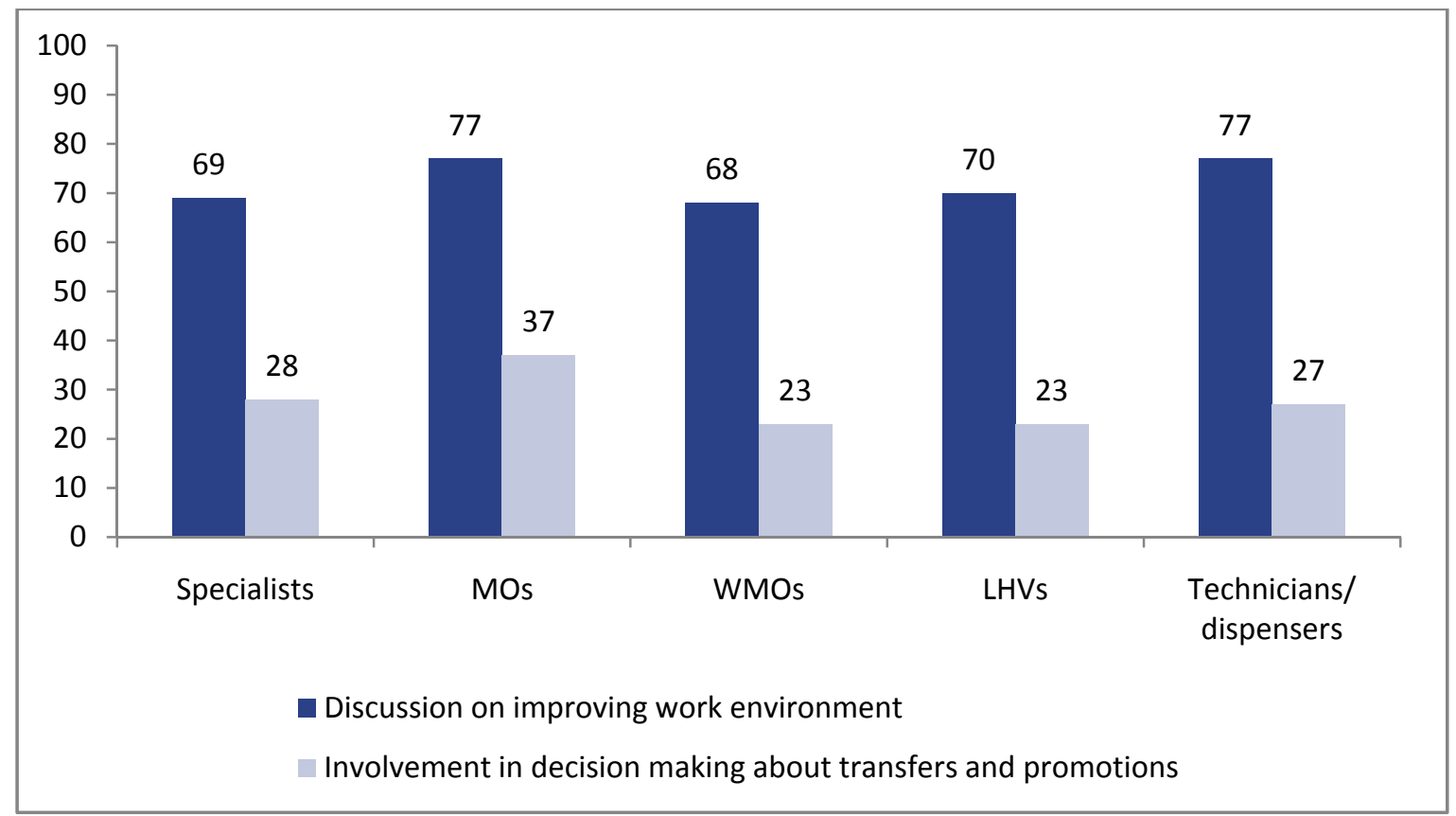

However, in cases of decisions pertaining to staff transfer or promotions, less than a third of the providers in each cadre were involved in such decision-making. While this low percentage is understandable for lower cadres such as LHVs and technicians/dispensers who may not have staff reporting to them, the proportion of MOs and specialists who are not involved in this level of decision-making is an area that can be improved.

Two major components of supportive supervision are providing assistance in performing tasks and offering support to employees in the discharge of their duties. Figure 3.8 below shows the extent to which providers reported receiving assistance and support from their supervisors. This includes providing support if there are problems, taking action on complaints lodged by supervisees and generally assisting them in doing their job better. Nearly three-quarters of male and female medical officers and fourth-fifths of LHVs and dispensers reported receiving support from their supervisors. However, only two-thirds of specialists reported receiving support from their supervisors. 
Figure 3.8: Proportion of providers reporting receiving support

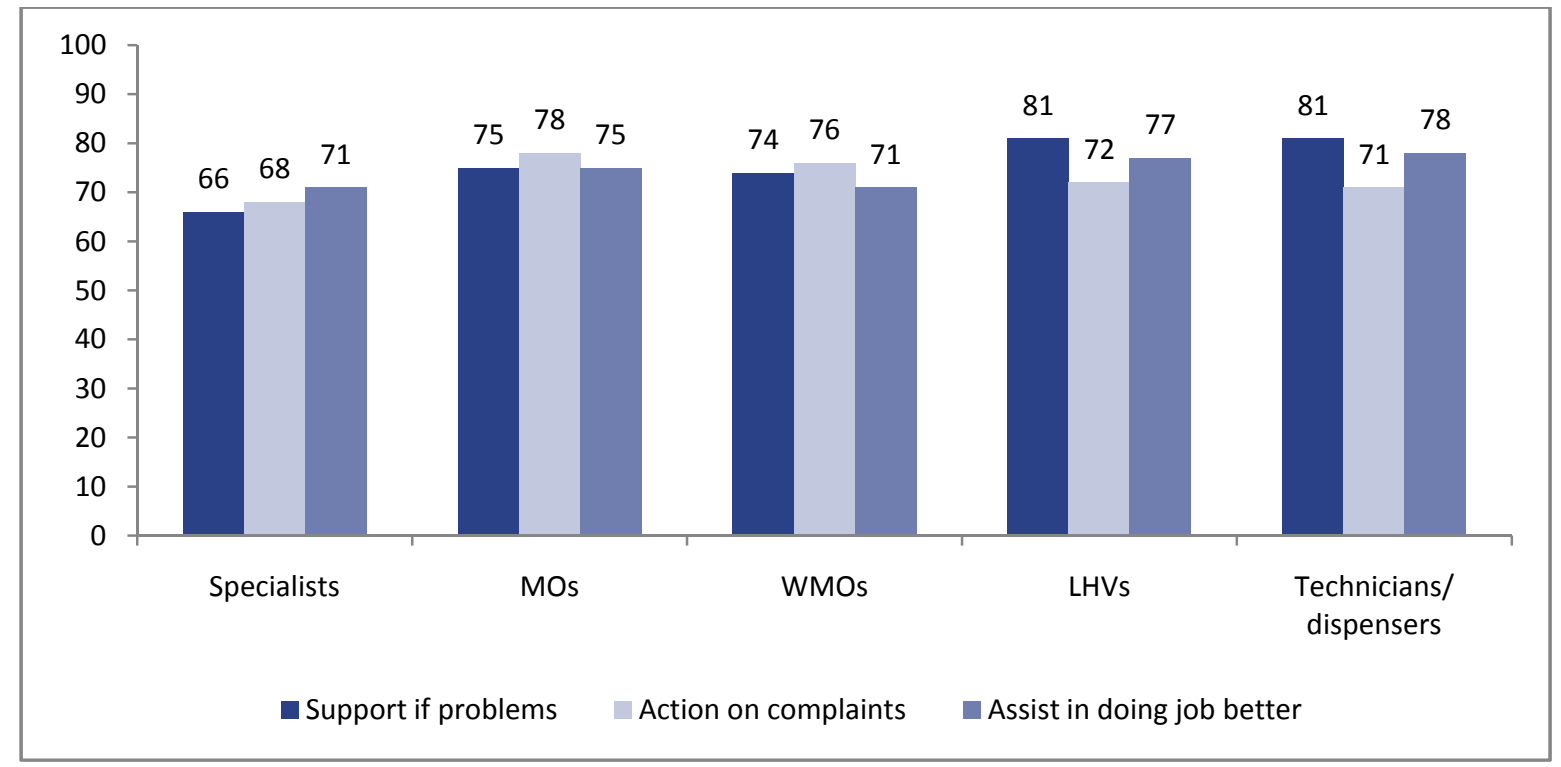

Support activities also include offering timely appreciation and encouragement. This includes giving credit to the staff member for the work that they do, express satisfaction with their performance through feedback and appreciate good performance. As shown in figure 3.9, a high proportion of providers do have supervisors who express satisfaction at their routine performance and give due credit for their work. However, the proportion of providers who reported receiving formal appreciation and encouragement when they did well was lower, and especially low in the case of WMOs and specialists. Providers were asked in the IDIs to elaborate upon the mechanism by which feedback is provided.

"We have a monthly meeting and have to give a briefing on our work. Feedback is also given during the supervisory visits to our facility. Written feedback is rarely given." WMO, district Layyah, South Punjab

Figure 3.9: Proportion of providers reporting receiving appreciation and encouragement

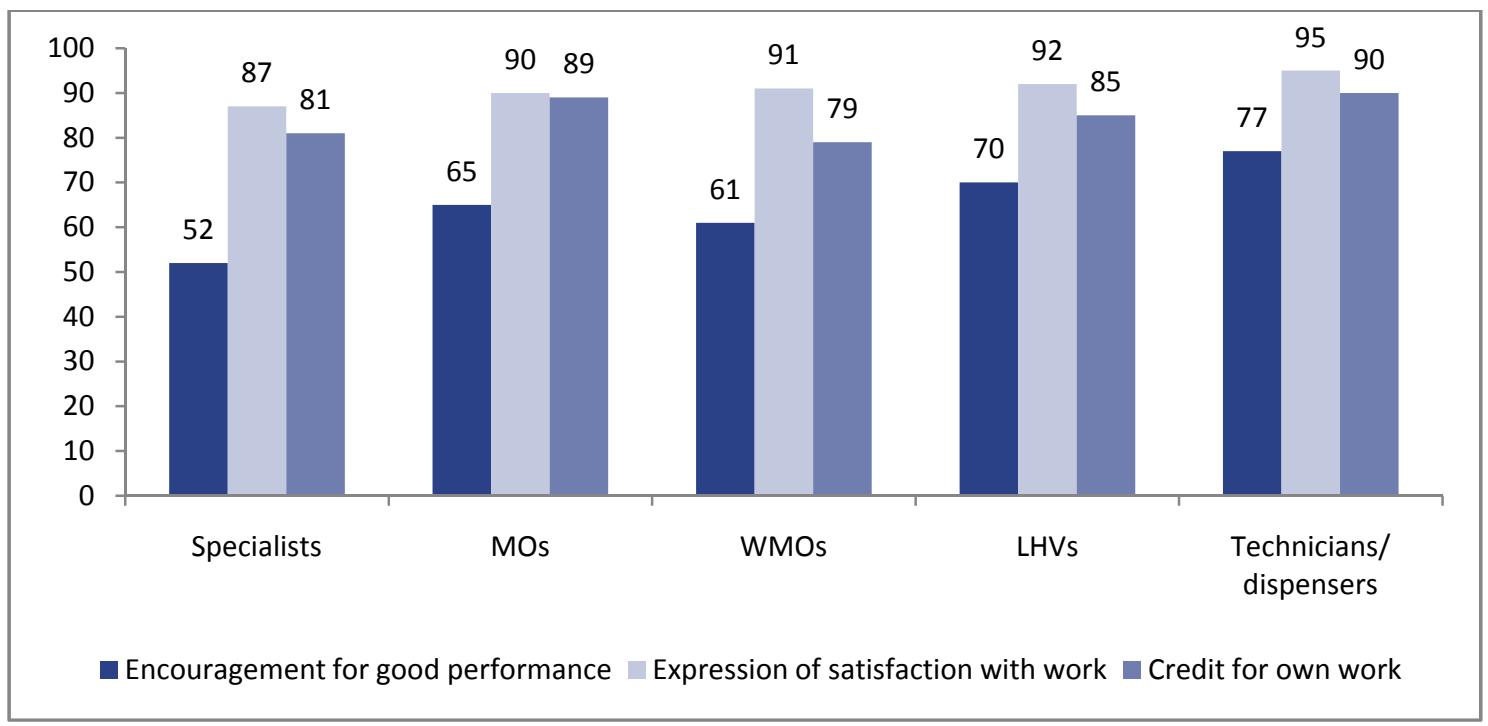


Extent of supportive supervision received by providers: A composite index on supportive supervision was developed using the seven variables below. Individual answers were scored as follows: Scoring: No $=0$, sometimes $=1$, yes $=2$.

Scores ranged from 0 to 14 . Scores 0 to 5 were labelled as non-supportive supervision, 6 to 10 as moderate support, and a score above 11 as supportive supervision. The seven variables include:

1) Encouragement by supervisor on performance of a good job;

2) Discussions with supervisor on improving the workplace environment;

3) Support to supervisor in resolving problems;

4) Involving employees in decision making regarding transfers and promotions of subordinates;

5) Giving importance to employees' opinions regarding performance of facility;

6) Supervisors taking action on employees' complaints;

7) Supervisors offering assistance to their employees' in doing their job better.

According to this scale, a higher proportion of technicians and dispensers reported receiving supportive supervision at $63 \%$, followed by MOs. Only half of the WMOs and specialists interviewed reported receiving supportive supervision. However, for all cadres, only a tenth reported receiving non-supportive supervision.

Figure 3.10: Proportion of providers receiving level of supportive supervision by cadre

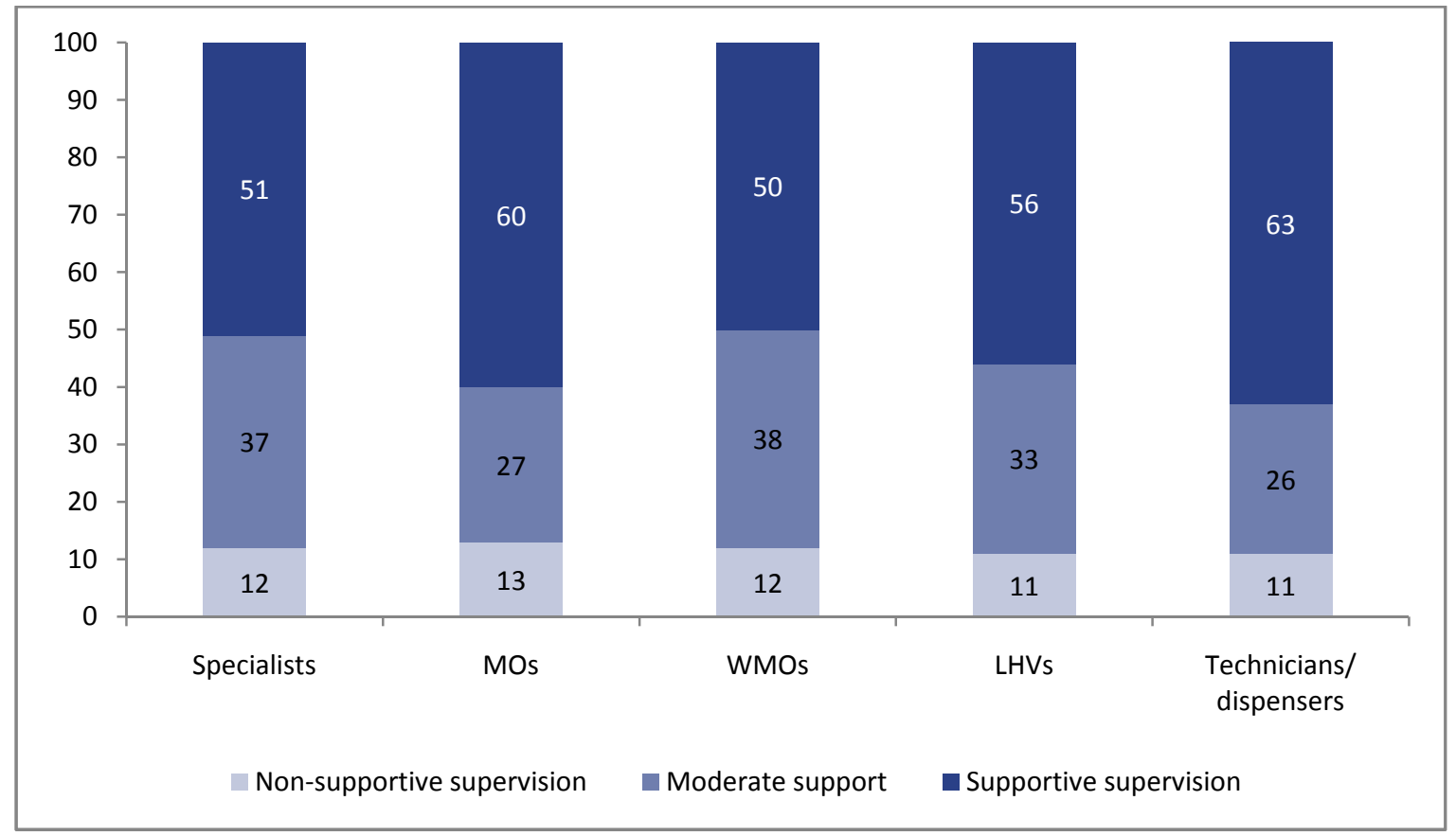

A regional analysis of the proportion of providers who received supportive supervision showed that the highest proportion was reported in Balochistan where three-quarters of the respondents reported receiving 
it. Proportions were also high in AJK and Sindh. Less than half the providers in GB and KP receive supportive supervision, and only $13 \%$ of the providers in FATA reported receiving supportive supervision (figure 3.11).

Figure 3.11: Proportion of providers receiving supportive supervision - regional analysis

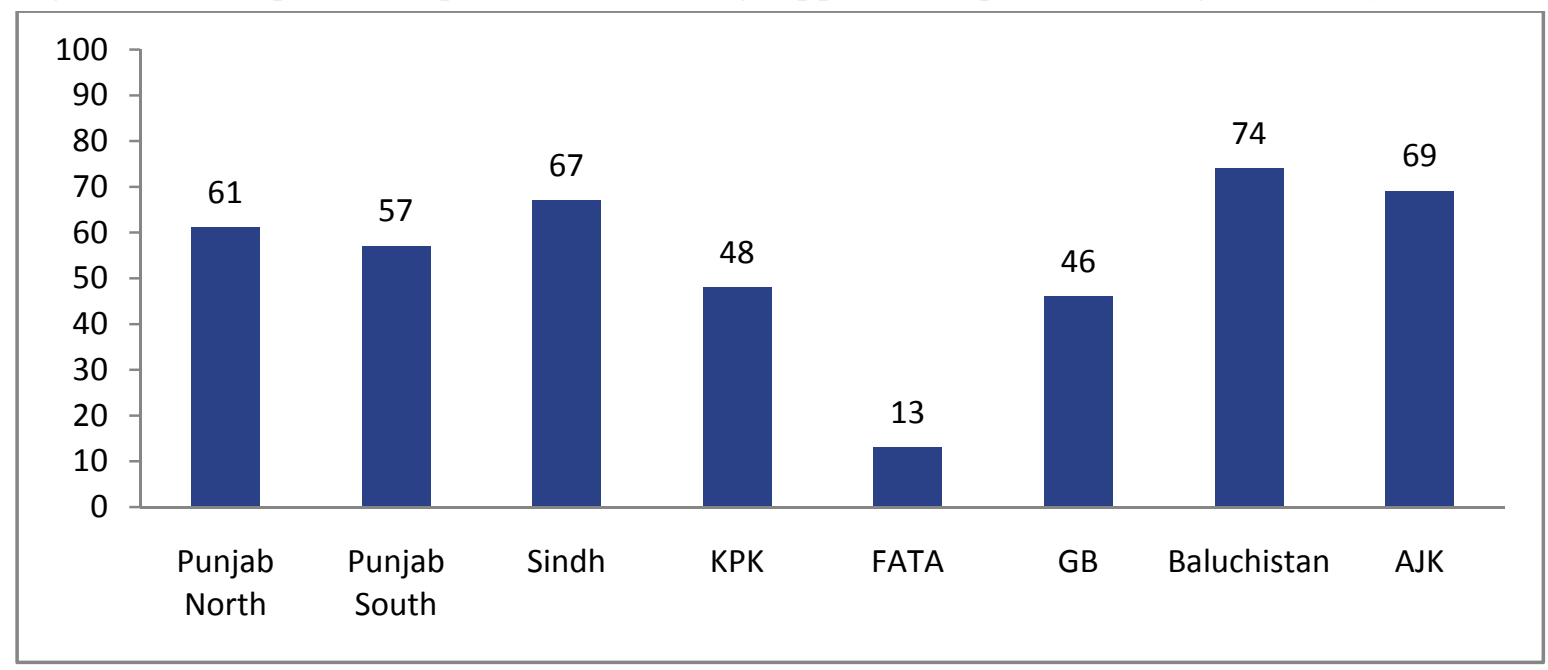

The analysis of supervision by job type shows that majority (two thirds) of contractual providers received supportive supervision in comparison to half of the permanent employees signifying that contractual employees have a better supervisory system in place (figure 3.12). Systems of accountability exist both in the government and PPHI and PRSP, but with fewer facilities to cover, we can assume that supervision and monitoring perhaps is easier. Additionally, PPHI has designated officials for visits to facilities and monitoring performance of and communicating with providers.

Figure 3.12: Proportion of contractual vs. Permanent providers receiving supportive supervision

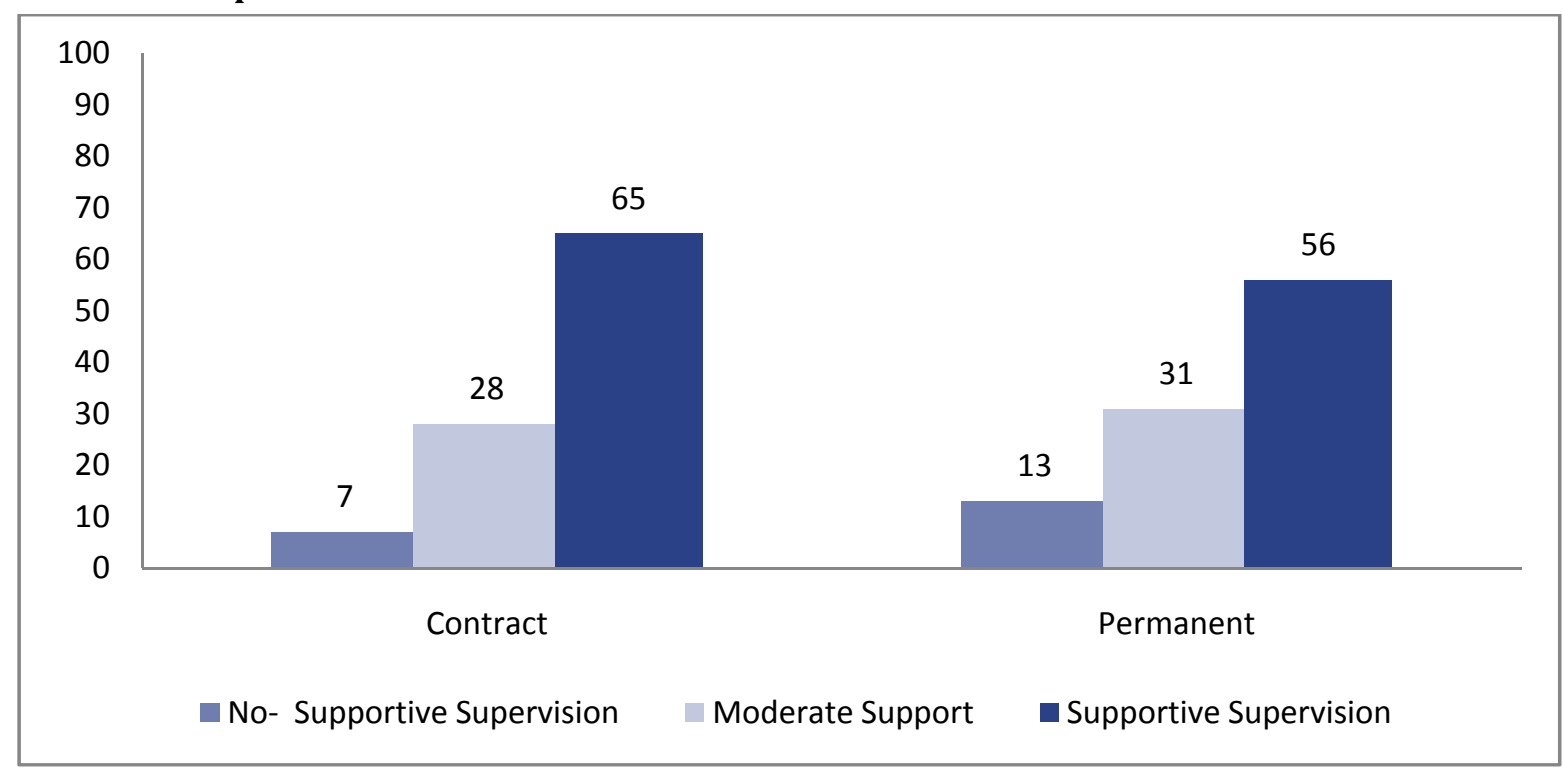




\section{Managers' views on supporting staff}

In order to better understand and obtain a 360 degree perspective on the existing supervisory system, we obtained the views of managers/supervisors

Communication with healthcare providers:Managers were asked about the ways that healthcare providers registered complaints with them. More than half of the managers reported that providers registered complaints during meetings. About a third said they received applications and the remaining reported receiving complaints through the immediate supervisor of the provider. The majority of managers said there was a supervisory visit schedule in place and $85 \%$ said they met with their district facility staff on a monthly basis. Three-quarters of the managers said they made facility visits without informing the staff beforehand.

Decision-making and assistance:Only a tenth of the managers reported not involving their providers in decision-making regarding the implementation of various activities, implying a high level of involvement. When asked about the ways they provided assistance to their providers in increasing their productivity and performing better, the most frequently reported answer was 'by providing support and assistance when needed.' This was followed by on-job 'needs based trainings,' 'meetings for problem solving,' and 'verbal appreciation.'

\section{Summary}

- Specialists need more support from their supervisors

- A high proportion of providers in FATA, followed by GB, are dissatisfied with the supervision they are receiving

- More than two-thirds of all cadres of providers reported being involved by their supervisors in decisions regarding improving the work environment of their facility.

- A high proportion of providers reported that supervisors expressed satisfaction with their performance and gave them credit for their work.

\section{3: Work Environment}

A non-conducive work environment can be a major cause of dissatisfaction for employees affecting the functioning of the health system especially in terms of attracting and retaining staff (Gow et al 2012). For the purpose of this study, the work environment has been defined as a combination of the working conditions and infrastructure present at the facility. We have included the following areas within the work environment:

- Work conditions - that include office and infrastructure

- Workload

- Feeling of safety and security at work, travelling to work and living arrangements 


\section{Work conditions}

The availability of necessary infrastructure such as electricity, staff washrooms, and separate officesare an important prerequisite in creating a positive and favourable work environment.

\section{(a) Designated office space}

The condition in which people work has a tremendous effect on their level of pride for themselves and for the work they are doing. This includes providing a certain degree of personal space to the staff (Syptak et al. 1999).

Having a separate office for providers is linked to the type of facility the provider works at. As shown in figure 3.13 below, a higher proportion of providers at $\mathrm{BHU}$ and $\mathrm{MCH}$ centres have a separate designated office as compared to providers working at the larger facilities i.e. DHQs and THQ hospitals. This may be explained by the fixed layout of BHUs and the small number of designated staff at BHUs and MCH centres. In larger facilities and hospitals where there is a space constraint, it is more likely that providers have to share offices.

Figure 3.13: Proportion of providers having separate designated office by type of facility

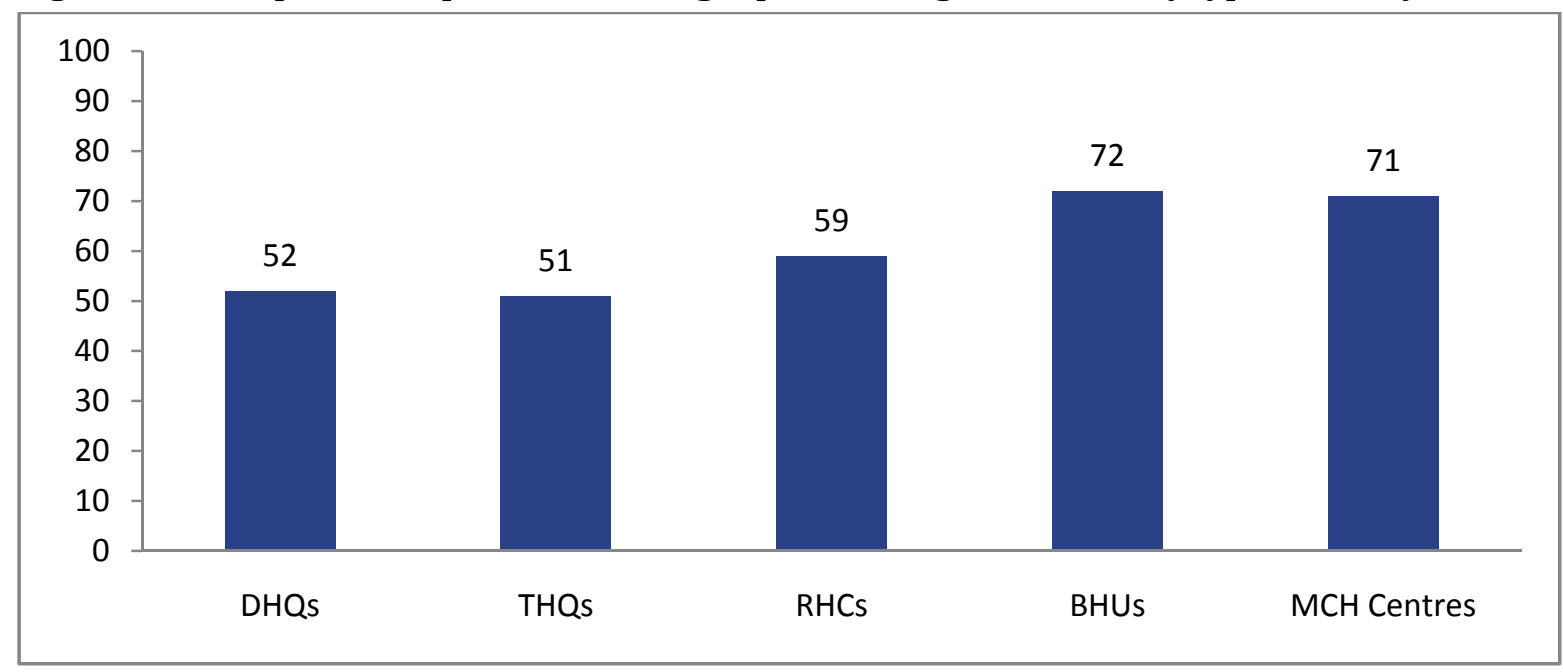

Figure 3.14 below shows the proportion of providers who have their own separate designated office. A higher proportion of specialists and MOs had their own offices as compared to other cadres. Less than twothirds of technicians and LHVs and less than half of the WMOs had their own offices. A separate office facilitates the work of the providers as it helps in ensuring privacy for their clients and providers are therefore able to make clients more comfortable. 
Figure 3.14: Proportion of providers who have a separate designated office by cadre

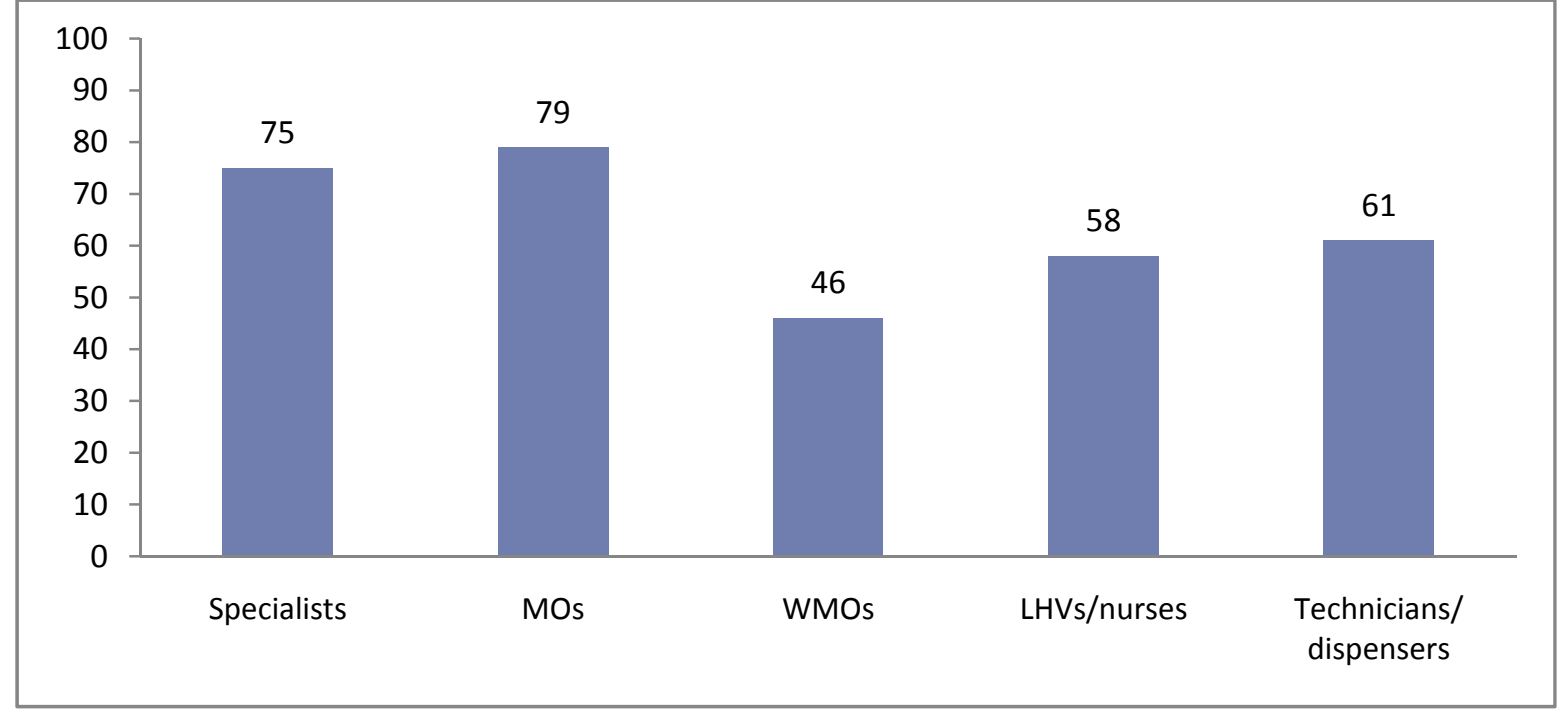

Providers were asked if the facility they worked at had drinking water available and if refreshments were sold nearby. Figure 3.15 shows that these services were the highest at tertiary-level facilities, DHQs, and THQs, which are located in relatively urban areas compared to RHCs, BHUs, and $\mathrm{MCH}$ centres. This is especially true regarding the availability of refreshments, which at $54 \%$, was particularly low at BHUs.

Regionally, the availability of drinking water was the lowest in Balochistan and FATA at $58 \%$ and 59\%, respectively. Nearby availability of refreshments was also the lowest in FATA, followed by KP. The Majority $(93 \%)$ of the respondents reported that there was a staff washroom available at their facility.

Figure 3.15: Availability of drinking water and refreshments near facility

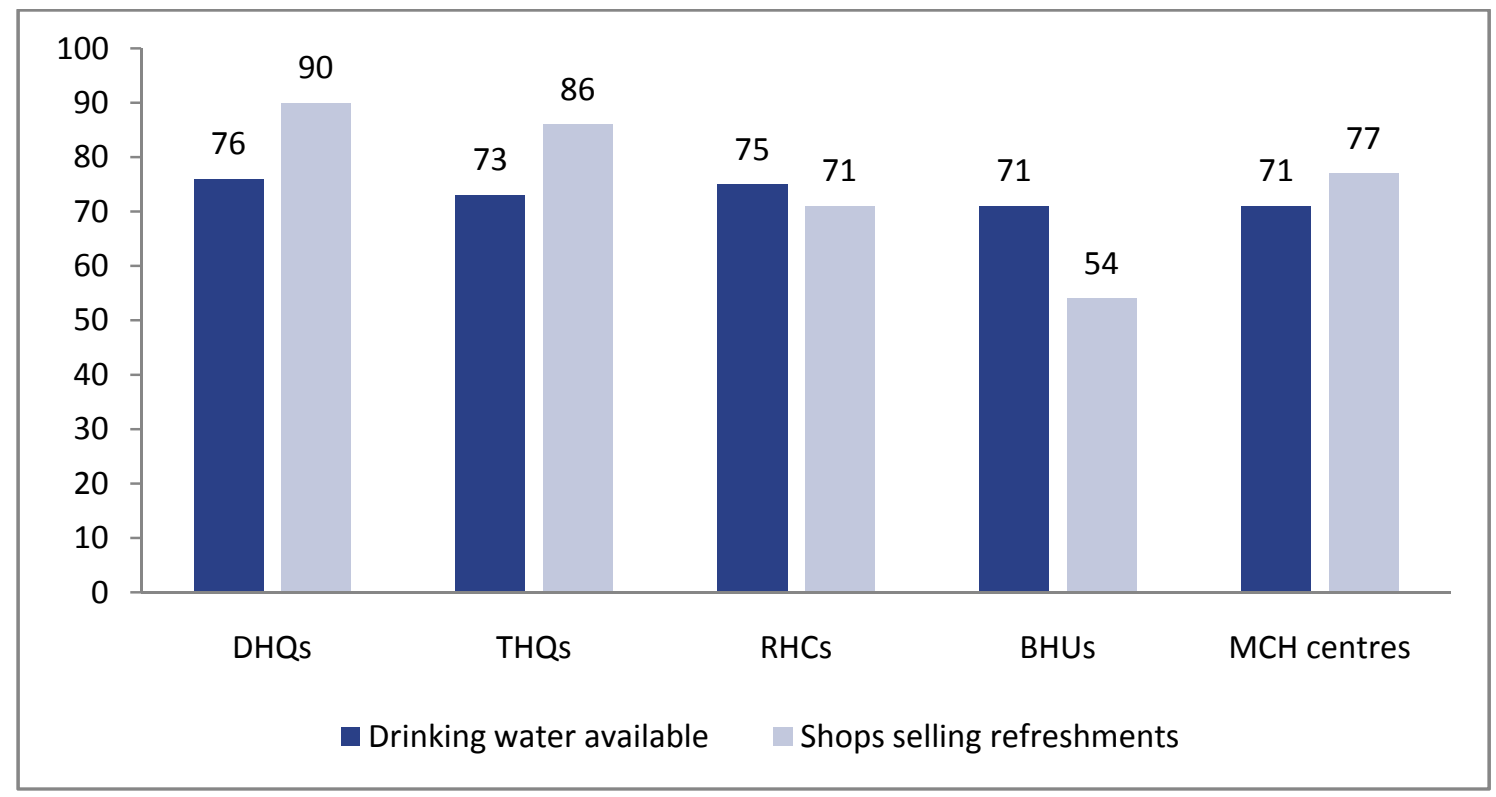




\section{(b) Infrastructure availability}

Electricity was available in almost all facilitieswith $95 \%$ of the providers reporting that their facilities were electrified, and $48 \%$ reporting that a backup generator was available. However, as reported by one respondent in the IDI, "Electricity was not available for long stretches of time. We have not had electricity for the last five days." In Balochistan and FATA, the availability of electricity was slightly lower at $87 \%$ and $83 \%$ respectively. Availability of electricity is a basic requirement that impacts on the work environment and upon providers' productivity and comfort levels as illustrated by the statement of a provider in FATA: "We have problems with weather and infrastructure. We do not have fans and do not have generators for backup electricity. There is no water either. These are very basic needs." WMO, FATA

\section{Workload}

Providers were asked about their perceived workload. Figure 3.16 show that more than half of the providers in each cadre perceived their workload to be excessive. This was the highest in the case of specialists; almost three-fourths of the specialists reported feeling overworked. This is understandable as the nature of work of the specialists entails their assuming some administrative responsibilities in addition to providing care. The lowest proportion of providers reporting excessive workload and feeling stressed were LHVs/nurses. About half of the rest of the cadres reported having excessive workload and almost equivalent levels of stress. Providers were asked whether their client load had changed in the past two years and $67 \%$ of all respondents reported that it had increased. More than three-quarter of WMOs and Specialists reported that their client load had increased followed by $69 \%$ of technicians, $65 \%$ of LHVs and $63 \%$ of MOs.

During the IDIs, specialists explained as to why they felt they were overworked.

"The biggest problem that we have is the shortage of staff; there are too few doctors compared to the amount of patients that we get. So managing this can be very difficult." Gynaecologist, Gwadar

"There is a shortage of staff. The female wing is never clean or tidy. I have not even been given my own phone, or even a midwife. I have to do all the work myself." Specialist, Gilgit

"Workload isa big problem. Every patient demands to be seen first. Sometimes I have to be on duty for 24 hours. Often there is an emergency at night - at times we have to do duty during the day and the night."WMO, Skardu 
Figure 3.16: Proportion of providers who experience stress and report excessive workloads by cadre

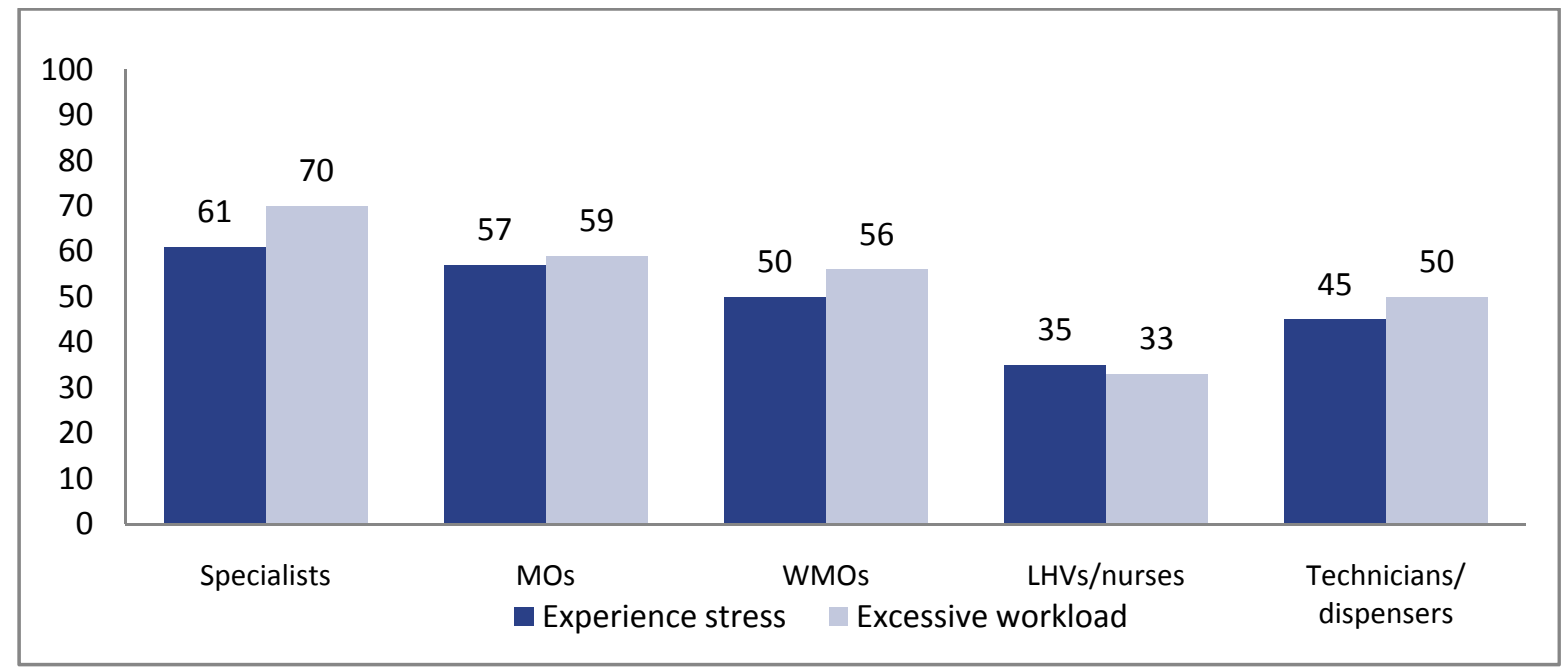

To ascertain how existing workload was impacting respondents' social lives, they were asked if they had time to meet friends and relatives after working hours; only $21 \%$ of specialists and a third of the WMOs answered in the affirmative. The highest proportion of providers who reported being able to meet and give time to friends and relatives were technicians and dispensers with $52 \%$ reporting being able to do so (data not shown).

Another variable used to gauge level of socialization with colleagues as well as level of workload was the frequency with which providers got to meet with their colleagues and discuss different aspects of their work. Almost half the respondents reported doing this sometimes; $45 \%$ stated they did so often, and only $5 \%$ never participated in these activities (data not shown).

Figure 3.17 shows the proportion of providers by cadre who socialized with their colleagues. The lowest proportion was of LHVs and specialists. In case of the other providers nearly half reported engaging in such socialization.

Figure 3.17: Proportion of providers reporting opportunities to socialize with their colleagues by cadre

\begin{tabular}{|c|c|c|c|c|c|}
\hline 100 & & & & & \\
\hline 90 & & & & & \\
\hline 80 & & & & & \\
\hline 70 & & & & & \\
\hline 60 & & & & & 51 \\
\hline 50 & 47 & 50 & 50 & & $\partial \perp$ \\
\hline 40 & & & & 39 & \\
\hline 30 & & & & & \\
\hline 20 & & & & & \\
\hline 10 & & & & & \\
\hline 0 & & & & & \\
\hline & Specialists & MOs & WMOs & LHVs/nurses & Technicians/dispensers \\
\hline
\end{tabular}


Three-quarters of specialists were engaged in private practice while a third of MOs and WMOs, and a quarter of technicians were also involved in working after office hours. Further analysis revealed that private practice was significantly associated $(p<0.05)$ with stress levels (figure 3.18 ).

"People who work in the public sector should not work late hours in their Private Practice-this really affects safe delivery of services. They are not able to pay attention to their job and additionally they start referring [patients] to their own private practice. So a line has to be drawn very clearly. Otherwise the system will not improve." MS, Hafizabad

"I also do private practice so as a result I work very hard and am very overburdened", IDI, Paediatrician, FATA

Figure 3.18: Proportion of providers who report having a private practice in addition to their regular job

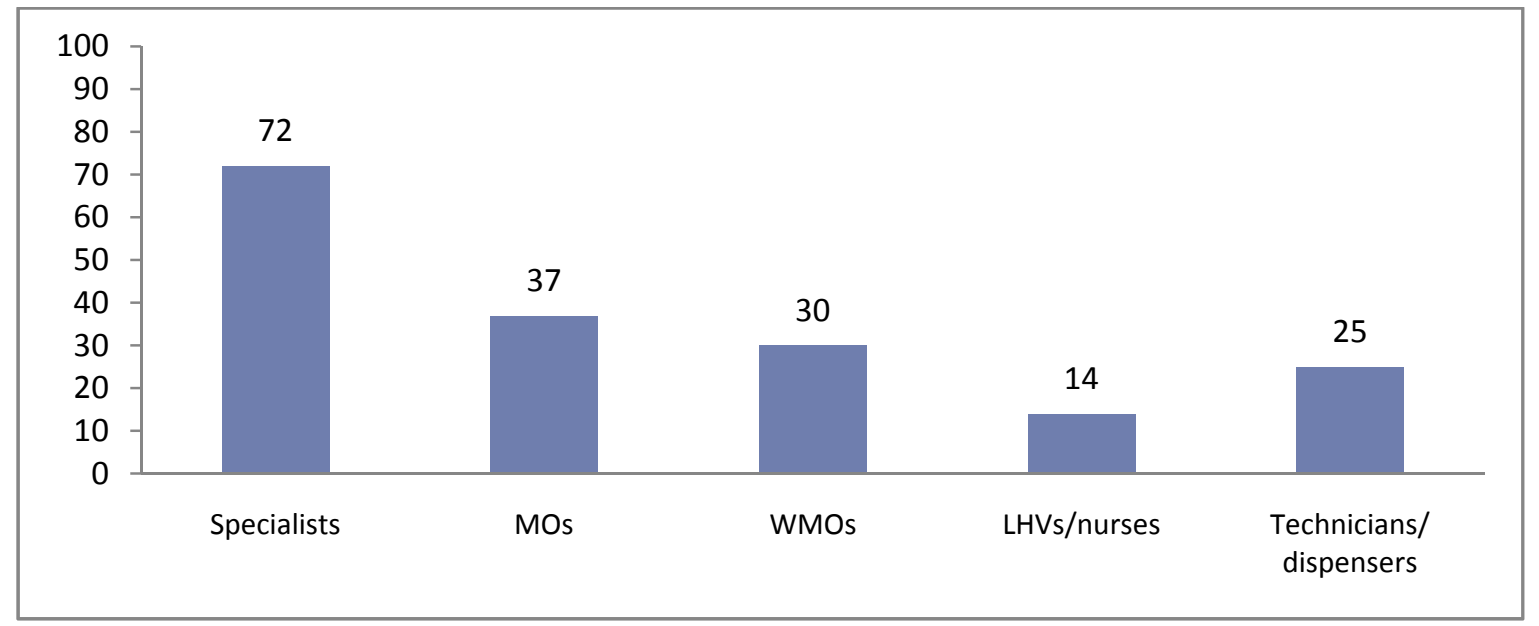

Managers' recognition of staff being overworked

Figure 3.19 below shows the breakup of responses of managers when asked whether providers ever complained about being overworked. It is seen that half of the managers admitted that they received this complaint and $11 \%$ said they sometimes received this complaint from their staff.

Figure 3.19: Proportion of managers who reported receiving complaints from staff on being overworked

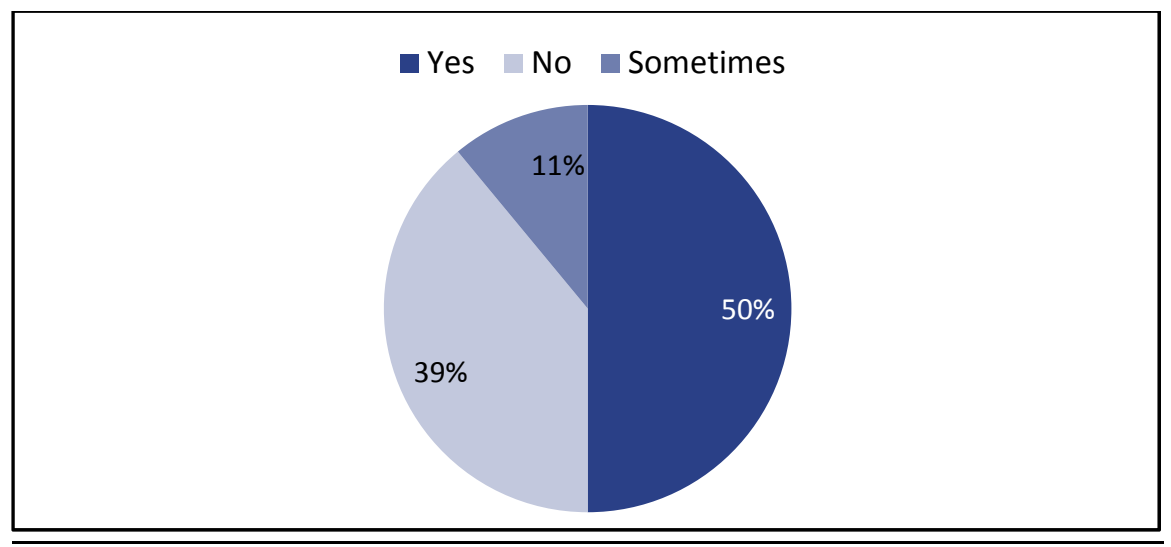




\section{4:Social Factors Influencing MNCH Staff Motivation and Retention}

According to Franco et al (2002) communities also influence worker motivation through expectations based on how they perceive services should be delivered.

In this chapter we examine two elements that influence the socio cultural context in which worker perform their duties. These include political and community interference and providers' perceptionsregardingsafety at their place of work and while travelling to work.

\section{Figure 3.20: Factors influencing Health Worker's Motivation}

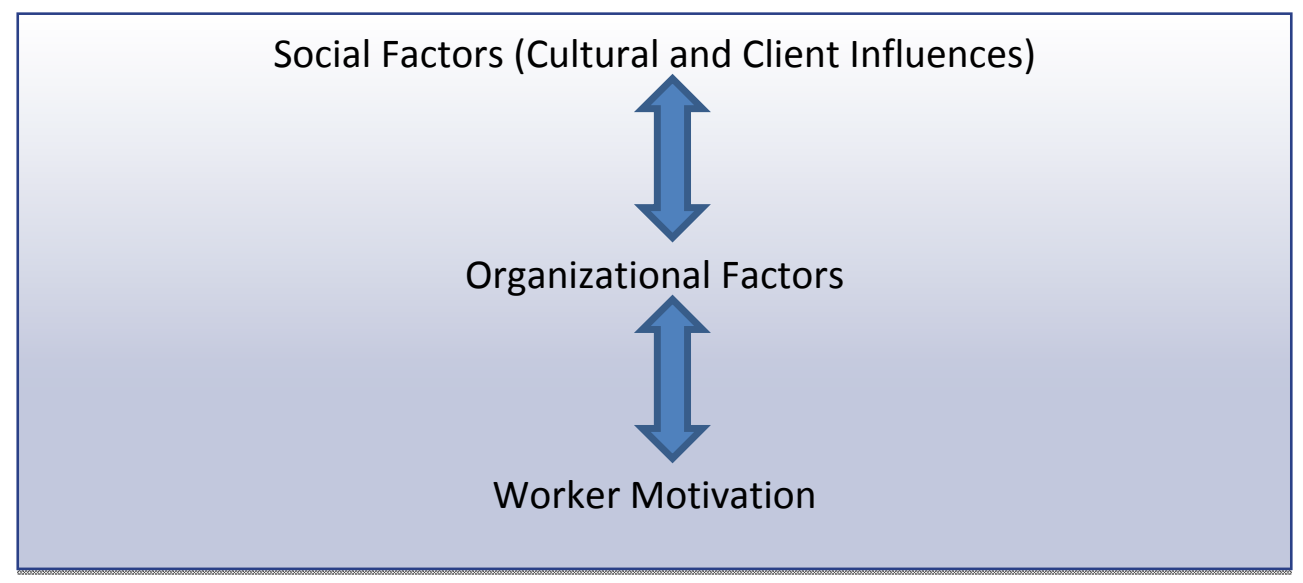

Source: Franco et al. 2002

\section{Political Interference}

\section{External interference in work}

This is divided into political and community interference. Political interference has been defined here as interference that negatively influences the work of the providers by elected representatives, politicians and leaders of political parties, and public officer holders. Community interference includes interference by community notables/influential people of the area. Figure 3.21 shows the levels of external interference reportedly experienced by providers across regions. 
Figure 3.21: Proportion of providers experiencing political and community interference by region

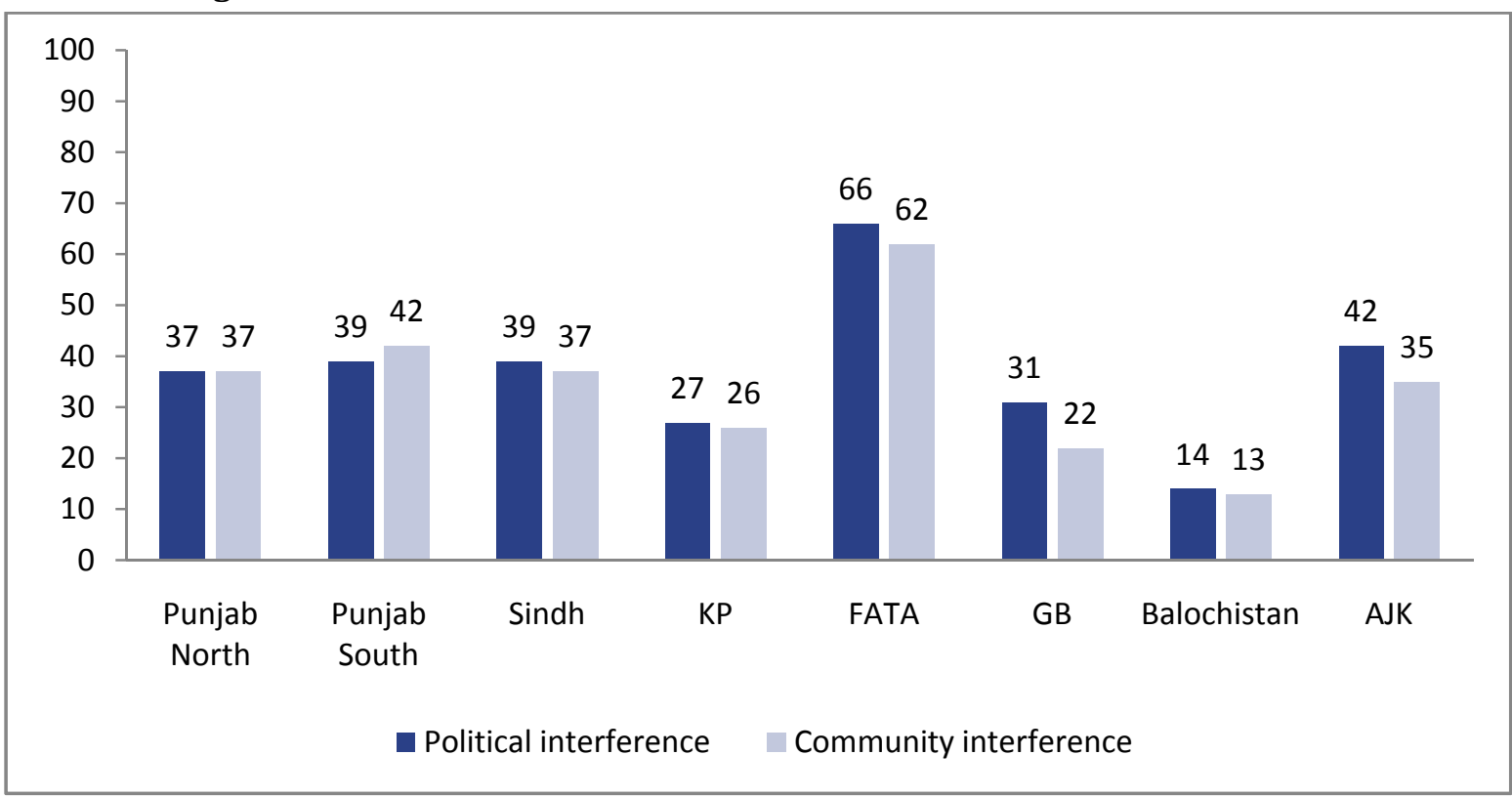

The highest proportion of interference was reported in FATA where nearly two-thirds of providers experienced both forms of interference. This was followed by AJK with the second highest proportion of political interference, and Southern Punjab reported high levels of community interference. The proportion of providers who reported interference was relatively lower in Balochistan, GB, and KP. There was also a significant difference in levels of political interference experienced by males and females, with a higher proportion of male providers reporting experiencing political interference $(p<0.01)$.A possible explanation for this is that male providers are often at the forefront and have to deal with political interference more than female providers, especially LHVs and nurses. The provincial managers from Balochistan, while commenting on why providers in Balochistan reported less political interference, were of the view that most providers belong to the area where they work and are well respected and well known in their communities. By type of facility, we found that nearly half of all providers in secondary care facilities (THQs/DHQs) reported political interference in their work compared to $30 \%$ of providers in primary level care facilities (BHUs/RHCs). This difference was statistically significant $(p<0.01)$.

Participants were asked in-depth as to what forms of interference they experienced that affected their work. Frequently reported forms were pressure from influential community members to give priority to their patients and to make home visits. Providers also mentioned the extra burden of dealing with MLCs and pressure from influential quarters to produce MLC reports according to their wishes.

"MLCs bring in a lot of political interference too. This is a major demotivating factor. You have to do what they say because if they act on their threats you will be the one suffering. Example is my window was broken because someone attacked me for not listening to their MLC demands."IDI,MO, Lahore 
When asked how external interference can be reduced, most providers were of the opinion that this can only be stopped if the higher officials take a bold decision to withstand interference by insisting on following and obeying the laid down rules and procedures related to transfers, and promotions.

Views of providers on withstanding political interference

"This is in the hands of district authorities, they should think about their health workers first and about political people later." IDI,WMO, Layyah

"Political interference can only be reduced at higher levels if people stop caving in to it." IDI, Anaesthetist, Rajanpur

"Political interference takes place because politicians are not aware that what they are asking for is not correct or lawful. It can be reducedby educating them and creating awareness and engaging with them." IDI, Specialist, Bhimber, AJK

\section{Safety and Security Issues}

Feeling of safety and security at work and travelling to work and living arrangements

The majority of the providers (81\%) reported feeling safe within their work environment. Feeling safe and secure at work and while commuting to work contributes to a positive work environment. Feelings of safety depend, to a large extent, on staff feeling physically unthreatened, especially while working in far-flung rural areas.

The presence of a boundary wall around the facility contributes to perceived and actual safety levels for providers and patients. Almost a quarter of the providers reported not having a boundary wall around their facilities. Similar findings were obtained from the health facility assessment carried out as part of the study. A lower proportion of the RHCS, BHUs, and $\mathrm{MCH}$ centres had boundary walls, as compared to DHQs and THQs. There was a significant association between having a boundary wall and feeling safe, with providers in facilities without boundary walls feeling significantly less safe than those with boundary walls $(p<0.05)$.

Providers were asked how many kilometres they travelled to reach their place of work. It was found that while majority (40\%) travelled less than $5 \mathrm{~km}$; 19\% travelled between 6 to 15 kilometres, $15 \%$ between 16 to 30 kilometres, $8 \%$ between 31 and 60 kilometres and another $17 \%$ travelled above 60 kilometres. It was also found that there was a significant negative correlation between kilometres travelled and feeling safe while travelling from home to work. Three quarters of the providers travelling less than 5 kilometres felt safe, which dropped to $37 \%$ in providers travelling between 31 and 60 kilometres.

Providers who used transport other than their own were asked if they felt safe while travelling from their homes to their place of work. Perceptions of safety varied from region to region. Comfort in using public transport was lowest in FATA, AJK, and Southern Punjab and highest in Balochistan where two-thirds of respondents felt comfortable. Safety while travelling from home to work was also the lowest in FATA followed by South Punjab and Sindh. It is seen that nearly 47 percent of providers in FATA had to travel more than 60 kilometres to get to work, and a quarter of the providers in Sindh travelled more than 30 Kilometres. Both regions are also facing a deteriorating law and order and security situation. Perceptions of safety while traveling from home to work were highest in KP and GB (figure 3.22). 
Figure 3.22: Safety and comfort levels of providers while using public transport - regional analysis

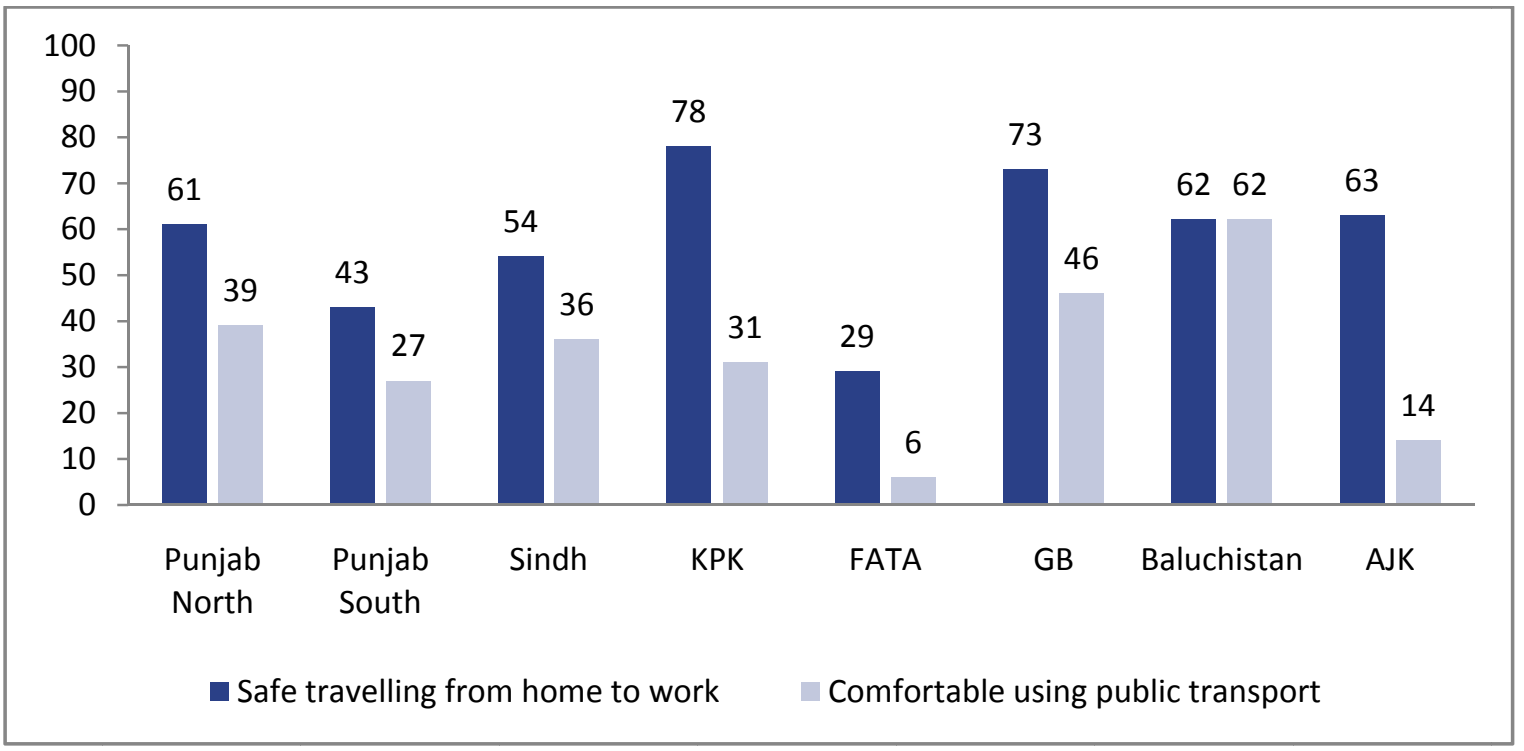

Because of the rural location of most facilities, the areas where the providers' reside also define their perceived safety levels while at work and on their way to work. As shown in figure 3.23, 20\% of all providers live within the premises of the facilities that they work at. Another $56 \%$ live within the city and $23 \%$ live in another city. Of the providers who live within the premises, a third are specialists, a quarter are LHVs and MOs, $15 \%$ are WMOs, and $9 \%$ are technicians and dispensers. The reason for the higher proportion of specialists residing within the facility is probably because most specialists are posted in the larger tehsil and district level hospitals where accommodation is available for them. The highest proportions of providers who live within the city but outside the premises of the facility are technicians, dispensers and WMOs.

Figure 3.23: Residential status of providers by cadre

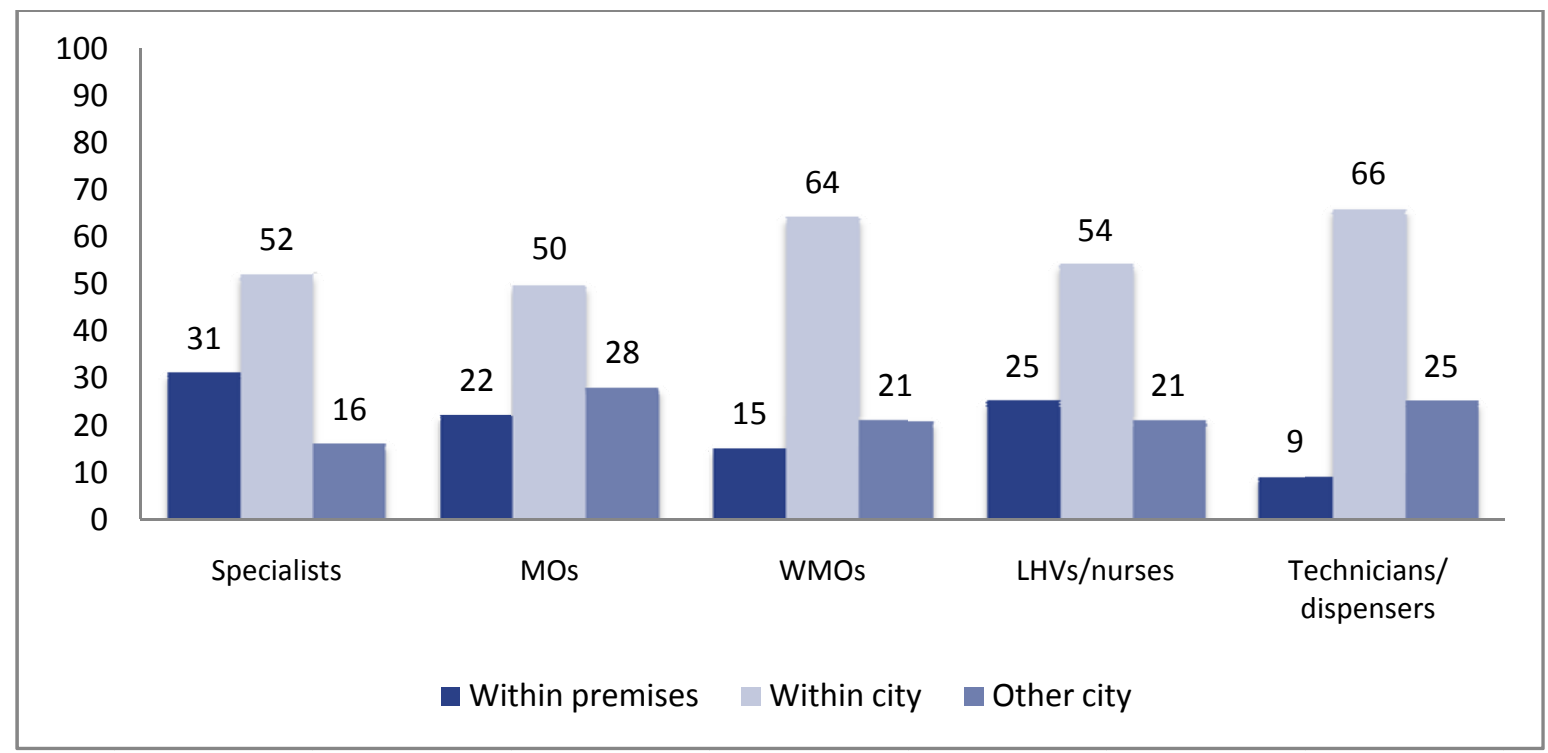


With the exception of specialists, a quarter of all providers live in another city. The nature of the providers' work requires that they are readily available at their place of posting to provide services especially during emergencies. The fact that the majority of the providers live outside the premises of their facility, and away from the city of their posting means that they have to bear the inconvenience of traveling to and from their place of work on a daily basis, and often are not able to attend emergency cases at night due to the distance from their facility.

"Many women leave their jobs because of harassment when traveling...men make comments at us when we go out and we do not feel safe" LHV, Khanewal

"Women have many problems because of the environment. If you get them posted far away from home, then they will have trouble travelling. If they have evening timings then they have problems with security. Being female, their mobility is very limited." MO, Hyderabad

Figure 3.24 shows the proportion of providers using public transport who felt safe and comfortable doing so. Less than a third of the providers in each cadre felt comfortable using public transport. Safety levels while travelling from home to work were highest for WMOs and technicians of whom two-thirds reported feeling safe. A smaller proportion of LHVs, MOs, and specialists felt safe. A possible explanation for WMOs feeling safer than other cadre is that (as reported in the FGDs,) when travelling long distances women will often have to bring a male family member with them for safety. This may affect their travel experiences.

The distance travelled to reach the facility also influenced perception of safety with nearly $63 \%$ of respondents who travelled more than 30 kilometres to reach their place of work reporting feeling unsafe during travel.

Figure 3.24: Proportion of providers who feel comfortable using public transport and who feel safe while travelling from home to work

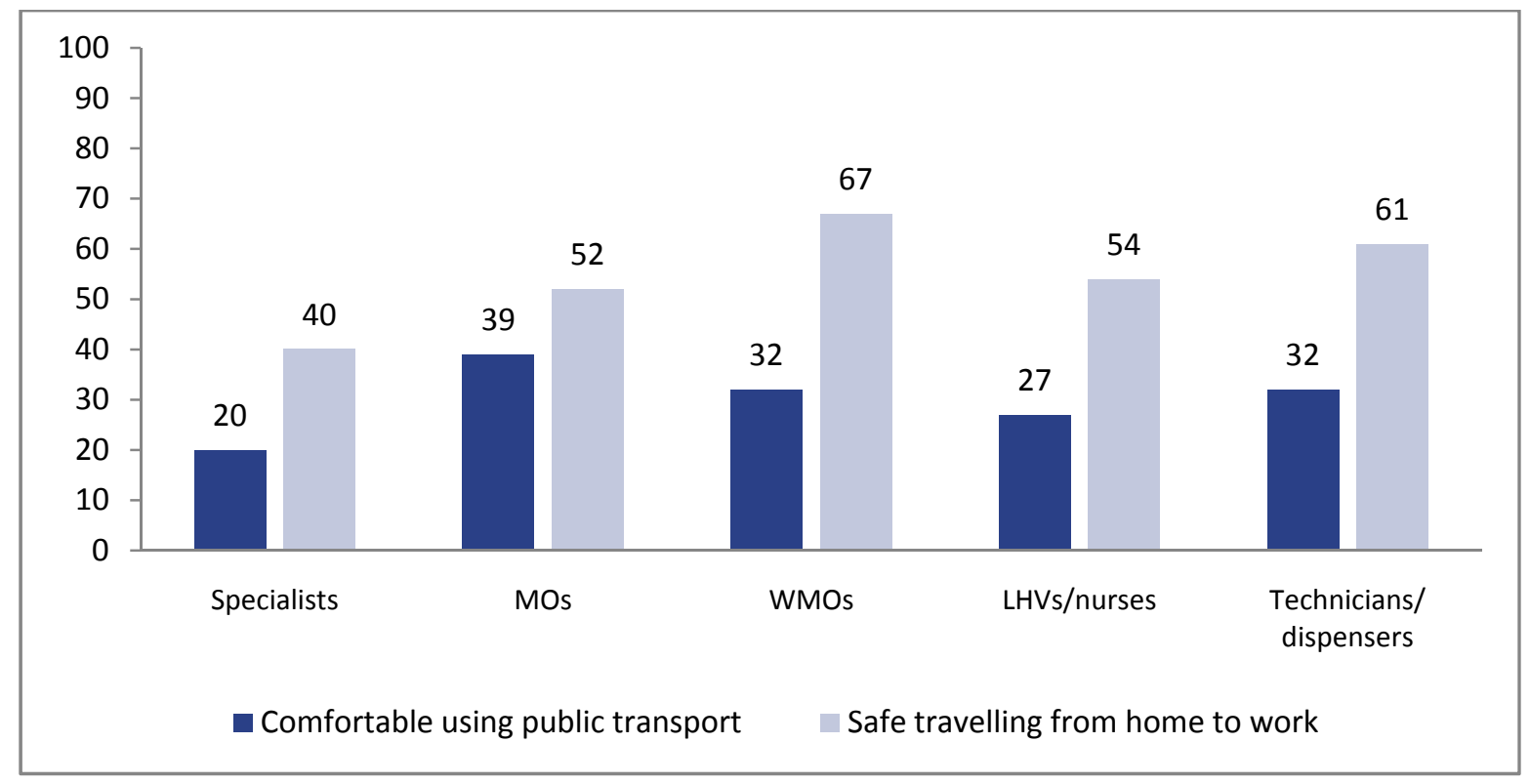


In the IDIs, providers highlighted the need for the government to construct residential facilities where the staff could stay. Many staff members have to reside in the city away from the facilities and incur a significant proportion of their salary on transportation. As an IDI respondent, an MS from AJK pointed out, "If staff themselves are not comfortable, how will they be able to deliver services with ease?"

A majority of respondents demanded that a higher transport allowance should be given in case residential facilities are not provided.

Managers' views on issues related to travel, safety, work environment and political interference Travelling, work environment, and interference: Managers were asked whether their staff ever complained to them about safety issues such as an unsafe workplace environment (including sexual harassment), feeling unsafe while travelling, and being threatened by influential persons. $42 \%$ of respondents reported receiving complaints about the work environment, $54 \%$ about safety while travelling and $50 \%$ about threats. As shown in the figure 3.25the frequency of reports about unsafe work environment were the highest in FATA where all managers said they had received complaints, followed by Sindh where three quarters of the managers had received complaints. About half of the managers in Southern Punjab, KP, GB, and AJK had also received complaints about the work environment. This frequency was the lowest in Balochistan and Northern Punjab.

Figure 3.25: Proportion of managers reporting receiving complaints regarding travel, work environment, and political interference by regions

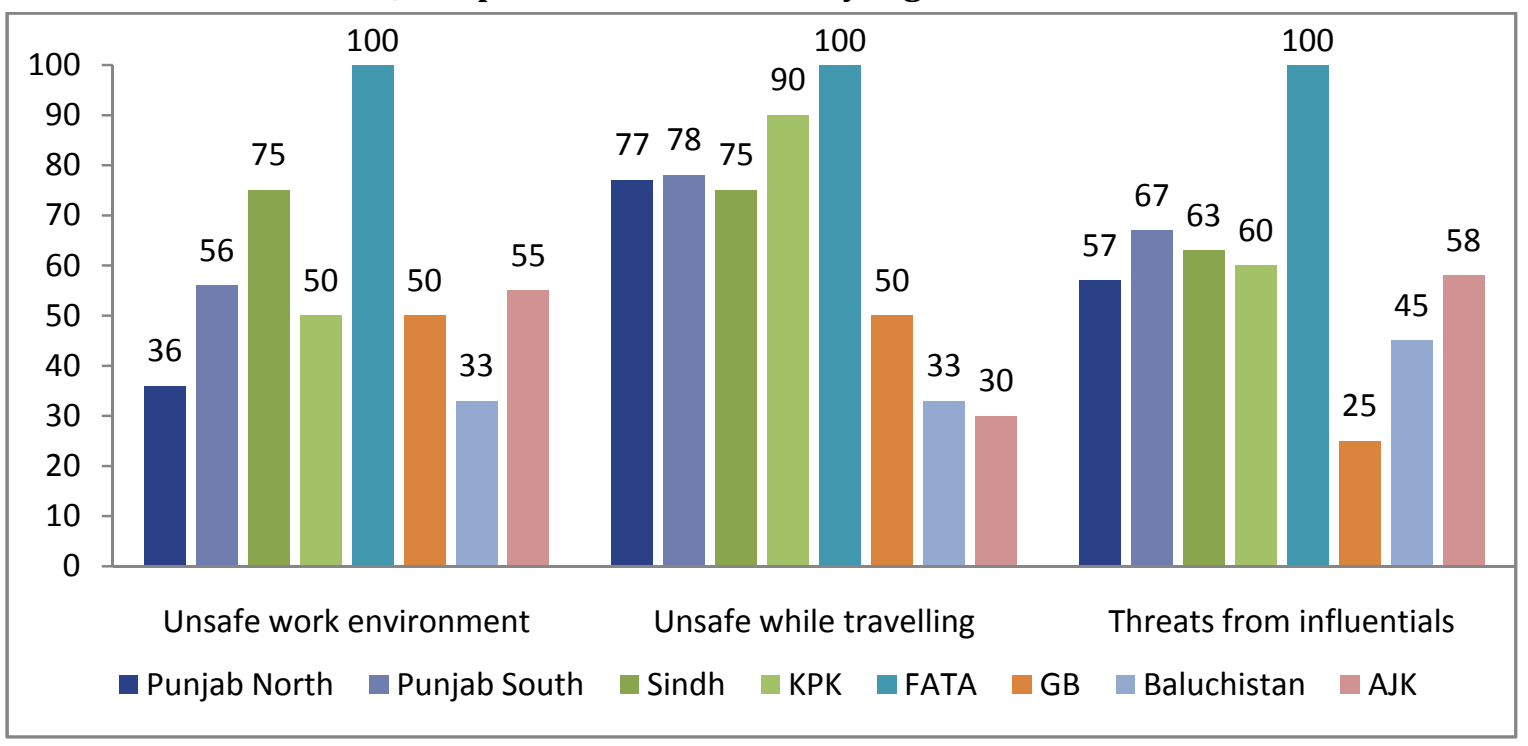

Complaints about feeling unsafe while travelling were also reported by all managers in FATA. With the exception of Balochistan and AJK, this was reported highly in all regions.

All managers in FATA received complaints about threats from influential people and three quarters in Southern Punjab and around half in all other regions. Only a quarter of the managers interviewed reported receiving complaints about this in Balochistan. 


\section{INDIVIDUAL LEVEL FACTORS INFLUENCING STAFF MOTIVATION AND OUTCOMES}

Health workers are motivated when individual goals are aligned to that of the organization and workersbelieve that they can accomplish the task entrusted to them. Almost all major theories on workers motivation (Maslow 1954, Vroom 1964, Lockstathan 1984) concur on three broad influences on workers motivation - a) goals, motives and values b) self-concept and (c) cognitive expectations about the relationship between actions and their consequences (Franco 2002). In this section we assess what workers feel in terms of general job satisfaction, pride in their work and satisfaction with their salary (affective outcomes); in terms of what workers think regarding their progress towards achieving goals and receiving recognition on the basis of promotions they have received (cognitive outcomes) and finally workers' behaviours in terms of getting along with others, their potential to perform based on training received and the relevance of work entrusted to them (behavioural outcomes) (Franco et al 2000).

\section{1: Motivating and demotivating factors:}

Providers were asked to identify the top three motivating and demotivating factors within the context of their current job and in general that influence them to continue working at their present position optimally. The top three motivating factors that were identified include an opportunity to serve the community, growth and responsibility through promotions and respect received from peers and the community. The demotivating factors include inadequate salary, availability of essential staff, medicines and equipment and issues related to commuting from their residence to their place of work.

Top three Maintenance and Motivating factors
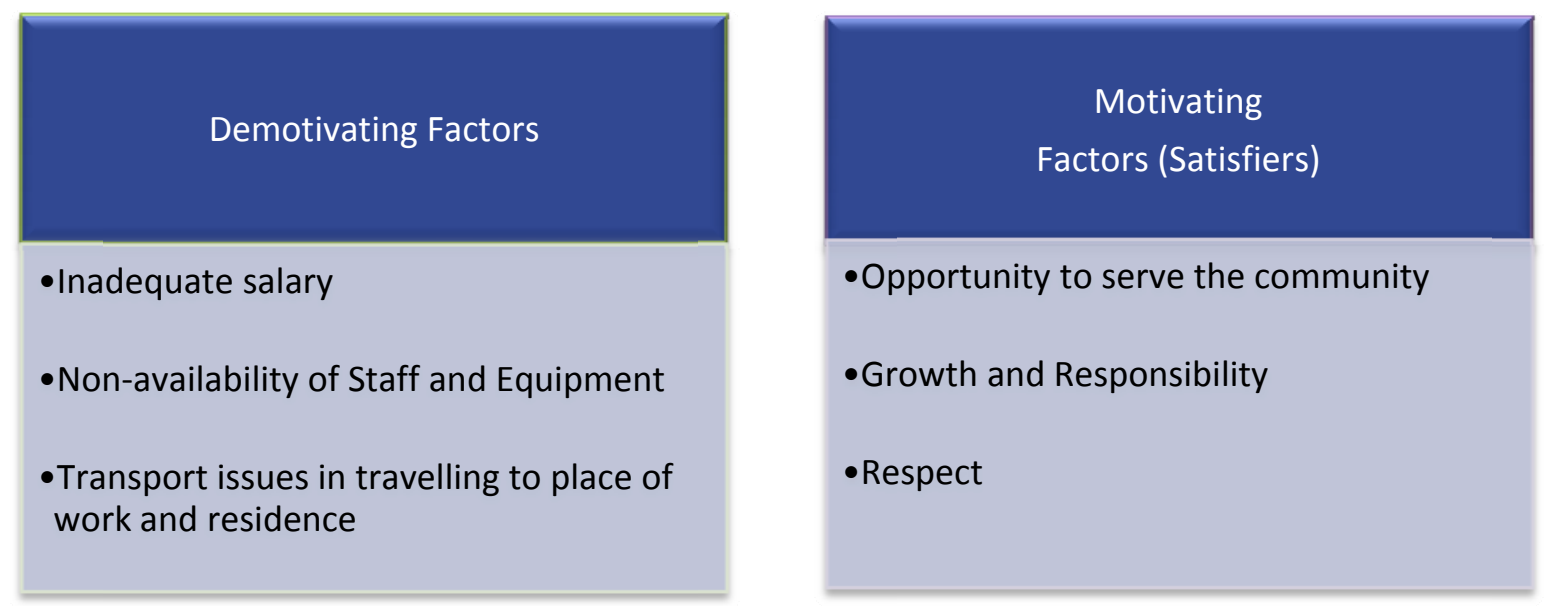


\section{2:Pride in Work}

An important aspect of intrinsic motivation is having personal gratification from one's job and a feeling of pride in what one was accomplishing. This is a step higher than being satisfied with the nature of the work one is entrusted with. According to figure 4.1, this proportion was highest among providers who worked at lower level facilities ( $\mathrm{MCH}$ centres and BHUs), slightly lower at RHCs, THQs and DHQs. This may be associated with the size of the facility, its staffing and autonomy enjoyed by providers at smaller facilities. Moreover, providers at lower level facilities (BHUs and $\mathrm{MCH}$ centres) are closer to the community and have direct interaction with the people, which results in greater satisfaction.

Figure 4.1: Proportion of provider reported having pride in their work by type of facility

\begin{tabular}{|c|c|c|c|c|c|}
\hline 100 & & & 94 & 96 & 97 \\
\hline 90 & 85 & 89 & & & \\
\hline 80 & & & & & \\
\hline 70 & & & & & \\
\hline 60 & & & & & \\
\hline 50 & & & & & \\
\hline 40 & & & & & \\
\hline 30 & & & & & \\
\hline 20 & & & & & \\
\hline \multirow{2}{*}{$\begin{array}{r}10 \\
0\end{array}$} & & & & & \\
\hline & DHQs & THQs & RHCs & BHUs & $\mathrm{MCH}$ centres \\
\hline
\end{tabular}

\section{3:General Job Satisfaction}

Motivation and job satisfaction are two distinct concepts. Job satisfaction does not necessarily lead to motivation and improved performance. However, job satisfaction does influence motivation and is closely related to staff retention. Job satisfaction is defined as the extent to which a person likes his or her job (Franco et al 2002) and is a composite indicator of several functions including salary and benefits including allowances, the work environment, rewards and appreciation and other non-monetary variables (Gow 2012). Greater satisfaction with one's job is associated with the provider's commitment to working towards organizational goals but is not a prerequisite for motivation (Hackman and Oldhan 1976). To measure providers' job satisfaction levels, we used the internationally recognized Job Descriptive Index (JDI) and Job in General (JIG) self-reported measures (Smith et al. 1969). The JDI has been described as the most popular and widely used measure of job satisfaction (Buckley, Carraher, \& Cote, 1992; DeMeuse, 1985; Zedeck, 1987). The instrument has been translated into 9different languages and administered in at least 17 countries. Researchers have ascertained that the instrument has yielded scores with high internal consistency that can be used for a variety of respondent populations and are predictive of a number of organizationally relevant outcomes. 
The JDI scale measures satisfaction with different facets of the job satisfaction: the work itself, pay, promotion, supervision, and relationship with co-workers and the JIG scale measures overall satisfaction with the job. It measures 'global satisfaction,' meaning that participants are asked to think about how satisfied they are with their job in a broad, overall sense.

\section{Methodology}

Both the JDI and JIG consist of short lists of phrases and adjectives that describe different facets of the job or the job overall. Respondents select "Yes," "No," or "?" in response to each word or short phrase. A "Yes" response means that the adjective or phrase describes the job situation, "No" means that the adjective or phrase does not describe the job situation, and "?" indicates that the respondent cannot decide: as "yes" = 3 , "no" = 0 , and "undecided (?)"= 1. Each JDI facet (described earlier) scale contains either 9or 18 adjectives or phrases describing various aspects of the respondents' work experiences. A JDI facet score and a JIG score was calculated for each respondent by summing the values for the items in each facet and the JIG. Overall scores for the work, supervision, and co-worker facets of the JDI and the JIG were compiled by summing the values of the 18 items. Two of the JDI facets, pay and promotion, have only nine items. For these two facets only, the final scores were calculated by summing the value of the nine items on each facet and doubling the sum to produced final scores. This doubling of the two shorter facets effectively equates the lengths of all JDI and JIG scales. Hence the range of possible scores on each scale is $0-54$.

For the purpose of this analysis, the healthcare providers included in the study were categorized into four different groups. The first group labelled "specialists" included administrators/MSs, gynaecologists, paediatricians, and anaesthetists. The second group, "MOs" comprised both MOs and WMOs. The third group, "LHVs" included LHVs, staff nurses, and charge nurses. The last group, "health technicians" consisted of male health technicians, operating theatre technicians, lab technicians, and dispensers.

Descriptive statistics are used to describe the basic features of the data. Arithmetic mean, median, and standard deviation for respondents were computed for the various dimension of job satisfaction assessed by the JDI for the different provider categories as stated above. The data is also disaggregated by gender in order to identify differences in job satisfaction levels between male and female providers. T-tests were used to compare the differences in mean values.

For analysing the results, we took the mid value. $20 \%$ above and below this middle value was considered as a neutral range. Scores below this range indicated dissatisfaction and above indicated satisfaction(Stanton et al. 2001).

\section{Results}

Figure 4.2 shows the satisfaction level of specialists. It shows the percentage of participants who responded in the upper tier of satisfied, the middle band of neutral, and the lower tier of dissatisfied.

It is evident from the figure that specialists are highly satisfied with work attheir present job (84\%), supervision (82\%), relationships with co-workers (80\%), and JIG (92\%). 
In the pay facet, only about half (47\%) of the specialists are satisfied. In the promotion facet, four-fifths of the providers are in the dissatisfied category.

Figure 4.2: Satisfaction levels of Specialists - all facets

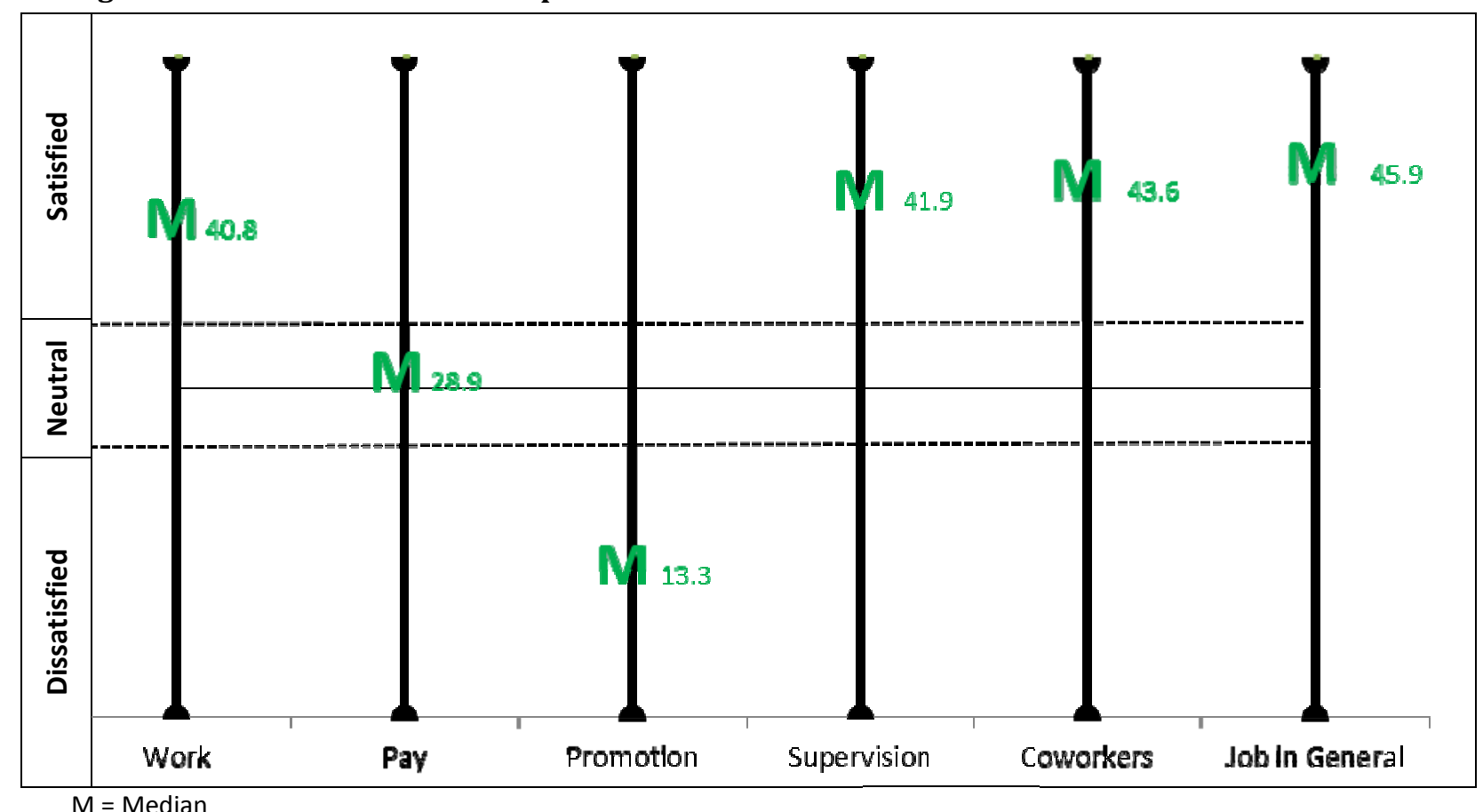

Table 4.1: Satisfaction levels of specialists - all facets

\begin{tabular}{|c|c|c|c|}
\hline \multirow{2}{*}{ Facet } & Satisfied & Neutral & Dissatisfied \\
\hline & (\%) & (\%) & (\%) \\
\hline Work on present job & 84 & 9 & 7 \\
\hline Pay & 47 & 20 & 34 \\
\hline Opportunities for promotion & 8 & 12 & 80 \\
\hline Supervision & 82 & 9 & 9 \\
\hline People on your present job & 80 & 7 & 13 \\
\hline JIG & 92 & 7 & 1 \\
\hline
\end{tabular}

Figure 4.3 illustrates the satisfaction level of the MOs, which follows the trends of the specialists. The majority of the MOs (78\%) were dissatisfied by opportunities for promotion in their jobs. The proportion of MOs in the neutral range was slightly higher than that of specialists. 
Figure 4.3: Satisfaction levels of MOs - all facets

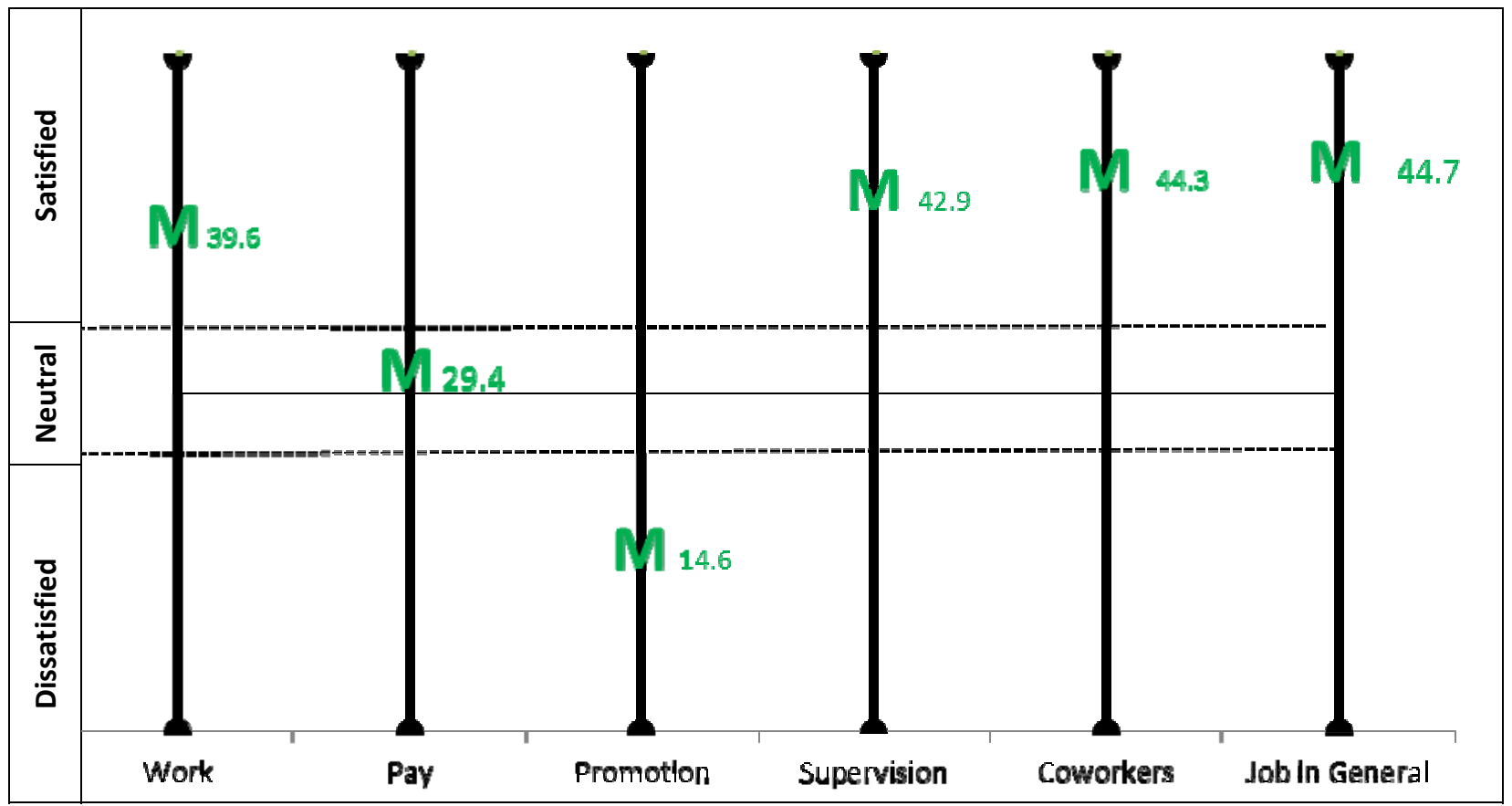

$M=$ Median

Table 4.2: Satisfaction levels of MOs - all facets

\begin{tabular}{|c|c|c|c|}
\hline \multirow{2}{*}{ Facet } & Satisfied & Neutral & Dissatisfied \\
\hline & $(\%)$ & (\%) & $(\%)$ \\
\hline Work on present job & 80 & 13 & 7 \\
\hline Pay & 47 & 20 & 33 \\
\hline Opportunities for promotion & 9 & 13 & 78 \\
\hline Supervision & 83 & 11 & 6 \\
\hline People on your present job & 83 & 9 & 8 \\
\hline JIG & 89 & 8 & 3 \\
\hline
\end{tabular}

Figures 4.4 and 4.5show the satisfaction level of LHVs/staff nurses and technicians. Both groups of healthcare providers were highly satisfied with work on their present jobs, supervision, co-workers, and Job in General (JIG). Three-fourths of the LHVs were dissatisfied by current opportunities for promotion. A high proportion (53\%) of the technicians are dissatisfied with their current pay. 
Figure 4.4: Satisfaction levels of LHVs/staff nurses - all facets

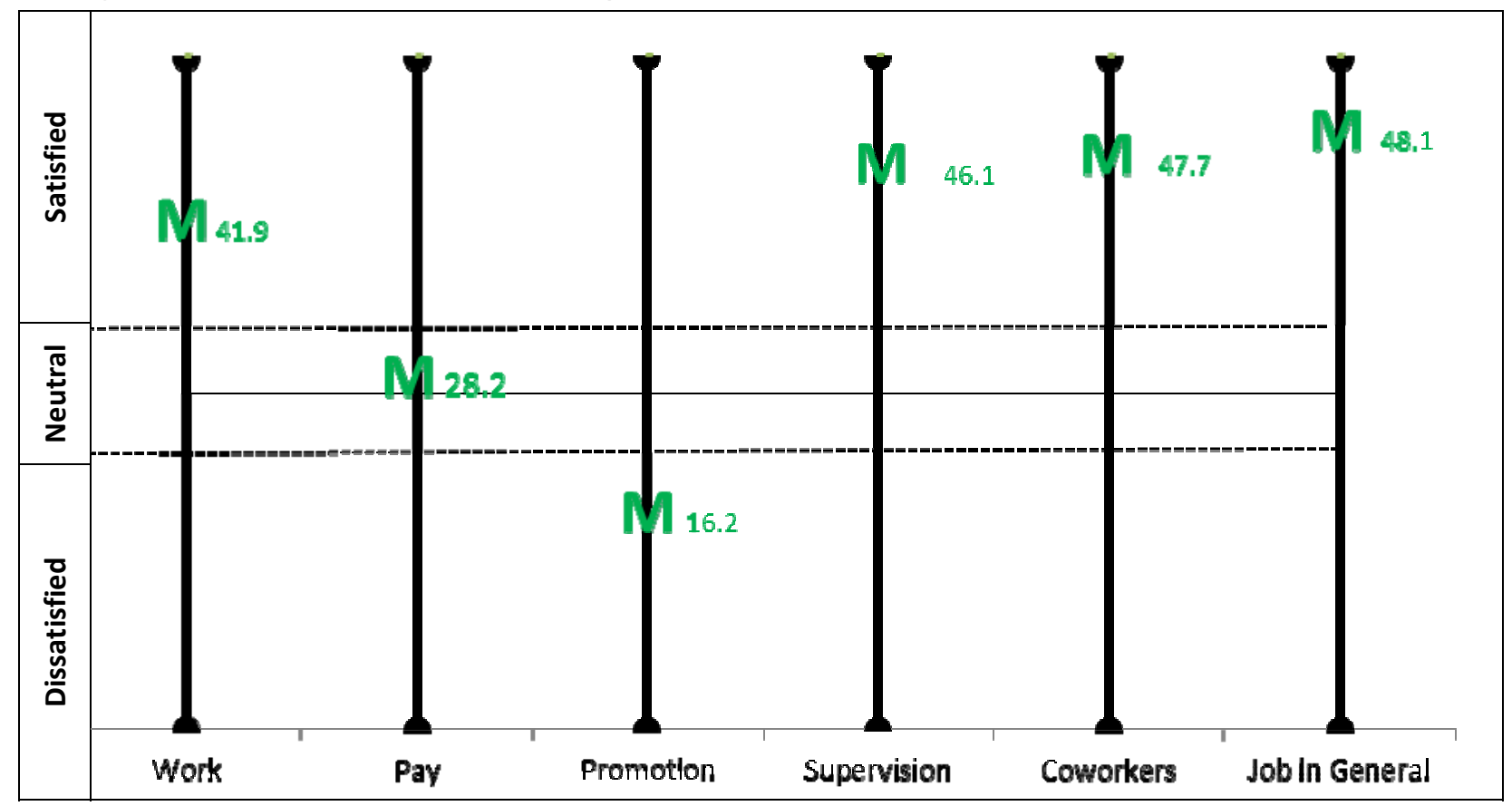

Figure 4.5: Satisfaction levels of technicians/dispensers - all facets

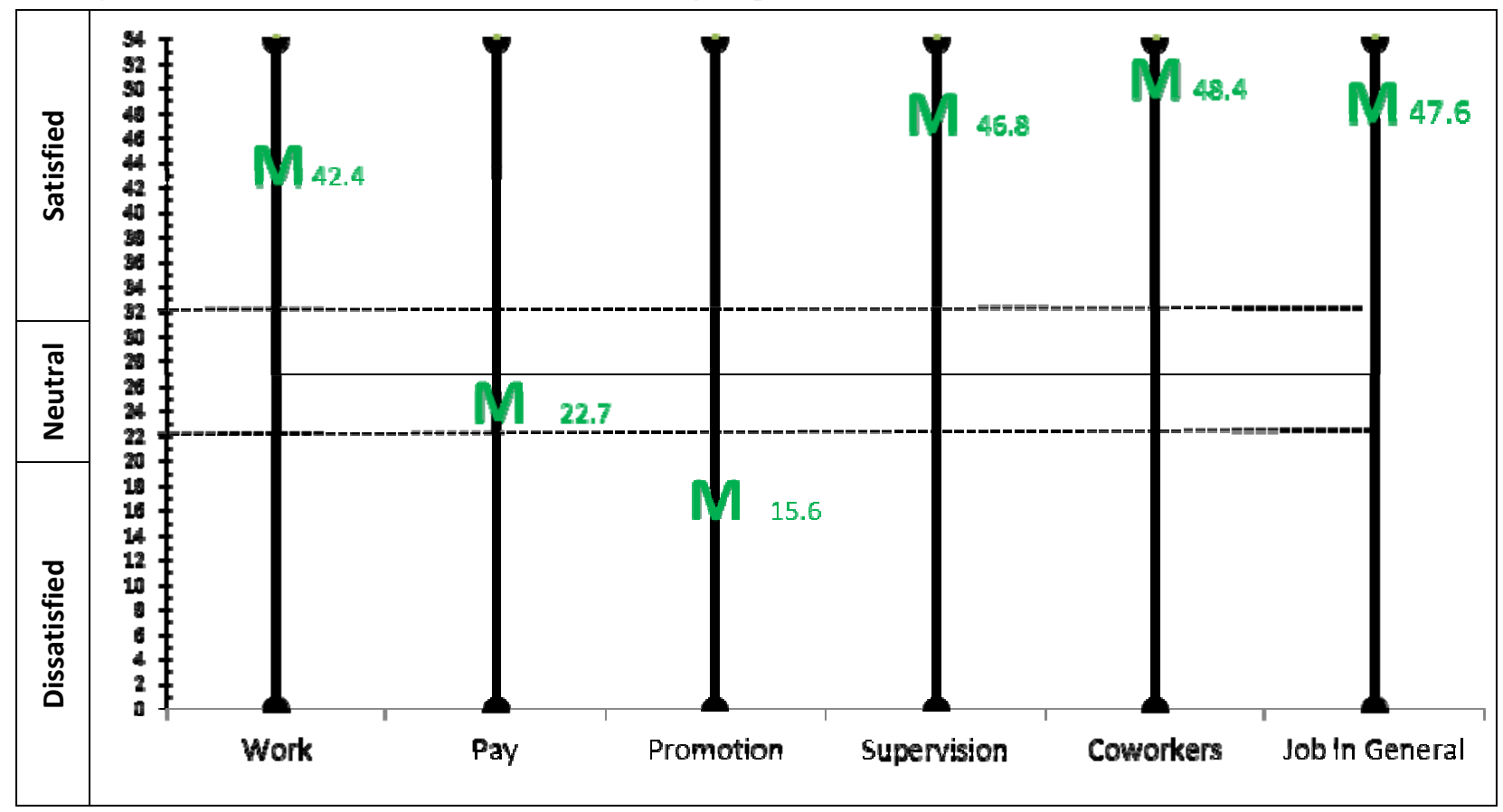

78 
Table 4.3: Satisfaction levels of LHVs/staff nurses - all facets $\quad n=498$

\begin{tabular}{|c|c|c|c|}
\hline & Satisfied & Neutral & Dissatisfied \\
\hline Facet & (\%) & (\%) & (\%) \\
\hline Work at present job & 91 & 7 & 2 \\
\hline Pay & 42 & 21 & 37 \\
\hline Opportunities for promotion & 11 & 15 & 74 \\
\hline Supervision & 92 & 5 & 3 \\
\hline People on your present job & 94 & 3 & 3 \\
\hline JIG & 98 & 2 & 0 \\
\hline
\end{tabular}

Table 4.4: Satisfaction levels of technicians/dispensers - all facets $\quad n=312$

\begin{tabular}{|c|c|c|c|}
\hline & Satisfied & Neutral & Dissatisfied \\
\hline Facet & (\%) & (\%) & (\%) \\
\hline Work on present job & 92 & 6 & 2 \\
\hline Pay & 25 & 22 & 53 \\
\hline Opportunities for promotion & 12 & 12 & 76 \\
\hline Supervision & 93 & 5 & 2 \\
\hline People on your present job & 94 & 4 & 2 \\
\hline JIG & 97 & 2 & 1 \\
\hline
\end{tabular}

JDI scores by cadre and gender

There was no significant difference in the mean scores of female specialists and male specialists on any of the facets. Within MOs and WMOs, the only significant difference is mean scores in the pay facet; WMOs scored significantly higher than MOs, indicating higher satisfaction with their pay.

JDI scores by age and gender

Age is also a factor that contributes to job satisfaction. Healthcare providers were divided into three age brackets: $\leq 30,31-44$ years, and $\geq 45$ years. Within specialists, younger providers scored higher on many aspects of job satisfaction. In the younger age group, both males and females showed high mean values for work at existing jobs, supervision, relationships with co-workers, and for jobs in general, as compared with older groups. However, the younger group scored lower on facets of pay and opportunities for promotion than the older groups did. Male providers in the $\leq 30$ years category scored much lower on opportunities for promotion than their female counterparts.

\section{Reasons for job satisfaction:}

In order to understand the high job satisfaction levels recorded by the respondents we revert to the qualitative research findings. From the in-depth interviews it is clearly borne out that healthcare providers in Pakistan are drawn to this profession with a desire to help people, especially the poor and suffering 
humanity. For them their reward was the inner satisfaction achieved from mitigating the plight of others, the gratitude and respect received from their patients and community. The following quotes provide insights into the reasons why providers are happy with the nature of their work despite facing many hardships.

"My motivation to work in the health sector is helping the poor people who come to the facility and taking care of them. They pray for you and they are happy when you treat them. Taking care of people makes me happy".Deputy Medical Superintendent, Benazirabad, Sindh

"Although initially I did not get paid a lot, there was a lot of respect from the people. There is also job security. I am in my own community and receive gratitude fromthe people". Women Medical Officer, FATA

"It makes me happy when I can help a patient, and this is what gives us encouragement and motivation. People give us respect which gives us joy".MO, Kalat, Balochistan

"I take care of patients, especially those who come from remote areas, and it gives me happiness that I can help them (they can benefit from my help) and I also get a salary. I am fulfilling my reason for becoming a doctor". MO, Kalat, Balochistan

"When we treat patients and make them feel well, they pray for us. Taking care of people is my foremost reason for doing this job, not for financial consideration. We are providing these services in return for their prayers and appreciation. For instance, we worked hard to help people during the floods in 2010-11". Medical Superintendent, Dadu, Sindh

Despite the high levels of satisfaction reported by the providers with their job in general, the low scores related to salary and promotion clearly identifies the two areas that will require the attention of policy makers to prevent attrition in the future.

\section{4:Salary Satisfaction}

Although salary dissatisfaction does not contribute directly to staff motivation, it can eventually lead workers to switch their jobs, especially if their basic needs are not being met (Franco et al 2002). We tried to see if providers were dissatisfied or not with the salary they were receiving. We compared respondents' perceptions regarding salary on the basis of gender, cadre, province or region, length of service, comparison between contractual and permanent employees, and comparison with the private sector.

Salary dissatisfaction by gender:Compared to female providers, male providers were reportedly more dissatisfied with their current salaries $(p<0.05)$ (Figure 4.6). 
Figure 4.6: Proportion of respondents reporting salary dissatisfaction by gender

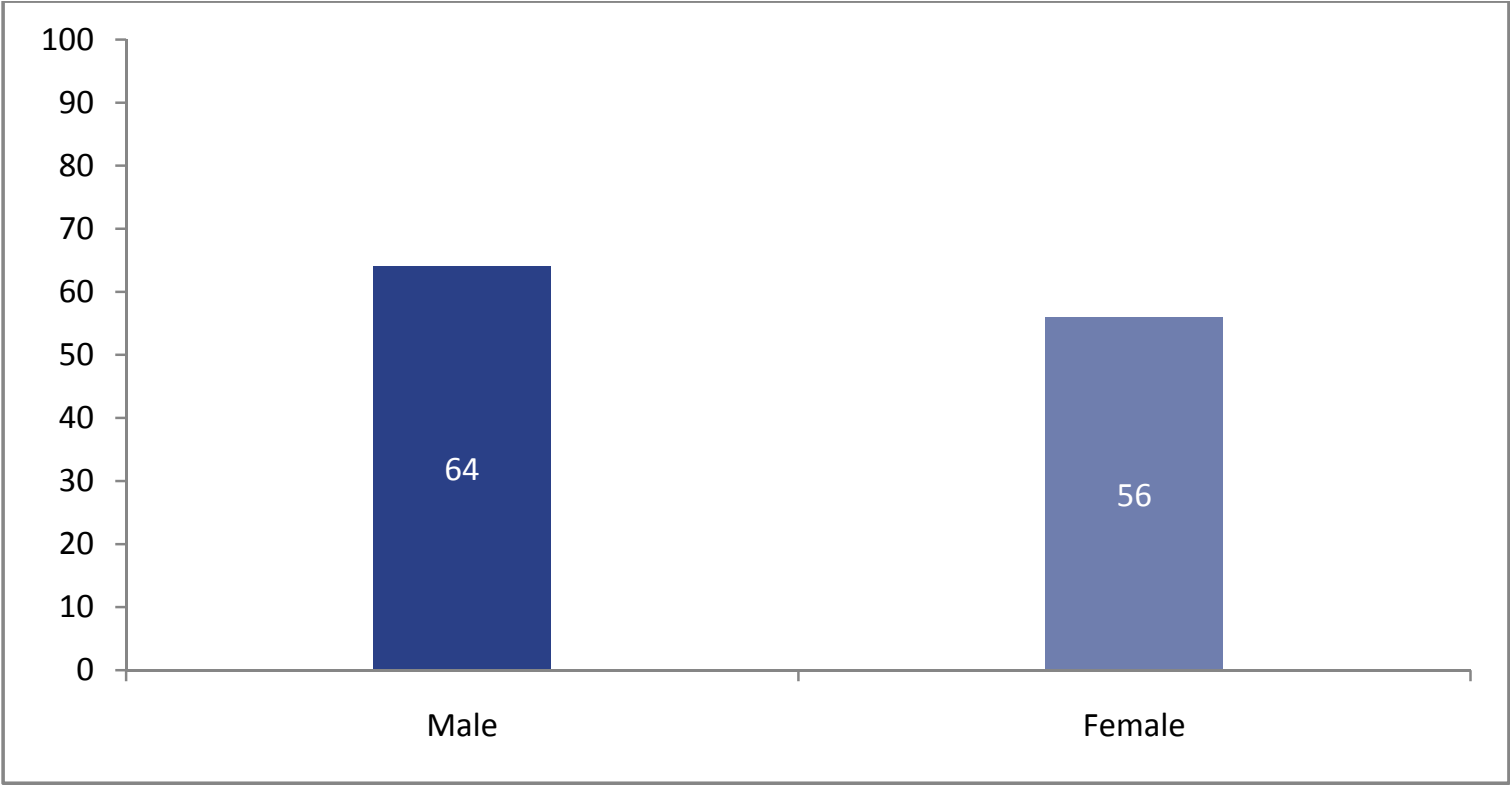

This gender differential was further explored on the basis of contribution made by males and females to the total household incomes. A higher proportion of male providers reported that their salary was the major or only source of income for their household. In comparison, a higher proportion of female providers reported making either no contribution or a partial contribution from their salary to the total household income $(p<0.01)$ (figure 4.7)

Figure 4.7: Proportion of providers reporting level of contribution of salary to overall household income by gender

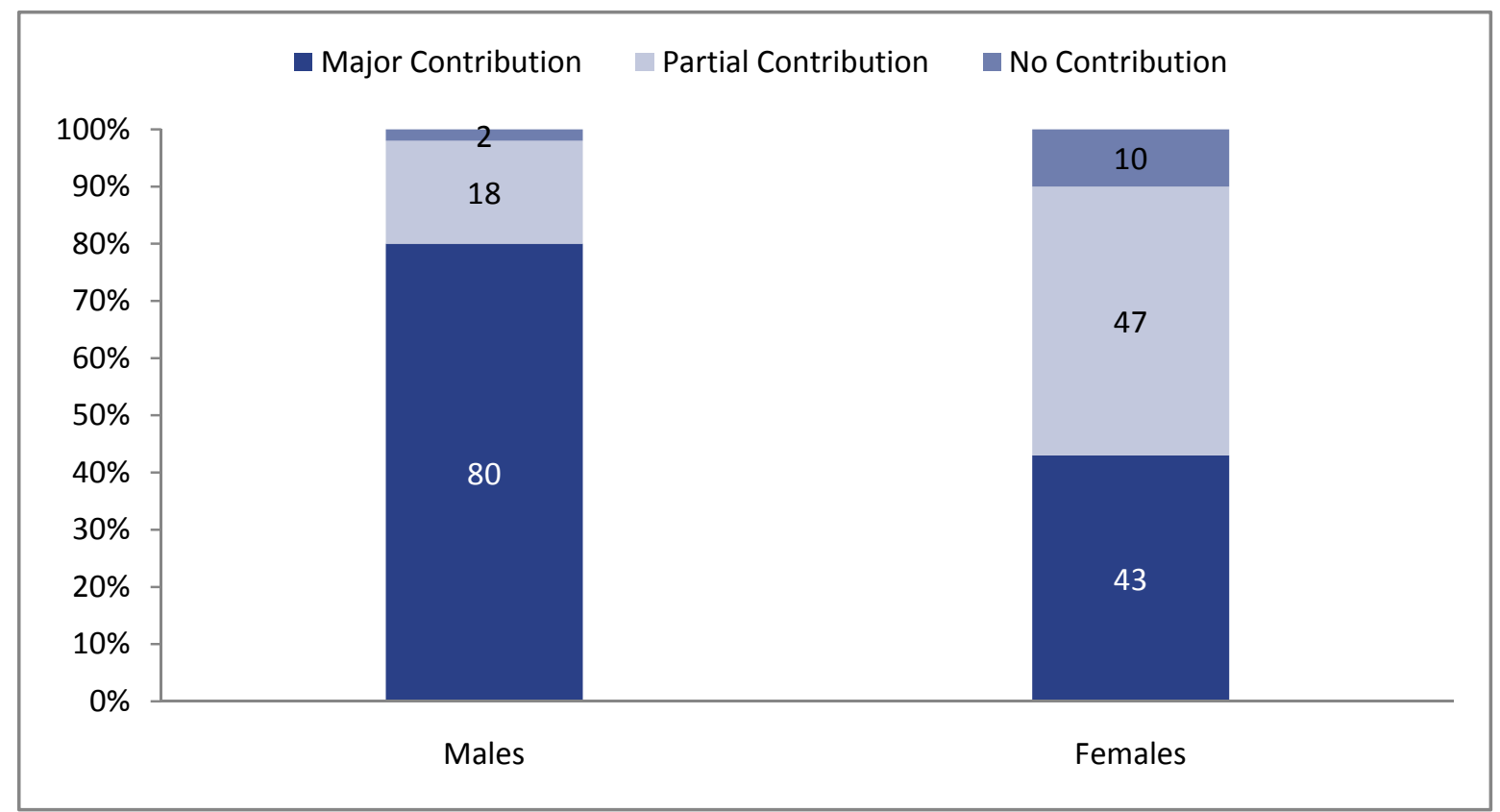


Salary dissatisfaction - regional differences:It was seen that salary dissatisfaction by region was highest in FATA. In other regions, nearly two-thirds of the respondents were dissatisfied with their salaries. Levels of dissatisfaction were the lowest in Sindh and GB where about half the providers reported being dissatisfied with the salary they were receiving (figure 4.8).

Figure 4.8: Proportion of respondents who reported dissatisfaction with current salary by region

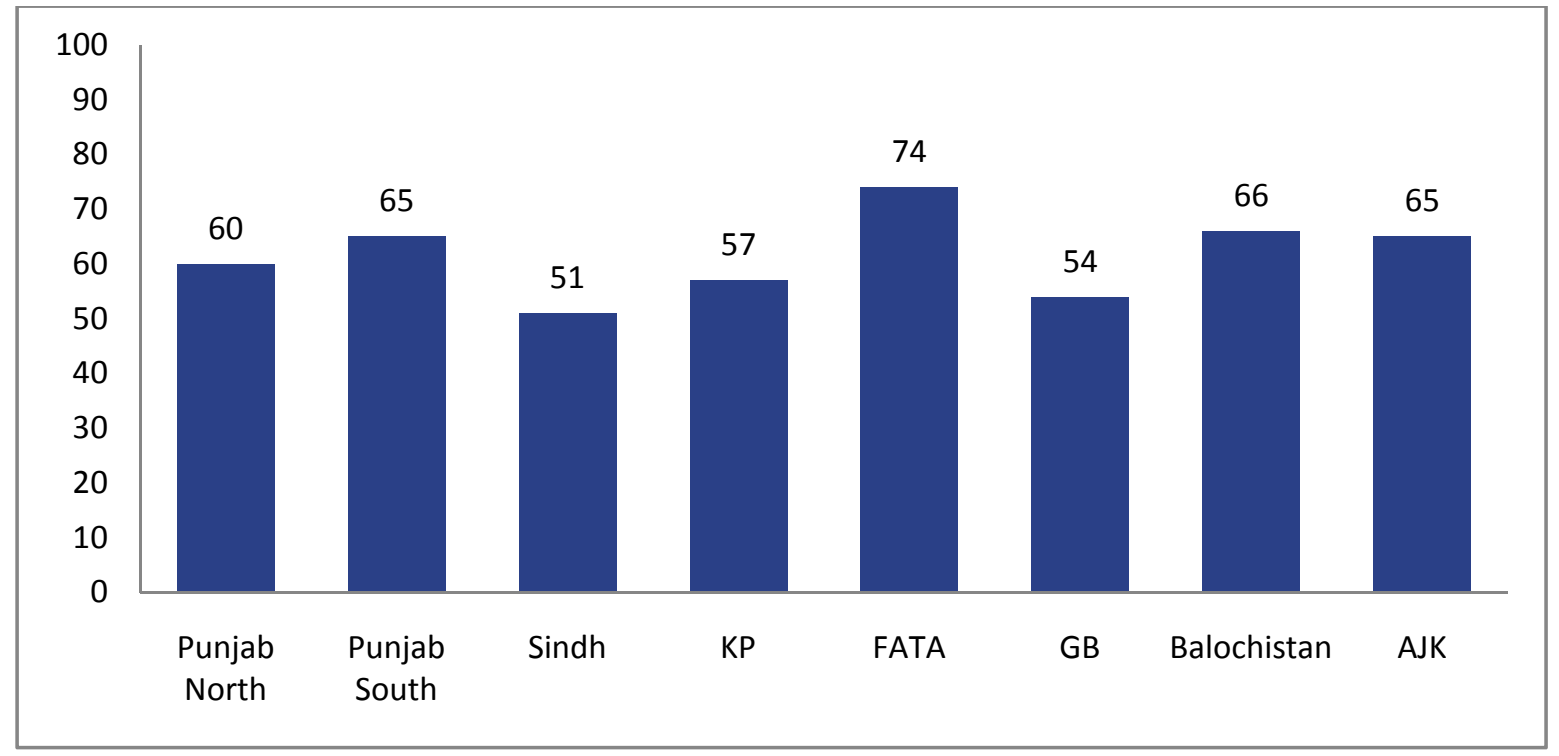

Salary dissatisfaction by cadre:Two third of technicians, dispensers, and 60 percent LHVs reported dissatisfaction with salary; this was followed by MOs and Specialists. About half of the WMOs (48\%) reported dissatisfaction (figure 4.9). 9 out of the 22 medical superintendents also reported dissatisfaction with their current level of salary.

Figure 4.9: Proportion of respondents that reported dissatisfaction with current salary by cadre

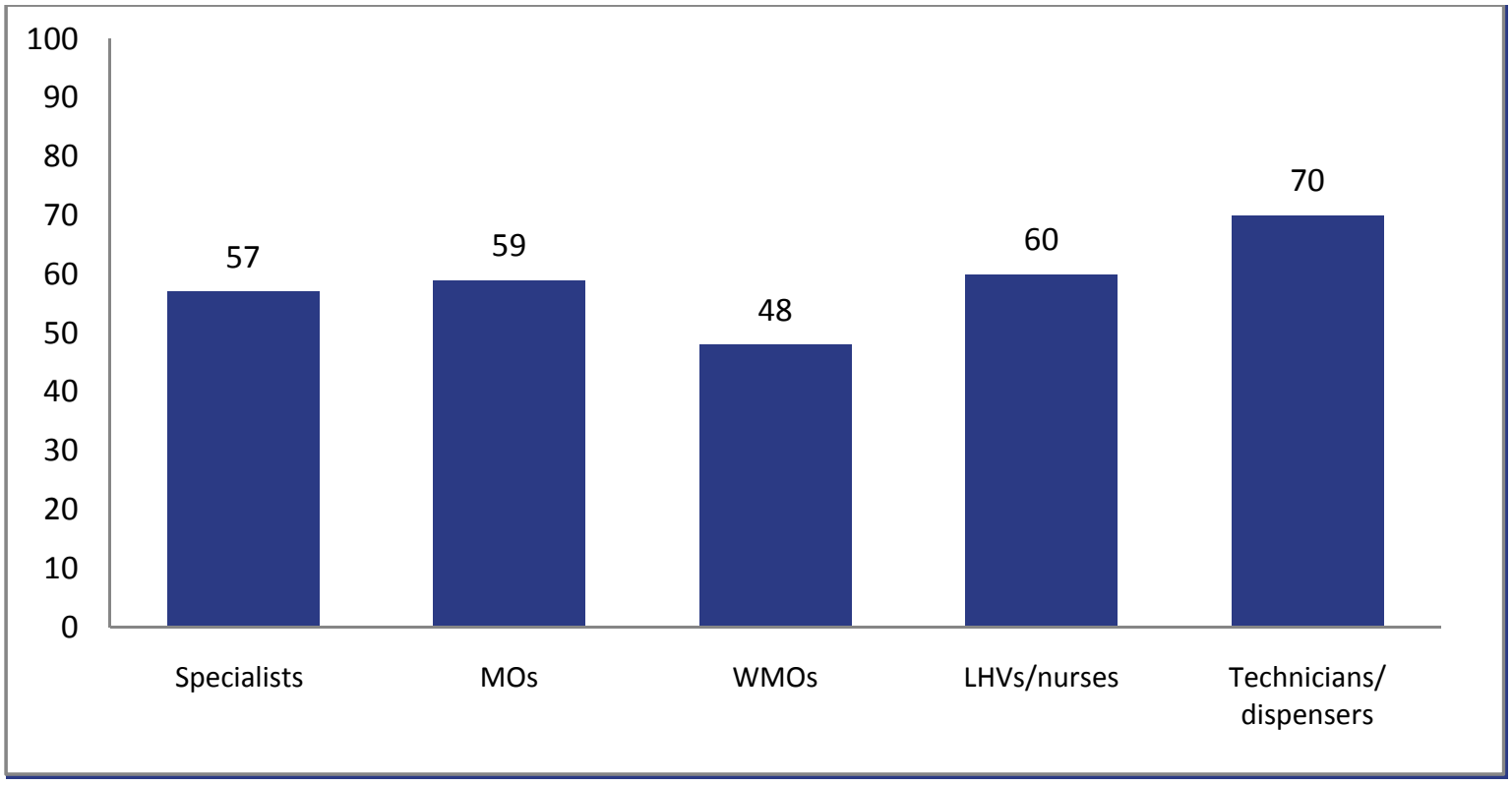


The responses from the FGD's clearly point to the plight of lower-cadre providers who are not receiving adequate salaries and as a result face various hardships.

"If I talk about doctors, the allowances available to them are sufficient. But lower staff employees do not get enough incentives. They do not get transport allowances. The cold area allowance is also not enough. They do not get residence allowanceseither, which is why they face so many challenges." Obstetrician, Skardu

"In this time of inflation, this pay does not cover our food and expenses. I cannot cover transport or school fees." LHV, Multan

Salary dissatisfaction relative to years of experience:In figure 4.10, we illustrate the relationship between levels of dissatisfaction with current salary and years of experience. Salary dissatisfaction was lower among those providers who have recently joined the service. It then consistently rose, reaching a plateau among respondents with work experience of 11 years and above. It stands to reason that personal needs, requirements, and obligations are fewer at the beginning of the career and therefore, salary is not considered that important.

\section{Figure 4.10: Salary dissatisfaction relation to years of experience}

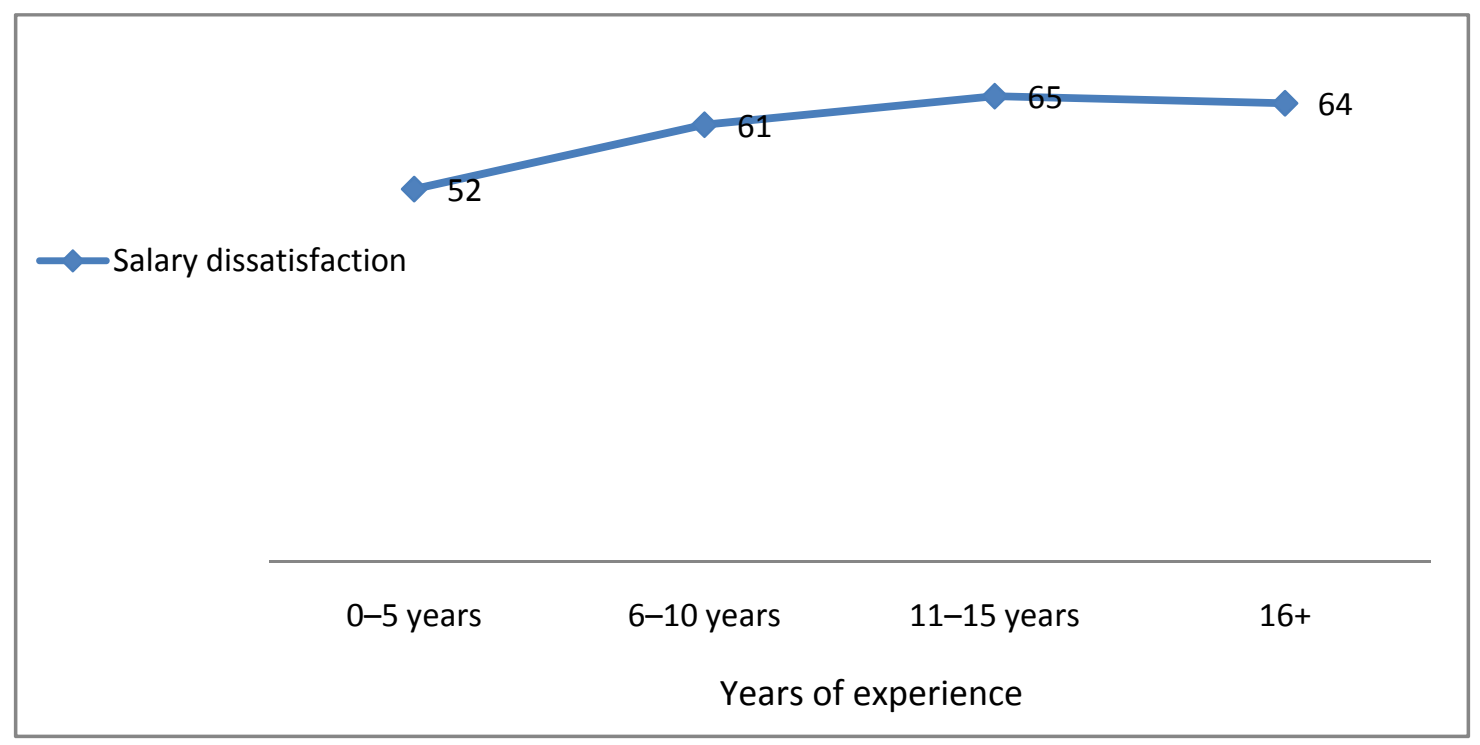

Perception of providers comparing their salary to that offered by the private sector:Providers were asked to compare their current salary to what they would expect to receive if they worked in the private sector (figure 4.11). The majority of all providers perceived their current salary to be lower than that of the private sector. Nearly two-thirds of specialists, MOs, and dispensers/technicians and half of WMOs and LHVs were of this opinion. A third of the WMOs perceived their salary to be higher than that of the private sector. Less than $16 \%$ of all cadres across the board thought that private sector salaries were the same as their own. The market for specialists in the private sector is more lucrative and absorptive, contributing to the favourable perception of the specialists regarding private sector salaries. 
Figure 4.11: Perception of respondents regarding the salary they are currently receivingvis-àvis that offered in the private sector

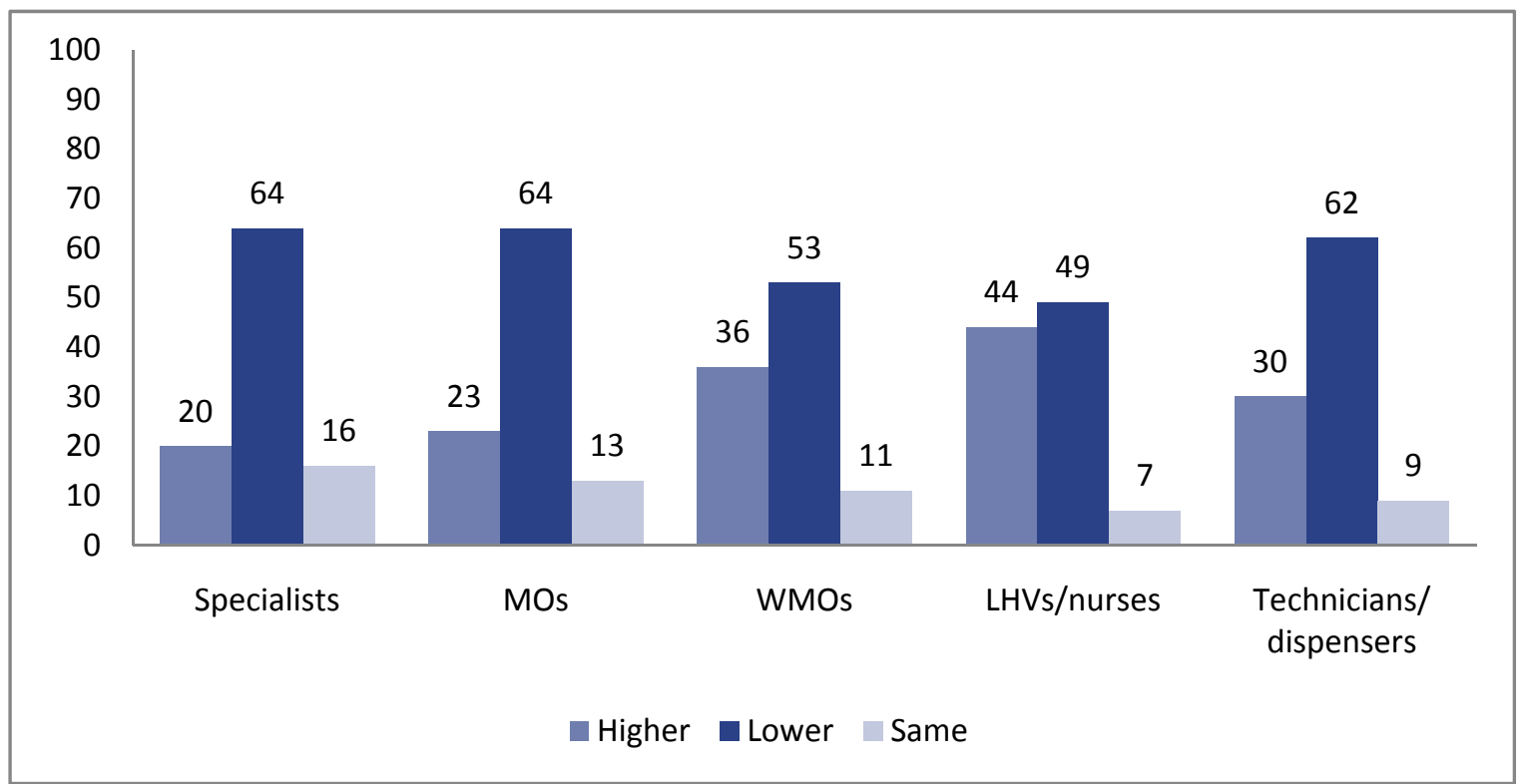

When comparing contractual and permanent providers, we found that $52 \%$ of contractual employees compared to $58 \%$ of permanent employees believe that their salaries were lower than the private sector. On the other hand, $16 \%$ of contractual employees compared to $8 \%$ of permanent providers believed that their salary was the same as that offered in the private sector (figure 4.12).

Figure 4.12: Perception of own salary relative to private sector, differentiated by permanent vs. contractual employees

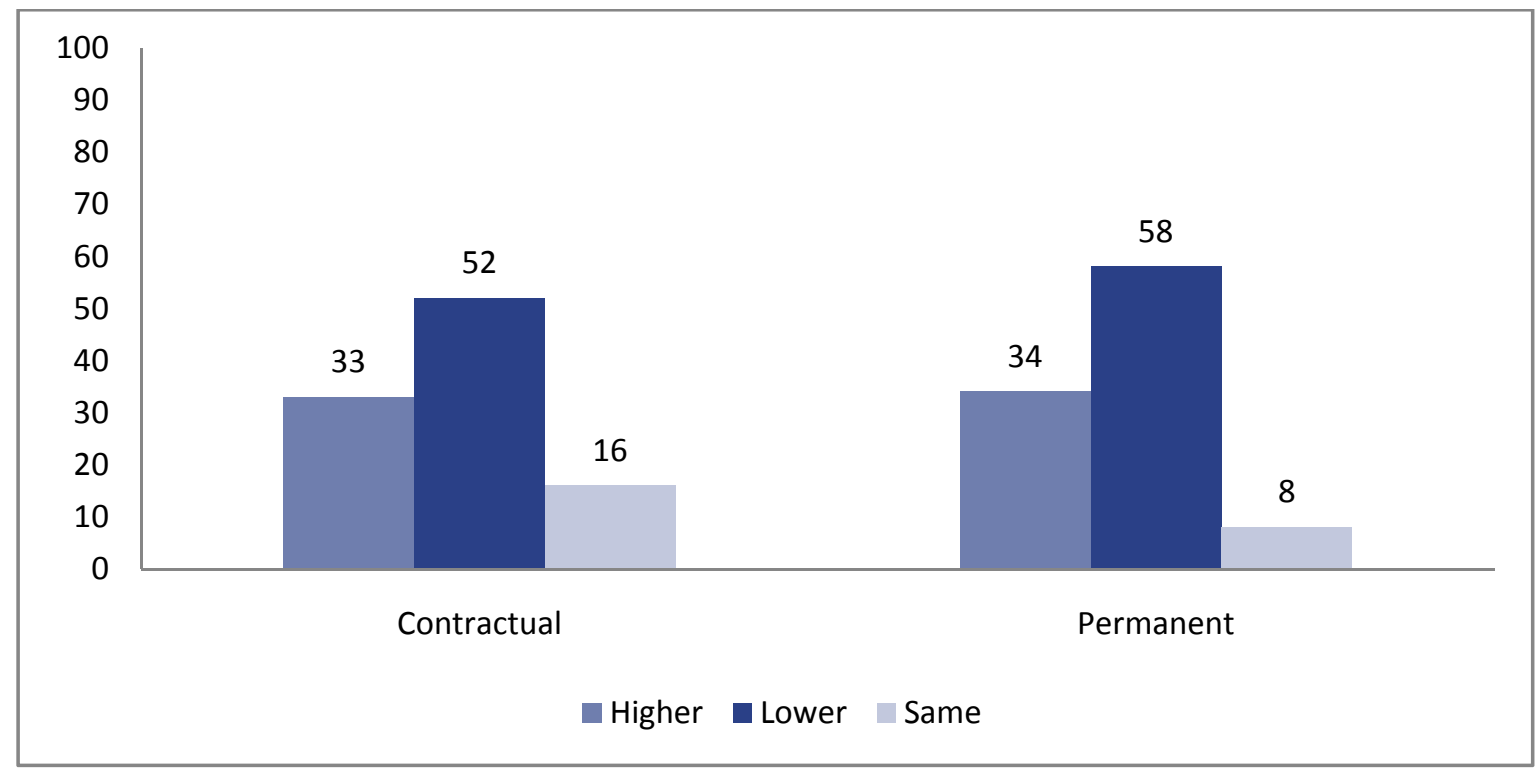

Factors associated with salary dissatisfaction:Logistic regression analysis was used to explore the relationship between salary dissatisfaction and certain demographic characteristics. The results shows that compared to the reference group of LHVs/nurses, WMOs were 1.5 times more likely to be dissatisfied with 
their salary $(p<0.05)$. Relative to the providers who perceived their salary to be lower than the private sector (reference group), providers who perceived it to be about the same, or higher than the private sector providers, had significantly higher odds of not being dissatisfied with their salary $(p<0.01)$.

Providers with less than five years of experience (reference group) had higher odds of being not dissatisfied with their salary than those providers who had worked for more than ten years $(p<0.01)$. There was no significant difference between salary satisfaction of male and female providers.

Table 4.5: Factors associated with salary dissatisfaction

\begin{tabular}{|c|c|}
\hline Variable & Adjusted Odds Ratio (95\% Cl) \\
\hline \multicolumn{2}{|l|}{ Gender } \\
\hline Female & (Ref) 1.0 \\
\hline Male & $.91(.46-1.8)$ \\
\hline \multicolumn{2}{|l|}{ Cadre } \\
\hline LHVs/nurses & (Ref) 1.0 \\
\hline Specialists & $1.2(.66-2.3)$ \\
\hline MOs & $1.0(.51-2.2)$ \\
\hline WMOs & $1.5(1.0-2.3)^{*}$ \\
\hline Technicians & $.64(.31-1.3)$ \\
\hline MS & $1.0(.27-3.2)$ \\
\hline \multicolumn{2}{|l|}{ Comparison with private sector salary } \\
\hline Perception about lower than private & (Ref)1.0 \\
\hline About the same & $3.2(2.1-4.8)^{* *}$ \\
\hline Perception about higher than private & $2.7(2.1-3.5)^{* *}$ \\
\hline \multicolumn{2}{|l|}{ Years of experience } \\
\hline$<5$ years & (Ref)1.0 \\
\hline $6-10$ years & $.73(.50-1.0)$ \\
\hline $11-15$ years & $.60(.40-.88)^{*}$ \\
\hline$\geq 15$ years & $.72(.52-.98)^{*}$ \\
\hline \multicolumn{2}{|l|}{ Contribution to household income } \\
\hline No contribution & (Ref) 1.0 \\
\hline Large & $.94(.58-1.5)$ \\
\hline Substantial & $.91(.55-1.5)$ \\
\hline
\end{tabular}

*Significant at $p<0.05, * *$ Significant at $p<0.01$

Managers' views on providers' salary:During the managers' interviews we tried to ascertain if the views of the managers and providers regarding the perception of salary offered in the public and private sector matched or not. Half of the managers felt that both gazetted (grade 17 and above) and non-gazetted (grade 1-16) staff was receiving salary that was lower than the private sector. 


\section{Summary of Key Findings}

- Salary dissatisfaction is high among all providers, especially dispensers/technicians and LHVs;

- $\quad$ Salary dissatisfaction is the highest among providers in FATA, followed by Balochistan;

- Salary dissatisfaction increases with duration of service

- Majority of the providers feel proud working for their facility/hospital

- Opportunity to serve the community, opportunities for growth, and respect were the top three motivating factors identified by providers

- Results from the JDI show that overall reported job satisfaction is high

\section{5:Organizational commitment and willingness to consider leaving government service based on dissatisfaction}

According to Herzberg, as quoted by Franco et al (2002), if staff felt that their basic needs were not being met, such as the inadequacy of the salary they were receiving or if they felt that the work conditions were not safe or organizational policies were not being properly followed, they would consider moving and leaving their present job. To gauge dissatisfaction levels with their current job, respondents were asked if they would consider moving and seeking alternative options, given the opportunity.

The willingnessto leave was assessed with relation to region, gender, cadre and salary. Nearly a third of all providers $(n=425)$ reported that they would consider leaving government service. The reasons or compulsions that would lead staff to seek alternate sources of employment are depicted in Figure 4.13. The most cited reason was better salary prospects available in the private sector followed by easier commutation from home to office and better work environment in the private sector.

Figure 4.13: Reasons given by providers considering the shift to the private sector

Better salary (87\%)*

Easier commute (30\%)*

Conducive work environment (27\%)*

Increased medical and other benefits (27\%)*

Better prospects for promotion (24\%)*

Lack of political interference $(21 \%)^{*}$

*Multiple Responses 
Figure 4.14 shows the breakdown by gender of the providers who would consider leaving. The proportion of male providers who would leave is significantly greater than female providers $(p<0.01)$.

Figure 4.14: Providers who would consider shifting, breakdown by gender $(n=425)$

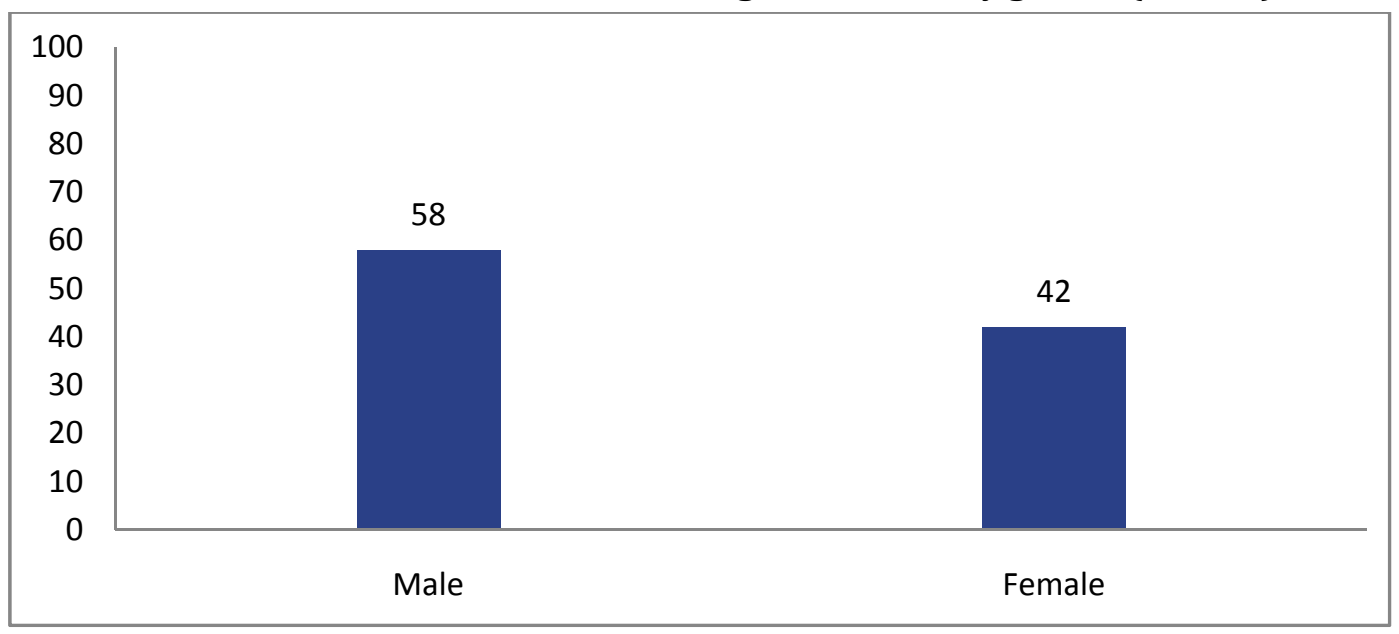

As seen in Figure 4.15 the highest proportion of staff whoreported that they would consider moving to the private sector were MOs (44\%), followed by specialists, WMOs, and dispensers.

MOs were more inclined to move while the LHWs were less so. Male providers are the major contributors to a household's total income and so for themsalary is an important deciding factor. On the other hand, since opportunities for lower cadres are limited in the private sector, and salaries are perceived to be lower as well, a smaller proportion of LHVs would consider shifting. Amongst the medical superintendents, 8 out of 22 providers would consider leaving their public sector jobs for the private sector.

Figure 4.15: Providers who would consider shifting to the private sector, by cadre $(n=425)$

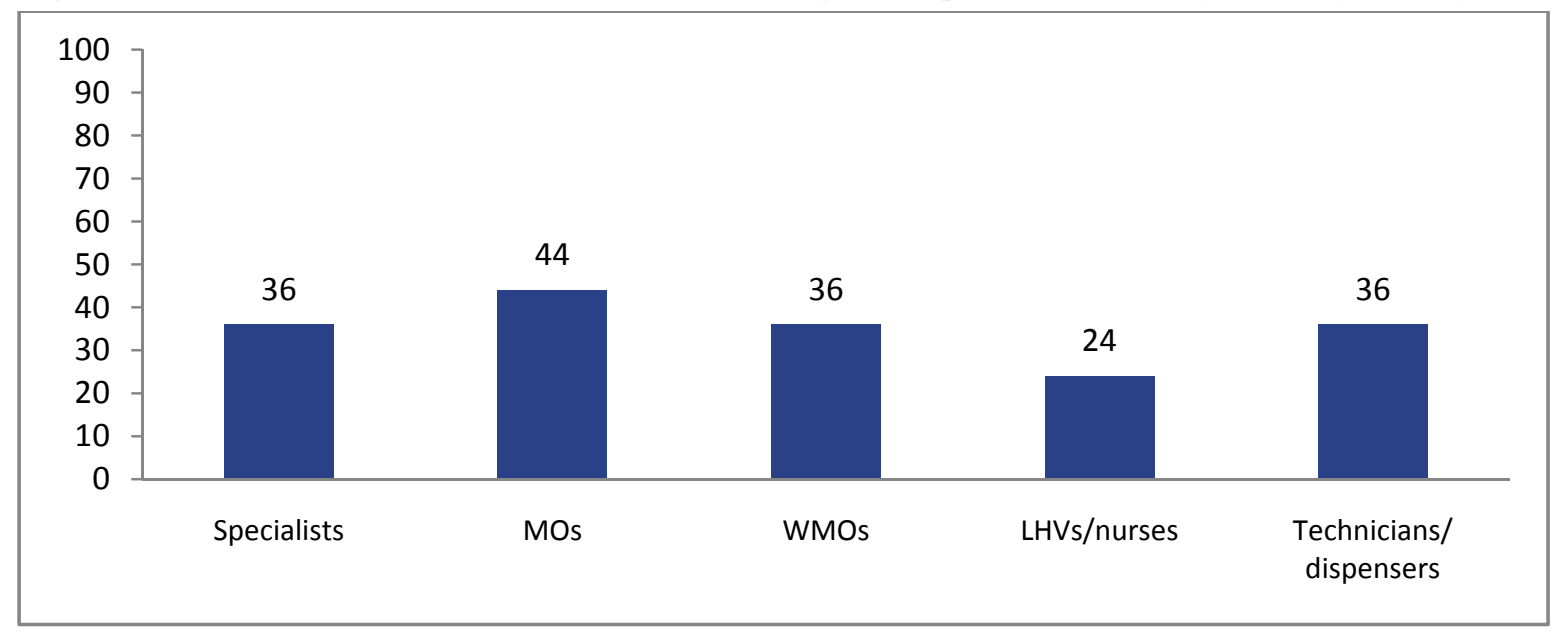

Importance of salary in retaining providers: Among the respondents who reported that they would leave their present job if an opportunity was available, the highest proportion was the group of workers who were dissatisfied with their salary. 
Figure 4.16: Proportion of providers who would consider leaving by level of salary satisfaction

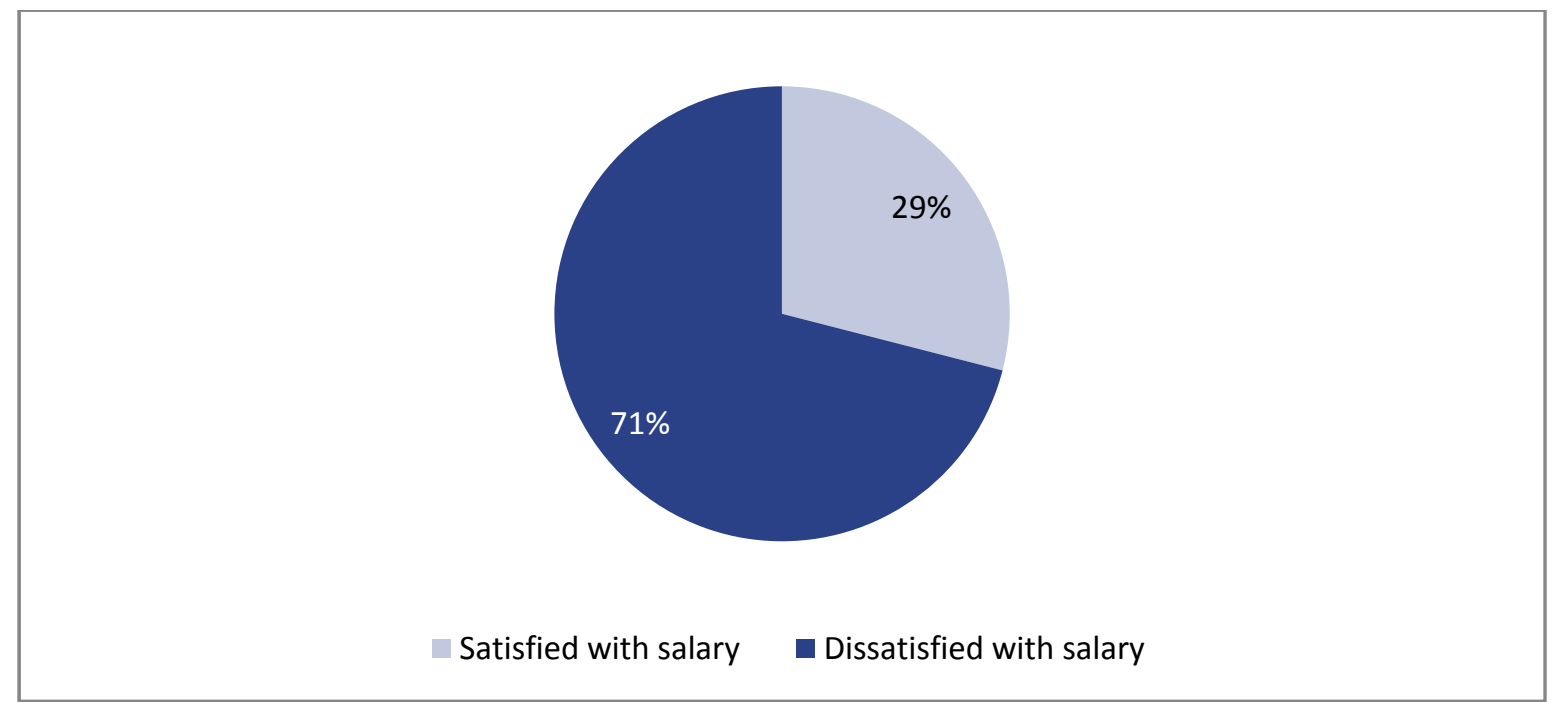

A breakdown of the providers who would consider shifting by region shows that the highest proportion of providers was from AJK followed by Sindh. The lowest proportions were from GB and Balochistan.

Figure 4.17: Proportion of providers who would consider leaving government service breakdown by region

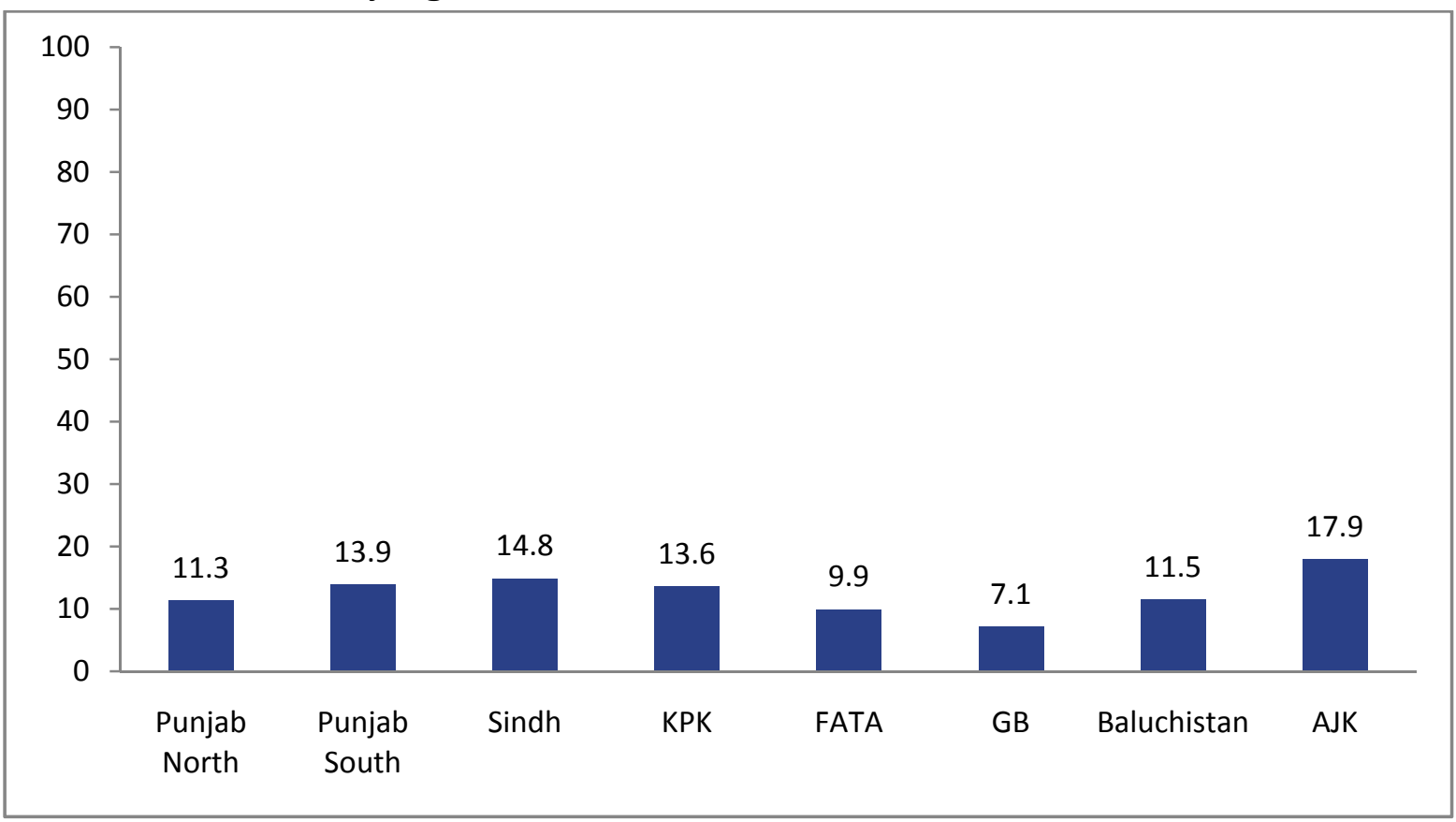

An analysis of providers who would leave based on district rankings (figure 4.18) shows that a slightly higher proportion of providers would leave servicewho belonged to the lower and medium ranked category of districts than from the higher ranked category. (For district ranking please see Annex 1-b) 
Figure 4.18: Proportion of providers who would consider leaving government service by district ranking

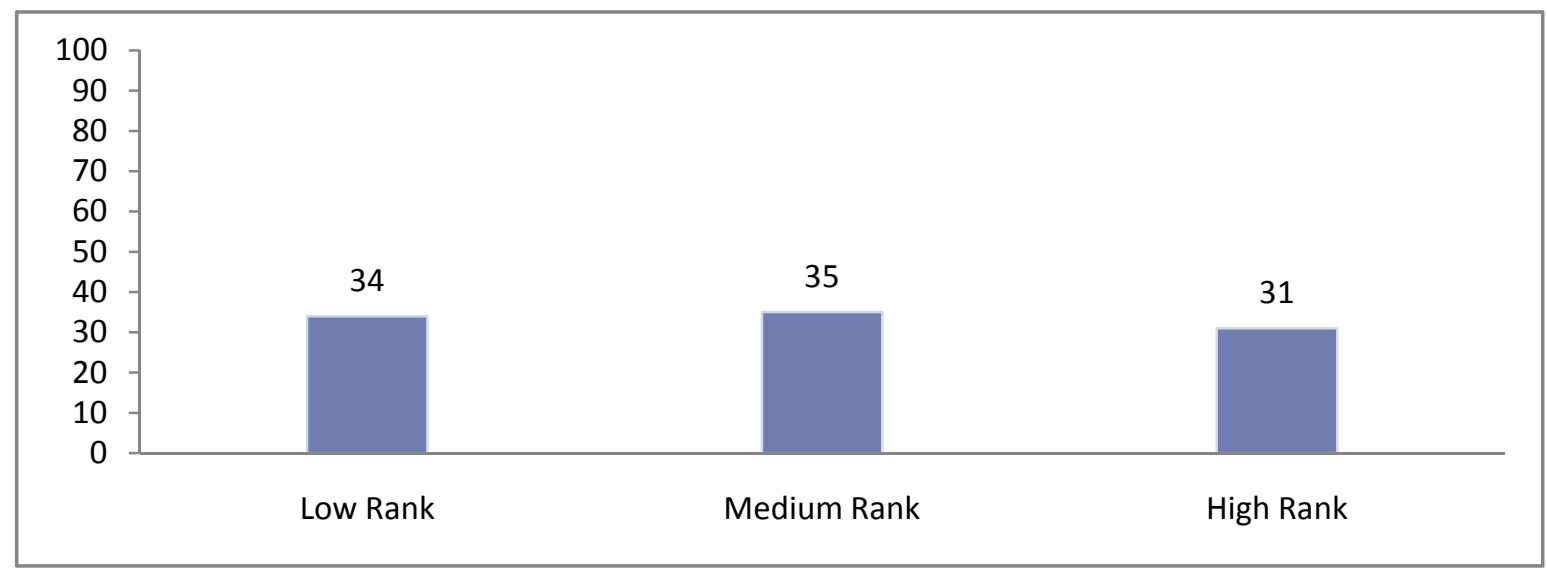

Of those providers who would leave, two-thirds had never received a promotion, and only $5 \%$ had received two promotions while only $1 \%$ had received three promotions.

This clearly shows the relationship between opportunities for growth and organizational commitment. The association between promotion status and consideration to leave for the private sector was statistically significant $(p<0.01)$.

Figure 4.19: Proportion of providers who would consider leaving government service by promotion status

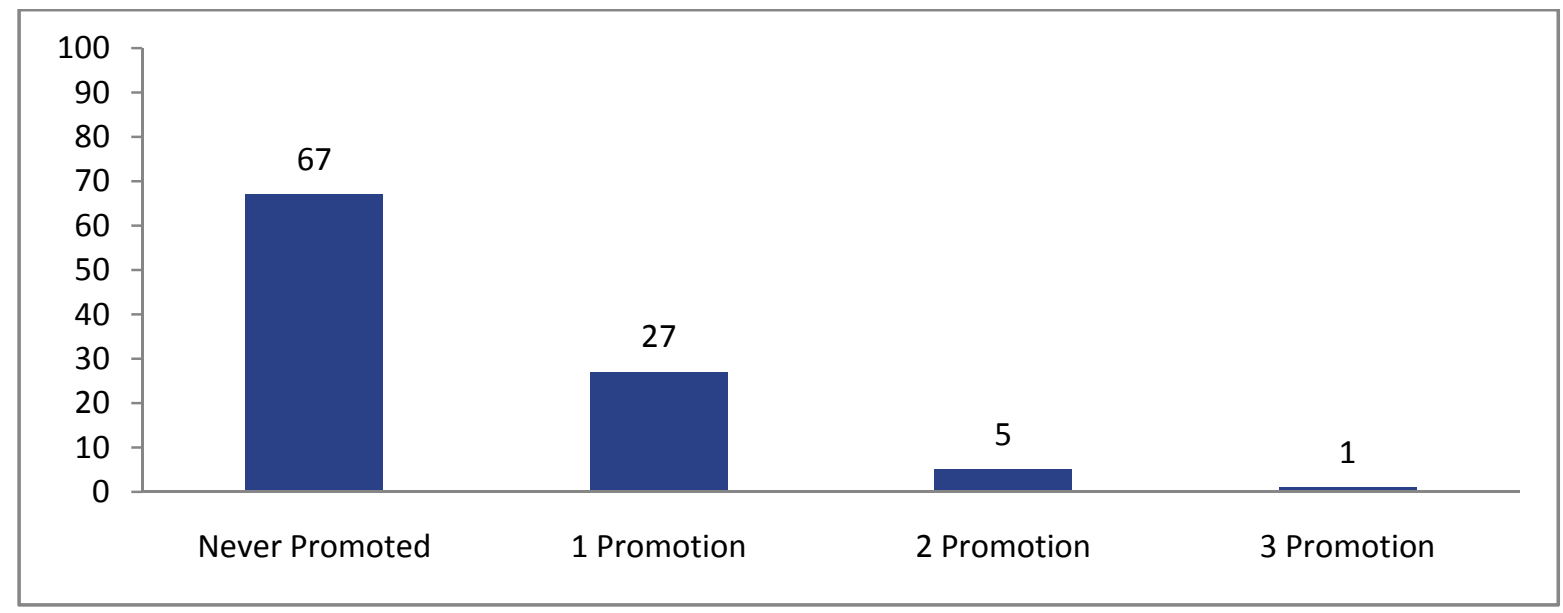

The effect of medicine, equipment, and infrastructure availability on job commitment

Figure 4.20 illustrates the relationship between availability of essential infrastructure ${ }^{2}$ required for provision of services especially those related to $\mathrm{MNCH}$ and job commitment. It can be seen that as the availability of essential infrastructure increases at the facility, the proportion of providers who would consider leaving shows a gradual decline. 
Figure 4.20: Infrastructure' ${ }^{3}$ : Proportion of providers that would leave due to poor infrastructure

\begin{tabular}{|c|c|c|c|}
\hline \multirow{2}{*}{$\begin{array}{l}\text { Proportion of } \\
\text { providers that } \\
\text { would leave due... }\end{array}$} & 36 & 33 & 31 \\
\hline & $0-3$ items & $\begin{array}{l}\text { 4-7 items } \\
\text { Infrastructure }\end{array}$ & $>7$ items \\
\hline
\end{tabular}

Figure 4.21 looks at the effect of availability of medicine on the same outcome. A number of key medicines required for provision of $\mathrm{MNCH}$ services were assessed. It was found that as is the case with infrastructure, as the availability of medicines increases, the proportion of providers who would consider moving to the private sector decreases. This reiterates the point that providers are more motivated to work in areas where medicine and infrastructure are available and their capacity to work is not hindered.

Figure 4.21: Medicines ${ }^{4}$ : Proportion of providers that would consider leaving due to availability of medicines

\begin{tabular}{|c|c|c|c|}
\hline \multirow{2}{*}{$\begin{array}{l}\text { Proportion of } \\
\text { providers that would } \\
\text { leave due to lack of... }\end{array}$} & 40 & 34 & 31 \\
\hline & 0-3 medicines & $\begin{array}{l}\text { 4-7 medicines } \\
\text { bility of Medici }\end{array}$ & $>7$ medicines \\
\hline
\end{tabular}

Multivariable analysis to assess factors Associated with Decision to Leave Government Service:

Logistic regression analysis was carried out to determine the association between the dependent variable i.e. considering leaving government service and moving to the private sector and various individual level factors.

Compared to the reference group of LHVs, the WMOs, MOs andtechnicians have significantly higher odds of considering shifting to the private sector ( $p<0.05$ for WMOs, $p<0.01$ for MOs and technicians). Those providers who had received one promotion were less likely to consider shifting than those who had received none $(p<0.05)$. Salary satisfaction also contributes to willingness to leave; those providers who

\footnotetext{
${ }^{3} 10$ essential elements of infrastructure: Electric supply, safe disposal mechanisms, boundary walls, water, blood transfusion facilities, operation theatres, laboratories, sterilizers, ambulances, and examination tables.

${ }^{4} 10$ essential medicines: Injectable antibiotics, Folic acid, Ferrous Sulphate, Syntocinon, Methergine, TT, Magnesium Sulphate, anticonvulsants, anti-hypertensive, IV fluids
} 
were satisfied with their salary were less likely to leave $(p<0.01)$ and those who perceived the private sector salary to be higher were more likely to consider leaving $(p<0.05)$.

Providers who had six to ten years of experience had higher odds of leaving than those who had worked for more than ten years $(p<0.05)$. This may be related to organizational loyalty and greater organizational commitment. Dissatisfaction with the ACR process also contributed to willingness to leave; with providers who were satisfied with the process significantly less likely to leave $(p<0.01)$. Providers who reported experiencing political interference had higher odds of leaving than those who did not $(p<0.05)$.

Table 4.6:Logistic regression showing association between providers' willingness to consider shifting and various individual-level factors

\begin{tabular}{|c|c|}
\hline Variable & Odds Ratio (95\% Cl) \\
\hline \multicolumn{2}{|l|}{ Cadre } \\
\hline LHVs & (Ref) 1.00 \\
\hline Specialists & $1.186(0.663-2.124)$ \\
\hline MOs & $1.059(1.396-3.038)^{* *}$ \\
\hline WMO s & $1.996(1.16-3.434)^{*}$ \\
\hline Technician/dispensers & $1.886(1.31-2.714)^{* *}$ \\
\hline \multicolumn{2}{|l|}{ No. of promotions } \\
\hline 0 & (Ref) 1.00 \\
\hline 1 & $0.701(0.51-0.965)^{*}$ \\
\hline 2 & $0.789(0.43-1.45)$ \\
\hline 3 & $0.423(0.131-1.361)$ \\
\hline \multicolumn{2}{|l|}{ Salary satisfaction } \\
\hline Dissatisfied & (Ref) 1.00 \\
\hline Satisfied & $0.558(0.410-0.759)^{* *}$ \\
\hline \multicolumn{2}{|c|}{ Salary comparison with private sector } \\
\hline Lower & (Ref) 1.00 \\
\hline Higher & $0.652(0.469-0.906)^{*}$ \\
\hline Same & $0.749(0.443-1.269)$ \\
\hline \multicolumn{2}{|c|}{ Work according to skills and qualifications } \\
\hline No & (Ref) 1.00 \\
\hline Yes & $0.821(0.567-1.189)$ \\
\hline \multicolumn{2}{|l|}{ Years of experience } \\
\hline$>10$ years & (Ref) 1.00 \\
\hline $0-5$ years & $1.402(0.961-2.046)$ \\
\hline $6-10$ years & $1.749(1.118-2.735)^{*}$ \\
\hline \multicolumn{2}{|l|}{ Satisfaction with ACR } \\
\hline No (Ref) & 1.00 \\
\hline Yes & $0.546(0.399-0.748)^{* *}$ \\
\hline \multicolumn{2}{|c|}{ Experience political interference } \\
\hline No & (Ref) 1.00 \\
\hline Yes & $1.358(1.012-1.824)^{*}$ \\
\hline
\end{tabular}




\section{Managers' views on staff turnover and vacant positions}

Managers were asked if they thought staff turnover was one of the major problems faced by the department. $38 \%$ of the respondents agreed that it is, while the rest did not. $65 \%$ of the managers reported that turnover is seen more commonly among female providers than male. According to the respondents, the main reasons for male providers leaving government service are inadequate salary and children's education; for female providers it is those reasons as well as poor housing facilities and transportation problems. However, none of the supervisors could provide accurate data on the number of staff who have left service in the past year. We also found through manager interviews that the main reasons for vacant positions are lack of funds for recruitment, coupled with a dearth of providers wanting to work in rural areas.

\section{Provider Perceptions on Efforts by the Government to Retain Staff}

As mentioned earlier in the literature review, in order to prevent attrition of staff, the government has introduced a number of changes in recent years to retain them at the workplace. These include incentives such as revision of salaries and granting rural and/or cold area allowances. It was also seen that contractual staff employed by PPHI receive high financial incentives as well as a hard area allowance.

Figure 4.22 below shows the proportion of providers who reported that the government was making efforts to retain qualified employees. Some efforts cited include competitive pay, regular praise and appreciation, retirement benefits, job security, and improvements in work environment. Less than a third of the providers from all cadres reported that significant efforts were being made by the government to retain staff. Only $16 \%$ of the specialists reported that the government was taking steps to retain staff. We can infer that perhaps specialists require more lucrative incentives to be convinced to stay in service.

Figure 4.22: Proportion of providers reporting retention efforts by the department

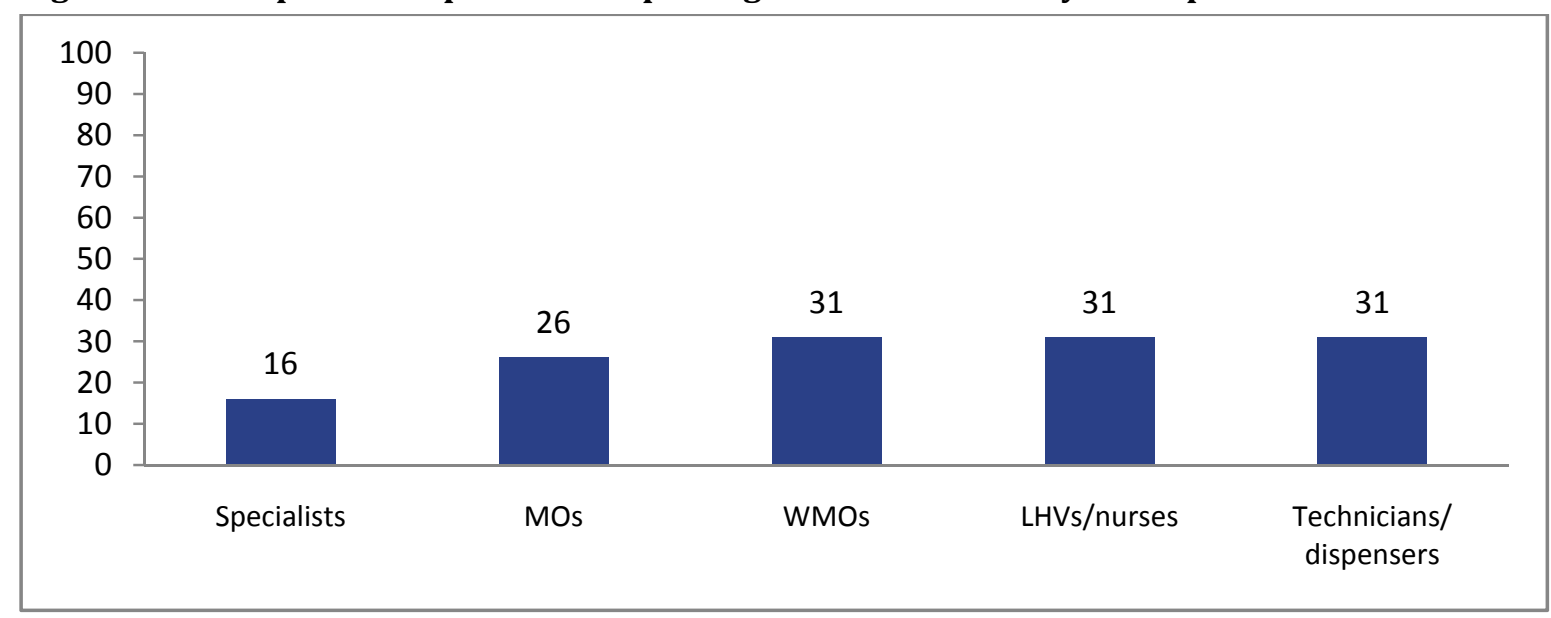

When assessed by region, as shown in Figure 4.23 below, the highest proportion of retention efforts were being reported by respondents in Balochistan, Sindh and AJK. Less than a quarter of the providers in Punjab, $K P$, FATA, and GB were of the perception that the government was making efforts to retain qualified employees. 
Figure 4.23: Proportion of respondents reporting retention efforts by region

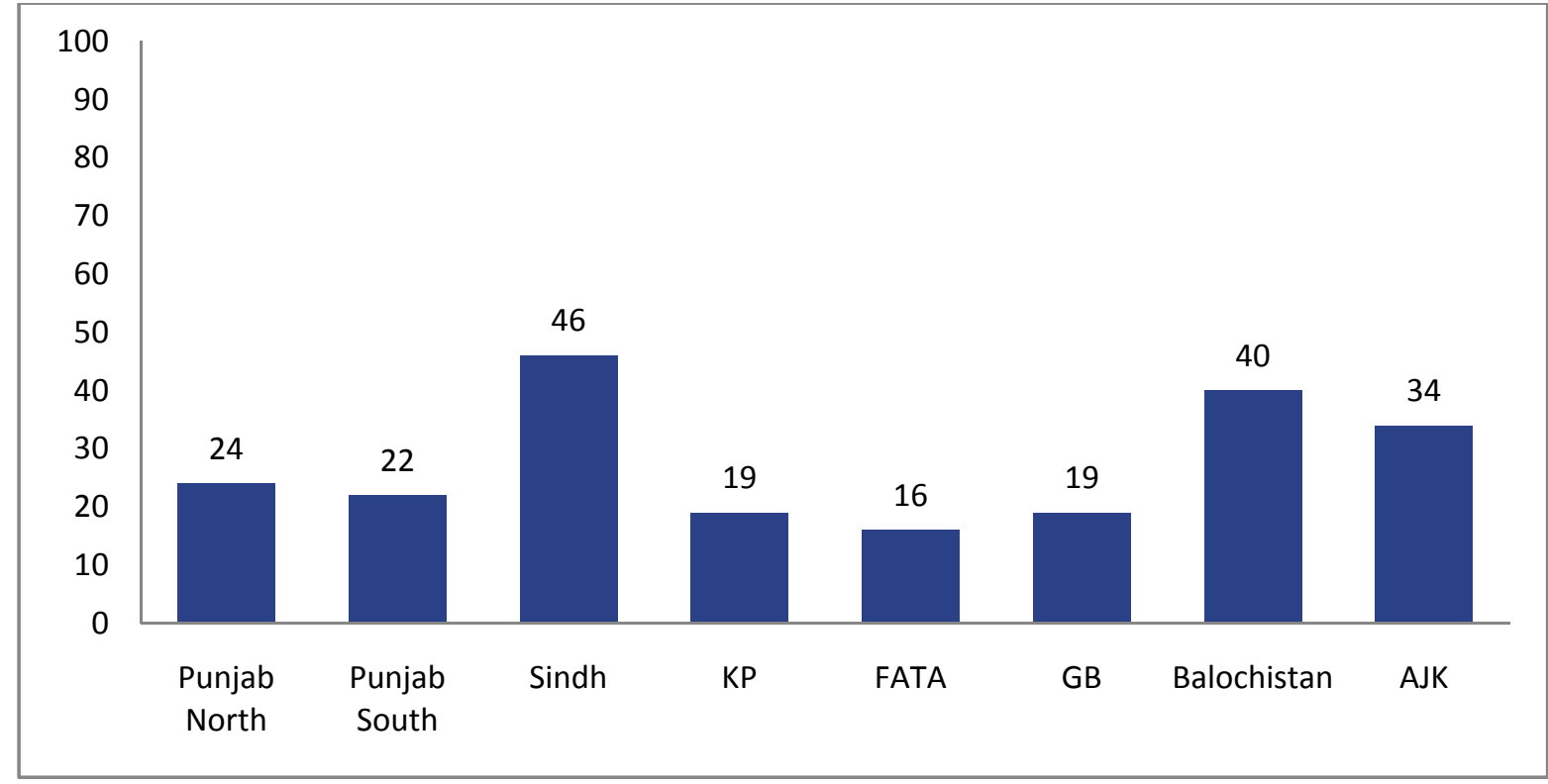

\section{Summary}

- A third of providers say they would consider leaving government service and moving if and when an opportunity arose, mainly due to political interference, low current salaries, and a lack of promotion;

- Male providers compared to female are more likely to leave;

- The availability of essential infrastructure and medicines influences providers' willingness to stay in their jobs.

- Two-thirds of managers do not perceive turnover to be a major problem in their departments.

\section{6: Relations with co-workers and socializing}

Respondents were asked about the attitudes of their colleagues towards them. Most reported that attitudes were positive with more than half of the providers reporting that their colleagues were friendly and helpful with $85 \%$ reporting that they were co-operative. A minority of the participants i.e. less than $10 \%$ and $5 \%$ respectively thought their colleagues were competitive or non-co-operative.

In order to gauge whether providers were able to have a work-life balance, they were asked if they got time to meet their friends and relatives after work. Less than half the providers $(42.6 \%)$ said that they did get time to socialize, while around one third (34.1\%) said they sometimes were able to and the remaining quarter $(23.3 \%)$ reported they did not get time. 


\section{7:Nature of Work}

\section{Satisfaction with work}

Providers were asked whether they were satisfied with the work they were performing at their current positions. More than three-quarters of the respondents (figure 4.24) were highly satisfied with their current work. Based on cadre, the highest proportion of providers who had a 'high' level of satisfaction were technicians/dispensers and LHVs. It was seen that the level of work satisfaction increases with years of experience and reaching a plateau after 20 years.

Figure 4.24: Proportion of providers by level of satisfaction with their current work by cadre

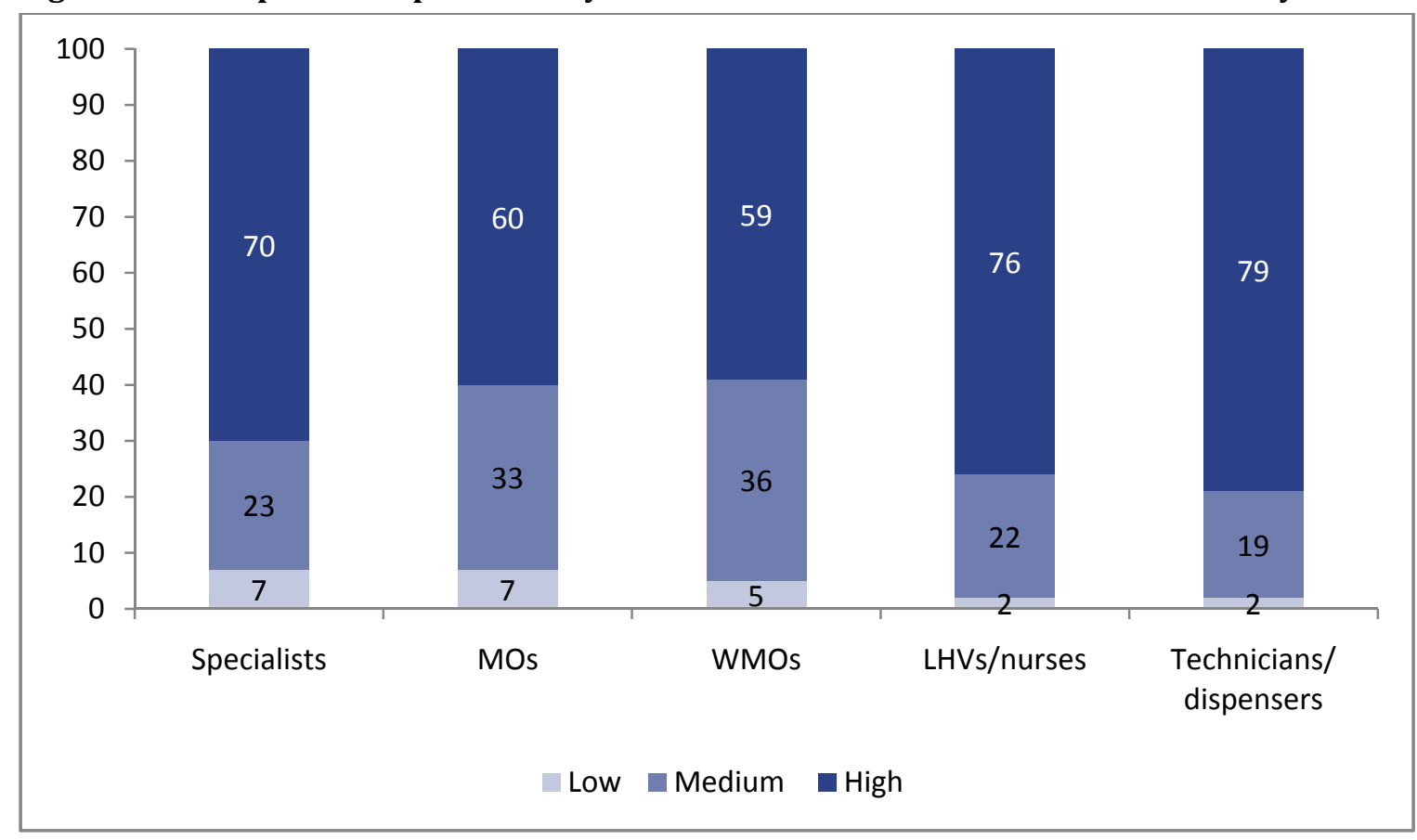

\section{Relevance of work-what workers do}

Satisfaction with the nature of the work is to a great extent dependent upon how well the skills and qualifications of providers are in congruence with the kind of work assigned to them. As illustrated in figure 4.25 , by cadre we found that almost $90 \%$ of LHVs and technicians/dispensers are being given appropriate work according to their respective skills. A matter of concern is that a fifth of the specialists and MOs were of the view that the work entrusted to them was not relevant to their qualifications. Both LHVs and dispensers have a well-defined scope of work from which they do not often deviate. On the other hand, specialists and MOs are also involved in administrative work. At times, due to lack of available positions, qualified staff is not given a position according to their qualification. As seen in Chapter 3,14\% of MOs who are qualified as specialists are working as MOs. This also explains why LHVs and dispensers are more satisfied with their work. 
Figure 4.25: Proportion of providers satisfied with the relevance of work with their skills by cadre

\begin{tabular}{|c|c|c|c|c|c|}
\hline 100 & \multirow[b]{3}{*}{79} & \multirow[b]{3}{*}{79} & & \multirow[b]{2}{*}{90} & \multirow[b]{2}{*}{89} \\
\hline & & & & & \\
\hline 80 & & & 83 & & \\
\hline 70 & & & & & \\
\hline 60 & & & & & \\
\hline 50 & & & & & \\
\hline 40 & & & & & \\
\hline 30 & & & & & \\
\hline 20 & & & & & \\
\hline \multirow[t]{2}{*}{10} & & & & & \\
\hline & Specialists & MOs & WMOs & LHVs/nurses & $\begin{array}{c}\text { Technicians/ } \\
\text { dispensers }\end{array}$ \\
\hline
\end{tabular}

\section{8:Training and Development}

Training healthcare professionals is an important component of personal and professional growth. It not only ensures that providers have the skills needed to improve the quality of services provided but it also enhances their levels of motivation. Healthcare providers need on-going professional development courses as well as technical capacity building courses for growth and development.

To gauge the existing training status, providers were asked if they had ever received trainings after joining government service, and if so, whether it was long-term training (defined as three months or longer), or short-term training (less than three months). Majority (three-quarters) of the respondents had only received short-term trainings. $18 \%$ had not received any training at all. Only $7 \%$ of the providers had received both long and short-term trainings. By level of facility, three-fourths of the providers in secondary care facilities (DHQs and THQs) had ever received training while a higher proportion (85\%) of providers at primary care facilities (BHUs/RHCs) had ever received trainings signifying higher training opportunities for primary care providers.

By cadre, it was seen that the highest proportion of providers who had never received any training were WMOs, followed by nearly a quarter of specialists and a fifth of MOs(figure 4.26). A much lower proportion of WMOs and LHVs had received long-term training i.e. $5 \%$ and $4 \%$, respectively. In the case of WMOs, this could be attributed to the fact that most of them were relatively new entrants into government service. In the case of LHVs who have been in service for a much longer duration, it reflects the lack of a pathway for professional growth for this particular cadre of workers. 
Figure 4.26: Training status of providers by cadre

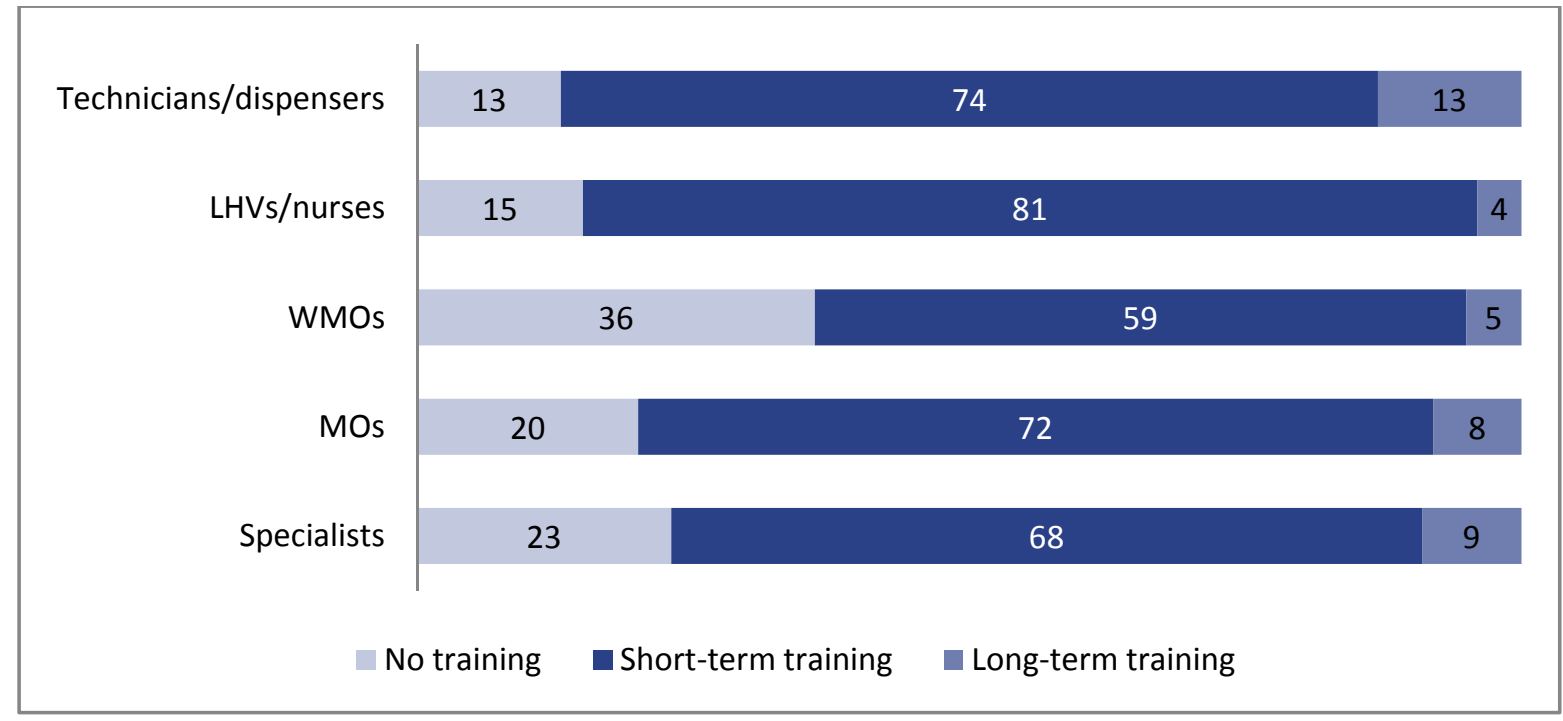

\section{9: Progress towards Achieving Goals}

A sense of achievement and personal growth through attainment of self-identified goals are important determinants of intrinsic motivation as they lead to a sense of fulfilment and satisfaction. According to Franco et al. (2002) health workers are motivated when there is an alignment between individual and organizational goals and workers have the capacity to undertake the assigned tasks. Providers were asked if they had a vision/goal of what they want to achieve and accomplish in life, and whether or not they were satisfied with the progress they had made towards achieving said goals.

As seen in figure 4.27, when asked about whether they had a set goal/vision, majority of providers reported that they did. The lower-level providers (LHVs and technicians/dispensers) expressed a greater degree of satisfaction with the progress they had made towards achieving their respective goals as compared to the MOs and specialists. We can assume that lower cadre providers have more limited goals that they aspire to achieve. 
Figure 4.27: Proportion of providers who have a vision and are satisfied with progress towards achieving it by cadre

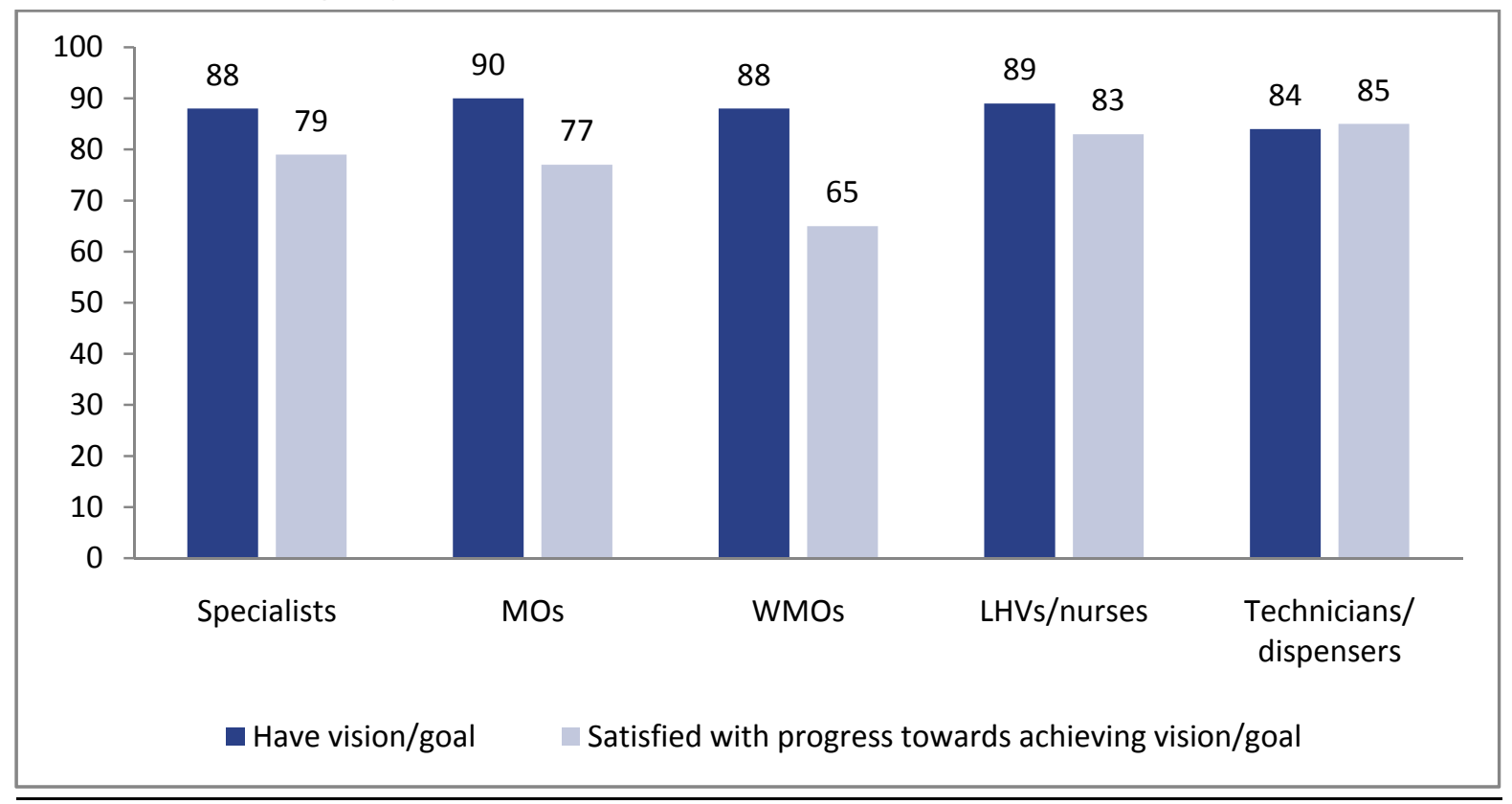

The level of satisfaction in achieving personal goals was also analysed in the context with years of experience or length of service (figure 4.28). The level of satisfaction was higher for providers who had been in the job for more than 20 years giving them more time and experience to attain their goals.

Figure 4.28: Proportion of providers satisfied with progress towards achieving their vision/goal by years of experience

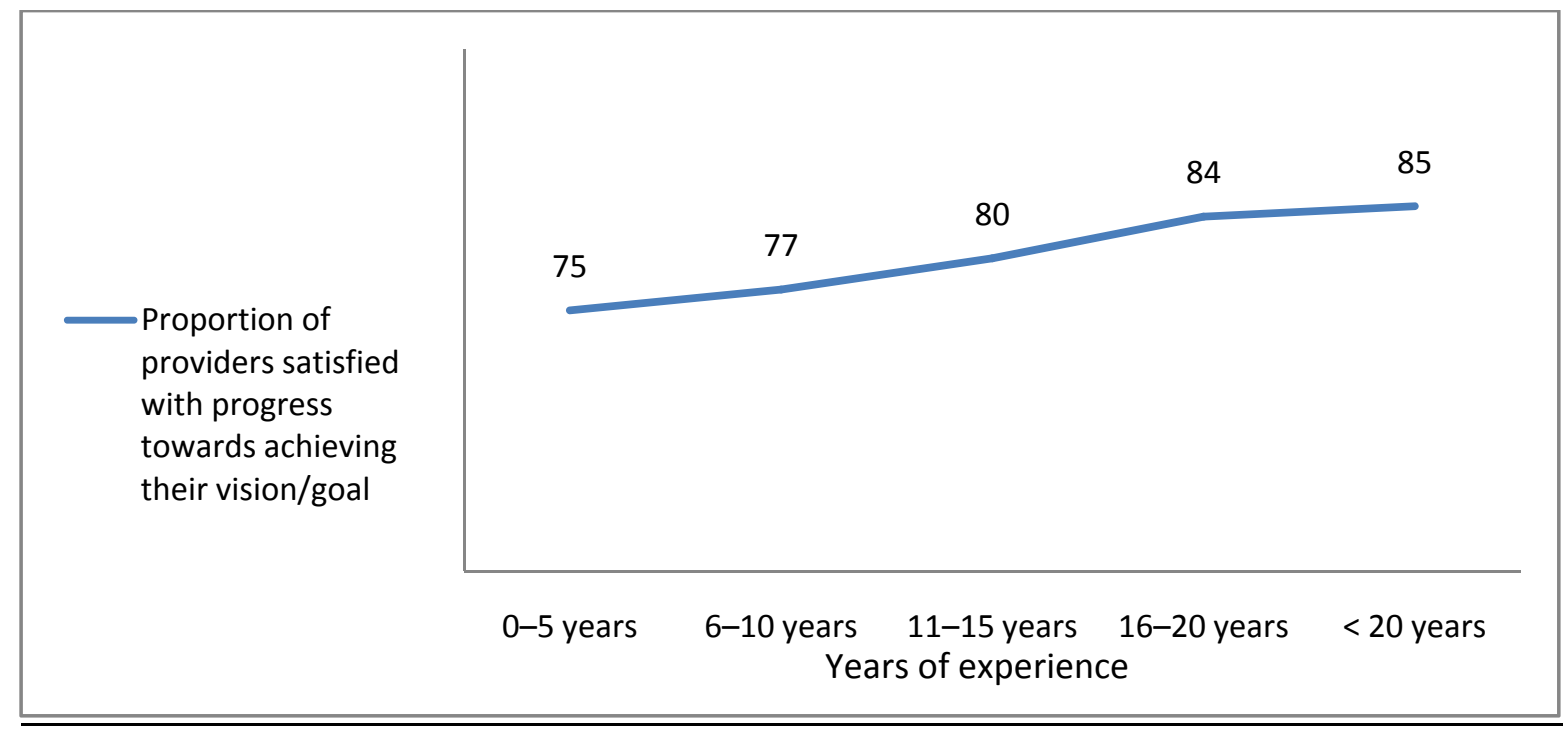




\subsection{0:Recognition Received}

Achievement and recognition are major determinants that influence motivation. To gauge the recognition employees were receiving for their efforts, providers were asked whether they received verbal appreciation when they performed well, and if they had ever received written letters of appreciation or been nominated for an award. As shown in figure 4.29 all cadres reported receiving verbal appreciation, ranging from $73 \%$ in specialists to $86 \%$ in technicians. However, a very small proportion of providers had ever been nominated or received any official recognition in the form of an award or letter or certificate of appreciation for their performance. The highest proportion of providers (nearly a quarter) who had received an award or letter of appreciation were specialists. The lowest within this category were WMOs and LHVs.

Figure 4.29: Proportion of providers receiving appreciation from supervisors by cadre

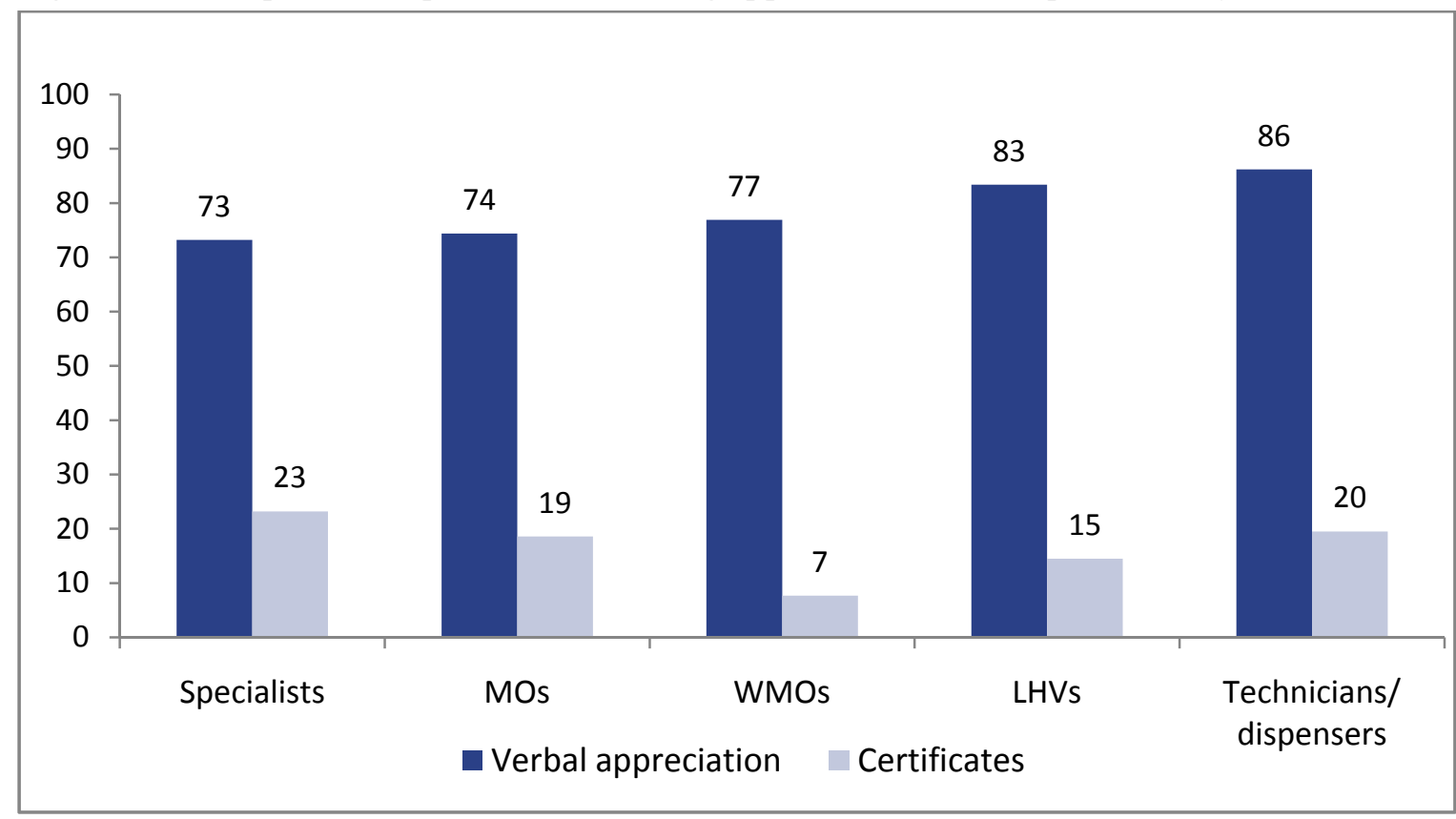

To ascertain the importance of receiving recognition and reward for performance, providers were asked if they considered monetary benefits or non-monetary benefits more important in influencing their motivation levels. A significantly higher proportion of providers reported being motivated by non-monetary benefits $(p<0.01)$ (figure 4.30), which include praise and appreciation and receiving respect from the community. 
Figure 4.30: Proportion of providers motivated by monetary vs. non-monetary benefits

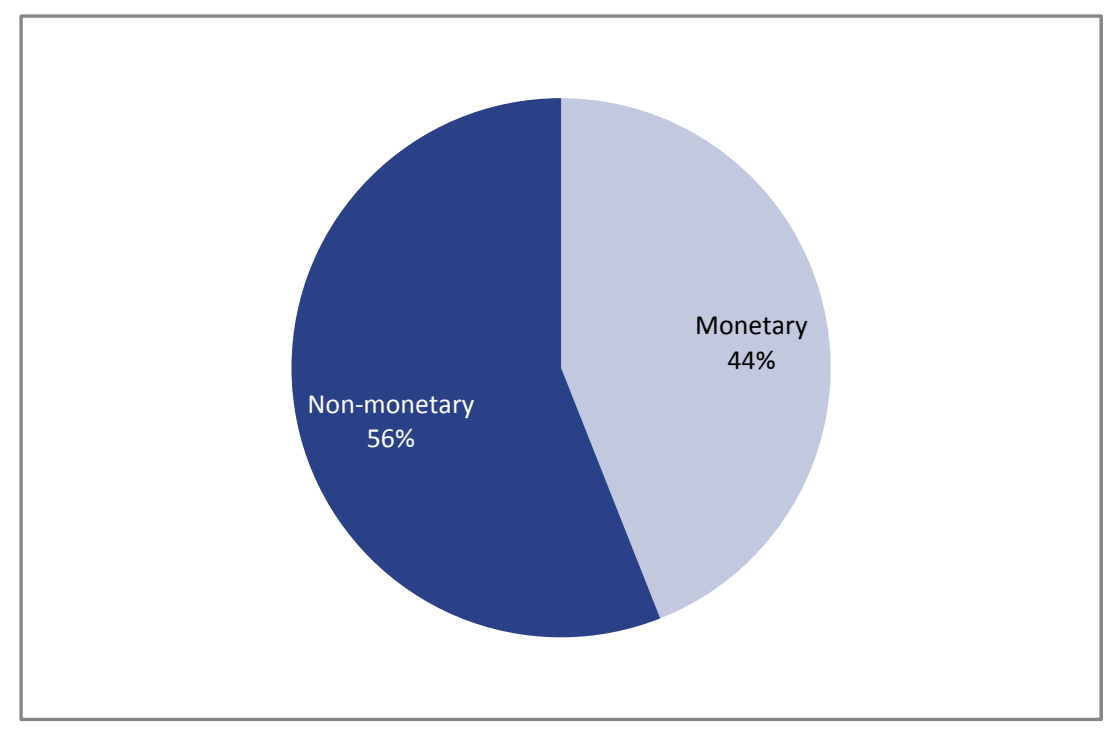

In the IDIs, the providers highlighted the importance of non-monetary benefits including the spiritual rewards they received from their patients in terms of prayers and blessings, eloquently recorded as follows:

"I am very motivated by seeing the results of my efforts (in terms of seeing my patients recover) and also by the gratitude and prayers that I receive from them. "WMO, 27 years, district Toba Tek Singh, Punjab

"It makes me happy when I can help a patient, and this is what gives us encouragement and motivation. People give us respect which gives us joy."IDI, MS, Kotli, AJK

\subsection{1:Promotions Availed}

\section{Level of post-promotion status by cadre}

An increase in responsibility is manifest by regular promotion in one's position. In this section, we discuss the promotion status of providers by cadre and region. Staff promotions were assessed on the basis of how often staff received promotions in relation to the duration of their service. It was found that $90 \%$ of WMOs have never been promoted since joining service (figure 4.31). A possible reason for this is that the majority of WMOs have been newly inducted into the system with $51 \%$ having experience of less than five years. Three quarters of the MOs and two-thirds of LHVs had also never received a promotion and half of the specialists had also not been promoted since they joined service. About $50 \%$ of providers who had been promoted once included MSs, specialists, and dispensers/technicians. Amongst the providers who had received three or more promotions, the highest proportion was that of medical superintendents (MS). 
Figure 4.31: Promotion Status of providers by cadre

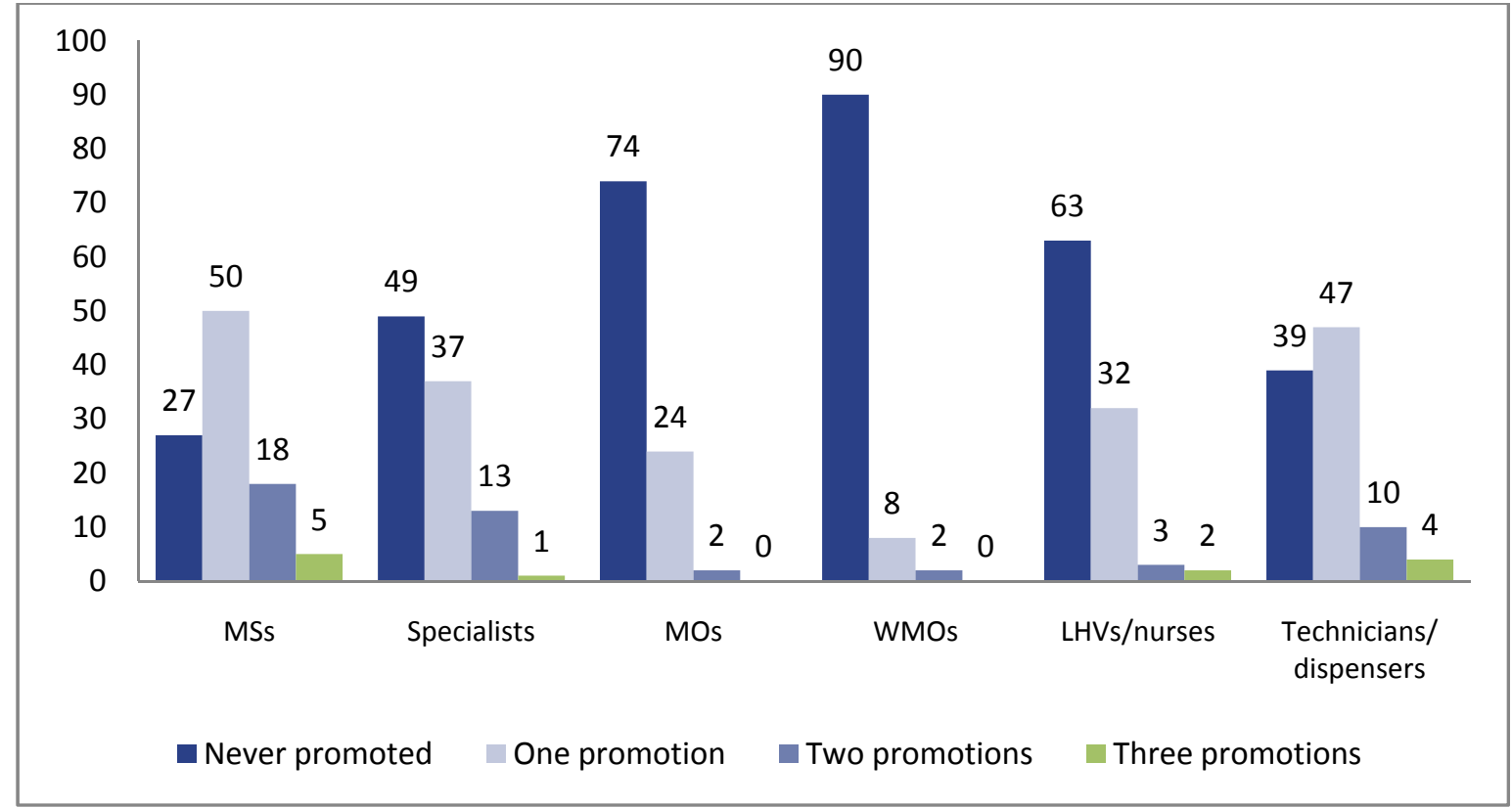

Regionally, the highest proportion of providers who have never been promoted was reported in KP and Sindh. Two-thirds of the providers in GB and Punjab North had also never been promoted. Among providers who had received one promotion, the largest proportion was reported in FATA followed by one-third of the providers in GB, Balochistan, and North Punjab. In Southern Punjab, 6\% of providers reported having received three promotions which was the highest amongst the regions.

Figure 4.32: Promotion status of providers by region

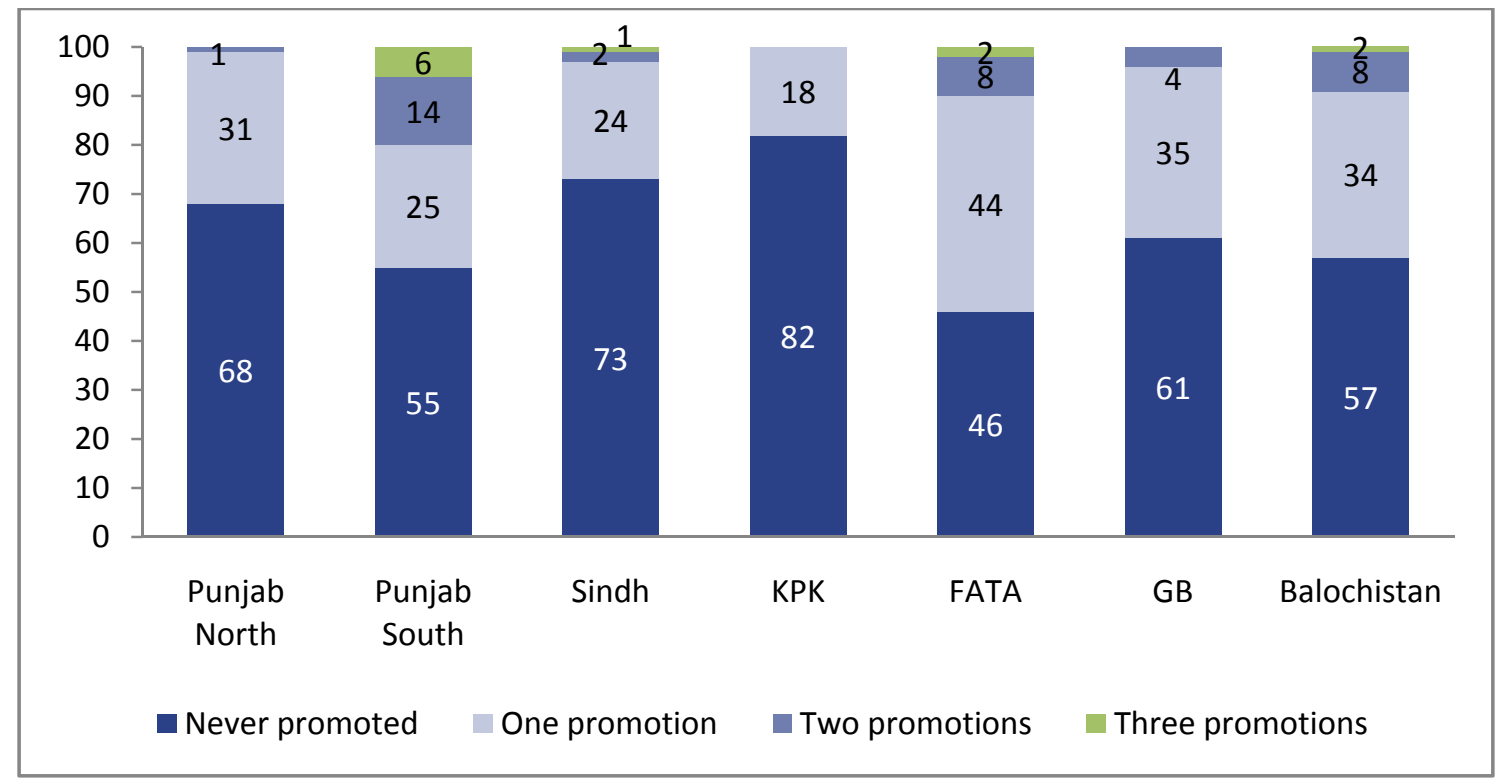




\section{Level of promotion status of providers by years of experience}

Providers were asked how long they had been in the same grade and position in order to gauge whether or not the existing service structure rules were being followed.

According to the existing service rules, promotion from grade 17 to 18 takes $3-5$ years, from grade 18 to 19 about 3-7 years, from grade 18 to 19 about 10years, and from grade 19 to 20 about 10-12 years.

It was found that $87 \%$ of providers who had less than 5 years of experience reported that they had never been promoted. It was also seen that $82 \%$ of the providers who had 5-10 years of service had never been promoted, while $32 \%$ had never been promoted even after 16 years of service (figure 4.33). This implies that service rules regarding promotions are not being fully adhered to.

Figure 4.33: Promotion status of providers by years of experience

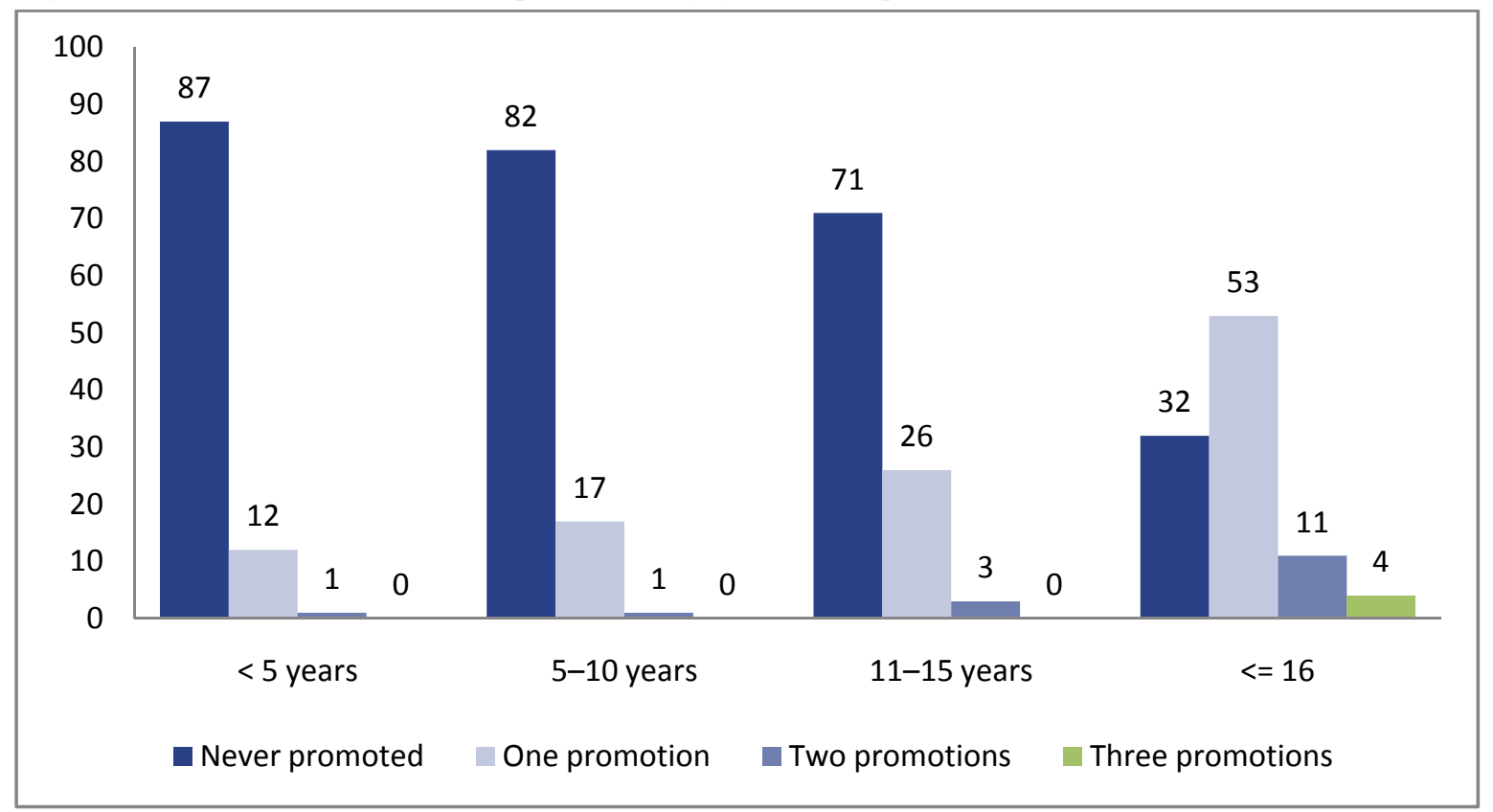

Figure 4.34 shows the proportion of providers who had been at the same grade the longest i.e. for more than 10 years. It is seen that a fifth of MOs and LHVs had never been promoted. Slightly more than a quarter of specialists and a fifth of WMOs workin the same grade for 6 to 10 years. 
Figure 4.34: Distribution of providers at the same grade by cadre by length of service

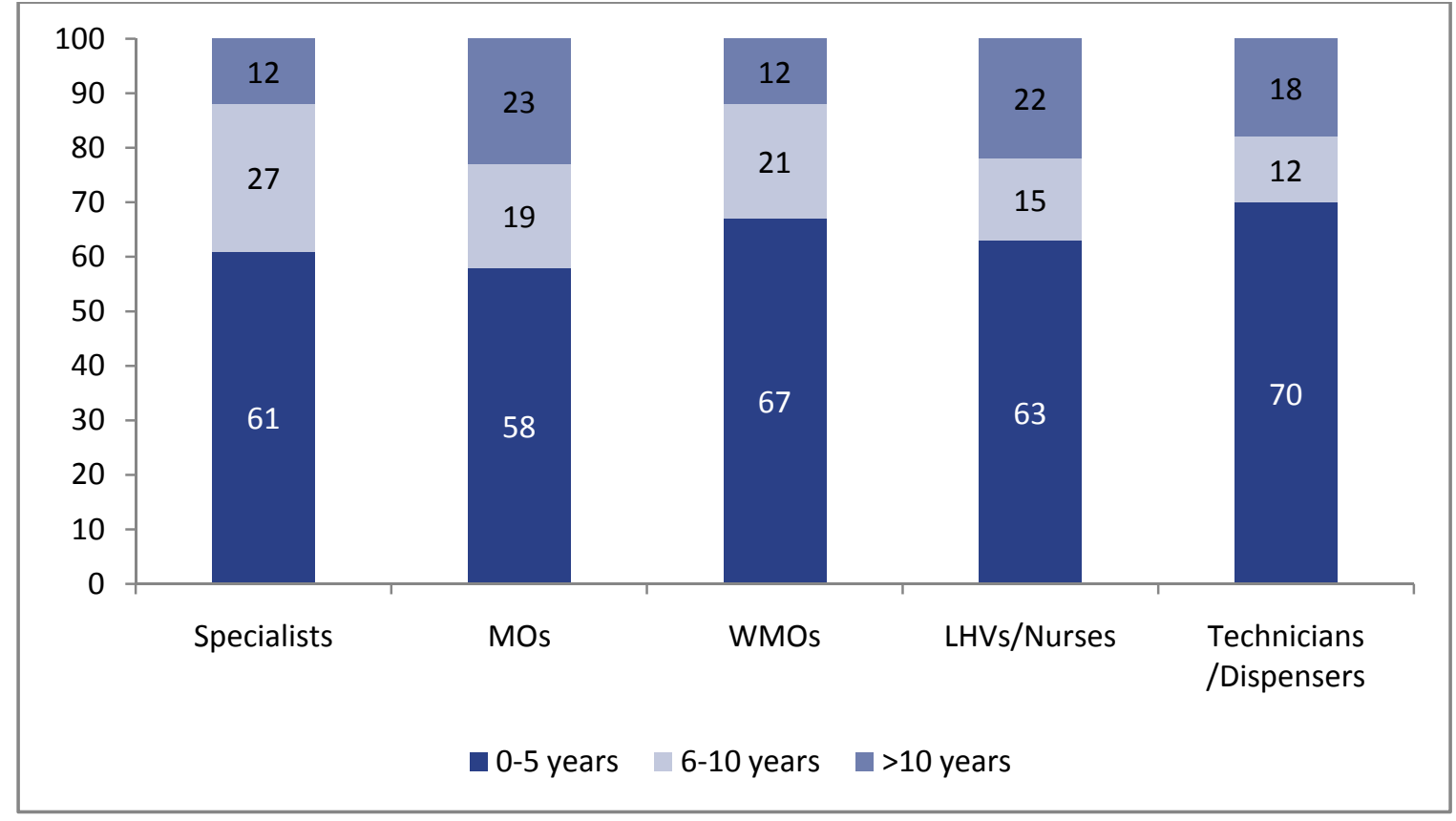

\subsection{2:Self-Actualization}

One of the most important motivators is self-actualization i.e. the ability to recognize and put to use one's full potential. Self-actualization is achieved when the nature of work matches the skills, capacity and inclination of the staff.

To assess the level of self-actualization achieved by the respondents, a composite index was constructed using responses from eight Likert Scale attitudinal questions ${ }^{5}$. Scores were stratified into two categories, the above fiftieth percentile were taken as attainment of self-actualization and the lower fiftieth as nonattainment.

Figure 4.35 shows that as compared to specialists and medical officers, lower cadre staff i.e. LHVs and dispensers feel self-actualized. The differences are statistically significant. These findings further lend credence to the earlier findings where we find that LHVs have a higher degree of organizational commitment to remain in their job; report higher degree of having met their personal and professional

1. From a professional perspective, how satisfied are you with your position at your current job place?

2. Do you enjoy most of the time going to work every day?

3. I have a vision/goal of what I want to achieve and accomplish in my life .

4. I have moments where my heart is filled with feeling to absolute contentment.

5. My accomplishments are recognized and appreciated by others.

6. I am at a point in my life where I am able to pursue my interests and goals without getting distracted by financial, domestic or other concerns.

7. I am proud to be working for this hospital.

8. This job or work that I am currently engaged makes me feel good about myself. 
goals and vision; and report a higher degree of job satisfaction and relevance of their work to their existing skills.

Figure 4.35: Proportion of providers who feel they have reached self-actualization by Cadre

\begin{tabular}{|c|c|c|c|c|c|}
\hline 100 & \multirow[b]{2}{*}{85} & \multirow[b]{2}{*}{88} & \multirow[b]{2}{*}{88} & \multirow[b]{2}{*}{89} & \multirow{2}{*}{90} \\
\hline 90 & & & & & \\
\hline 80 & & & & & \\
\hline 70 & & & & & \\
\hline 60 & & & & & \\
\hline 50 & & & & & \\
\hline 40 & & & & & \\
\hline 30 & & & & & \\
\hline 20 & & & & & \\
\hline 10 & & & & & \\
\hline \multirow{2}{*}{0} & Specialists & MOs & WMOs & LHV /Nurse & $\begin{array}{l}\text { Technicinas } \\
\text { /Dispensers }\end{array}$ \\
\hline & & & ctualizati & & \\
\hline
\end{tabular}





\section{FEMALE PROVIDERS' PERCEPTIONS ON WORKING IN THE PUBLIC SECTOR: FINDINGS FROM QUALITATIVE RESEARCH}

\section{1: Introduction}

The qualitative component included Focus Group Discussion (FGDs) that were carried out with female healthcare providers in remote and rural areas of Pakistan. These FGDs were conducted for triangulation purposes and were carried out prior to finalization of quantitative data collection tools in order to inform and aid the development of these tools and to refine the structured questionnaire. The qualitative findings also helped provide insights and a contextual understanding of the perceptions of femalehealthcare providers on factors that contribute to their motivation and retention.

This section of the report provides the objectives behind these interviews and the methods used. It concludes with a discussion on our findings.

\section{2: Specific Objectives}

The specific objectives were to:

- Probe the reasons for the selection of careers and future career strategy

- Provide a forum for raising issues related to work and understanding of how cultural diversity influences the work environment

- Ascertain factors that influence job satisfaction, motivation and constraints faced in discharge of duties

\section{3: Methodology}

The districts for data collection were selected randomly. One district per strata and two FGDs in each district (one with WMOs and one with LHVs) were conducted except in the Federally Administered Tribal Areas (FATA), where only one FGD was held because of limited female staff. WMOs and LHVs were selected for the study to understand the problems and issues confronting female providers.

Fifteen FGDs were conducted in all seven regions: seven groups of LHVs and seven groups of WMOs, and one mixed group. Discussions were held with 108 female providers who were selected through nonrandomized, purposive, and convenience sampling (Table 5.1). 
Table 5.1: Number of FGDs conducted in each stratawith number of participants

\begin{tabular}{|c|c|c|c|c|}
\hline \multirow[b]{2}{*}{ Strata } & \multirow[b]{2}{*}{ No. of FGDs } & \multicolumn{2}{|c|}{$\begin{array}{l}\text { Participants in each } \\
\text { strata }\end{array}$} & \multirow[b]{2}{*}{ Demographics } \\
\hline & & WMOs & LHVs & \\
\hline Balochistan & 2 & 6 & 6 & \\
\hline KP & 2 & 10 & 7 & \\
\hline AJK & 2 & 8 & 8 & \\
\hline Sindh & 2 & 5 & 7 & 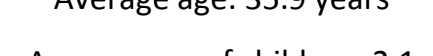 \\
\hline Punjab & 4 & 15 & 13 & Average no. or cnilaren: 2.1 \\
\hline GB & 2 & 7 & 8 & 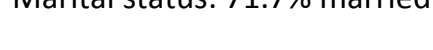 \\
\hline FATA & 1 & 3 & 6 & \\
\hline Total & 15 & 54 & 54 & \\
\hline
\end{tabular}

The FGDs were conducted in the districts where participants resided. Permission was taken from the participants using a consent form ensuring that their participation was voluntary. All FGDs were recorded.

Each session was conducted by a facilitator and a note-taker. FGDs were recorded and transcribed by notetakers in the field on an on-going basis to ensure completeness and accuracy. Data from transcripts was converted into data display matrices to facilitate analysis.

Instruments and measures

FGDs were conducted using pre-constructed guides. These questions guided the responses that provided the content analysed in this report.

Analysis

Data were analysed following a content analysis approach through which emergent themes were identified, coded, and analysed iteratively (Hsieh and Shannon 2005). Transcripts were first reviewed using an open coding approach. Codes that were identified in this process were recorded and developed into a codebook. When this preliminary review of the transcripts was complete, codes were reviewed and grouped according to categories: contextual factors, which include organizational and social factors. These categories were identified inductively, but were validated against the literature. Organizational and social factors examined the individual's perceptions about motivating and de-motivating factors within their context.

Guided by the research question and the conceptual framework, data were reviewed with the specific intent of identifying the interplay between different categories of motivating and demotivating factors and how these factors affected motivational outcomes.

Data displays were constructed to model the key areas of interaction outlined above. Two rounds of data review were conducted to populate these matrices. Transcripts were reviewed and text was selected and input into the appropriate cells of the data display matrices during the first. The definition, application, and grouping of certain codes were refined based on a more in-depth understanding of the data, during this round of transcript review. 


\section{4: Motivating factors}

Organizational factors:There are a number of organizational factors related to working in the government sector that were cited as motivating factors.

Job security and benefits:The job security associated with working in the public sector was a recurring theme. Another recurring theme related to public sector benefits was that of pension and retirement benefits. Of 108 respondents, 51 (the majority of whom were WMOs) cited job security as a motivating factor and 28 cited retirement benefits. The importance of government retirement benefits was felt more amongst the LHVs than the WMOs. Another motivating factor identified by 21 respondents was the short and fixed official daily duration of duty for employees in the public sector; 22 respondents said this facilitated their private practice.

Around 32 respondents spoke of the benefits of working in the public sector in terms of comparing their work with that in the private sector where there was a perception of lack of autonomy, poor work environment and low pay.

"Government job is permanent and secure, but the private sector has no job security. We are enjoying maternity leave with pay, and in the government sector people also avail loan facilities." WMO, FATA

"I was made redundant after 16 months in the private sector. But this is a more secure job." WMO, Lasbella

"It is a secure job and government employment offers a pension/retirement fund." WMO, Mardan

Challenging nature of work: Around25 respondents, mostly WMOs, cited the nature of the cases, the heavy workload, and other challenges they faced at their jobs, as motivating factors because it added to their skill and expertise.

"There is very high client load here and this is good because it gives us many opportunities to learn and build our skill set." WMO, Lasbella

"We get to work with experienced senior doctors." WMO, Mardan

Salary and allowances:This came up twice with existing salary being reported both as a motivating and demotivating factor.

'Good salary' and 'hard area allowance' were motivating factors identified by a few of the respondents (27), the majority of whom were WMOs. Salary as a motivating factor was reported with highest frequency in the districts of Shikarpur (Sindh) and Mardan (KP). Satisfaction with hard area allowances came up the most in Khanewal (Punjab) amongst both LHVs and WMOs. A good salary acting as a motivator was also reported by LHVs in Muzaffarabad (AJK). 
"We receive PKR 40,000 as salary in urban facilities. Rural facilities give us an extra PKR 12,000 allowance, so this makes it more attractive."WMO, Khanewal

"As compared to the private sector, government salary is handsome, but inflation rate is high."WMO, Multan

Importance of encouragement and positive reinforcement: Participants were asked whether they thought supervision was important and if their supervisors could play a role in affecting their motivation levels - 46 respondents out of 108 identified the importance of recognition, encouragement, and positive reinforcement by supervisors as a motivating factor. This was most commonly reported by LHVs in Balochistan, Punjab, and AJK.

"Supervisors should be helpful...if the supervisor is good and appreciates us, we will do good work. My supervisor asked me to make corrections in the register with love and respect and this gave me courage."LHV, Lasbella

"If supervisors encourage their staff, they do good work. If he is not co-operative, they do not work properly. He should be a good communicator and support his staff. He should control himself when he is angry and not be angry at his lower staff."WMO, Multan

Gratitude from community:Another common theme in motivating factors was related to the respect that providers receive from community members, especially when working in rural communities (as opposed to urban ones). Around 31 providers reported that one of the main reasons they took their jobs was because of the respect, gratitude, and prayers received from clients within such a profession.

"There is an opportunity to serve people and get prayers from them."LHV, Mardan

"We get respect as well as gifts, and people of the community consider us influential. It is true that people are not paying the same respect in urban areas." $\mathbf{L H V}$, Muzzaffarabad

"Serving poor people motivates us to work in rural areas - we get respect from the people of the community."WMO, Lasbella

Social Factors: Social factors examine health workers' lives in a wider context, taking into account their social environment. Factors impact health workers by being a part of this environment or system and include community expectations, societal values, peer pressure, family support, and financial considerations, among others.

Status:39respondents identified the status and respect associated with government jobs as an important motivating factor.

"There is no tension in a government job. Government employees are given much respect in society." LHV, Mardan 
"We receive respect everywhere due to being government employees and doctors."WMO, Muzzaffarabad

"People respect you if you are a government servant and we feel honoured."WMO, Multan

"People respect and value us. In turn, we serve the poor people and are able to run our homes better [because of the money we earn]." WMO, Khanewal

"The people give us respect and pray for us and this respect gives us self-confidence."LHV, Multan

Familial support: The importance of family support and acceptance and encouragement of health workers jobs was mentioned consistently across districts by 61 out of 108 respondents. Family support worked both as a motivating and demotivating factor. A number of participants reported applying for government jobs or accepting them once they had been offered a place because they had been influenced by a family member who also worked in the health department or because working as a health professional was a parent's desire.

"In my childhood, my father wished to educate me as a doctor but I was unsuccessful for various reasons. My father and two brothers are doctors. Whenever I went to the hospital with them as a child, I thought 'I will serve the poor,' but unfortunately I could not, so my father advised me to join the medical field as LHV."LHV, Shikarpur

"My older brother told me during my LHV training that I must join the government sector because this is a very respected job."LHV, FATA

Internal motivation:Motivation stemming from a personal source and independent of health providers' social context was a common theme that arose from respondents' answers. Commonly reported factors in this area were compassion, wanting to serve humanity and one's own people, inner satisfaction, and, feeling passionate about the profession. A large number of providers' cited internal motivation as a reason for taking and staying in their jobs.

"There are no facilities [here] and we are working for the sake of the community to facilitate them in their hard lives." LHV, Skardu

"I sincerely love this profession. That is why I took this job. I am passionate about surgery and love performing ultrasounds and deliveries."WMO, Lasbella

"It is important [to work in these areas] because people use unskilled birth attendants and this leads to maternal and child mortality."LHV Multan 


\section{5: Demotivating factors}

\section{Organizational factors}

Dissatisfaction with salary, benefits, and facilities:As stated before, while a regular salary was an important factor in deciding to opt for government service, majority of respondents in all districts were not satisfied with existing salaries, benefits, and facilities. All of these respondents demanded the provision of higher salaries and better benefits. Dissatisfaction with benefits and facilities was reported at a higher frequency than dissatisfaction with salary.

"The government does not give us any facilities. Salary raises are just one issue." WMO Gilgit

Dissatisfaction with salary was mentioned in relation to the work done, as well as rising living costs. This issue was seen to be most common amongst LHVs.

"The benefits and incentives are nothing in terms of our duty hours and services...our system cannot improve until and unless we are provided incentives according to our performance."WMO Muzaffarabad

WMOs appeared more satisfied with their salaries in Multan, but the same could not be said for the LHVs. Low salaries, no allowances, and not getting facilities according to their grades, were commonly reported problems in all provinces. Respondents from both Gilgit (GB) and FATA stated that they desired higher salaries and better allowances, especially for hard areas.

"This pay does not cover our food and expenses, due to inflation. It cannot cover transport or school fees for our children."LHV, Multan

You will be amazed at the injustice if you compare our salaries with those of judges, teachers, and other government officials"WMO, Gilgit

"Such a low salary package means we are not even able to pay our children's school fees."LHV, FATA

Irregular promotions and absence of a service structure:The absence of a proper service structure was reported in all districts. Around 36 participants out of 108 cited this as an important demotivating factor. Some respondents were unhappy with the way promotions took place i.e. without taking into account their level of education or professional expertise and experience. They mentioned the importance of 'having influence' or knowing someone who could pull strings to get one promoted. This problem was reported most frequently amongst LHVs. Some LHVs were dissatisfied with the service structure and felt that the disparity between an LHV's grade and other medical staff's grades was unfair.

"I have not been promoted for the last 12 years but my juniors have been promoted because they have influence."WMO, Lasbella

Favouritism/ Partiality:Inequality at work among employees was a common theme that was presented by WMOs and LHVs. Around 54 respondents out of 108 reported experiencing some form of inequality and 
discrimination at their workplace. This was felt in the form of favouritism towards higher cadres, gender discrimination, and general favouritism between staff:

"We should also be sent for higher courses like doctors and nurses. We know more than doctors at times and spend more time with patients."LHV, Shikarpur

"The most demotivating factor is injustice in our society. We are doing our best to improve healthcare, but other employees do nothing and are the favourites...in our culture, the one who does nothing is more important than you." WMO, Muzaffarabad

"Promotion procedures are not fair according to our qualifications and seniority." LHV, Khanewal

"We have not been promoted for a long time. We have been working in the same grade for 25 years. Even nurses have been appointed in the 16th grade, but we are still in 9th grade."LHV, FATA

"Nurses are appointed to higher grades than us. There is a big difference between the doctor and LHV grade, but also a big difference between the nurses and LHV grade, and this is unfair."LHV, FATA

Political interference:Political influence/pressure from prominent people in the system and within the community was one of the main demotivating factors reported. This was reported by 46 respondents and took different forms as reported by FGD participants. Issues related to political interference came up in all districts/provinces, with the exception of GB.

"Due to political influence from the community, they say if you do not agree with us we will transfer you to another hard area." WMO, Khanewal

Participants also reported being pressured and threatened into giving priority to patients from influential families in the community. A common response regarding interference and being influenced was that females were always more susceptible to this and were easier targets. Therefore, they were threatened more and would do as they were told out of fear.

"Dominant people of the community force us to take illegal cases (medico legal) and file illegal reports." WMO, Shikarpur

Another aspect of political interference was that of medico legal cases (MLCs). This issue was most prominent in the districts of Khanewal and Multan in Punjab, but also came up in Shikarpur (Sindh), and was only reported by WMOs. WMOs reported being forced and threatened to manipulate the results of medico-legal reports to serve the interests of a particular group,as well as being blamed for taking bribes to do MLCs, when the junior staff was actually doing them. This was a serious allegation due to the severity of the punishment if caught. 
According to the responses received, WMOs seemed to face political interference more than LHVs did. This could be attributed to the fact that WMOs had to deal with MLCs, whereas LHVs did not.

"Females face many problems; sexual harassment, pressure, and threats to make illegal certificates [in MLCs]."WMO, Multan

Sexual harassment:Female providers reported experiencing sexual harassment in the workplace and on their way to work, which was reported with the greatest frequency in district Lasbella, Balochistan. Here, providers narrated incidents of colleagues leaving their jobs because of sexual harassment by administrative staff.

"One of senior LHV quit the job and left the province as the local influential people were harassing her", LHV, Lasbella

Sexual harassment was reported in other districts as well - both LHVs and WMOs from Mardan (KP) mentioned safety issues for females, threats received from males, and a perceived lack of security. In the FGD with LHVs in Muzaffarabad, the issue of sexual harassment came up many times; females faced transport issues due to fears of harassment, had aspersions cast on their characters, and difficulties with night visits due to feeling insecure. They also reported feeling mentally tortured, so much so that some felt forced to quit their jobs. The issue also arose in Khanewal and Multan amongst both LHVs and WMOs, in Shikarpur amongst WMOs, as well as in FANA FATA.

"Women are not secure. They are often verbally harassed by male collegues."WMO, Shikarpur

Lack of accountability:Alack of accountability was reported in Balochistan, Sindh, KP, Punjab, GB, and AJK. This was seen as a demotivating factor in situations when respondents felt that their colleagues could get away without performing their duty as there was no way to keep a check on their activities, especially in hard areas.

"Health providers who get posted to far flung areas do not perform their duty. They keep half their salary and give half to the clerk."LHV, Lasbella

"Only a few staff show up and then mark their attendance and leave. No one is there to do the job."LHV, Multan

"We are not answerable to anyone as we are posted in far flung areas of villages." LHV, Mardan

Participants in an FGD in district Khanewal, Punjab described how the lack of accountability translated into misuse of autonomy in lower cadres such as dispensers and assistants, who sat in for doctors in their absence and prescribed incorrect medication to clients.

Infrastructure and equipment:FGD participants in all districts reported facing many problems because of the infrastructure and equipment available at their facility. Around 29 out of 108 participants reported 
problems with facility infrastructure, such as the lack of running water and the absence of a boundary wall. Another 31 out of 108 reported facing difficulties in their jobs because of a lack of proper equipment particularly that related to the provision of $\mathrm{MNCH}$ services such as ultrasound machines and incubators. Both LHVs and WMOs reported feeling demotivated because they were unable to use their skills to help patients.

"There is no need to come to work since there is no medicine and no equipment." LHV, Mardan

Another problem related to infrastructure was the absence of basic facilities such as electricity and gas, and feeling safe at work. This was mentioned by 41 providers, most of whom were LHVs, and it was found that this significantly affected their productivity and motivation.

"There is no boundary wall, and I am afraid when I am on duty at night." WMO, Muzaffarabad

Unavailability and shortage of medicines:Theunavailability and shortage of medicines was another problem reported by 30 providers. It was reported that clients were constantly turned away because of frequent medicine stock outs, which also often led to the loss of clients.

Both LHVs and WMOs from Muzaffarabad (AJK) and providers from Skardu (GB) complained about the lack of medicines and the community's aggressive behaviour or dissatisfaction with the providers' when they could not supply them. This was echoed by LHVs in Lasbella (Balochistan) who reported conflicts with patients due to a lack of medicine, and no action being taken by management. The lack and irregular supply of medicine was also reported in Mardan (KP), Shikarpur (Sindh), FANA FATA, and with a high frequency in Khanewal (Punjab), by both LHVs and WMOs.

"Medicines should be available within the facility, because most of the time, we cannot give medicine to patients and they get annoyed by this." LHV, Skardu

"The shortage of medicine is a main demotivating factor. We do not have a single painkiller."WMO, Khanewal

More influential community members also threatened health workers when the medication they required was not available.

"If we do not have medicine, we prescribe them and ask them to purchase it from market. They become aggressive." WMO, Muzzaffarabad

"We try our best to provide good healthcare facilities and medicines to our clients... when unsatisfied people complain about us due to a shortage of medicines, we feel demotivated...if we perform our duties and people are unhappy with us, we feel very bad." WMO,

\section{Muzaffarabad}

Lack of staff:Staff shortage at facilities was a problem reported particularly in Balochistan and GB. Around 21 respondents identified this as a problem, and it was found that there was a perceived shortage of both support staff and skilled professionals. Respondents reported that there were many vacant posts that were 
not being filled. This increased patient loads for existing staff for which they did not think they were being fairly compensated. Some providers expressed a strong dissatisfaction with their workload.

"It discourages us when the staff is not available on the facility. Midwives are under controlled by influential community personnel in the area and come on duty once or twice in a week."LHV, Lasbella

Community issues:Resistance and problems from the community also took the form of providers feeling helpless because they felt that they were unable to get through to the community.

"Most people in this community do not listen to us. If we try to educate them about the dangers of home deliveries [instead of going to the hospital], they do not even try to understand."LHV, Shikarpur

In the case of LHVs, this also translated into a feeling of a lack of respect and appreciation. They reported that community members often only considered doctors to be healthcare providers.

"There are WMOs and there are LHVs. If the WMO does something wrong, people will say he/she is doing the right thing. No one listens to us and this is discouraging."LHV, Multan

Geographical and weather constraints: A few health providers $(n=10)$ working in northern areas such as Skardu (GB) that are affected by extreme weather conditions reported facing many barriers to delivering care because of the climate. The blockage of roads due to snowfall means a breakdown in an already weak healthcare system.

Providers expressed concerns about not being able to reach their clients in such weather, not having a referral system, and not being able to comfortably provide services in the absence of heating facilities. Workers felt demotivated because of these hindrances in their ability to deliver services to the community.

"During snowfall, all roads are closed and we cannot do anything for the community." LHV, Skardu

"We should be provided heating systems for the cold season so that we can easily provide services to our clients." LHV, Skardu

"We suffer in terms of transportation in the cold season. The government should provide us proper transportation." LHV, Skardu

\section{Socio- cultural factors:}

Gender dynamics:Gender dynamics in society and the constraints and problems they create for providers was the most frequently reported theme and was mentioned by 72 out of 108 respondents.

"Women face many more problems as compared to men. A man can go anywhere but if a woman goes outside, she had to face many comments from the community."LHV, Shikarpur 
Many female providers in rural areas also experience difficulties because of the conservative environment around them. This translates into problems with transport, mobility, and in some areas, even forces providers to work for hours on end without food or water due to an inability to move around alone. This lack of mobility was reported as a problem in all regions. However, in case of women who serve their local communities they face fewer problems from within their community; this is particularly true for areas like Balochistan and the Northern Areas, especially Skardu, but also for parts of South Punjab.

"In our area, people look down upon professional women. We are serving our community, but they do not understand this." LHV, Skardu

"There is gender discrimination in our society and women are not respected even if they are educated and working as a [medical] officer."WMO, Multan

WMOs in Mardan stated that females had no decision making power in 'this society.' WMOs in Muzaffarabad mentioned the 'social setup' of the community as such that females had fewer opportunities than men, especially female healthcare providers. In Shikarpur, LHVs reported that even if they used their mobile phones, the staff would use it as an excuse to gossip about them. A WMO from Khanewal also reported that females were more likely to get into trouble with their seniors.

"Females are answerable to a higher authority, especially in the case of arriving late to work.

Males rarely face such problems. "WMO, Khanewal

Familial issues:A few of the providers reported not being able to do the work they wanted, especially if it required them to leave their homes to do it, and if they did not have family support.

"When we do not have support from our own families, how can we sustain our jobs?"WMO, Muzaffarabad

However, obtaining this form of support is also perceived as difficult because of security concerns, work environment, and a lack of family benefits. Around 30 out of 108 respondents reported being demotivated because of the lack of facilities for their children (such as good schools) in their catchment areas.

A few providers mentioned that they had considered leaving their jobs in the future due to lack of educational opportunities for their children. Another issue that crept up was the lack of work nurseries or family (when posted away from home) who would be able to take care of their children, leaving the health workers with no place to leave their young children when they went to work. This problem was identified by both LHVs and WMOs.

Many participants also reported not being comfortable working in far-flung areas when they had left their children at their home stations, which were geographically far away.

"We are so far from our homes. Our children miss us so much and we cannot take care of them in terms of raising them and dealing with their education." LHV, Skardu 
Safety and security:At times, women feel that the communities they are posted in are unsafe and they feel insecure living, travelling, or working there. This can also lead to reduced support from their families who do not want them to stay there. It also negatively impacts their motivation levels. Security and safety issues were highlighted by 61 out of 108 respondents and were perceived to be a demotivating factor across districts.

"We have to visit homes for deliveries no matter what the environment is. Sometimes, we take a gun with us when we go for deliveries in far flung areas."LHV, Mardan

There were extreme safety issues reported by many respondents in FANA FATA such as curfew situations, bomb blasts, and high levels of insecurity caused by the Taliban.

"We face curfew situations and bomb blasts and we feel very insecure and unsafe in this regard."LHV FATA

Cultural differences:A demotivating factor reported frequently by respondents was the difference between their own culture and that of the area they were working in, which resulted in a cultural clash and manifested itself in problems for them. Some respondents mentioned this in the context of a perceived discrimination between local providers and those posted from other locations.

LHVs in Mardan and Skardu attributed their lack of mobility (i.e. from health facility to the market) to the community's 'culture.' They also said that they were not liked by religious people in the community. Local language problems were felt by WMOs in Mardan and by LHVs in Shikarpur and Khanewal. Some LHVs in Shikarpur said they suffered due to differences in their customs, and LHVs in Khanewal said the local staff did not co-operate with them. LHVs in Muzaffarabad said that the norms of the rural communities were not what they were used to as there were more prohibitions. They said local people were treated with more respect.

"The language issue is a major one as people speak Punjabi and some Siraiki."LHV, Khanewal

Transportation:Around31 out of 108 respondents reported problems related to transportation, the majority of whom were LHVs. Transportation is not provided to most providers and because the areas in which they work are often very far from where they live or the nearest city or town. They reported experiencing many problems with transportation, including problems with finding public transport, the unacceptability of the transport system, harassment experienced on the way to work, and large portions of salary spent on transport.

"A family member travels with me when I go to work at the BHU, due to insecurity and the fact that the BHU is far away. Poor transport facilities cause many problems. "WMO, Khanewal

"Transportation is a big issue for far flung areas. There is only one bus which takes us to our duty station and if we miss it, we are late, which could be an issue."LHV, Mardan 
"Male providers can get lifts but female providers cannot. We take 3-4 hours to reach our duty station because we have to change our routes three or four times."LHV, Mardan

Effect on worker capability and performance:Motivation was also attributed to providers' ability and capacity to perform at their jobs. When asked why they had taken that job, a frequent response was "because I was trained for it."

"There were no safe delivery services in these areas, and now, due to us, people can have the facility of deliveries. "WMO, Mardan

Confidence in their ability to do the job led to motivation to do it.

"In the beginning I did not have enough knowledge about my job, but now that some time has passed, I have gained enough knowledge and am very comfortable doing this job."LHV, Skardu

Many respondents, the majority of whom were LHVs, also felt that there was a need for more training opportunities to be provided to them.

"LHVs need training so they can advance their knowledge and the range of things they can do"

\section{LHV, Multan}

\section{Summary:}

- Findings from the FGDs show that there are a number of factors that work to motivate and demotivate female health workers working in rural areas. These factors vary both regionally and across cadres.

- Although monetary factors were indeed a great source of motivation and dissatisfaction, the problem went beyond a simplistic understanding of motivation in terms of reward for performance.

- Factors that contributed to motivation were a complex interplay of the provider's society, family, colleagues, values and goals, internal motivation and capabilities, and their own perceptions of safety, security, appreciation, and responsibility.

- There was a very low number that would actually leave their jobs. The main reasons for this included among others, compassion, internal motivation, job security, autonomy, respect, and a bad private sector job market, especially for LHVs and nurses.

- Categorizing the results geographically helped in understanding region-specific issues, such as safety and security and terrain issues in GB and FATA, involvement in medico-legal cases in Punjab, and the lack of staff in GB and Balochistan. 



\section{DISCUSSION AND RECOMMENDATIONS}

\section{1:Discussion}

The effectiveness, efficiency, and quality of the healthcare delivery system areclosely dependent upon the willingness and capability of health personnel to undertake the tasks assigned to them diligently (Franco et al. 2002; Hornby and Sidney 1988). There are a varied number of theories and models available that have been used to identify and understand the determinants of motivation. These include Maslow's theory of needs (1943) followed by the two-factor theory of Herzberg (1959) and the expectancy theory by Vroom (1964). More recently Franco et al (2002) have applied a model that they have used to study health workers motivation in several countries. The main objective of this study was to analyse and identify the determinants of retention and motivation in Pakistan.

Our study has been able to identifyissues pertaining to human resource availability in the health sector at a national scale. The study shows that a sizeable number of staff positions are vacant. This includes two third positions of gynaecologists in Punjab and three fourths in Sindh. A third of positions of women medical officers in Punjab and Sindh and slightly more than a half in GB and FATA are vacant. As a result, the provision of specialized $\mathrm{MNCH}$ care in rural areas remains a major challenge. A positive finding is that most positions for LHVs are filled in all regions.

We found through manager interviews that the main reasons for vacant positions are a lack of funds for recruitment, coupled with a dearth of providers wanting to work in rural areas. The Health Department has to make it attractive for providers, especially specialists to work in these areas. Moreover, the number of staff positions will also need to be enhanced based on the increased client load experienced due to a rapid growing population and clientele.

This study also shows that the number of existing public sector facilities available is not commensurate with the size of the district population. The lack of functionality of these facilities to offer a full range of services further compromises service availability. Additionally in the absence of a full range of equipment and supplies required to promote $\mathrm{MNCH}$ care, staff cannot be expected to deliver what is expected from them. The findings show that only $14 \%$ rural health centres, in the sampled districts, have all six signal functions available for providing BEmOC and $45 \%$ of the assessed THQ and DHQ hospitals have all the eight signal functions for delivering CEmOC services. Additionally only 30\% of the THQ and DHQ hospitals, in the sampled districts, have a full range of contraceptives available. A review of the literature indicated that the situation in public health facilities has remained static and the utilization and satisfaction levels with BHUs have remained the same in the past three decades with only a fifth of the population reporting use of the first level facilities for their health needs due to the prevalent situation (Shaikhet al2010). The lack of equipment also results in staff frustration and attrition (Awases et al. 2004; Dovlo 1996; Stillwell 2004) and providers who havethe necessary infrastructure and medicine available at their facilities were less likely to consider leaving their jobs. 
The absence of skilled health care providers and essential equipment and medicines at health facilities affects maternal and neonatal survival outcomes adversely. Previous studies conducted in Pakistan also reflect lack of essential newborn equipment such as baby scales, foetal stethoscopes or bulb syringes at the BHU, RHC and THQ level facilities (Fikree et. Al, 2006) and the trend has not changed as found in our study. This is consistent with the international literature which shows that there is little effect of institutional delivery on neonatal mortality because of the lack of equipment and poor quality of care provided to the newborn in resource poor settings (Lohela et al 2012 and Tura et al 2013)

An important finding of our study is that a third of providers are dissatisfied with their present job to the extent that they are willing to consider leaving service. This is important as Pakistan is already facing a persistent shortage of health workers to serve in the rural areas. The results from this study show that male medical officers and specialists are more likely to move, due to not only economic reasons but also commuting long distances to reach work and lack of infrastructure at their workplace. The study results show that a high proportion of providers are dissatisfied by their current salary. By cadre, we see that nearly two-third of dispensers are dissatisfied by their current salary, followed by $60 \%$ of LHVs. Low salary and inadequate allowances lead to staff dissatisfaction, attrition, absenteeism, and poor quality of care (Gow et al. 2012). Previous studies conducted in Faisalabad and Karachi have also found that majority of providers do not think that they are paid according to their skills and qualifications or that the facilities and benefits they receive are adequate. It was also found that pay and benefits are often at the top of the list of reasons for dissatisfied health professionals (Khuwaja et al 2004 and Bano et al 2005)

Both the quantitative and qualitative data clearly show that providers were attracted to the healthcare profession because of the altruistic nature of work, an intrinsic desire to serve their community and to benefit others. In general providers are satisfied with their jobmainly due to a feeling of inner satisfaction that they associate with helping those in need and the respect offered to them by the community they serve.

Work related stress linked to a perception of excessive workload has also been highlighted by this study. This was specially mentioned by the specialists who relate it to the absence of support staff. As a result providers have to perform many activities in addition to their own job. A high patient load for providers often works to reduce the duration and quality of the patient-provider interaction. Additionally, work stress can lead to staff burnout; conceptualized as a form of emotional exhaustion. This in turn contributes to absenteeism, high staff turnover and reduced productivity (Pendukeni 2004). This is consistent with findings from other studies conducted in Pakistan. Khuwaja et al (2002) conducted a study in Karachi on doctors working in teaching hospitals and found that half of their respondents rated their stress levels as 'high' to 'very high' and reported that it led to poor performance at work and negatively affected the physical and mental health of doctors.

Another area that influences performance is promotion. While a career structure for health workers does exist, according to the majority of respondents, it is not being adhered to mainly due to political considerations and a poor mechanism to measure and evaluate performance. An important finding from this study is that $32 \%$ of all providers had never been promoted despite being in service for more than 16 
years. The majority of providers reported dissatisfaction with the current staff appraisal mechanism reporting that it lacked objectivity as it fails to capture staff performance and accomplishments.

While there is a career pathway available for medical officers and specialists, opportunities for the nongazetted staff are limited. Among respondents who said that they would consider leaving service, twothirds had not received a single promotion since they had joined service.

The results from this study clearly point out that while supervisory mechanisms exist and providers are being supported; there are no formal mechanisms to record appreciation, provide positive feedback, acknowledge or reward good performance. Evidence from outside Pakistan shows that non-financial rewards such as praise and recognition can play a significant role in improving staff performance (Otaala and Mahlalela 2004).

The literature shows that training can improve both skills and motivation levels by enhancing the capacity of staff to do their job well (Mutale et al. 2013; Agyepong et al. 2004, Willis-Shattuck et al. 2008; Martineau and Martinez 1996). Of the providers interviewed, $18 \%$ had not received any training at all since they joined the service. This study has pointed to the need for increased investment in long-term skills development training along with refresher trainings. Training can also help in task sharing and task shifting to fill in staff shortages by increasing the skills and competencies of existing staff who can then take on additional responsibilities. A human resource development strategy is currently not available within the health sector in Pakistan. The province of Punjab had developed a strategy entitled "Training 2000 Program" that identified the types of training for various cadres; however, it was never fully implemented.

The provinces and districts in Pakistan are not homogenous and this has been captured by the variation in results across regions. For instance, FATA and the hilly and mountainous GB region that recently received provincial status have remained backward in terms of development for a long time. For this reason, the results from these regions standout as compared to other regions. Providers in FATA were more concerned with safety and security issues while political interference was reported across the board in all regions. They also reported a higher degree of dissatisfaction with the current performance appraisal systemand not receiving support from their supervisors. It is hoped that the administrative reforms introduced in the region will improve the situation. Similarly, though one province, North and South Punjab also have differences that have been highlighted in this study. For instance there is greater salary and promotion dissatisfaction, safety concerns and higher proportion of facilities lacking basic equipment and supplies in Southern Punjab as compared to the north. A higher proportion of providers in South Punjab were considering shifting to the private sector.

This study also highlightsissues specifically confronting female healthcare providers that include societal restrictions on their mobility, security and safety, issues at work, travel to place of work, harassment and perceived discrimination in promotions.

A positive finding that this study has highlighted is the congruence between the views of the providers and those of program managers regarding the problems and issues faced by the providers at their place of work. This shows that managers are to a large extent cognizant of the problems faced by their staff. These 
problems include issues related to non-availability of infrastructure such as boundary walls, lack of residences for staff, inadequate allowances for those working in rural areas and lack of essential equipment and supplies.

This study clearly highlights the issues confronting healthcare providers working in the public health system. Providers are dissatisfied with their existing salary and benefits, prospects for growth and promotion, and availability of equipment, supplies and medicines at their facilities. Specialists are of the view that the work given to them is not relevant to their qualifications and are also stressed and overworked. In order to expand coverage of healthcare, the health departments need to take steps to address these grievances. However, it is interesting to note that despite not being satisfied with their current salary and promotion status, providers are generally satisfied with their job and two-thirds would not consider leaving even if given an opportunity. Additionally, self actualization levels for providers were also found to be high.

We acknowledge that a major limitation of this study is that it does not capture the perception of those providers who have already left government service. The study instead focuses on the perceptions of providers who remain within the system, who may have higher levels of motivation than those who have left.

\section{2: Recommendations}

These recommendations to enhance staff retention and improve health worker motivation are primarily directed at policymakers including the elected representatives who are in a position to influence implementation, and key officials of the Health Sector Reform Units in the provinces who can incorporate these into the overall health sector reform policies and strategies that are currently being developed.

Health sector reforms must take into consideration steps that can enhance providers' motivation through a re-definition of the overall mission and goal of the health system, introducing new communications processes, measuring and rewarding individual performance, and putting into place a human resource management system (WHO 1989). Based on the findings of this study we are putting forward a set of specific recommendations.

The recommendations have been developed in consultation with provincial managers who were invited to Islamabad at a meeting on March 14, 2013, where the preliminary results of the study were shared.

- Ensuring Implementation of a Human Resource for Health Management System: All provinces must ensure implementation of a "Human Resources for Health Management System" that includes the following components:

\section{$0 \quad$ Training and development}

A staff training and career development strategy must be established to include routine new and refresher trainings as part of a continuing education system. The training must include updates in clinical and administrative management working with communities inter-personal communications and leadership skills. Training strategies could include on the job trainings, meetings, seminars, elearning and distance learning schemes. As part of pre-service training, medical curricula in 
community medicine must focus on problems faced by rural communities, and students should spend time working in the community as a part of their practical training and internship. These trainings will help providers to be better equipped in dealing with issues peculiar to rural communities. The management's commitment to training and developing the health workforce capacity along with improving service delivery also works to increases motivation in that it sends a signal to the workforce that they are valued by the system. The system must also include clear staff job descriptions describing individual roles and responsibilities that should be handed over to the providers upon assuming a new post, thereby, increasing clarity and ownership.

\section{Filling of vacant posts}

There should be a functioning DHIS that can be used to dynamically identify areas of staff vacancies and these can then be met either though redistribution of existing staff from urban to rural areas, or hiring of new staff. The vacant posts for all cadres and especially for WMOs and specialists, as identified thought the PC-1 of the department, must be filled through holding of regular public service commission. Wherever possible, providers should be recruited from the areas in which they are to serve. Additionally, the government should consider an alternative strategy of developing skills of lower cadre staff and through task sharing fill in the gaps of specialized care e.g. medical officers in basic anaesthesia and LHVs in assisted vaginal delivery.

\section{- Strict adherence to organizational policies on recruitment, transfer, and promotion:}

All provincial health departments must adhere to the existing staff recruitment, promotion, and transfer policies. Holding of timely Departmental Promotional Committees (DPC) is important for this process. At the same time, certain administrative reforms are also necessary - these include revision of the existing performance evaluation system and introduction of new forms and examination system that can objectively measure staff performance ensuring adherence to the requirements of the existing career structure. Introducing examination system to "grade" providers as practiced in the armed forces and performance indicators along which evaluations can be conducted need also be introduced. Adherence to organizational policies will also minimize political interference as suggested by the study respondents.

- Improving the Physical Work Environment and Ensuring the Availability of Equipment, Medicine, and Supplies:

All provinces must undertake a comprehensive facility infrastructure assessment; draw up a list of infrastructure repair, refurbishment and upgradation requirements and also carry out new construction such as of boundary walls and staff residences. Inventory of essential supplies and equipment that is needed for providing $\mathrm{MNCH}$ services should also be analysed for shortages. It should be ensured that there is a functioning system in place for availability of supplies and medicines. If all facilities are equipped to meet their mandate, then the burden on higher level facilities is reduced, and the quality of care delivered increases at all facility levels. 


\section{- Putting in Place a National Private Practice Regulation Policy}

A national private practice regulation policy can contribute to improving provider performance as it will help in ensuring that providers are able to rationally devote time to their official duties, both within and after office hours and to their private practice. As tried out in the armed forces, private practice may be restricted after office hours to the confines of the facility where staff is posted and its timings strictly regulated. Alternatively, increasing the non-practicing allowance for providers who do not have a private practice can also be a workable strategy.

\section{- Incentives for Attracting and Retaining Staff}

A comprehensive rural services package needs to be developed that clearly incentivizes and makes working in the rural areas more attractive, especially for female providers. This should include monetary and non-monetary rewards, including a salary package that is competitive to the market.Provincial managers have suggested dividing the districts into zones and based on hardship level such as non-availability of schools, security situation, and accessible roads; the providers in these zones should be offered higher financial incentives.The package should include increasing the existing allowances to compensate for the working conditions in the rural regions of the country and a travelling allowance especially for those providers who have not been provided residence within the facility premises need to be revised to cover inflation. It has been seen that non-monetary rewards influence motivation more substantially such as recognition and rewarding good performance. Some non-monetary incentives that can be introduced includeletters, certificates or shields of appreciation awarded to staff who meet pre-developed indicators, and consideration of providers with outstanding performance for civil awards such as pride of performance awards.

Posting in rural areas should be on tenure basis and must be made mandatory by the Pakistan Medical and Dental Council (PMDC) as a requirement for registration. To increase access to specialized care in rural areas, the College of Physicians and Surgeons of Pakistan should make serving in these areas a requirement for obtaining post graduate fellowship qualifications.

To increase the availability of female providers especially WMOs and female specialists in rural areas, a specific tenure system should be introduced and postings should be made on a rotation basis. Female paramedical staff should, wherever possible be from the same area of their positing and residences for female providers must be provided to ensure their safety and security as well as enable them to be available to cater to emergency cases during late hours. 


\section{BIBLIOGRAPHY}

1. Agyepong, I.A., P. Anafi, E. Asiamah, E.K. Ansah, D.A. Ashon, and C. Narh-Dometey (2004). Health Worker (Internal Customer) Satisfaction and Motivation in the Public Sector in Ghana. Int $J$ Health Plann Manage. 19 (4):319-36.

2. Awases, M., A. Gbary, J. Nyori, R. Chatora (2004). Migration of Health Professionals in Six Countries: $A$ Synthesis Report. Brazzaville: World Health Organization Regional Office for Africa.

3. Bano S, Aslam SK, Zafar S. 2005. Problems of Female Doctors Working in Hospitals. Journal of Agriculture and Social Sciences 1(4).

4. Benson, S. and S. Dundis. 2003. "Understanding and Motivating Healthcare Employees: Integrating Maslow's Hierarchy of Needs, Training, and Technology." J Nurs Manage 11: 315-320.

5. Bowling, N. A., Hendricks, E. A., \& Wagner, S. H. 2008. Positive and negative affectivity and facet satisfaction: A meta-analysis. Journal of Business and Psychology, 23, 115-125.

6. Buckley, M. R., Carraher, S. M.,\&Cote, J. A. (1992). Measurement issues concerning the use of inventories of job-satisfaction. Educational and Psychological Measurement, 52, 529-543.

7. Callen M, Gulzar S, Hasanain A, Yasir Khan Y. 2013. The Political Economy of Public Employee Absence: Experimental Evidence from Pakistan. Dial Development Conference 2013. Accessed August 28, 2013. http://dial2013.dauphine.fr/fileadmin/mediatheque/dial2013/documents/Papers/123 US Callen Gulz ar Hasanain Khan.pdf

8. Cooper-Hakim, A., \& Viswesvaran, C. 2005. The construct of work commitment: Testing an integrative framework. Psychological Bulletin, 131, 241-259.

9. DeMeuse, K. P. (1985).Acompendium of frequently used measures in industrial-organizational psychology. The Industrial-Organizational Psychologist, 23, 53-59.

10. Dieleman, M. and J.W. Harnmeijer. 2006. Improving Health Worker Performance: In Search of Promising Practices. The Netherlands: Royal Tropical Institute.

11. Dieleman, M., J. Toonen, H. Toure, and T. Martineau. 2006. "The Match between Motivation and Performance Management of Health Sector Workers in Mali." Hum Resour Health 4:2.

12. Dieleman, M., P. Cuong, A. Le, and T. Martineau. 2003. “Identifying Factors for Job Motivation of Rural Health Workers in North Viet Nam." Hum Resour Health1:1.

13. Dolea, C., L. Stormont, and J.M. Braichet. 2010. Evaluated strategies to increase attraction and retention of health workers in remote and rural areas. World Health Organization bulletin 88: 379-385.

14. Dubois, C.A. and D. Singh. 2009. "From Staff-mix to Skill-mix and Beyond: Towards a Systemic Approach to Health Workforce Management." Hum Resour Health7:87.

15. Farooq, U., A. Ghaffar, I.A. Narru, D. Khan, and R. Irshad. 2004. “Doctors' Perception about Staying in or Leaving Rural Health Facilities in District Abbottabad." J Ayub Med Coll Abbottabad 16(2): 64-9.

16. Fikree, F., A.M. Mir, and I. Haq. 2006. "She May Reach a Facility but Will Still Die! An Analysis of Quality of Public Sector Maternal Health Services, District Multan, Pakistan." J Pak Med Assoc 56(4):156-63.

17. Fort, A., and L. Voltero. 2004. "Factors Affecting the Performance of Maternal Healthcare Providers in Armenia." Hum Resour Health 2:8. 
18. Franco, L.M., S. Bennet, R. Kanfer, and P. Stubblebine. 2000. Health Worker Motivation in Jordan and Georgia: A Synthesis of Results. Major Applied Research 5, Technical Paper 3. Bethesda, MD: Partnerships for Health Reform Project, Abt Associates Inc.

19. Franco, L.M., S. Bennett, R. Kanfer. 2002. "Health Sector Reform and Public Sector Health Worker Motivation: A Conceptual Framework." Soc Sci Med 54(8): 1255-66.

20. Gopalan, S.S., S. Mohanty, and A. Das. 2012. “Assessing Community Health Workers' Performance Motivation: A Mixed-methods Approach on India's Accredited Social Health Activists (ASHA) Programme." BMG Open 2(5).

21. Government of The Punjab. 2011. Chief Minister's Health Initiative for Attainment and Realization of MDGs: Providing 24/7 EmONC Services at Selected Health Facilities. CHARM Annual Report 2011, National Program for Family Planning and Primary Healthcare. Lahore: Government of the Punjab.

22. Gow J., G. George, S. Mwamba, L. Ingombe, and G. Mutinta. 2012. "Health Worker Satisfaction and Motivation: An Empirical Study of Incomes, Allowances, and Working Conditions in Zambia." International Journal of Business and Management 7(10):37-48.

23. Haq, Z. and A. Hafeez. 2009. "Knowledge and Communication Needs Assessment of Community Health Workers in a Developing Country: A Qualitative Study." Hum Resour Health7:59.

24. Haq, Z., Z. Iqbal, and A. Rahman. 2008. "Job Stress among Community Health Workers: A Multi-method Study from Pakistan." Int J Ment Health Syst2(1): 15.

25. Henderson, L.N. and J. Tulloch. 2008. "Incentives for Retaining and Motivating Health Workers in Pacific and Asian countries." Hum Resour Health6:18.

26. Herzberg, F., B. Mausner, and B.B. Snyderman. 1959. The Motivation to Work. New York: John Wiley.

27. HLSP. 2012. Roadmap for Health Systems Strengthening in Sindh Province to support USAID/Pakistan's RMNCH Programs in Pakistan. London: HLSP.

28. Hongoro, C., and C. Normand. 2006. Health Workers: Building and Motivating the Workforce, Disease Control Priorities in Developing Countries. In: Jamison, D.T., J.G. Breman, A.R. Measham (Eds.). 2006. Disease Control Priorities in Developing Countries. Washington (DC): World Bank.

29. Hornby, P. and E. Sidney. 1988. Motivation and Health Service Performance. WHO/EDUC/88-196. Geneva: World Health Organization.

30. Huitt, W. 2007. "Maslow's Hierarchy of Needs." Accessed May 25, 2013. http://www.edpsycinteractive.org/topics/regsys/maslow.html.

31. Isaac, R.G., W.J. Zerbe, and D.C. Pitt. 2001. "Leadership and Motivation: The Effective Application of Expectancy Theory." Journal of Managerial Issues13:2.

32. Khuwaja AK, Qureshi R, Andrades M, Fatmi Z, Khuwaja NK. 2004. Comparison of Job Satisfaction and Stress among Male and Female Doctors in Teaching Hospitals of Karachi. J Ayub Med Coll Abbottabad16(1):23-7.

33. Lohela T, Campbell OMR, Gabrysch S. 2012. Distance to care, facility delivery and early neonatal motality in Malawi and Zambia. PLoS ONE 7 (12).

34. Leonard, K. L. and Masatu, M. C. 2010. Professionalism and the know-do gap: exploring intrinsic motivation among health workers in Tanzania. Health Econ., 19: 1461-1477. doi: 10.1002/hec.1564

35. Maddox, R.N. 1981. "Two-factor Theory and Consumer Satisfaction: Replication and Extension." Journal of Consumer Research 8:1. 
36. Mahmood, A, M.J. Arshad, and S. Maqsood. 2012. Situation analysis of health facilities with special reference to family planning services in Pakistan. Islamabad: Population Council.

37. Maji, D., Y. Hutin, R. Ramakrishnan, S. Hossain, S. De. 2010. "Strategies to Improve the Performance of Female Health Workers in West Bengal: A Cross-sectional Survey." Natl Med J India 23(3): 137-42.

38. Malik, A.A., S.S. Yamamoto, A. Souares, Z. Malik, R. Sauerborn. 2010. "Motivational Determinants among Physicians in Lahore, Pakistan." BMC Health Serv Res 10:201.

39. Martineau, T. and J. Martinez. 1996. Human Resources and Health Sector Reforms: A Discussion Paper. In: Martinez, J. and T. Martineau (Eds.). Workshop on Human Resources and Health Sector Reforms: Research and Development Priorities in Developing Countries. Liverpool: Liverpool School of Tropical Medicine.

40. Martinez, J., M. Pearson, R. England, M. Donoghue, H. Lucus, M.S. Khan, B. Haq, M. Hayat, Moinuddin, H. Qureshi, and M. Jogezai. 2010. Third Party Evaluation of the PPHI in Pakistan: Findings, Conclusions, and Recommendations. Islamabad: Technical Resource Facility.

41. Maslow, A. 1954. Motivation and Personality. New York: Harper.

42. Maslow, A.H. 1943. "A Theory of Human Motivation." Psychological Review 50,370-396.

43. Mathauer I., and I. Imhoff. 2006. "Health Worker Motivation in Africa: The Role of Non-financial Incentives and Human Resources Management Tools." Hum Resour Health 4:24.

44. Mbindyo, P.M., D. Blaauw, L. Gilson, and M. English. 2009. "Developing a Tool to Measure Health Worker Motivation in District Hospitals in Kenya." Hum Resour Health7:40.

45. McMahon, R., E. Barton, F. Ross, and World Health Organization. 1992. On Being In Charge: A Guide to Management in Primary Health Care. Geneva: World Health Organization.

46. Mir, A.M., and Gull S. 2012. "Countdown to 2015: A Case Study of Maternal and Child Health Service Delivery Challenges in Five Districts of Punjab." J Pak Med Assoc 62: 1308.

47. Mir, M.A. and G. Rashida. 2007. Challenging the Gender Paradigm in Rural Pakistan: A Case Study of Empowered Lady Health Workers. In: Reichenbach, L. 2007. Exploring the Gender Dimensions of the Global Health Workforce. Boston: Global Equity Initiative and Harvard University Press.

48. Mumtaz, S. Salway, M. Waseem, and N. Umer. 2003. "Gender-Based Barriers to Primary Healthcare Provision in Pakistan: The Experience of Female Providers." Health Policy Plan18(3): 261-9.

49. Mumtaz, Z. and S. Salway. 2005. "I Never Go Anywhere: Extricating the Links between Women's Mobility and Uptake of Reproductive Health Services in Pakistan." Soc Sci Med 60(8):1751-65.

50. Mutale, W., H. Ayles, V. Bond, M.T. Mwanamwenge, and D. Balabanova. 2013. "Measuring Health Workers' Motivation in Rural Health Facilities: Baseline Results from Three Study Districts in Zambia." Hum Resour Health 11(1): 8.

51. Otaala, B. and P. Mahlalela. 2004. Proceedings of the workshop on enhancement of leadership in higher education. September 27th-29th. Windhoek: University of Namibia.

52. Pendukeni, M. 2004. Thesis on "Impact of HIV/AIDS on the Health Workers and Provision of Care in Namibia." Diss. University of Cape Town.

53. Pakistan Initiative for Mothers and Newborns (PAIMAN). 2005. Health Facility Assessment. Pakistan Iniiatives for Mothers and Newborns. Accessed August 28, 2013. http://paiman.jsi.com/Resources/Docs/health-facility-assessment-paiman-original-districts.pdf 
54. Rahman, S.M., N.A. Ali, L. Jennings, M.H. Seraji, I. Mannan, R. Shah, A.B. Al-Mahmud, S. Bari, D. Hossain, M.K. Das, A.H. Baqui, S. El Arifeen, and P.J. Winch. 2010. "Factors Affecting Recruitment and Retention of Community Health Workers in a Newborn Care Intervention in Bangladesh." Hum Resour Health8:12.

55. Rector, P. and B.H. Kleiner. 2002. "Creating Productivity in Public Institutions." Management Research News 25(3): $43-50$.

56. Rehman S (2012). A Study of Public Sector Organisations with Respect to Recruitment, Job Satisfaction and Retention. Global Business and Management Research: An International Journal 4 (1) pp. 76-89.

57. Reichenbach, L. 2007. The Overlooked Dimension: Gender and the Global Health Workforce. In: Reichenbach, L. 2007. Exploring the Gender Dimensions of the Global Health Workforce. Boston: Global Equity Initiative and Harvard University Press.

58. Reid, S. 2004. Monitoring the effect of the new rural allowance for health professionals. Durban: Health Systems Trust.

59. Sathar, Z.A., A Jain, S. Ramarao, M. ul Haque, J. Kim. 2005. "Introducing Client-centred Reproductive Health Services in a Pakistani Setting." Stud Fam Plann 36(3) 221-34.

60. Seims, L.R., J.C. Alegre, L. Murei, J. Bragar, N. Thatte, P. Kibunga, and S. Cheburet. 2012. "Strengthening Management and Leadership Practices to Increase Health Service Delivery in Kenya: An Evidence-based Approach."Hum Resour Health10(1): 25.

61. Shaikh BT, Rabbani F, Safi N, Dawar Z. 2010. Contracting of primary healthcare services in Pakistan: Is up-scaling a pragmatic thinking? J Pak Med Assoc 60 (5).

62. Smith, P.C., L.M. Kendall, and C.L. Hulin. 1969. The Measurement of Satisfaction in Work and Retirement. Chicago: Rand McNally.

63. Ssengooba, F., S.A. Rahman, C. Hongoro, E. Rutebemberwa, A. Mustafa, T. Kielmann, and B. McPake. 2007. "Health Sector Reforms and Human Resources for Health in Uganda and Bangladesh: Mechanisms of Effect." Hum Resour Health5:3.

64. Stanton JM, Sinar EF, Balzer WK, Julian AL, Thoresen P, Aziz S, Fisher GG, Smith PC. Development of a Compact Measure of Job Satisfaction: The Abridged Job Descriptive Index. Educational And Psychological Measurement, 2001, 61(6): 1104-1122.

65. Syptak, J.M., D.W. Marsland, and D. Ulmer. 1999. “Job Satisfaction: Putting Theory into Practice.” Fam Pract Manag 6(9):26-30.

66. Technical Resource Facility. 2012. Health Facility Assessment - Pakistan National Report. Islamabad: Technical Resource Facility.

67. Tura G, Fantahun M, Worku A. 2013. The effect of health facility delivery on neonatal mortality: systematic review and meta-analysis. BMC Pregnancy and Childbirth 13(18).

68. Tynan et al. 2013. Sociocultural and individual determinants for motivation of sexual and reproductive health workers in Papua New Guinea and their implications for male circumcision as an HIV prevention strategy. Human Resources for Health 11 (7).

69. University of Aberdeen. 2007. Toolkit I: A guide and tools for maternal mortality programme assessment. MODULE 4, Tool 5: Health Worker Incentives Survey (HWIS). Aberdeen: University of Aberdeen.

70. Vroom, V.H. 1964. Work and Motivation. New York: Wiley. 
71. Wibulpolprasert, S. and P. Pengpaiboon. 2003. "Integrated Strategies to Tackle the Inequitable Distribution of Doctors in Thailand: Four Decades of Experience." Hum Resour Health 1:12.

72. Willis-Shattuck, M., P. Bidwell, S. Thomas, L. Wyness, D. Blaauw, and P. Ditlopo. 2008. “Motivation and Retention of Health Workers in Developing Countries: A Systematic Review." BMC Health Serv Res 8:247.

73. Witter, S., Fretheim, A., Kessy, F., Lindahl, A.K. (2012) Paying for performance to improve the delivery of health interventions in low and middle-income countries. Cochrane Database of Systematic Reviews, Issue 2.

74. Witter, S., Zulfiquar, T., Javeed, S., Khan, A., Bar, A. (2011) Paying health workers for performance: a district-based case study in Pakistan. Human Resources for Health journal 9(23).

75. World Health Organisation. 2000. The World Health Report 2000 - Health Systems: Improving Governance. Geneva: World Health Organisation.

76. World Health Organisation. 2006. The World Health Report 2006: Working Together for Health. Geneva: World Health Organization.

77. Yami, A., L. Hamza, A. Hassen, C. Jira, and M. Sudhakar. 2011. "Job Satisfaction and Its Determinants among Health Workers in Jimma University Specialized Hospital, Southwest Ethiopia." Ethiop J Health Sci 21:19-27.

78. Zedeck, S. (1987, October). Satisfaction in union members and their spouses. Paper presented at The Job Satisfaction: Advances in Research and Practice Conference, Bowling Green, Ohio.

79. Zurn P., C. Dolea, and B. Stilwell. 2005. Nurse Retention and Recruitment: Developing a Motivated Workforce. Geneva: World Health Organization.

80. Assessment ofManagement Information System [MIS] of National Program for Family Planning and Primary Health Care(FALAH2012) http://www.popcouncil.org/pdfs/2012RH AssessmentMIS-LHWProg.pdf 


\section{ANNEXURES}

Annex 1 (a): List of Sampled Districts for the Qualitative Component

\begin{tabular}{ll}
\multirow{2}{*}{ Region } & District(s) \\
\hline Sindhab & Multan \\
\cline { 2 - 2 } & Khanewal \\
\hline KP & Shikarpur \\
\hline AJK & Mardan \\
\hline Gilgit-Baltistan & Muzaffarabad \\
\hline Balochistan & Gilgit \\
\hline \multirow{2}{*}{ FATA } & Skardu \\
\hline
\end{tabular}




\section{Annex 1 (b): District ranking on the basis of socio-economic index and skilled birth attendance}

\section{Punjab-Income Poverty at District Level}

\begin{tabular}{|c|c|c|}
\hline Sr. & District & Rank \\
\hline 1 & Rawalpindi & 1 \\
\hline 2 & Lahore & 2 \\
\hline 3 & Jhelum & 3 \\
\hline 4 & Gujrat & 4 \\
\hline 5 & Sialkot & 5 \\
\hline 6 & Attock & 6 \\
\hline 7 & Mandi Bahauddin & 7 \\
\hline 8 & Chakwal & 8 \\
\hline 9 & Bhakkar & 9 \\
\hline 10 & Toba Tek Singh & 10 \\
\hline 11 & Gujranwala & 11 \\
\hline 12 & Narowal & 12 \\
\hline 13 & Faisalabad & 13 \\
\hline 14 & Sahiwal & 14 \\
\hline 15 & Hafizabad & 15 \\
\hline 16 & Khushab & 16 \\
\hline 17 & Sargodha & 17 \\
\hline 18 & Sheikhupura & 18 \\
\hline 19 & Kasur & 19 \\
\hline 20 & Okara & 20 \\
\hline 21 & Vehari & 21 \\
\hline 22 & Jhang & 22 \\
\hline 23 & Bahawalnagar & 23 \\
\hline 24 & Mianwali & 24 \\
\hline 25 & Pakpattan & 25 \\
\hline 26 & Multan & 26 \\
\hline 27 & Khanewal & 27 \\
\hline 28 & Bahawalpur & 28 \\
\hline 29 & Leiah & 29 \\
\hline 30 & Rahim Yar Khan & 30 \\
\hline 31 & Lodhran & 31 \\
\hline 32 & Dera Ghazi Khan & 32 \\
\hline 33 & Rajanpur & 33 \\
\hline 34 & Muzaffargarh & 34 \\
\hline
\end{tabular}

Source: The data is from a paper by Mr. Haroon Jamal, titled "Income Poverty at District Level: An application of small area estimation technique" publised by the SPDC in 2007 
Punjab-Percentage of SBA* who assisted with delivery-PSLM 2010-11

\begin{tabular}{|c|c|c|c|}
\hline Sr. & District & Percentage of SBA* & Rank \\
\hline 1 & Islamabad & 73 & 1 \\
\hline 2 & Lahore & 67 & 2 \\
\hline 3 & Gujrat & 64 & 3 \\
\hline 4 & Rawalpind & 61 & 4 \\
\hline 5 & Sheikupur & 61 & 4 \\
\hline 6 & Chakwal & 60 & 5 \\
\hline 7 & Sialkot & 57 & 6 \\
\hline 8 & Sargodha & 54 & 7 \\
\hline 9 & TT Singh & 53 & 8 \\
\hline 10 & Gujranwal & 52 & 9 \\
\hline 11 & Faisalaba & 49 & 10 \\
\hline 12 & Nankana S & 49 & 10 \\
\hline 13 & Bahawal N & 48 & 11 \\
\hline 14 & Khushab & 46 & 12 \\
\hline 15 & Jehlum & 45 & 13 \\
\hline 16 & Hafizabad & 44 & 14 \\
\hline 17 & Multan & 44 & 14 \\
\hline 18 & Jhang & 43 & 15 \\
\hline 19 & Narowal & 42 & 16 \\
\hline 20 & Sahiwal & 41 & 17 \\
\hline 21 & Vehari & 41 & 17 \\
\hline 22 & Mianwali & 41 & 17 \\
\hline 23 & Mandi Bah & 39 & 18 \\
\hline 24 & Okara & 35 & 19 \\
\hline 25 & Pakpattan & 35 & 19 \\
\hline 26 & Bahawalpu & 33 & 20 \\
\hline 27 & Chiniot & 32 & 21 \\
\hline 28 & Kasur & 32 & 21 \\
\hline 29 & Attock & 32 & 21 \\
\hline 30 & Khanewal & 31 & 22 \\
\hline 31 & Layyah & 31 & 22 \\
\hline 32 & Rahimyar & 28 & 23 \\
\hline 33 & Bhakhar & 26 & 24 \\
\hline 34 & DG Khan & 23 & 25 \\
\hline 35 & Lodhran & 20 & 26 \\
\hline 36 & Muzaffar & 19 & 27 \\
\hline 37 & Rajanpur & 16 & 28 \\
\hline
\end{tabular}

*SBA, Skilled Birth Attendant, it includes Doctor, Nurse \& Midwife

Source: PSLM 2010-11 by FBS 
SINDH -Income Poverty at District Level

\begin{tabular}{|c|c|c|}
\hline Sr. & District & Rank \\
\hline 1 & Karachi & 1 \\
\hline 2 & Hyderabad & 2 \\
\hline 3 & Sanghar & 3 \\
\hline 4 & Sukkur & 4 \\
\hline 5 & Khairpur & 5 \\
\hline 6 & Mirpur Khas & 6 \\
\hline 7 & Tharparkar & 7 \\
\hline 8 & Nawabshah & 8 \\
\hline 9 & Naushahro Feroze & 9 \\
\hline 10 & Jacobabad & 10 \\
\hline 11 & Badin & 11 \\
\hline 12 & Dadu & 12 \\
\hline 13 & Ghotki & 13 \\
\hline 14 & Larkana & 14 \\
\hline 15 & Thatta & 15 \\
\hline 16 & Shikarpur & 16 \\
\hline
\end{tabular}

Source: The data is from a paper by Mr. Haroon Jamal, titled "Income Poverty at District Level: An application of small area estimation technique" publised by the SPDC in 2007 
SINDH-Percentage of SBA* who assisted with delivery-PSLM 2010-11

\begin{tabular}{|c|c|c|c|}
\hline Sr. & District & Percentage of SBA* & Rank \\
\hline 1 & Karachi & 88 & 1 \\
\hline 2 & Hyderabad & 77 & 2 \\
\hline 3 & Mir Pur K & 55 & 3 \\
\hline 4 & Nowshero & 50 & 4 \\
\hline 5 & Maitari & 50 & 4 \\
\hline 6 & Sukkur & 48 & 5 \\
\hline 7 & Umer Kot & 43 & 6 \\
\hline 8 & Nawabshah & 42 & 7 \\
\hline 9 & Badin & 38 & 8 \\
\hline 10 & Tando All & 38 & 8 \\
\hline 11 & Sanghar & 38 & 8 \\
\hline 12 & Jamshoro & 37 & 9 \\
\hline 13 & Kashmore & 35 & 10 \\
\hline 14 & Tando Mud & 33 & 11 \\
\hline 15 & Shahdadko & 32 & 12 \\
\hline 16 & Larkana & 32 & 12 \\
\hline 17 & Ghotki & 31 & 13 \\
\hline 18 & Dadu & 31 & 13 \\
\hline 19 & Shikarpur & 29 & 14 \\
\hline 20 & Khairpur & 28 & 15 \\
\hline 21 & Thatta & 27 & 16 \\
\hline 22 & Jaccobaba & 18 & 17 \\
\hline 23 & Tharparka & 14 & 18 \\
\hline
\end{tabular}

*SBA, Skilled Birth Attendant, it includes Doctor, Nurse \& Midwife

Source: PSLM 2010-11 by FBS 


\section{KP - Income Poverty at District Level}

\begin{tabular}{|c|c|c|}
\hline Sr. & District & Rank \\
\hline 1 & Mansehra & 1 \\
\hline 2 & Abbottabad & 2 \\
\hline 3 & Haripur & 3 \\
\hline 4 & Swat & 4 \\
\hline 5 & Nowshera & 5 \\
\hline 6 & Kohat & 6 \\
\hline 7 & Batagram & 7 \\
\hline 8 & Bannu & 8 \\
\hline 9 & Lower Dir & 9 \\
\hline 10 & Dera Ismail Khan & 10 \\
\hline 11 & Tank & 11 \\
\hline 12 & Kohistan & 12 \\
\hline 13 & Peshawar & 13 \\
\hline 14 & Karak & 14 \\
\hline 15 & Malakand PA & 15 \\
\hline 16 & Swabi & 16 \\
\hline 17 & Charsadda & 17 \\
\hline 18 & Chitral & 18 \\
\hline 19 & Mardan & 19 \\
\hline 20 & Hangu & 20 \\
\hline 21 & Buner & 21 \\
\hline 22 & Lakki Marwat & 22 \\
\hline 23 & Shangla & 23 \\
\hline 24 & Upper Dir & 24 \\
\hline
\end{tabular}

Source: The data is from a paper by Mr. Haroon Jamal, titled "Income Poverty at District Level: An application of small area estimation technique" publised by the SPDC in 2007 
KP - Percentage of SBA* who assisted with delivery-PSLM 2010-11

\begin{tabular}{|c|c|c|c|}
\hline Sr. & District & Percentage of SBA* & Rank \\
\hline 1 & Peshawar & 58 & 1 \\
\hline 2 & Lower Dir & 51 & 2 \\
\hline 3 & Abbottaba & 49 & 3 \\
\hline 4 & Kohat & 46 & 4 \\
\hline 5 & Haripur & 46 & 4 \\
\hline 6 & Charsada & 44 & 5 \\
\hline 7 & Malakand & 44 & 5 \\
\hline 8 & Hangu & 41 & 6 \\
\hline 9 & Nowshera & 40 & 7 \\
\hline 10 & Swat & 39 & 8 \\
\hline 11 & Mardan & 36 & 9 \\
\hline 12 & Bannu & 36 & 9 \\
\hline 13 & Karak & 33 & 10 \\
\hline 14 & Swabi & 28 & 11 \\
\hline 15 & Batagram & 27 & 12 \\
\hline 16 & Lakki Mar & 27 & 12 \\
\hline 17 & Manshera & 23 & 13 \\
\hline 18 & DI Khan & 23 & 13 \\
\hline 19 & Upper Dir & 22 & 14 \\
\hline 20 & Bonair & 18 & 15 \\
\hline 21 & Chitral & 16 & 16 \\
\hline 22 & Tank & 16 & 16 \\
\hline 23 & Shangla & 12 & 17 \\
\hline 24 & Kohistan & 9 & 18 \\
\hline
\end{tabular}

*SBA, Skilled Birth Attendant, it includes Doctor, Nurse \& Midwife

Source: PSLM 2010-11 by FBS 


\section{Balochistan - Income Poverty at District Level}

\begin{tabular}{|c|c|c|}
\hline Sr. & District & Rank \\
\hline 1 & Quetta & 1 \\
\hline 2 & Ziarat & 2 \\
\hline 3 & Kalat & 3 \\
\hline 4 & Mastung & 4 \\
\hline 5 & Jaffarabad & 5 \\
\hline 6 & Bolan & 6 \\
\hline 7 & Gawadar & 7 \\
\hline 8 & Panjgur & 8 \\
\hline 9 & Khuzdar & 9 \\
\hline 10 & Loralai & 10 \\
\hline 11 & Barkhan & 11 \\
\hline 12 & Jhal Magsi & 12 \\
\hline 13 & Musakhel & 13 \\
\hline 14 & Kech & 14 \\
\hline 15 & Kharan & 15 \\
\hline 16 & Sibi & 16 \\
\hline 17 & Nasirabad & 17 \\
\hline 18 & Killa Abdullah & 18 \\
\hline 19 & Killa Saifullah & 19 \\
\hline 20 & Awaran & 20 \\
\hline 21 & Pishin & 21 \\
\hline 22 & Zhob & 22 \\
\hline 23 & Lasbela & 23 \\
\hline 24 & Chagai & 24 \\
\hline 25 & Dera Bugti & NA \\
\hline 26 & Kohlu & NA \\
\hline
\end{tabular}

Note: Two districts (Dera Bugti and Kohlu) were not enumerated (partly or fully) due to law and order situation in the province.

Source: The data is from a paper by Mr. Haroon Jamal, titled "Income Poverty at District Level: An application of small area estimation technique" publised by the SPDC in 2007 
Balochistan - Percentage of SBA* who assisted with delivery-PSLM 2010-11

\begin{tabular}{|c|c|c|c|}
\hline Sr. & District & Percentage of SBA* & Rank \\
\hline 1 & Quetta & 74 & 1 \\
\hline 2 & Sibbi & 49 & 2 \\
\hline 3 & Barkhan & 37 & 3 \\
\hline 4 & Gwadar & 36 & 4 \\
\hline 5 & Qillah Ab & 34 & 5 \\
\hline 6 & Jhal Mags & 30 & 6 \\
\hline 7 & Pashin & 29 & 7 \\
\hline 8 & Washuk & 28 & 8 \\
\hline 9 & Awaran & 24 & 9 \\
\hline 10 & Kohlu & 24 & 9 \\
\hline 11 & Jafarabad & 24 & 9 \\
\hline 12 & Nushki & 22 & 10 \\
\hline 13 & Mastung & 22 & 10 \\
\hline 14 & Ketch/Tur & 22 & 10 \\
\hline 15 & Panjgur & 22 & 10 \\
\hline 16 & Lasbilla & 21 & 11 \\
\hline 17 & Harnai & 21 & 11 \\
\hline 18 & Kalat & 19 & 12 \\
\hline 19 & Chagi & 18 & 13 \\
\hline 20 & Qillah Saif & 16 & 14 \\
\hline 21 & Lorali & 14 & 15 \\
\hline 22 & Nasirabad & 14 & 15 \\
\hline 23 & Ziarat & 12 & 16 \\
\hline 24 & Kharan & 11 & 17 \\
\hline 25 & Musakhel & 11 & 17 \\
\hline 26 & Khuzdar & 10 & 18 \\
\hline 27 & Bolan/Kac & 9 & 19 \\
\hline 28 & Zhob & 9 & 19 \\
\hline 29 & Sherani & 7 & 20 \\
\hline 30 & Dera Bugti & 4 & 21 \\
\hline
\end{tabular}

*SBA, Skilled Birth Attendant, it includes Doctor, Nurse \& Midwife

Source: PSLM 2010-11 by FBS 
Annex 2: Study Team

\begin{tabular}{|c|c|c|c|c|c|c|c|c|c|}
\hline S.No. & KP & S. Punjab & N. Punjab & Sindh & Balochistan & AJK & G\&B & FATA & PC Team \\
\hline 1 & $\begin{array}{l}\text { Falak } \\
\text { Shahid }\end{array}$ & Shazia Malik & Sadia Ashraf & Shabana Arif & Parveen Akhter & Faiza Sajid & Maria Ali & $\begin{array}{c}\text { Dr. Akhtiar } \\
\text { Ali }\end{array}$ & $\begin{array}{c}\text { Mumraiz } \\
\text { Khan }\end{array}$ \\
\hline 2 & Shumaila & $\begin{array}{l}\text { Mohsana } \\
\text { Kehkhashan }\end{array}$ & $\begin{array}{l}\text { Haroon } \\
\text { Mehmood }\end{array}$ & $\begin{array}{c}\text { Muhammad Ali } \\
\text { Raza Memon }\end{array}$ & Mazhar lqbal & Farah Deeba & Nazar Abbas & Nosheen & $\begin{array}{c}\text { Khan } \\
\text { Muhammad }\end{array}$ \\
\hline 3 & $\begin{array}{l}\text { Faisal } \\
\text { Sadiq }\end{array}$ & Asia Malik & $\begin{array}{c}\text { Zeeshan Ali } \\
\text { Khan }\end{array}$ & $\begin{array}{c}\text { Syed Inayat Ali } \\
\text { Shah }\end{array}$ & Muneera Sultana & $\begin{array}{l}\text { Waqar } \\
\text { Ahmed } \\
\text { Abbasi }\end{array}$ & Syed Touseef & $\begin{array}{c}\text { Fozia } \\
\text { Waheed }\end{array}$ & $\begin{array}{c}\text { Mansoor } \\
\text { Qaiser }\end{array}$ \\
\hline 4 & Wajid Ali & $\begin{array}{c}\text { Nazia } \\
\text { Mahmood }\end{array}$ & Mahreen Rabi & Afroz Channa & Maimoona & $\begin{array}{l}\text { Saqeeb } \\
\text { Ahmed }\end{array}$ & Sher Ali & $\begin{array}{c}\text { Noor } \\
\text { Muhammad }\end{array}$ & $\begin{array}{c}\text { Zeba } \\
\text { Tasneem }\end{array}$ \\
\hline 5 & $\begin{array}{c}\text { Syeda } \\
\text { Safia Bibi }\end{array}$ & $\begin{array}{l}\text { Abid Hussain } \\
\text { Naeem }\end{array}$ & Durriya Yousaf & $\begin{array}{c}\text { Altaf Ahmed } \\
\text { Gujar }\end{array}$ & Pervaiz Anwar & Istiaq Ahmed & $\begin{array}{l}\text { Muhammad } \\
\text { Naeem Ullah } \\
\text { Khan }\end{array}$ & Dr. Sartaj & $\begin{array}{l}\text { Lubna } \\
\text { Mehmood }\end{array}$ \\
\hline 6 & $\begin{array}{l}\text { Shabana } \\
\text { Tanoli }\end{array}$ & Asmat Rubab & $\begin{array}{l}\text { Haider Safder } \\
\text { Abbasi }\end{array}$ & Irum Shumaila & Fahmeda Anwar & $\begin{array}{c}\text { Syeda } \\
\text { Tasneem } \\
\text { Zohra }\end{array}$ & & Nazo Ibrahim & Bushra Bano \\
\hline 7 & $\begin{array}{l}\text { Yasmeen } \\
\text { Syed }\end{array}$ & Dr. Maaz & Asifa Ghani & Farzana Khan & Gull Zaman & $\begin{array}{c}\text { Muhammad } \\
\text { Naseem }\end{array}$ & & $\begin{array}{l}\text { Zubeda } \\
\text { Khanum }\end{array}$ & $\begin{array}{c}\text { Ashfa } \\
\text { Hashmi }\end{array}$ \\
\hline 8 & $\begin{array}{l}\text { Zahoor } \\
\text { Ahmed }\end{array}$ & $\begin{array}{l}\text { Syed Niaz } \\
\text { Hussain }\end{array}$ & Dr. Usman & Dr. Ali Jan Solangi & Dr. Norooz & $\begin{array}{c}\text { Shaheen } \\
\text { Kosar }\end{array}$ & & Kamal ud Din & $\begin{array}{l}\text { Shagufta } \\
\text { Parveen }\end{array}$ \\
\hline \multirow[t]{3}{*}{9} & $\begin{array}{c}\text { Sidra } \\
\text { Shakeel }\end{array}$ & & Sobia Noreen & Fiaz Ahmed & $\begin{array}{c}\text { Khan } \\
\text { Muhammad }\end{array}$ & Dr. Sakhi Jan & & & Usman Asif \\
\hline & & & & & & $\begin{array}{c}\text { Shaheen } \\
\text { Akhter }\end{array}$ & & & Waqas Abrar \\
\hline & & & & & & & & & Farzana Arif \\
\hline
\end{tabular}




\title{
Annex 3A: Institutional Review Board Approval
}

\section{(P) Population Council}

\author{
Institutional Review Board \\ Population Council \\ 1230 York Avenue \\ New York, NY 10065
}

\section{APPROVAL OF PROTOCOL}

DATE: $\quad$ August 2, 2012

TO: $\quad$ A. Mir, Principal Investigator

FROM: $\quad$ Nick Gontarz, IRB Administrator, on behalf of John Bongaarts, Chairman Institutional Review Board (IRB)

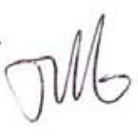

RE: $\quad$ Approval of Protocol 539 - Assessing Retention and Motivation of Public Health Care Providers (particularly Female Providers) in Rural Pakistan

The Institutional Review Board (IRB) on human research of the Population Council has approved the above request to involve humans as research subjects.
APPROVAL DATE OF PROTOCOL:
MAY 23, 2012

ADVERSE REACTIONS/COMPLICATIONS: All serious and/or unexpected side effects must be reported immediately by fax to the Population Council's SAE Desk (SAE Desk Fax No.: 212-3278673 ), which will notify the IRB of the Population Council.

MODIFICATIONS: All protocol changes involving subjects must have prior IRB approval.

If this project is to continue, it must be renewed as specified by the IRB. THE EXPIRATION DATE FOR THIS PROJECT IS MAY 23, 2013. This renewal application consists of a brief status report summarizing the results obtained during the past period and a short statement of the research plan for the coming year.

If you have any questions, please contact Nick Gontarz at telephone No. [212] 327-7112 or FAX No. [212] $327-7678$.

cc: IRB Records and Reports File for Protocol 539 


\section{Annex 3B: National Bioethical Committee (NBC) Pakistan Approval}

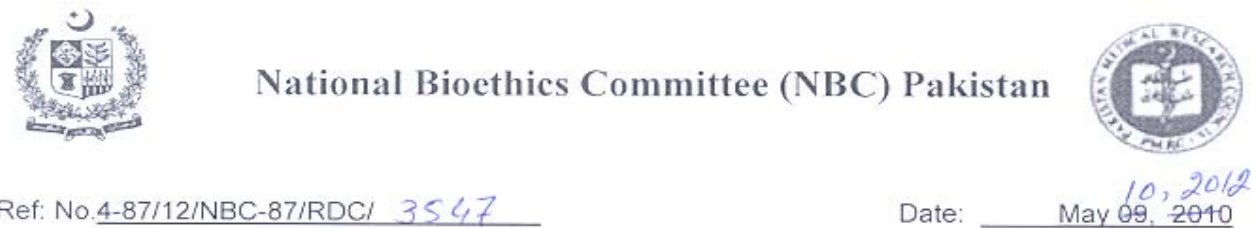

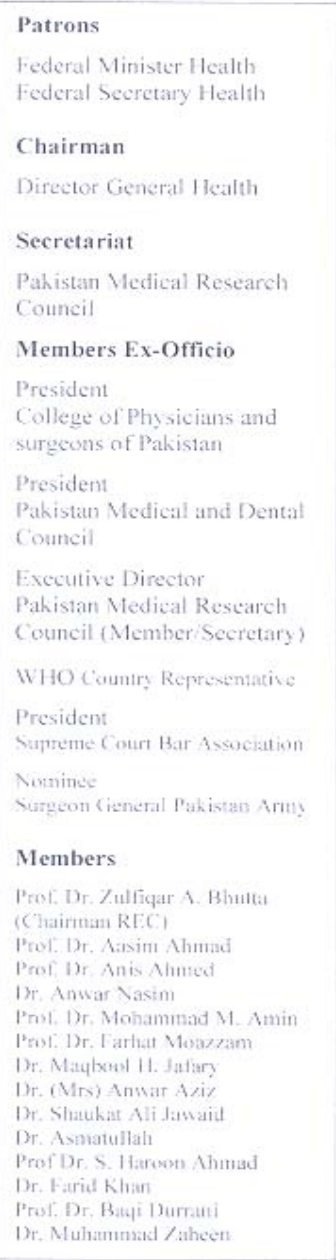

Dr. Sarah Hall

Program Manager

Research \& Advocacy Fund (RAF)

H. \# 9, Street 64

Sector F-8/4

Islamabad

Subject: Assessing retention and motivation of public health care providers (particularly female providers) in rural Pakistan (NBC-87)

Dear Dr Sarah,

I am pleased to inform you that the above mentioned project has been cleared by "Research Ethics Committee of National Bioethics Committee". However, despite the justification provided by you, the REC is still not satisfied with the inflated budget, especially which is earmarked for salaries and consultancies. A letter in this regard is also being written to the British Council to bring them on board and share with them the concerns of the NBC

Kindly keep the National Bioethics Committee Secretariat updated with the progress of the project and submit the formal final report on completion.

Yours sincerely

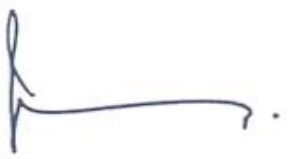

(Prof Dr. Zulfiqar A Bhutta)

Chairman

NBC-Research Ethics Committee

NBC Secretariat:

Pakistan Medical Research Council, Shahrah-e-Jamhuriat, Off Constitution Avenue, Sector G-5/2, Islamabad www pme org pk, e-mail pmrogisb consats net pk. Tet: 92-51-8207386, 9216793, 9205480, Fax 9216774, 9204559 
Annex 4: Types of facilities visited

\begin{tabular}{|c|c|c|c|c|c|c|c|}
\hline \multirow[b]{2}{*}{ Province } & \multirow[b]{2}{*}{ District } & \multicolumn{5}{|c|}{ Type of Facility } & \multirow[b]{2}{*}{ Total } \\
\hline & & DHQ & THQ & RHC & BHU & $\mathrm{MCH}$ & \\
\hline \multirow{4}{*}{ Punjab North } & Lahore & 1 & 2 & 3 & 10 & 15 & 31 \\
\hline & TT.Singh & 1 & 2 & 3 & 10 & 3 & 19 \\
\hline & Narowal & 1 & 1 & 4 & 11 & 4 & 21 \\
\hline & Hafizabad & 1 & 1 & 4 & 10 & 4 & 20 \\
\hline \multirow{4}{*}{ Punjab South } & Vehari & 1 & 2 & 4 & 10 & 7 & 24 \\
\hline & Layyah & 1 & 2 & 3 & 10 & 2 & 18 \\
\hline & Rajanpur & 1 & 2 & 3 & 10 & 2 & 18 \\
\hline & MuzaffarGharh & 1 & 2 & 3 & 10 & 3 & 19 \\
\hline \multirow{4}{*}{ Sindh } & Ghotki & 1 & 2 & 3 & 10 & 1 & 17 \\
\hline & Dadu & 1 & 2 & 3 & 15 & 1 & 22 \\
\hline & Hyderabad & 1 & 2 & 3 & 10 & 3 & 19 \\
\hline & Nawab Shah & 0 & 2 & 3 & 10 & 6 & 21 \\
\hline \multirow{4}{*}{ KP } & Swabi & 1 & 0 & 4 & 10 & 3 & 18 \\
\hline & Kohat & 2 & 0 & 6 & 10 & 2 & 20 \\
\hline & Chitral & 1 & 2 & 3 & 11 & 5 & 22 \\
\hline & Shangla & 1 & 2 & 2 & 10 & 0 & 15 \\
\hline \multirow{2}{*}{ FATA } & Khyber agency & 1 & 2 & 2 & 9 & 3 & 17 \\
\hline & Muhammad agency & 1 & 1 & 1 & 11 & 3 & 17 \\
\hline \multirow{3}{*}{ Gilgit-Baltistan } & Astore & 0 & 1 & 1 & 4 & 3 & 9 \\
\hline & Gilgit & 1 & 1 & 2 & 5 & 1 & 10 \\
\hline & Skardu & 1 & 2 & 3 & 8 & 4 & 18 \\
\hline \multirow{4}{*}{ Balochistan } & Gawadar & 1 & 0 & 3 & 11 & 4 & 19 \\
\hline & Kalat & 2 & 0 & 3 & 9 & 2 & 16 \\
\hline & Ketch/ Turbat & 1 & 0 & 3 & 10 & 2 & 16 \\
\hline & Noshki & 1 & 0 & 2 & 10 & 0 & 13 \\
\hline \multirow{5}{*}{ AJK } & Kotli & 1 & 2 & 3 & 10 & 4 & 20 \\
\hline & Bagh & 1 & 1 & 6 & 8 & 3 & 19 \\
\hline & Neelum & 1 & 1 & 1 & 10 & 4 & 17 \\
\hline & Bhimber & 1 & 0 & 3 & 10 & 4 & 18 \\
\hline & Total & 29 & 37 & 87 & 282 & 98 & 533 \\
\hline
\end{tabular}


Annex 5: Availability of Basic Em0C-Percentage of Unmet Need

\begin{tabular}{|c|c|c|c|c|c|c|c|}
\hline \multirow[b]{2}{*}{ Strata } & \multirow[b]{2}{*}{ District } & \multicolumn{6}{|c|}{ Basic EmOc } \\
\hline & & Population & Recommended & $\begin{array}{c}\text { Facilities } \\
\text { visited/existin } \\
\mathbf{g}\end{array}$ & Functional & Discrepancy & $\begin{array}{l}\text { Percentage of } \\
\text { unmet need }\end{array}$ \\
\hline \multirow{3}{*}{ Punjab North } & TT.Singh & $1,917,064$ & 15 & 6 & 2 & 13 & 87 \\
\hline & Narowal & $1,457,161$ & 12 & 6 & 0 & 12 & 100 \\
\hline & Hafizabad & $1,045,000$ & 8 & 4 & 1 & 7 & 88 \\
\hline \multirow{4}{*}{ Punjab South } & Vehari & $2,630,168$ & 21 & 11 & 0 & 21 & 100 \\
\hline & Layyah & $1,500,000$ & 12 & 3 & 1 & 11 & 92 \\
\hline & Rajanpur & $1,500,000$ & 12 & 6 & 0 & 12 & 100 \\
\hline & MuzaffarGharh & $3,586,160$ & 29 & 11 & 1 & 28 & 97 \\
\hline \multirow{4}{*}{ Sindh } & Ghotki & $1,380,450$ & 11 & 3 & 0 & 11 & 100 \\
\hline & Dadu & $1,426,598$ & 11 & 3 & 0 & 11 & 100 \\
\hline & Hyderabad & $1,500,000$ & 12 & 5 & 0 & 12 & 100 \\
\hline & Nawab Shah & $1,600,000$ & 13 & 8 & 4 & 9 & 69 \\
\hline \multirow{4}{*}{ Khyber Pakhtunkhwa } & Swabi & $1,600,000$ & 13 & 6 & 1 & 12 & 92 \\
\hline & Kohat & 748,000 & 6 & 5 & 2 & 4 & 67 \\
\hline & Shangla & 578,000 & 5 & 2 & 0 & 5 & 100 \\
\hline & Chitral & 424,000 & 3 & 3 & 1 & 2 & 71 \\
\hline \multirow{4}{*}{ Balochistan } & Kalat & 322,000 & 3 & 4 & 0 & 3 & 100 \\
\hline & Gawadar & 251,000 & 2 & 3 & 0 & 2 & 100 \\
\hline & Ketch/ Turbat & 558,000 & 4 & 6 & 0 & 4 & 100 \\
\hline & Nushki & 144,207 & 1 & 2 & 0 & 1 & 100 \\
\hline \multirow{4}{*}{ AJK } & Kotli & 802,333 & 6 & 4 & 1 & 5 & 84 \\
\hline & Bagh & 375,464 & 3 & 7 & 1 & 2 & 67 \\
\hline & Bhimber & 431,905 & 3 & 3 & 0 & 3 & 100 \\
\hline & Neelam & 188,000 & 2 & 1 & 0 & 2 & 100 \\
\hline \multirow{2}{*}{ FATA } & Khyber & 943,000 & 8 & 2 & 0 & 8 & 100 \\
\hline & Mohamand & 600,000 & 5 & 1 & 0 & 5 & 100 \\
\hline \multirow{3}{*}{ GB } & Astore & 100,000 & 1 & 1 & 0 & 1 & 100 \\
\hline & Gilgit & 243,634 & 2 & 2 & 0 & 2 & 100 \\
\hline & Skardu & 223,000 & 2 & 3 & 0 & 2 & 100 \\
\hline
\end{tabular}


Annex 6: Availability of CEmOC-Percentage of Unmet Need

\begin{tabular}{|c|c|c|c|c|c|c|c|}
\hline \multirow[b]{2}{*}{ Strata } & \multirow[b]{2}{*}{ District } & \multicolumn{6}{|c|}{ Comprehensive EmONc Services } \\
\hline & & Population & Recommended & $\begin{array}{c}\text { Facilities } \\
\text { visited/Existing }\end{array}$ & Functional & Discrepancy & $\begin{array}{r}\text { Percentage o } \\
\text { Unmet need }\end{array}$ \\
\hline \multirow[t]{3}{*}{ Punjab North } & TT.Singh & $1,917,064$ & 4 & 3 & 2 & 2 & 48 \\
\hline & Narowal & $1,457,161$ & 3 & 2 & 0 & 3 & 100 \\
\hline & Hafizabad & $1,045,000$ & 2 & 2 & 2 & 0 & 4 \\
\hline \multirow[t]{4}{*}{ Punjab South } & Vehari & $2,630,168$ & 5 & 3 & 1 & 4 & 81 \\
\hline & Layyah & $1,500,000$ & 3 & 4 & 1 & 2 & 67 \\
\hline & Rajanpur & $1,500,000$ & 3 & 3 & 2 & 1 & 33 \\
\hline & MuzaffarGharh & $3,586,160$ & 7 & 5 & 3 & 4 & 58 \\
\hline \multirow[t]{4}{*}{ Sindh } & Ghotki & $1,380,450$ & 3 & 5 & 2 & 1 & 28 \\
\hline & Dadu & $1,426,598$ & 3 & 4 & 1 & 2 & 65 \\
\hline & Hyderabad & $1,500,000$ & 3 & 4 & 2 & 1 & 33 \\
\hline & Nawab Shah & $1,600,000$ & 3 & 3 & 2 & 1 & 38 \\
\hline \multirow[t]{4}{*}{ Khyber Pakhtunkhwa } & Swab & $1,600,000$ & 3 & 2 & 1 & 2 & 69 \\
\hline & Kohat & 748,000 & 1 & 1 & 1 & 0 & 33 \\
\hline & Shangla & 578,000 & 1 & 3 & 0 & 1 & 100 \\
\hline & Chitral & 424,000 & 1 & 3 & 1 & 0 & 0 \\
\hline \multirow[t]{4}{*}{ Balochistan } & Kalat & 322,000 & 1 & 2 & 0 & 1 & 100 \\
\hline & Gawadar & 251,000 & 1 & 1 & 1 & 0 & 0 \\
\hline & Ketch/ Turbat & 558,000 & 1 & 2 & 1 & 0 & 10 \\
\hline & Nushki & 144,207 & 1 & 1 & 1 & 0 & 0 \\
\hline \multirow[t]{4}{*}{ AJK } & Kotli & 802,333 & 2 & 4 & 1 & 1 & 38 \\
\hline & Bagh & 375,464 & 1 & 1 & 1 & 0 & 0 \\
\hline & Bhimber & 431,905 & 1 & 1 & 1 & 0 & 0 \\
\hline & Neelam & 188,000 & 1 & 2 & 1 & 0 & 0 \\
\hline \multirow[t]{2}{*}{ FATA } & Khyber & 943,000 & 2 & 3 & 0 & 2 & 100 \\
\hline & Mohamand & 600,000 & 1 & 2 & 0 & 1 & 100 \\
\hline \multirow[t]{3}{*}{ GB } & Astore & 100,000 & 1 & 1 & 0 & 0 & 100 \\
\hline & Gilgit & 243,634 & 1 & 2 & 0 & 1 & 100 \\
\hline & Skardu & 223,000 & 1 & 2 & 1 & 0 & 0 \\
\hline
\end{tabular}




\section{Annex 7: Basic Information on Provinces and Regions}

\section{Punjab:}

Punjab is the most developed, populous, and prosperous province of Pakistan comprising approximately $55 \%$ of the country's total population. It is the second largest province in the country, at 205,344 km square $(79,284 \mathrm{sq} \mathrm{mi})$, after Balochistan, and is located on the northwestern edge of the geologic Indian plate in South Asia. The province is home to over half of Pakistan's populace. Punjabis comprise the largest ethnic group in the country.

- Maternal Mortality Rate

- Infant Mortality rate

- Child Mortality rate

- Total Fertility Rate:

- Women receiving antenatal care from a skilled provider:

\section{7/100,000 live births}

$81 / 1000$ live births

97/1000 live births

3.9 children per woman

78 percent

Source:

- Pakistan Demographic and Health Survey 2006-07 (2008). National Institute of Population Studies and Macro International Inc. Islamabad.

- $\quad$ Pakistan Demographic and Health Survey 2012-13: Preliminary Report (2013). National Institute of Population Studies and Measure DHS, ICF International.

Sindh:

Sindh is the third largest province in Pakistan, following Baluchistan and Punjab. It has a population of 42.4 million, making the people of Sindh the second largest ethnic group in the country. The 1998 national census of Pakistan showed Sindh to have a per annum Growth Rate of $2.8 \%$ and a population of 30.4 million. In 1951, Sindh comprised 18\% of Pakistan's population. Sindh's population density has also increased from 43 people per square kilometer in 1951 to 216 per Sq. Km in 1998. The population growth rate in Sindh's urban areas is also proportionately very high as compared to other areas of the country, and as a result the rural to urban population ratio changed from 40:60 to 52:48 in 2010.

- Maternal Mortality Rate

- Neonatal Mortality rate

- Child Mortality rate

- Total Fertility Rate:

- Women receiving antenatal care from a skilled provider:
$314 / 100,000$ live births

$81 / 1000$ live births

$101 / 1000$ live births

4.3 per woman

78 percent

Source:

- Pakistan Demographic and Health Survey 2006-07 (2008). National Institute of Population Studies and Macro International Inc. Islamabad.

- Multiple Indicators Cluster Survey Sindh (2009).

- Pakistan Demographic and Health Survey 2012-13: Preliminary Report (2013). National Institute of Population Studies and Measure DHS, ICF International. 


\section{Balochistan:}

Neighboring regions of Balochistan are Iranian Balochistan to the west, Afghanistan and Federally Administered Tribal Areas to the north and Punjab and Sindh to the east, and the Arabian Sea to the south. Balochistan is geographically the largest of the four provinces at $347,190 \mathrm{~km}^{2}$, but has the smallest population: approximately 6.3 million in 1994 . The population density is very low due to the mountainous terrain and scarcity of water.

- MMR 785 maternal deaths /

100,000 live

- Under-5 mortality rate as

89 per 1,000

- IMR 72 per 1,000

- Total fertility rate:

4.1children per woman

- Women receiving antenatal care from a skilled provider:

31 percent

Source:

- Pakistan Demographic and Health Survey 2006-07 (2008). National Institute of Population Studies and Macro International Inc. Islamabad.

- Multiple Indicators Cluster Survey Balochistan (2009).

- Pakistan Demographic and Health Survey 2012-13: Preliminary Report (2013). National Institute of Population Studies and Measure DHS, ICF International.

\section{Khyber Pakhtunkhwa:}

The province of Khyber Pakhtunkhwa is spread over 74,521 sq km, has a population of over $22 \mathrm{million}$. It comprises three major administrative parts: the first is composed of settled areas, the second is known as PATA (Provincially Administered Tribal Areas) and has a population of 831,000 people, and the third part is FATA (Federally Administered Tribal Areas), spread over 27,220 sq km, with a population of 3,764,000. PATA consists of the Malakand Agency and the districts of Upper Dir, Lower Dir, Chitral, Swat, Buner, Shangla, the pocket of Kala Dhaka/ "Black Mountains", Kohistan (which was previously part of the Swat State). The capital and largest city of the province is Peshawar.

- Maternal Mortality Rate

- Neonatal Mortality rate

- $\quad$ Child Mortality rate

- $\quad$ Total Fertility Rate

- Women receiving antenatal care from a skilled provider:
275/100,000 live births

\section{$41 / 1,000$ live births}

101/1,000 live births

4.3 children per woman

61 percent

Source:

- Pakistan Demographic and Health Survey 2006-07 (2008). National Institute of Population Studies and Macro International Inc. Islamabad.

- Pakistan Demographic and Health Survey 2012-13: Preliminary Report (2013). National Institute of Population Studies and Measure DHS, ICF International. 


\section{Gilgit Baltistan:}

Gilgit-Baltistan is located in northern Pakistan and is internationally contested by Pakistan, India and the native inhabitants of Gilgit Baltistan. Gilgit-Baltistan borders Afghanistan to the north, China to the northeast, the Pakistani administrated state of Azad Jammu and Kashmir (AJK) to the south, and the Indianadministered state of Jammu and Kashmir to the southeast. The territory of Gilgit-Baltistan consists of two Baltistan districts and five Gilgit districts and the main political centers are the towns of Gilgit and Skardu. Gilgit-Baltistan covers a territory of $72,496 \mathrm{~km}^{2}$ and has an estimated population of 1.8 million.

- Maternal Mortality Rate

600 per 100,000 live

births

- Infant Mortality rate

$122 / 1,000$ live births

- Pregnant women:

3.40

- Married women of Child Bearing Age (CBAs):

16.00

- Women receiving antenatal care from a skilled provider:

64 percent

- Immunisation (children 12-23 months - all vaccinations):

34 percent

Source:

- Pakistan Demographic and Health Survey 2006-07 (2008). National Institute of Population Studies and Macro International Inc. Islamabad.

- Pakistan Demographic and Health Survey 2012-13: Preliminary Report (2013). National Institute of Population Studies and Measure DHS, ICF International.

- Demographic and Health Survey Gilgit Baltistan 2008

- World Bank, ADB, Government of GB Economic Report (2011)

FATA:

The Federally Administered Tribal Areas (FATA) are located along Pakistan's north-western Hamalaya zone and south-western Sulaiman Mountains and run as a narrow tract along the river Indus. It consists of seven semi-autonomous agencies or administrative units - Khyber, Mohmand, Bajaur, Kurram, Orakzai, North Waziristan and South Waziristan. Additionally, the FATA include 'frontier regions' that adjoin the districts of Peshawar, Kohat, Bannu, Lakki Marwat, Tank and Dera Ismail Khan. This tangled mass constitutes an area of $27,224 \mathrm{sq} \mathrm{km}$ and is inhabited by around 3.17 million people who belong to different Pukhtoon or Pushtun tribes.

- Maternal Mortality Rate

- Infant Mortality rate

- The under-5 child mortality rate: births

- Deliveries taking place in hospitals or clinics:
380 per 100,000 live births

$86 / 1,000$ live births

$\mathbf{1 1 0}$ for males and $\mathbf{8 0}$ for femalesper 1000 live

27 percent

Source:

- Multiple Indicator Cluster Survey FATA (2009). 
AJK:

The State of Azad Jammu and Kashmir comprises an area of 5134 square miles (13,297 square kilometres). The topography of the area is mainly hilly and mountainous with many valleys and stretches of plains. The area is full of natural beauty with thick forests, fast flowing rivers and winding streams. The main rivers in AJK are Jehlum, Neelum and Poonch. The elevation ranges from 360 meters in the South to 6325 meters in the North. According to the 1998 population census, the State of Azad Jammu \& Kashmir had a population of 2.97 million, which is estimated to have grown to 3.4 million by 2004 .

- Maternal Mortality Rate

- Neonatal Mortality rate

- $\quad$ Child Mortality rate 9

- $\quad$ Total Fertility Rate
201/100000 live births

$62 / 1000$ live births

6/1000 live births

4.0 children per woman

Source:

- Pakistan Demographic and Health Survey 2006-07 (2008). National Institute of Population Studies and Macro International Inc. Islamabad.

- $\quad$ Multiple Indicators Cluster Survey AJK (2009). 